
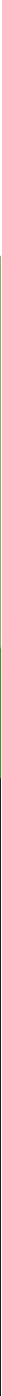


\section{Towards better utilisation of soil phosphorus in managed grassland systems}

Mart B.H. Ros 


\section{Thesis committee}

\section{Promotor}

Prof. Dr O. Oenema

Special Professor Nutrient Management and Soil Fertility

Wageningen University \& Research

\section{Co-promotors}

Prof. Dr J.W. van Groenigen

Personal chair at the Soil Biology Group

Wageningen University \& Research

Dr G.F. Koopmans

Researcher, Soil Chemistry and Chemical Soil Quality Group

Wageningen University \& Research

\section{Other members}

Prof. Dr M.J.I. Briones, University of Vigo, Spain

Dr E.K. Bünemann, Research Institute of Organic Agriculture (FiBL), Frick, Switzerland Prof. Dr J. Griffioen, Utrecht University

Prof. Dr M.K. van Ittersum, Wageningen University \& Research

This research was conducted under the auspices of the C.T. de Wit Graduate School for Production Ecology and Resource Conservation 


\title{
Towards better utilisation of soil phosphorus in managed grassland systems
}

\author{
Mart B.H. Ros
}

Thesis

submitted in fulfilment of the requirements for the degree of doctor

at Wageningen University

by the authority of the Rector Magnificus,

Prof. Dr A.P.J. Mol,

in the presence of the

Thesis Committee appointed by the Academic Board

to be defended in public

on Friday 29 March 2019

at 1:30 p.m. in the Aula. 
Mart B.H. Ros

Towards better utilisation of soil phosphorus in managed grassland systems, 212 pages.

PhD thesis, Wageningen University, Wageningen, the Netherlands (2019) With references, with summaries in English and Dutch

ISBN 978-94-6343-431-7

DOI https://doi.org/10.18174/471443 


\begin{abstract}
Managed grassland are an important agricultural land use and their productivity will need to increase over the coming decades to help meet the rising global food demand. Meanwhile, phosphorus (P) inputs into grasslands may decrease as a result of higher fertiliser prices or stronger agrienvironmental regulations. Better utilisation of soil $\mathrm{P}$ pools and higher use efficiency of $\mathrm{P}$ inputs may help increase yields with lower inputs. The main objective of this thesis is to investigate mechanisms and driving factors that determine $\mathrm{P}$ availability in grassland soils. In a review of the existing literature on $\mathrm{P}$ fertilisation of grasslands, a large variation in the response of grass to $\mathrm{P}$ fertilisation was documented. Application rate and soil $\mathrm{P}$ status were major factors determining the success of fertilisation, but the presence of legumes, the soil $\mathrm{pH}$, and organic matter content appeared to impact the results as well. This thesis also shows the potential role of grass species selection and management of soil fauna for increasing $P$ use efficiency, through a series of greenhouse and lab experiments. Deep-rooting grass species with long roots were better able to resist $\mathrm{P}$ deficiency, and grew better than other species both when P fertilisation was applied or withheld. Additionally, various earthworm species were shown to greatly increase available P concentrations in their casts, compared to the bulk soil. These local P 'hotspots' could be utilised by grass and led to yield increases under P-limited growing conditions. When chemical composition of the earthworm casts was further explored, a higher $\mathrm{pH}$ in the casts was found to have a minor effect on P availability, and it was hypothesised that competition for adsorption sites between dissolved organic matter and orthophosphate could contribute to the higher $\mathrm{P}$ availability. This thesis provides a variety of avenues to increase P use efficiency in managed grasslands, which should be explored further in field and farms studies to assess their true potential.
\end{abstract}





\section{Table of Contents}

1 Introduction

2 The effectivity of phosphorus fertilisation on grasslands across the world

3 What root traits determine grass resistance to phosphorus deficiency in production grassland?

4 Do earthworms affect phosphorus availability to grass? A pot experiment

5 Exploring the pathways of earthworm-induced phosphorus availability

6 General discussion

References

Affiliations of co-authors

Summary

Samenvatting

Dankwoord 
Chapter 1

\section{Introduction}


Over the coming 30 years, the world population is expected to grow to 9 billion people (Godfray et al., 2010). As a result, the food demand will rise alongside it, putting pressure on agriculture to increase its production. Moreover, dietary shifts in countries with rising economies may increase the demand for animal products even further, and with that the land required for food production (Kastner et al., 2012). With this comes an increasing concern to prevent soil degradation and excessive losses of nutrients from agricultural systems to the environment. It is projected that the total food demand will increase by $100-110 \%$ over the next decades (Tilman et al., 2011). Meeting these increasing food demands by 2030-2100 will require an enormous effort to sustainably intensify global agriculture and increase nutrient use efficiencies (Tilman et al., 2002). The availability and judicious use of fertilisers, as well as resources such as agricultural land and water, will play a crucial role in successfully achieving sustainable intensification of agriculture over the coming decades.

In addition to carbon, light, and water, plants require 14 nutrient elements $(\mathrm{N}, \mathrm{P}, \mathrm{K}, \mathrm{Mg}$, $\mathrm{Ca}, \mathrm{S}, \mathrm{Fe}, \mathrm{Mn}, \mathrm{Zn}, \mathrm{Cu}, \mathrm{B}, \mathrm{Mo}, \mathrm{Cl}, \mathrm{Ni}$ ), which they absorb from the soil solution. The growth and development of plants are distorted when the supply of one or more of these elements is suboptimal (Marschner, 2012). The rate at which plants take up nutrients is often limited by the supply of these nutrients to the plant roots. The nutrient supply is limited in most soils, which is why farmers apply animal manures and mineral fertilisers to cropland. Most often, the major growth-limiting elements are nitrogen $(\mathrm{N})$, phosphorus $(\mathrm{P})$, and potassium $(\mathrm{K})$, but other elements can be limiting as well. Excessive or inappropriate use of nutrients in crop and animal production can result in losses to the environment and create a range of unwanted environmental effects, possibly negatively affecting human health (Sutton et al., 2013). High concentrations of N and P in surface waters can result in eutrophication and biodiversity loss (Carpenter et al., 1998). The current losses of $N$ and $P$ to the atmosphere and surface waters exceed the so-called safe 'planetary boundaries' (Steffen et al., 2015). This indicates that losses of $N$ and $P$ to the environment have to be decreased, by proper management. 


\section{The global phosphorus challenges}

Although $\mathrm{P}$ is abundant on Earth, it is predominantly beyond the reach of plants and other biota that require it. The average concentration of $\mathrm{P}$ in the Earth's crust is around one gram per kilogram, which translates to $2000 \mathrm{~kg}$ of P per ha in the top $20 \mathrm{~cm}$ of soil. The fraction that is available to plants however, is small at short notice (a few percent). The amount of $\mathrm{P}$ in cropland soils and especially its availability to plants vary enormously across the globe, from very low values in highly weathered tropical soils to relatively high values in soils that have been fertilised regularly. Soils with a low $P$ status require $P$ inputs via manures and fertilisers to be able to produce and sustain high crop yields. These manures and fertilisers are not always available in sufficient amounts or may be expensive. Soils with a high $\mathrm{P}$ status are able to provide sufficient $\mathrm{P}$ to produce high crop yields, but may have a high risk of $\mathrm{P}$ losses to surface water bodies.

\subsection{Phosphate rock resources}

Phosphorus fertilisers are produced from phosphate rock, which occurs as a minable resource at a limited number of locations in the world, and contains around $5-13 \%$ of $\mathrm{P}$ (Cordell and White, 2011). Most $P$ in phosphate rock is present as fluorapatite $\left(\mathrm{Ca}_{10}\left(\mathrm{PO}_{4}\right)_{6} \mathrm{~F}_{2}\right)$ or other forms of apatite. This material is treated with sulphuric acid to produce either single superphosphate, or phosphoric acid, which is used for all other forms of mineral P fertiliser, but is also used in industrial processes, in the food industry, and for the production of animal feed supplements (Leikam and Achorn, 2005). The mining rate of phosphate rock has been increasing since the 1950s (Cordell et al., 2009). Currently, most rock phosphate is mined in China, the United States, Morocco and Western Sahara, as well as Russia (Table 1.1). This does however not represent the world's distribution of rock phosphate reserves: according to recent estimates by the US Geological Survey, over $70 \%$ of the reserves are located in Morocco and Western Sahara, whereas China has the second largest reserves with just under 5\% (USGS, 2018; Table 1.1). Hence, phosphate reserves are highly concentrated in a select number of countries, which might lead to geopolitical tensions in the future. The estimates of these reserves are subject to change, depending on interpretation, disclosure of information, and the discovery of new reserves. As a result, the views on when a shortage of economically profitable phosphate rock might occur vary widely across the scientific literature. Predictions on the lifetime of Earth's phosphate rock reserves range from decades to centuries (Cordell et al., 2009; Cordell and White, 2011; Van Kauwenbergh, 2010). Despite uncertainty about the exact size of the resources, it is essential to ensure long-term availability of $P$ fertilisers to feed a growing world population. For example, recent modelling results suggest that $\mathrm{P}$ inputs to the world's grasslands will have to increase fourfold to support the needed increase in grass yield of $80 \%$ by 2050 (Sattari et al., 2016). 
Table 1.1. Estimates of phosphate rock reserves and production per country, according to the 2017 report of the US Geological Survey (USGS, 2018).

\begin{tabular}{lrrrr}
\hline Phosphate rock & \multicolumn{3}{c}{ Reserves } & \multicolumn{3}{c}{ Production* } \\
& $(\mathrm{Tg})$ & $(\%)$ & $\left(\right.$ Tg yr $\left.^{-1}\right)$ & $(\%)$ \\
\hline Morocco and Western Sahara & 50000 & $(71.4)$ & 27.0 & $(10.3)$ \\
China & 3300 & $(4.7)$ & 140.0 & $(53.2)$ \\
Algeria & 2200 & $(3.1)$ & 1.3 & $(0.5)$ \\
Syria & 1800 & $(2.6)$ & 0.1 & $(0.0)$ \\
Brazil & 1700 & $(2.4)$ & 5.5 & $(2.1)$ \\
South Africa & 1500 & $(2.1)$ & 1.8 & $(0.7)$ \\
Saudi Arabia & 1400 & $(2.0)$ & 4.5 & $(1.7)$ \\
Jordan & 1300 & $(1.9)$ & 8.2 & $(3.1)$ \\
Egypt & 1300 & $(1.9)$ & 5.0 & $(1.9)$ \\
Australia & 1100 & $(1.6)$ & 3.0 & $(1.1)$ \\
United States & 1000 & $(1.4)$ & 27.7 & $(10.5)$ \\
Finland & 1000 & $(1.4)$ & 1.0 & $(0.4)$ \\
Russia & 700 & $(1.0)$ & 12.5 & $(4.8)$ \\
Other countries & 1700 & $(2.4)$ & 25.4 & $(9.7)$ \\
\hline World total & 70000 & & 263.0 & \\
\hline
\end{tabular}

* Production numbers are from 2016

\subsection{Global phosphorus imbalances and environmental impacts}

Current and future challenges in P management on a global scale are not just set by the quantity of $\mathrm{P}$ needed to increase crop production, but just as much by the distribution of that $\mathrm{P}$ throughout the world. Past fertilisation practices have led to great global imbalances of $\mathrm{P}$ in agricultural land due to differences in climate, access to technology, and agricultural practices (Bouwman et al., 2013; MacDonald et al., 2011; Sattari et al., 2012, 2016). Many regions, predominantly in tropical areas with highly weathered soils such as Africa, struggle with maintaining sufficient soil $\mathrm{P}$ availability to sustain optimal crop production (Sanchez, 2002). On the other hand, large parts of Western Europe, North America, and Oceania have seen high application rates of manure and fertilisers, partly associated with intensive livestock production. This has led to positive soil $\mathrm{P}$ balances and 
an accumulation of $\mathrm{P}$ in soil, which may ultimately result in losses of dissolved 'legacy $\mathrm{P}$ ' to surface water bodies (Kleinman et al., 2011; Sharpley et al., 2013). In several of these areas, animal manure is not only a resource, but has also become increasingly considered a pollutant. Losses of $\mathrm{P}$ to surface waters can stimulate primary production in freshwater ecosystems, as these systems are usually P-limited. The eutrophication of these ecosystems may result in high primary production of algae and cyanobacteria, changes in the ecological equilibria, decreased oxygen content of the water, and ultimately fish kills (Correll, 1998).

The global biogeochemical $\mathrm{N}$ and $\mathrm{P}$ cycles were included in the 'planetary boundaries concept', an approach introduced by Rockström et al. (2009) to frame key earth-system processes (such as climate change, stratospheric ozone depletion, and biogeochemical nutrient cycles) and the anthropological influence on these processes in a sustainability context. For each of these processes, the authors estimated boundaries beyond which human interference would be hazardous for long-term sustainability of the planet. For $P$, the boundary is based on $P$ fluxes from agricultural land to surface waters and ultimately oceans, using a global-scale approach (Carpenter and Bennett, 2011; Steffen et al., 2015). Currently the boundary for $P$ is crossed and especially in Western Europe, North America, and China the inputs of $P$ from land to the aquatic environment are relatively large (Steffen et al., 2015). Although this does not imply an immediate hazard to the planet's ecosystems, also given a certain degree of uncertainty involved in establishing the boundaries on a global scale, it indicates that a change in management of $\mathrm{P}$ resources is essential to securing a sustainable intensification of agriculture. Better conservation and recycling of $P$ in agricultural ecosystems and relocation of $\mathrm{P}$ from P-rich to $\mathrm{P}$-poor regions (e.g. in recycled $\mathrm{P}$ fertiliser or in food) may help achieve this goal (Carpenter and Bennett, 2011), as most of the P input into the aquatic environment originates from agriculture (Beusen et al., 2016).

\section{Phosphorus cycling in dairy farming}

Grassland provides feed to ruminant animals and is a main harbour of biodiversity. With an area of over 33 million $\mathrm{km}^{2}$, grasslands account for over $25 \%$ of the world's land cover. Two thirds of this area is associated with agriculture (FAO, 2017). In Europe, grassland is a dominating land-use form, comprising roughly 34\% of total agricultural land (Eurostat, 2016). In Western Europe, most are managed grassland used for dairy farming. Commonly, a distinction is made between (i) natural grassland with little or no anthropogenic influence; (ii) extensively managed grassland (which are often grazed by sheep, goat and beef cattle, and receive little or no fertiliser inputs); and (iii) intensively managed grassland (receiving regular fertiliser and/or manure inputs, often reseeded once every 5 to 10 years, and harvested 3 to 6 times per year by grazing or mowing). 
Figure 1.1 shows the $\mathrm{P}$ cycle of a grassland-based dairy farm. In these systems, milk and meat are produced as commodities and grasslands supply a major part of the cattle's diet, together with other feed crops such as (silage) maize. Phosphorus enters the farm through purchased feed, animals, and fertiliser, and it leaves the farm via the sales of milk and animals, and possibly via surplus forages and manure. Additionally, P can be lost from the farming system via leaching, overland flow and erosion. In common grassland-based dairy systems, $\mathrm{P}$ is mainly imported onto the farm in the form of concentrate feed, whereas milk is the largest source of P export (Cela et al., 2015; Rotz et al., 2005). The balance, defined as the difference between the amount of $P$ that is imported and exported, is an indicator of how much $\mathrm{P}$ is lost during production, or remains in the farm system. This can be used to assess how efficient and sustainable a farm is in terms of $P$ use. If the $P$ imports on a farm are much larger than the exports, it is likely that a major part of the difference remains in the system (within the circle in Fig. 1.1) and accumulates in soil, although alternatively it can be retained temporarily in feed stocks. If accumulation of P persist over multiple years, this can lead to a build-up of soil $\mathrm{P}$ and increased risk of soil P losses.

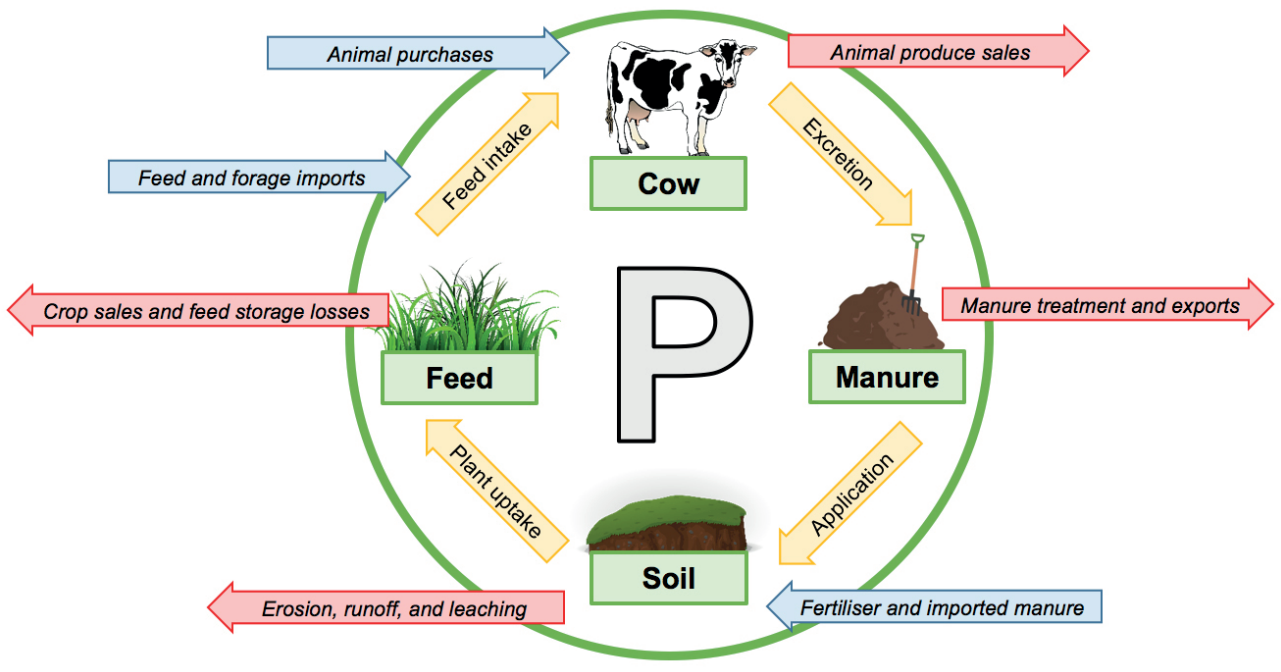

Figure 1.1. Scheme of the phosphorus cycle of a dairy farming system. The items in the green circle are on-farm pools in which phosphorus $(P)$ is stored. The yellow arrows indicate the processes associated with internal $P$ cycling on the farm, whereas the blue and red arrow represent fluxes of $P$ into and out of the system.

Because of its chemical properties, $\mathrm{P}$ is one of the least available nutrients in soil; most soils are not able to supply enough $\mathrm{P}$ for plants to achieve economically optimal growth. This is frequently the result of both a low native soil $P$ content and a low availability of the $P$ in soil. Fertilisation with manure or mineral fertiliser is therefore often important to increase P supply (Figs. 1.1 and 1.2). 
Most of the $\mathrm{P}$ that is harvested in crops and subsequently fed to livestock ends up in the excreted manure and can thus be recycled to fertilise the soil again. Effectively managing soil $P$ inputs via fertiliser and manure, and maintaining a soil P status that is optimal for plant growth are essential to achieve and maintain high and efficient production in these systems.

\section{Phosphorus in grassland soils in the Netherlands}

Throughout the twentieth century, many cropland and grassland soils in the Netherlands have been enriched with $\mathrm{P}$ through fertiliser and animal manure applications. The average $\mathrm{P}$ accumulation in the upper $0.5 \mathrm{~m}$ of agricultural soils in the Netherlands has been estimated at $2050 \mathrm{~kg} \mathrm{P} \mathrm{ha-1}$ (Schoumans and Chardon, 2015). Reijneveld et al. (2010) summarised the trend in soil P test levels of the top 10 to $20 \mathrm{~cm}$ of Dutch agricultural soils throughout this period. Although a significant increasing trend for the median soil P test value of arable land was found between 1970 and the early 2000s, the value for grassland remained more or less constant throughout this period. When analysed per soil type however, grasslands on sandy soils showed a significant increase of soil P test levels over the last two decades of the last century (Reijneveld et al., 2010).

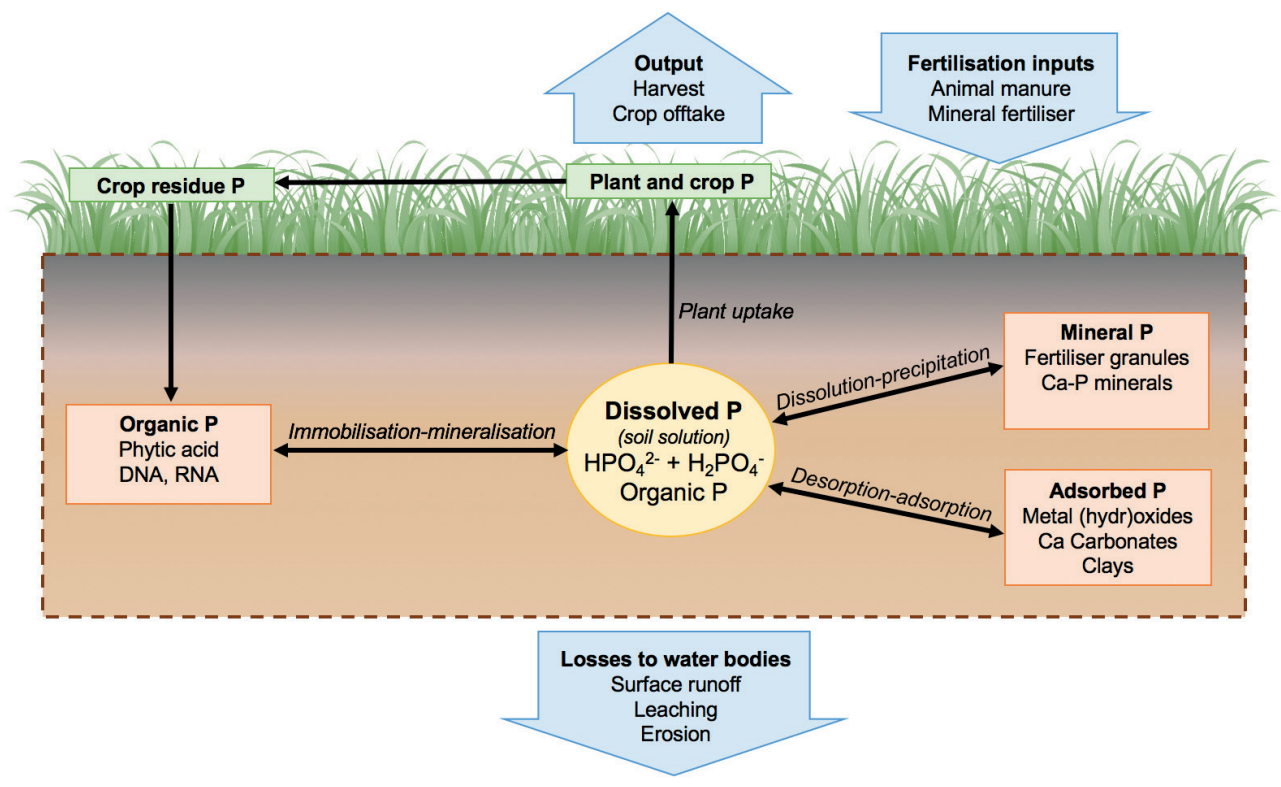

Figure 1.2. Simplified overview of different phosphorus (P) pools in soil (delineated by the dashed box) as well as major inputs and outputs of $P$ (blue arrows). 
The large reserves of soil $\mathrm{P}$ can pose an environmental threat through leaching or surface runoff of $\mathrm{P}$, depending on soil type and conditions, and can subsequently lead to eutrophication of ground- and surface waters (Jarvie et al., 2015; Koopmans et al., 2007; Sims et al., 1998; Van der Salm et al., 2012). To minimise $P$ losses from agricultural soils, inputs of $P$ have been stepwise restricted over the past decades in the Netherlands through regulatory $P$ input limits from 1985 onwards and through balanced $\mathrm{P}$ fertilisation from about 2015 , depending on soil P status (Reijneveld et al., 2010; Van Middelkoop et al., 2016). These policy measures have yet to lead to a significant decrease of the average soil P status (Reijneveld et al., 2010).

To determine the allowed $\mathrm{P}$ application rate, a soil $\mathrm{P}$ status is determined based on extractions with either ammonium lactate $(\mathrm{P}-\mathrm{AL})$ for grassland or water $\left(\mathrm{P}_{w}\right)$ for arable land. With balanced $\mathrm{P}$ fertilisation (or equilibrium $P$ fertilisation), total $P$ input equals $P$ withdrawal with harvested crops on soils with a so-called 'neutral' P status. For low P soils, permissible P inputs are slightly larger than P withdrawal, whereas P inputs for high P soils are smaller than P withdrawal (Anonymous, 2013; Van Middelkoop et al., 2016). This strategy would thus eventually result in a 'neutral' classification for all agricultural land (Jordan-Meille et al., 2012). Approximately 78\% of the Dutch grassland soils in the period 1996-2000 had P-AL values within the 'neutral' range. This indicates that a large part of Dutch grassland soils is subject to equilibrium $P$ fertilisation. Based on long-term field experiments (Van der Salm et al., 2009; Van Middelkoop et al., 2016; Verloop et al., 2010), there are indications that equilibrium $P$ fertilisation for grassland soils may lead to a (slight) decrease in P-AL. This can be explained by the fact that $P$ losses due to leaching and surface runoff are not taken into account in equilibrium $P$ fertilisation (Van Middelkoop et al., 2016). Also, the availability of soil $P$ for uptake by plants at equilibrium $P$ fertilisation may decrease over time as a result of soil processes that immobilise $P$, for instance a gradual fixation of $P$ by diffusion into soil metal (hydr) oxide particles, making $P$ less available (Barrow, 1983; Van Riemsdijk et al., 1984a, 1984b). Such a decrease in the soil $\mathrm{P}$ status can be expected to lead to reductions in crop yield and $\mathrm{P}$ uptake over time, as was suggested by results of a long-term field experiment of Van Middelkoop et al. (2016). This may ultimately result in a grass $\mathrm{P}$ content that is below the requirements of highly productive dairy cows (Valk and Šebek, 1999). It will thus be important to maintain an optimal P uptake by grass under the conditions of limited $\mathrm{P}$ application rates, which requires a better utilisation of the residual soil P pool.

\section{Phosphorus in soil}

In soil, $\mathrm{P}$ occurs in inorganic and organic forms. The distribution of $\mathrm{P}$ between organic and inorganic P pools can vary widely in agricultural soils (Stutter et al., 2012). Harrison (1987) reported that organic P usually comprises between 30 and $60 \%$ of the total P pool, whereas Menezes-Blackburn 
et al. (2018) found that on average (over 258 crop and pasture soils) $57 \%$ of soil $P$ was present as inorganic P. The ratio between organic and inorganic P may however be affected by P inputs, through applications of mineral fertiliser and animal manures (which often includes most of the P in inorganic form) (Dou et al., 2000; Toor et al., 2005). In soils that have undergone long-term manure applications, inorganic forms of $\mathrm{P}$ tend to dominate, making up over $70 \%$ of the total P pool (Annaheim et al., 2015; Dou et al., 2009; Koopmans et al., 2007; Lehmann et al., 2005; Schmieder et al., 2018). Below, I will first discuss the behaviour of inorganic P in soils, after which I will elaborate on the speciation and availability of organic $P$ forms.

\subsection{Inorganic $P$}

Plants use their roots to take up $\mathrm{P}$ as orthophosphate (ortho-P) anions from the soil solution (Hinsinger, 2001). Depending on the $\mathrm{pH}$ of the soil, ortho-P exists in several ionic forms, with the most common forms being $\mathrm{H}_{2} \mathrm{PO}_{4}^{-}$and $\mathrm{HPO}_{4}^{2-}$. The ortho-P concentrations in the soil solution are typically below $10 \mu \mathrm{M}$ (Bieleski, 1973), which is only a fraction of the amount of $\mathrm{P}$ that is taken up by plants annually. Over the course of a growing season, the soil solid phase supplies the remainder via buffering processes that lead to the release of $\mathrm{P}$ to the soil solution.

Phosphorus occurs in the soil solid phase in various forms and the amount in which these forms are present, in combination with the rates at which these forms are converted to soluble ortho- $P$, determines the amount of $P$ that is ultimately available for plant uptake (Fig. 1.2). In recently developed, unfertilised soils, most inorganic $P$ is present in the form of calcium (Ca) phosphates, such as apatite. Soil formation and weathering processes lead to the dissolution of these minerals and gradually release ortho-P into the soil solution, where it can interact with other parts of the soil. Depending on the $\mathrm{pH}$, texture, and the mineral composition of the soil, $\mathrm{P}$ reacts with different soil constituents. Adsorption of ortho-P to aluminium ( $\mathrm{Al}$ ) and iron ( $\mathrm{Fe}$ ) (hydr)oxides and oxidic edges of clay minerals generally governs the directly available fraction of $\mathrm{P}$ in non-calcareous soils (Beek, 1979; Gérard, 2016; Hinsinger, 2001; Koopmans et al., 2004), whereas in calcareous soils, P can adsorb to the surface of calcite $\left(\mathrm{CaCO}_{3}\right)$ or form precipitates of Ca-P minerals (Schoumans, 2014; Sø et al., 2011). Important Fe (hydr)oxides present in acid and neutral soils include poorly crystalline ferrihydrite and goethite, whereas gibbsite is a major Al (hydr)oxide (Schwertmann, 1991; Weng et al., 2012). Hiemstra et al. (2010a) demonstrated the presence of Fe (hydr)oxide nanoparticles with a size of 1 to $10 \mathrm{~nm}$ in topsoils of agricultural land with a specific surface surface area (SSA) of 200 to $1200 \mathrm{~m}^{2} \mathrm{~g}^{-1}$ oxide.

The adsorption of ortho-P to metal (hydr)oxide surfaces is a complex function of the type and properties of the metal (hydr)oxide (mainly the specific surface and site density of reactive groups), and environmental factors like the $\mathrm{pH}$ and ionic composition of the soil solution as well as the presence of organic matter (Hiemstra, 2013; Hiemstra et al., 2010a; Wang et al., 2013; 
Weng et al., 2012). Surface complexation models like the Charge Distribution (CD) model (Hiemstra and Van Riemsdijk, 1996) can be used to describe the adsorption behaviour of ortho-P to metal (hydr)oxide surfaces. The CD model describes the mineral surface of Fe (hydr)oxides with a certain site density of reactive groups which can be protonated or deprotonated and can bind ions from solution. In the CD model, the adsorption behaviour of ortho-P to Fe and Al (hydr)oxides and oxidic clay mineral edges present in soils is represented by goethite, for which the model has been extensively calibrated (Hiemstra et al., 2010a). The mechanistic nature of the CD model enables the prediction of the change in ortho- $\mathrm{P}$ adsorption as a result of variation in $\mathrm{pH}$, concentrations of interacting cations and anions, and the amount of organic matter adsorbed to metal (hydr) oxides. The CD model has been used successfully to explore and describe the effects of oxide properties and environmental factors on ortho-P adsorption in mono- and multiple component systems (Rietra et al., 2001; Weng et al., 2012, 2008) as well as soil samples (Hiemstra et al., 2013). For instance, calcium has been shown to facilitate the adsorption of ortho-P to goethite in synthetic systems (Rietra et al., 2001) and in soils (Weng et al., 2011), whereas organic matter may decrease adsorption of ortho-P by competing for the same adsorption sites on the surface of metal (hydr) oxides (Hiemstra et al., 2010b, 2013; Weng et al., 2012). Including these interactions is important, as disregarding such competition effects between organic matter and ortho-P for adsorption sites may result in an underestimation of the solubility of ortho-P in soils (Regelink et al., 2015). Surface complexation models like the CD model can give a mechanistic insight in adsorption process of ions. Various databases are available from which parameters can be drawn, which makes surface complexation models applicable to a wide range of different soils (Groenenberg and Lofts, 2014).

The acid ammonium oxalate extraction method of Schwertmann (1964) can be used to extract amorphous metal (hydr)oxides from soil, as well as the ortho-P adsorbed to them. From the concentrations of $\mathrm{Fe}$ and $\mathrm{Al}$ in the extract $[\mathrm{Fe}+\mathrm{Al}]_{\mathrm{ox}^{\prime}}$ the sum of metal (hydr)oxides can be calculated, whereas the concentration of $\mathrm{P}\left(\mathrm{P}_{\text {ox }}\right)$ can be interpreted as reversibly bound $\mathrm{P}$ (Hiemstra et al., 2010a; Koopmans et al., 2004; Lookman, 1995). The P-saturation index $(\alpha)$ is subsequently calculated as the molar ratio of $\mathrm{P}_{\text {ox }}$ and $[\mathrm{Fe}+\mathrm{Al}]_{\mathrm{ox}}$ (Van der Zee and Van Riemsdijk, 1988):

$\alpha=\frac{P_{o x}}{[F e+A l]_{o x}}$

The P-saturation index $(\alpha)$ can be interpreted as the $\mathrm{P}$ loading of metal (hydr)oxides, and the ortho-P concentration in soil solution at equilibrium is related to the P-saturation index (Schoumans and Groenendijk, 2000). The maximum value of $\alpha$ (i.e. $\alpha_{\max }$ ) has been found to vary between 0.4 and 0.6 (Freese et al., 1992; Maguire et al., 2001; Van der Zee et al., 1988; Van der Zee and Van Riemsdijk, 1988). Multiplication of $\alpha_{\max }$ with $[\mathrm{Fe}+\mathrm{Al}]_{\mathrm{ox}}$ in the denominator of equation 1.1 gives the $\mathrm{P}$ sorption capacity of a soil, which in turn can be used to calculate the degree of $\mathrm{P}$ saturation when 
using $\mathrm{P}_{\text {ox }}$ in the numerator. The concept of the $\mathrm{P}$ saturation degree was originally introduced by Van der Zee and Van Riemsdijk (1988) and is nowadays widely used as an indicator of the risk of potential P leaching to groundwater and sub-surface leaching to surface waters (Schoumans and Chardon, 2015).

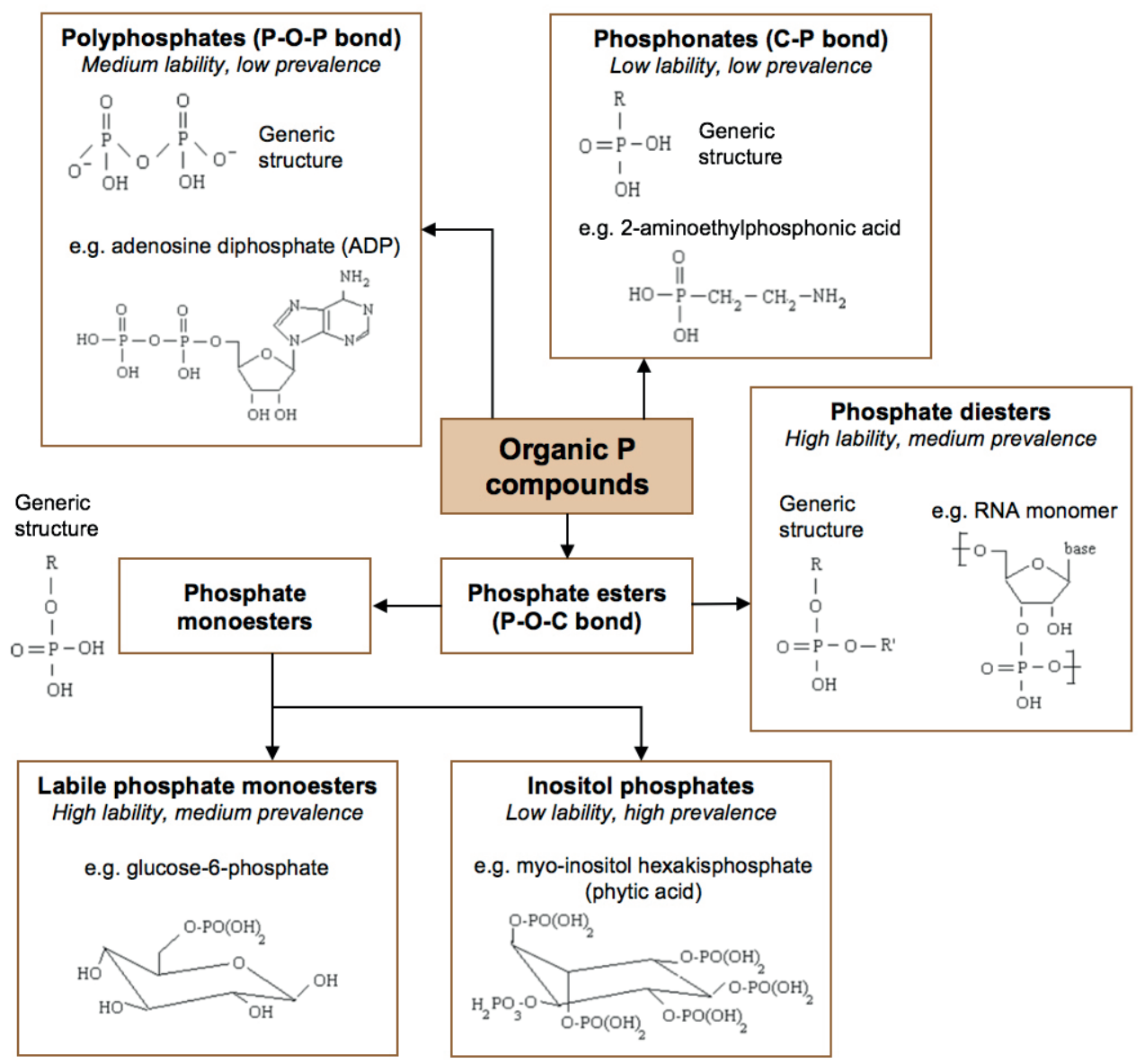

Figure 1.3. Overview of groups of organic $P$ forms with generic and example structures and information on the relative lability and prevalence in soil. The ' $R$ ' in chemical formulae denotes an organic group. Adapted from George et al. (2018). 


\subsection{Organic $P$}

Organic P compounds are molecules in which a carbon (C) atom from an organic moiety is connected to a P atom, either directly or indirectly. These compounds can be categorised into ortho-P esters, organic polyphosphates, and phosphonates, based on the nature of the bond between the $\mathrm{P}$ atom and its surroundings (Condron et al., 2005). Figure 1.3 shows a summary of the various organic $P$ compounds that occur in soil. Ortho-P esters are characterised by an ester bond (C-O-P) and can be subdivided into mono- and diesters, depending on the occurrence of one or two ester bonds per $\mathrm{P}$ atom. Polyphosphates consist of multiple $\mathrm{P}$ atoms linked together through anhydride (P-O-P) bonds. In the case of organic polyphosphates, these are linked to an organic complex through an ester bond. Phosphonates contain a direct C-P link, which is more resistant to oxidation and hydrolysis than an ester bond. Of these different groups, ortho-P monoesters are by far the most prominent in soil (Condron et al., 2005). In a review of global literature, Menezes-Blackburn et al. (2018) found that they comprise on average $31 \%$ of total $P$ in arable soils and $35 \%$ in pasture soils, and that they represent more than $70 \%$ of the organic $P$ fraction (Menezes-Blackburn et al., 2018). Nash et al. (2014) summarised organic $P$ in grasslands studies and reported numbers of comparable magnitude, with ortho-P monoesters making up between $21 \%$ and $37 \%$ of total soil $\mathrm{P}$.

The most prevalent ortho-P monoesters in soil are inositol phosphates (Fig. 1.3). Inositol is a hexahydroxy-cyclohexane that can bind one to six ortho-P molecules. While inositol can differ in the number of ortho-P groups it carries, and occurs in different isomeric forms, myoinositolhexakisphosphate, or phytic acid, is the most predominant form in soil (Turner et al., 2002). In phytic acid, all six hydroxide groups of the inositol are substituted with ortho-P. Plants produce this compound as a way to store $\mathrm{P}$, mainly in their seeds, so it is added to soil through dead plant material and seeds (Nash et al., 2014; Turner et al., 2002). On dairy farms, cattle manure can also be a source of phytic acid in soils: Toor et al. (2005) found that phytic acid accounted for $5-14 \%$ of total $\mathrm{P}$ in dairy cattle manure, and up to $29 \%$ of total $\mathrm{P}$ in the faeces. Although concentrations of inositol phosphates like phytic acid in plant material are usually smaller than those of ortho-P diesters, they are more prevalent in soil (Turner et al., 2002). The relatively high abundance and stability of phytic acid in soil results from their affinity to adsorb strongly to the surfaces of metal (hydr)oxides. The presence of six ortho-P moieties in phytic acid means that one molecule can form several bonds. Although not all of these ortho-P groups may be involved in the adsorption reaction (Ognalaga et al., 1994), the occupation of multiple binding sites and the larger negative charge density of the molecule compared to ortho-P, cause phytic acid to have a high affinity for adsorption in soils (Leytem et al., 2002). As a result, it is sparingly available for enzymatic hydrolysis that can make the ortho-P groups available for uptake by plants. In addition to phytic acid, other organic $\mathrm{P}$ forms in soil include labile ortho-P monoesters, such as sugar phosphates, and diesters like deoxyribonucleic acid (DNA), ribonucleic acid (RNA) and phospholipids. These compounds are usually present in soil in low concentrations because of their low stability (Turner et al., 2002). 


\section{$5 \quad$ Improving the utilisation of soil phosphorus}

With a growing demand for agricultural produce, a possible decrease in the long-term security of phosphate rock resources, and possible restrictions on $\mathrm{P}$ inputs as implemented in the Netherlands, it becomes increasingly evident that better utilisation of the soil P pool is required. Intensively managed, grassland-based dairy systems are important land-use system in many parts of the world, and yields of grasslands will have to increase with lower P inputs than in the recent past. Smart use of the available resources is therefore key and it will be vital to understand the (soil) factors that determine effective use of soil $P$ and $P$ inputs. Finding ways to access soil $P$ that was previously unavailable can reduce the need for additional $\mathrm{P}$ inputs. Organisms such as plants and soil fauna interact with the soil $P$ cycle, and can alter or manipulate soil $P$ availability. A better understanding of these interactions, and how they affect the $\mathrm{P}$ dynamics in soil, may help utilise those characteristics and improve the P use efficiency.

\subsection{The role of root characteristics}

Plants have various strategies to increase P uptake under P-limiting conditions. They may for instance increase root growth and root to shoot ratios, alter root distribution, increase root hair length and density or form mycorrhizal symbioses (Richardson et al., 2011, 2009a). Besides structurally altering root characteristics, some plants (like white lupin) have other mechanisms to enhance their $\mathrm{P}$ acquisition; they may exude organic anions to enhance the release of $\mathrm{P}$ adsorbed at metal (hydr) oxide surfaces to the soil solution through competitive binding, or secrete enzymes that improve solubilisation and hydrolysis of organic P compounds (Richardson et al., 2011, 2009a). While these enzymes (phosphatases and phytases) can be produced by soil microorganisms (Paredes et al., 2011), plants are also capable of exuding them. Plant species that exhibit these strategies may also augment $P$ availability for subsequent or neighbouring crops (Li et al., 2007).

Studies on the differences in $\mathrm{P}$ uptake by various grassland and pasture species and varieties are still scarce. Caradus (1980) demonstrated differences in biomass production of pasture grasses and legumes under two different $\mathrm{P}$ conditions, and proposed these were related to differences in root morphology. Elberse and Berendse (1993) reported variation amongst eight grass species in responsiveness to nutrient availability. The authors found that species originating from nutrientpoor environments allocated less biomass to root production than species from nutrient-rich environments. Studies have also reported differences in rooting depth and root morphology between grass species and cultivars (e.g. Elberse and Berendse, 1993; Deru et al., 2000; Nie et al., 2008; Picon-Cochard et al., 2012), and these characteristics may be changed by P fertilisation (Hill et al., 2006). Moreover, grass species may be affected differently by the presence of arbuscular mycorrhizal fungi. Wilson and Hartnett (1998) showed that warm-season grasses were generally 
more responsive than cool-season grasses and that there was variation in the response within both groups at the species level. As grass species from nutrient-poor environments often have root characteristics different to those from nutrient-rich systems (Elberse and Berendse, 1993), these characteristics can be used as a guide for the selection of species. Currently, grass species and varieties used in managed grasslands are often selected based on their yield potential under nutrient-rich conditions (Smit et al., 2005; Whitehead, 2000) rather than their root characteristics. If the soil P status of these grasslands decreases as a result of lower P inputs, selecting grass species based on their root characteristics may become a viable strategy to maintain high yields under supoptimal conditions.

\subsection{The role of earthworms}

The role of soil macrofauna in $\mathrm{P}$ cycling and $\mathrm{P}$ availability to plants is a subject that has not seen a lot of attention. As ecosystem-engineers, earthworms alter the physico-chemical properties of the soil surrounding them by burrowing and by their feeding behaviour (Jones et al., 1994). For example, earthworm burrows are soil macropores that may act as preferential flow paths for rainfall and improved soil aeration (Devliegher and Verstraete, 1997; Schrader et al., 2007). They feed on fresh litter and organic matter associated with soil particles (Curry and Schmidt, 2007), and mix organic matter and nutrients into the soil, stimulating mineralisation and increasing soil fertility. Additionally, their burrow walls and casts are hotspots of microbial activity (Tiunov and Scheu, 2000).

Earthworms have historically been associated with benefits to soil and plants, and have recently been shown to increase crop yields in agroecosystems by 25\% on average (Van Groenigen et al., 2014). Although their role in soil $C$ and $N$ cycling has been studied extensively, indeed remarkably few studies have been conducted on the relation between earthworms and soil $P$ availability (Le Bayon and Milleret, 2009). Increases in plant-available P as well as phosphatase activity in earthworm casts have been documented (Satchell and Martin, 1984; Sharpley and Syers, 1976), but the mechanisms that underlie these effects remain largely unclear. Furthermore, few studies have aimed to link earthworm-induced increases of $\mathrm{P}$ availability to a resulting increase in plant growth. Earthworm-induced effects on plant production are often studied in light of their influence on soil N cycling, rather than P cycling (Van Groenigen et al., 2014). Nevertheless, increases in plant growth as a result of enhanced $\mathrm{P}$ availability may prevail in absence of $\mathrm{N}$ limitation. If the previously reported influence of earthworms on the $\mathrm{P}$ cycle could be translated into such an increase in plant growth and $\mathrm{P}$ uptake, managing the earthworm community in grasslands could become a viable strategy for increasing soil $P$ utilisation. 


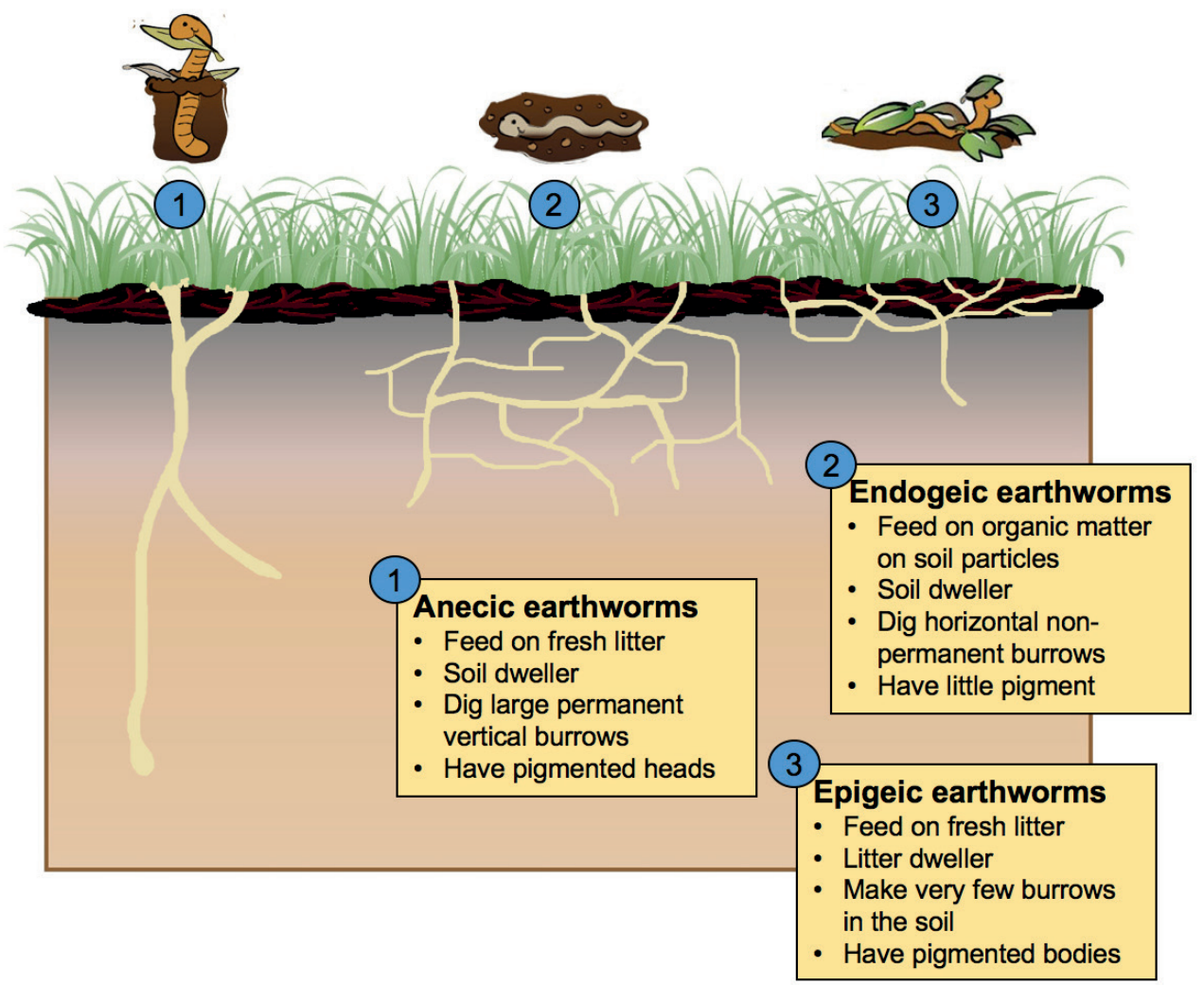

Figure 1.4. Characteristics of the three ecological categories of earthworms. Some species may show attributes frome multiple categories.

Depending on their feeding strategies and burrowing behaviour, different species of earthworms may have a varying impact on soil P dynamics (Fig. 1.4). According to Bouché (1977), earthworms can roughly be categorised into three ecological categories. Epigeic species tend to dwell in the topsoil and on the soil surface and feed mainly on litter and dead plant material. Anecic earthworms create a limited amount of permanent, vertical oriented burrows that connect the sub soil with the soil surface. They too feed on litter, transporting it down and incorporating organic matter in their burrows. Endogeic species are geophagus; they make non-permanent burrows in the subsoil and feed mainly on soil particles and associated organic matter. Although these categories are an effective means of describing earthworm behaviour, many species show attributes belonging to different ecological groups and cannot be assigned to a single group (Bouché, 1977). 


\section{Objectives and thesis outline}

With P inputs into grassland-based dairy farms likely to be limited and the global demand for dairy products likely to be growing rapidly in the coming decades, there is impetus to better utilise soil $P$ in grassland soils. My thesis research aims at investigating mechanisms and driving factors that determine $P$ availability in grassland soils, and at exploring the potential of these factors to increase the $\mathrm{P}$ utilisation in managed grasslands. The specific objectives of my thesis research are:

- to identify the (soil) factors that drive the success of P fertilisation of grassland on a global scale;

- to assess the difference in resistance of various grass species to P deficiency and link this to their morphological root traits;

- to quantify the effect of different earthworm species on $\mathrm{P}$ availability and grass $\mathrm{P}$ uptake; and

- to explore the temporal P dynamics in earthworm casts and model the mechanisms that drive $P$ availability in casts.

Chapter 2 is a review of published peer-reviewed studies of field experiments on $\mathrm{P}$ fertilisation of grassland. Using a meta-analysis approach, the effects of $\mathrm{P}$ application rate on grass biomass production were quantified. Additionally the influence of soil properties, such as soil P status, pH, and soil organic matter content were taken into account. This allowed me to identify key drivers that determine the effectivity of $\mathrm{P}$ fertilisation of grasslands on a global scale.

Chapter 3 focuses on the root characteristics of different grass species used in managed grassland in Western Europe. It describes a greenhouse experiment of ten months, with various grass species and a soil with low $\mathrm{P}$ availability. There were $\mathrm{P}$ application treatments to create either optimal growing conditions or a P-limiting environment. Differences in yield, nutrient uptake, and root characteristics are reported and disentangled using structural equation modelling.

In Chapters 4 and 5, the role of earthworms in (improving) the bioavailability of $\mathrm{P}$ is explored. Chapter 4 reports on an incubation study in which three different earthworm species were incubated for 2.5 months in pots with soils and grown over with perennial ryegrass in a greenhouse experiment. Phosphorus application treatments included a control in which $\mathrm{P}$ fertilisation was withheld, a treatment with application of organic $P$ (phytic acid), and one with application of ortho-P. The effect of the individual species on the growth and $P$ uptake of the grass was determined and linked to the water-extractable P concentration in the earthworm casts, which is used as here a proxy for the amount of readily available $P$. 
Chapter 5 describes the results of a second greenhouse experiment with the earthworm species Lumbricus terrestris. Here, the effect of the earthworm's presence on growth and $\mathrm{P}$ uptake of annual ryegrass is reported and the results of an incubation experiment of cast material and bulk soil over a period of 28 days are described. Additionally, for the first time, the CD model was applied to earthworm casts to show how $\mathrm{pH}$ and competition between ortho-P and organic matter can affect the $P$ dynamics in the casts.

Finally, in Chapter 6, the results from the previous chapters are discussed and put into context. I have formulated recommendations and potential measures to better utilise soil $\mathrm{P}$, and assess under which conditions these may prove most promising. Additionally, I discuss possible directions for further research to enable a more sustainable use of P. For instance on how to close the gap between the process-oriented research presented in this thesis and the on-farm situation in practice. 
Chapter 2

\section{The effectivity of phosphorus fertilisation on grasslands across the world}

Mart B.H. Ros, Gerwin F. Koopmans, Diego Abalos, Oene Oenema, Hannah M.J. Vos, Jan Willem van Groenigen

This chapter is to be submitted. 


\begin{abstract}
As phosphorus $(P)$ is one of the most limiting nutrients for crops, fertilisation is essential to feed the world. However, declining reserves demand far more effective $P$ use. Here, we study the effectiveness of $P$ fertilisation in grasslands in a global meta-analysis of 67 studies and 1227 observations. Overall, yield increased $36 \%$ after fertilisation but the response differed dramatically between systems: it was $80-100 \%$ higher in (a) tropical vs temperate regions; (b) grass/legume mixtures vs grass monoculture; and (c) soil pH of 5-6 vs other pHs. Soils with low $\mathrm{P}$ availability reacted disproportionately strong to fertilisation. A kilogram of $P$ fertiliser was 5-10 times more effective in Oceania or Africa than in other parts of the world. Our results show how we should more judiciously use a crucial resource: small fertiliser application rates to P-deficient soils result in stronger yield benefits than larger rates applied to less deficient soils.
\end{abstract}




\section{Introduction}

Global food demand will rise substantially over the coming decades. Meeting this demand while simultaneously decreasing the environmental footprint of agriculture is one of the most formidable challenges of the $21^{\text {st }}$ century (Godfray et al., 2010; Muller et al., 2017; Tilman et al., 2011). Consumption of meat and dairy products is projected to double over the 2000-2050 period as a result of the growing world population (Steinfeld et al., 2006). As one of the main feed sources for livestock, grasslands are an indispensable component of dairy and meat production chains. With over 33 million $\mathrm{km}^{2}$, permanent grasslands account for over $25 \%$ of the world's land cover and over two thirds of this area is utilised for agriculture, making it the most dominant land use (FAO, 2017). Sustainably increasing the production of the grasslands that underlie dairy and meat production is therefore crucial to ensure future global food security (Alexandratos and Bruinsma, 2012; Oenema et al., 2014).

Phosphorus $(\mathrm{P})$ is pivotal in the sustainable intensification of these grasslands. It is an essential nutrient, often limiting plant growth (Hinsinger, 2001). Fertilisation to alleviate this limitation is essential for sustaining productivity in agricultural systems across the world. As the world's $P$ reserves are decreasing, the importance of judicious $P$ use will increase over the coming century. Although estimates of the exact size of global $P$ reserves vary, it is widely acknowledged that the costs of high quality $P$ fertilisers will increase, as will the global demand for these fertilisers (Cordell and White, 2011; Simpson et al., 2011; Van Kauwenbergh, 2010; Van Vuuren et al., 2010). A combination of differences in climate, agricultural development, and fertilisation practices has led to great global imbalances of $\mathrm{P}$ in agricultural land (Bouwman et al., 2013; MacDonald et al., 2011; Sattari et al., 2012, 2016). In parts of Europe, North America, and China, historical applications of manure and fertilisers have resulted in consistently positive $\mathrm{P}$ balances and a corresponding increased risk of eutrophication of surface waters (Sharpley et al., 2013). Many other regions, predominantly in tropical areas, struggle with maintaining sufficient soil $\mathrm{P}$ availability to sustain optimal rates of crop production (Van der Velde et al., 2014). Recent predictions suggest that global P inputs in grasslands will have to increase fourfold to support an $80 \%$ increase in grass yield projected for 2050 (Sattari et al., 2016).

The widespread occurrence of regions with low P soils and high P soils as well as the projected increase in cost and demand of $P$ fertilisers necessitate a more justified use of $P$ resources. This raises the question whether we apply fertilisers at the right rates to the right soils. The success of fertiliser application is often subject to conditions created by climate and management (Simpson et al., 2014; Syers et al., 2008) and is strongly governed by soil properties such as $\mathrm{pH}$ and concentrations of metals (Hinsinger, 2001; Kovar and Claassen, 2005; McLaughlin et al., 2011). For grassland however, there is only fragmentary country- or region-specific data available for these relationships, and global assessments are lacking (Valkama et al., 2016; Whitehead, 2000). Here we use meta-analysis on a global database of 67 studies and 1227 observations with a wide range of soil properties and climatic conditions to assess the general effect of $P$ fertilisation on grassland 
production across the world. Furthermore, we identify soil-related driving factors that determine the success of fertiliser applications.

Our dataset included studies and observations from field experiments all over the world (Supplementary Fig. 2.1), although there was a strong underrepresentation of African studies (only one study from Nigeria was included). Most studies originated from Europe and North America, but due to several studies with many observations from the Australian continent, there were almost as many observations from Oceania. The number of observations obtained per study ranged from 1 to 204. We analysed our dataset using two different metrics: the response ratio (RR) as measure for the relative increase in yield as a result of $P$ fertilisation, and $P$ agronomic efficiency (PAE) expressing the absolute yield increase per unit of $\mathrm{P}$ applied.

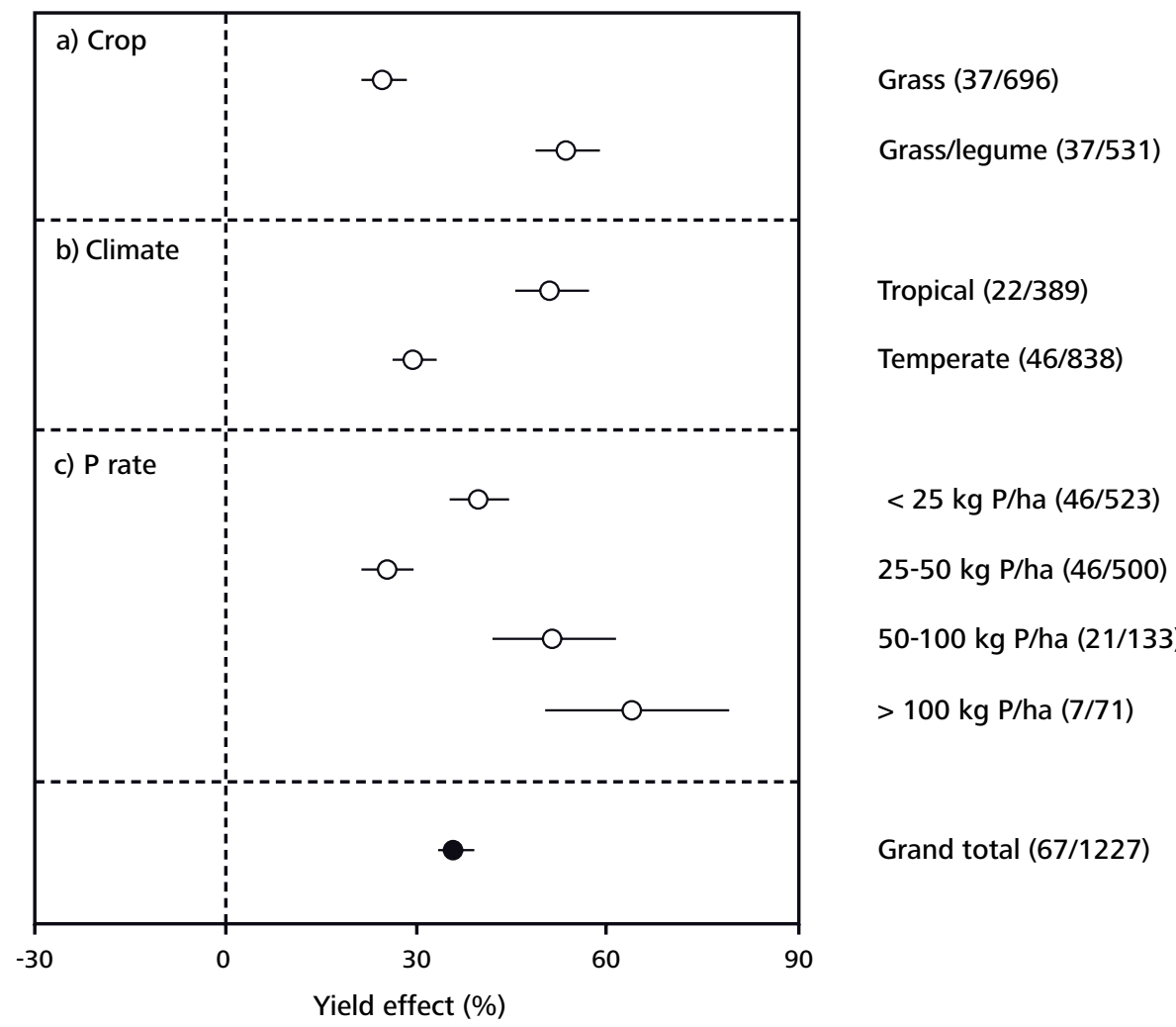

Figure 2.1. Impact of phosphorus (P) fertilisation for the controlling factors crop (a), climate (b), and $P$ rate ( $c$ ) expressed per category. Effect sizes (response ratio) were weighted by the inverse of the variance (VP). The 95\% confidence intervals are represented by the error bars, and the number of studies and observations per category are between brackets. 


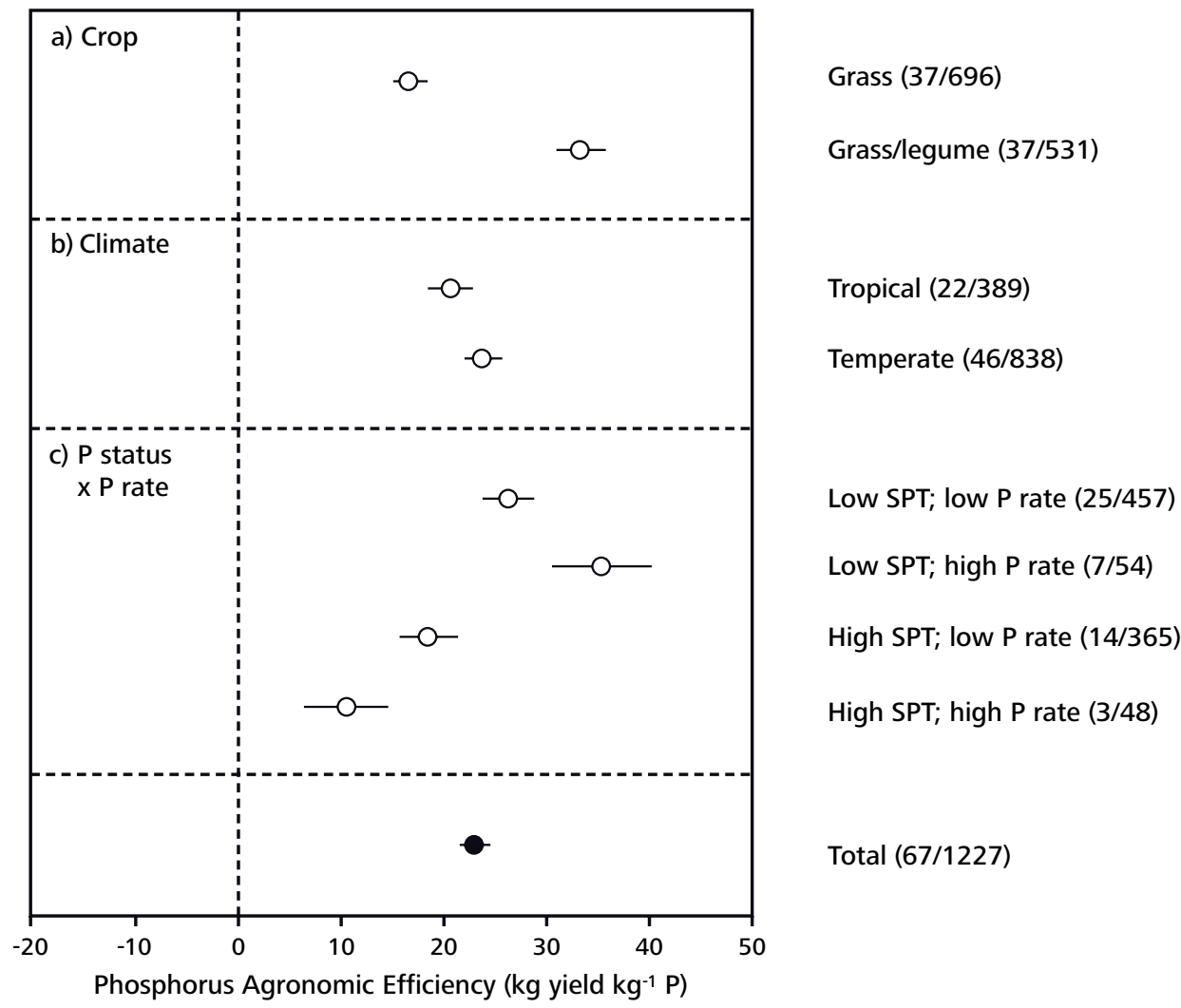

Figure 2.2. The Phosphorus agronomic efficiency for different controlling factors per subgroup. The effect is expressed for crop ( $a)$, climate (b), and $P$ status (Olsen-equivalent) $\times P$ rate (c). Low SPT: $\leq 10 \mathrm{mg} P$ kg-1; high SPT: $>10 \mathrm{mg} P \mathrm{~kg}^{-1}$; low rate: $P$ rate $\leq 50 \mathrm{~kg} P$ ha-1; high rate: $P$ rate $>50 \mathrm{~kg} \mathrm{P} \mathrm{ha-1}$. The 95\% confidence intervals are represented by the error bars, and the number of studies and observations per category are between brackets.

\section{Factors controlling the success of phosphorus fertilisation}

On average, $\mathrm{P}$ fertilisation increased grassland yield by 36\% (95\% confidence interval from 33 to 39\%; Fig. 2.1; Supplementary Table 2.3). In absolute terms, this means that applying P fertiliser resulted in a PAE of $23 \mathrm{~kg}$ dry yield per $\mathrm{kg}$ of $\mathrm{P}$ applied (Fig. 2.2; Supplementary Table 2.5). As expected, higher $\mathrm{P}$ application rates led to higher yields in general: application rates below $25 \mathrm{~kg} P$ $\mathrm{ha}^{-1}$ resulted in a RR of $40 \%$ on average, whereas applying over $100 \mathrm{~kg} \mathrm{P} \mathrm{ha}^{-1}$ increased grass yield by almost $65 \%$. An exception to this pattern were grasslands fertilised with $25-50 \mathrm{~kg} \mathrm{P} \mathrm{ha}^{-1}$, which responded to a lesser extent than those in other categories. This is likely an artefact due to relatively 
high average soil P status of studies included in this category, as illustrated in Supplementary Fig. 2.3, which may have led to relatively high yields in the control treatments. Unsurprisingly, the PAE was the highest with low $\mathrm{P}$ application rates (Supplementary Table 2.5): when applying small amounts of $P$ fertiliser, yields increased by $40 \mathrm{~kg}$ per $\mathrm{kg} P$ applied, whereas this was only $11 \mathrm{~kg} \mathrm{~kg}^{-1}$ $\mathrm{P}$ at rates higher than $100 \mathrm{~kg} \mathrm{P} \mathrm{ha}^{-1}$. This indicates that finding a balance between $\mathrm{P}$ input and yield response is crucial. For the studies in our database for which nitrogen (N) fertilisation rates were known, studies with $\mathrm{N}$ application rates over $200 \mathrm{~kg} \mathrm{~N} \mathrm{ha}^{-1}$ responded slightly weaker than did

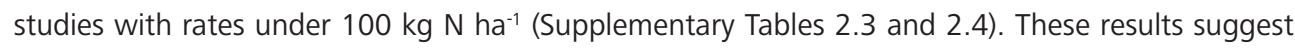
that differences in yield responses found were mainly driven by $\mathrm{P}$ availability in soil and $\mathrm{P}$ application rate. If $\mathrm{N}$ limitation of the crops would have played a prominent role, we would expect an overall increase in response to $P$ fertiliser with increasing $N$ rates. Instead, the RR was $11 \%$ yield at $N$ rates above $200 \mathrm{~kg} \mathrm{ha}^{-1}$ and $19 \%$ at $\mathrm{N}$ applications $<200 \mathrm{~kg} \mathrm{ha}^{-1}$.

Legumes like alfalfa or clover are regularly included in grassland mixtures, mainly because they provide extra protein $\mathrm{N}$ inputs by establishing a symbiosis with $\mathrm{N}$-fixing microorganisms (Whitehead, 2000). Our meta-analysis shows that systems that included legumes responded stronger to $P$ fertilisation than systems without legumes (Fig. 2.1). On average grass/legume studies showed a yield increase of 54\%, whereas grass-only systems responded with $25 \%$ more yield. These numbers corresponded with a PAE of $33 \mathrm{~kg} \mathrm{~kg}^{-1}$ for grass/legume and $17 \mathrm{~kg} \mathrm{~kg}^{-1}$ for grassonly systems, meaning that $P$ fertilisation was roughly twice as effective in grasslands with legumes than in those without legumes. This might partially be explained by the fact that legumes generally require more $P$ than grasses, and can acquire it less easily due to thicker roots and shorter root hairs (Hill et al., 2010, 2005; Simpson et al., 2011).

\section{Do we apply phosphorus fertilisers to the right soils?}

We distinguished between regions by grouping studies conducted in tropical and subtropical regions (i.e. latitudes $\leq 35^{\circ}$ ) versus those in temperate and boreal regions (latitudes $>35^{\circ}$ ). Soils in (sub)tropical regions can be highly weathered, nutrient poor, and often have a low P availability due to abundant presence of adsorbents like Al and Fe oxides (Hinsinger, 2001). Soils in many temperate regions (e.g. North America, Europe, and New Zealand) have been exposed to decades of manure and fertiliser applications, resulting in a build-up of soil $\mathrm{P}$ levels well beyond crop requirements and a corresponding decrease in yield response to P fertiliser application (Sharpley et al., 2013; Toor and Sims, 2015). On average, studies in tropical regions showed a yield increase of 51\%, compared to $30 \%$ in temperate locations (Fig. 2.1, Supplementary Table 2.3). However, as yields of tropical grasslands were relatively low, the PAE of fertiliser application did not differ significantly between the two regions ( 21 and $24 \mathrm{~kg} \mathrm{~kg}^{-1}$ for tropical and temperate regions, respectively; Fig. 2.2, Supplementary Table 2.5). Grouping studies by continent led to more pronounced differences (Supplementary Tables 2.3 and 2.4). We found a significant increase in yield on all continents, with 
a clear difference between a low RR in studies from Asia, North America, and Europe (15-28\% yield increase) and a high RR (58-94\% increase) for South America, Oceania, and Africa. The PAE ranged from $11 \mathrm{~kg} \mathrm{~kg}^{-1}$ for studies in Asia to $55 \mathrm{~kg} \mathrm{~kg}^{-1}$ for studies in Oceania and even $107 \mathrm{~kg} \mathrm{~kg}^{-1}$ for the one African study included in our dataset (Supplementary Table 2.5). These patterns roughly coincide with the grassland P inputs modelled for these continents by Sattari et al. (2016). Areas that responded strongly to $P$ fertilisation (Africa and Oceania) tend to have low $P$ inputs, whereas Western European countries with more intensively managed grasslands with relatively high $\mathrm{P}$ inputs in past decades, showed a weak response to $\mathrm{P}$ fertilisation.

Table 2.1. Controlling factors and categories distinguished in the meta-analysis.

\begin{tabular}{lllll}
\hline Controlling factors & Categories & & \\
\hline Crop & Grass & Grass/legume & & \\
P application rate & $\leq 25 \mathrm{~kg} \mathrm{Pha}^{-1}$ & $25-50 \mathrm{~kg} \mathrm{P} \mathrm{ha}^{-1}$ & $50-100 \mathrm{~kg} \mathrm{P} \mathrm{ha}^{-1}$ & $>100 \mathrm{~kg} \mathrm{P} \mathrm{ha}^{-1}$ \\
Climate & tropical $\left(\leq 35^{\circ}\right)$ & temperate $\left(>35^{\circ}\right)$ & & \\
P status (Olsen-equivalent) & $\leq 5 \mathrm{mg} \mathrm{P} \mathrm{kg}{ }^{-1}$ & $5-10 \mathrm{mg} \mathrm{P} \mathrm{kg}{ }^{-1}$ & $10-25 \mathrm{mg} \mathrm{P} \mathrm{kg}^{-1}$ & $>25 \mathrm{mg} \mathrm{P} \mathrm{kg}^{-1}$ \\
P status $\times$ P rate* & low SPT, low P rate & low SPT, high P rate & high SPT, low P rate & high SPT, high P rate \\
Soil pH & $\leq 5$ & $5-6$ & $6-7$ & $>7$ \\
Soil OM content & $\leq 2 \%$ & $2-5 \%$ & $5-10 \%$ & $>10 \%$ \\
Soil clay content & $\leq 10 \%$ & $10-25 \%$ & $>25 \%$ & \\
N application rate & $\leq 50 \mathrm{~kg} \mathrm{~N} \mathrm{ha}^{-1}$ & $50-100 \mathrm{~kg} \mathrm{~N} \mathrm{ha}^{-1}$ & $100-200 \mathrm{~kg} \mathrm{~N} \mathrm{ha}^{-1}$ & $>200 \mathrm{~kg} \mathrm{~N} \mathrm{ha}^{-1}$ \\
\hline
\end{tabular}

* SPT = Soil phosphorus test. Low SPT: $\leq 10 \mathrm{mg} \mathrm{P} \mathrm{kg-1;} \mathrm{high} \mathrm{SPT:}>10$ mg P kg-1; low rate: P rate $\leq 50 \mathrm{~kg} P$ ha-1; high rate: $\mathrm{P}$ rate $>50 \mathrm{~kg} \mathrm{P}$ ha-1.

\section{$4 \quad$ Understanding the underlying factors: soil properties}

We used various soil parameters as controlling factors (Table 2.1) to identify what soil properties might drive the observed differences in yield response to $P$ fertilisation. One of the most important parameters is the agronomic $\mathrm{P}$ status of the soil. The soil $\mathrm{P}$ status is usually assessed by a soil $\mathrm{P}$ test (SPT) method in which a specific chemical solution is used to extract P from soil. Based on the resulting SPT value, soil is classified as deficient or sufficient, depending on how the yield of a crop responds to the SPT, which requires series of P fertilisation trials (Jordan-Meille et al., 2012; Nawara et al., 2017). Because soil type, climate, and crop response vary considerably across the world, each country and sometimes even region has its own SPT method and classification system 
(Jordan-Meille et al., 2012; Sharpley et al., 2012). The amount of P extracted by different SPTs differs significantly and depends on the nature of the extraction solution as well as the extraction procedure (Nawara et al., 2017). To avoid comparing classifications that may substantially differ per country, we converted SPT values of different methods to Olsen-equivalent values wherever possible using conversion formulas published in peer-reviewed papers (see Supplementary Methods). We found that grasslands on soils with the lowest SPT values ( $\leq 5 \mathrm{mg} \mathrm{P} \mathrm{kg}^{-1}$ ) responded disproportionately strong to P fertilisation with a yield increase of 109\% (Fig. 2.3, Supplementary Table 2.3). Conversely, studies on soils with SPT values $>5 \mathrm{mg} \mathrm{P} \mathrm{kg}^{-1}$ resulted in an increase of $6-23 \%$. Although yield response dramatically decreased with increasing SPT values, the responses at relatively high SPT values (10-25 and $>25 \mathrm{mg} \mathrm{P} \mathrm{kg}^{-1}$ ) were still statistically significant. Johnston et al. (2013) reported critical values (SPT levels for which the yield is $95 \%$ of the maximum yield) for grass of 23-25 mg kg-1 Olsen P. These critical values explain why the RR for soils in the highest category is so small.

The strong relative response to $\mathrm{P}$ fertilisation on soils with the lowest SPT values was not merely the result of the low yield of the control treatments. The same pattern can be observed in the PAE; $49 \mathrm{~kg} \mathrm{~kg}^{-1} \mathrm{P}$ applied on soils with $\leq 5 \mathrm{mg} \mathrm{P} \mathrm{kg}^{-1}$ ) versus $8-20 \mathrm{~kg} \mathrm{~kg}^{-1}$ on soils with SPT values $>5 \mathrm{mg} \mathrm{P} \mathrm{kg}^{-1}$. These results suggest that applying $\mathrm{P}$ fertilisation on soils with SPT values $\leq 5 \mathrm{mg} \mathrm{P} \mathrm{kg}^{-1}$ can be 2.5 to 6 times as effective as on soils with higher SPT values in terms of absolute yield increases. Figure 2.2 shows that both relatively low $\left(\leq 50 \mathrm{~kg} \mathrm{P} \mathrm{ha}^{-1}\right)$ and relatively high ( $>50 \mathrm{~kg} \mathrm{P} \mathrm{ha}^{-1}$ ) P application rates on soils with a low P status ( $\leq 10 \mathrm{mg} \mathrm{P} \mathrm{kg}^{-1}$ Olsen-equivalent) were more effective than any $P$ fertilisation rates on soils with a relatively high $P$ status $(>10 \mathrm{mg}$ $\mathrm{P} \mathrm{kg}{ }^{-1}$ Olsen-equivalent). Furthermore, high application rates on soils with a low $\mathrm{P}$ status had the highest PAE. The high PAE of large application rates may be the result of the binding behaviour of $\mathrm{P}$ in soil: in soils with a low $\mathrm{P}$ status (where relatively more $\mathrm{P}$ adsorption occurs), relatively high $P$ inputs are required to raise the level of plant-available $P$, so grassland on these soils will benefit relatively more from high application rates. Conversely, applying large amounts of $\mathrm{P}$ to soils with a relatively high $\mathrm{P}$ status ( $>10 \mathrm{mg} \mathrm{P} \mathrm{kg}^{-1}$ ) showed a low PAE. Future studies should focus on combining these responses with global maps of soil $\mathrm{P}$ status to further determine the places where $P$ fertiliser is most effectively applied.

Soil $\mathrm{pH}$ is known to be a crucial parameter in determining the availability of $\mathrm{P}$ to crops (Hinsinger, 2001). In acidic mineral soils, adsorption of $\mathrm{P}$ to Fe and $\mathrm{Al}$ (hydr)oxides is often the main factor that governs the levels of plant available $\mathrm{P}$. In contrast, $\mathrm{P}$ is more likely to form poorly soluble Ca-P precipitates, that decrease plant available $\mathrm{P}$, in soils with $\mathrm{pH}$ values above 7 . The relative availability of soil $\mathrm{P}$ is highest at soil $\mathrm{pH}$ levels of 5 to 7 , which would imply that around this $\mathrm{pH}$ fertiliser $\mathrm{P}$ application would yield the strongest responses. In our meta-analysis, the highest RR (60\% yield increase; Fig. 2.3) was found on grasslands with a soil pH of 5 to 6 , whereas lower and higher $\mathrm{pH}$ levels resulted in lower (11-26\%) yield responses. We observed the same pattern for PAE, where studies with a pH of 5 to 6 had a $37 \mathrm{~kg}$ yield increase per $\mathrm{kg}$ of $\mathrm{P}$ fertilised, whereas for soils with a pH above 7 this was only $10 \mathrm{~kg}$ (Supplementary Table 2.5). The relatively low yield response 
to $\mathrm{P}$ application for soils with $\mathrm{pH}$ values of 6 to 7 might be related to the relatively high SPT values for these soils (Supplementary Fig. 2.3).

We found a positive correlation between the soil OM content and yield response to $\mathrm{P}$ fertilisation (Fig. 2.3). On average, yield increased on average by only $11 \%$ following $P$ application to soils with an OM content below $2 \%$ (PAE was $5.4 \mathrm{~kg} \mathrm{~kg}^{-1}$ ). Yield responses were much higher $(41-79 \%)$ in soils with an OM content of $>5 \%$. The PAE was 8 times as high in soils with $>5 \%$ $\mathrm{OM}$ as in soils with $<2 \% \mathrm{OM}$. Phosphorus and OM compete for binding sites on the same soil reactive surfaces, which means that naturally present $\mathrm{OM}$ can decrease the adsorption affinity of $P$ and increase its solubility (Hiemstra et al., 2010b; Regelink et al., 2015). Consequently, $P$ application to soils with a higher OM content is likely to lead to higher levels of soil soluble $\mathrm{P}$ that is readily available to crops, causing $\mathrm{P}$ fertilisation to become more effective. Moreover, higher OM levels in soils can improve soil structure and water holding capacity, enhance aeration and infiltration, and prevent soil erosion. Soils with a relatively high OM content may also have a higher nutrient mineralisation rate. All these effects may alleviate any constraints of plant growth besides $P$ limitation, rendering $P$ applications more effective.

Lastly, we observed an increased response in soils with a relatively high clay content. In fact, in soils with a clay content below $10 \%$, grassland production was not significantly increased by $P$ fertilisation, whereas in soils with more than $25 \%$ we found a yield response of $73 \%$ (Fig. 2.3; Supplementary Table 2.4). Clay is known to be able to retain water and nutrients in soil, and thereby decreases the risks of drought and nutrient limitations. However, considering the size of the subset of studies for which we had information on soil texture (merely 13 studies and 324 observations), these results should be assessed cautiously. 


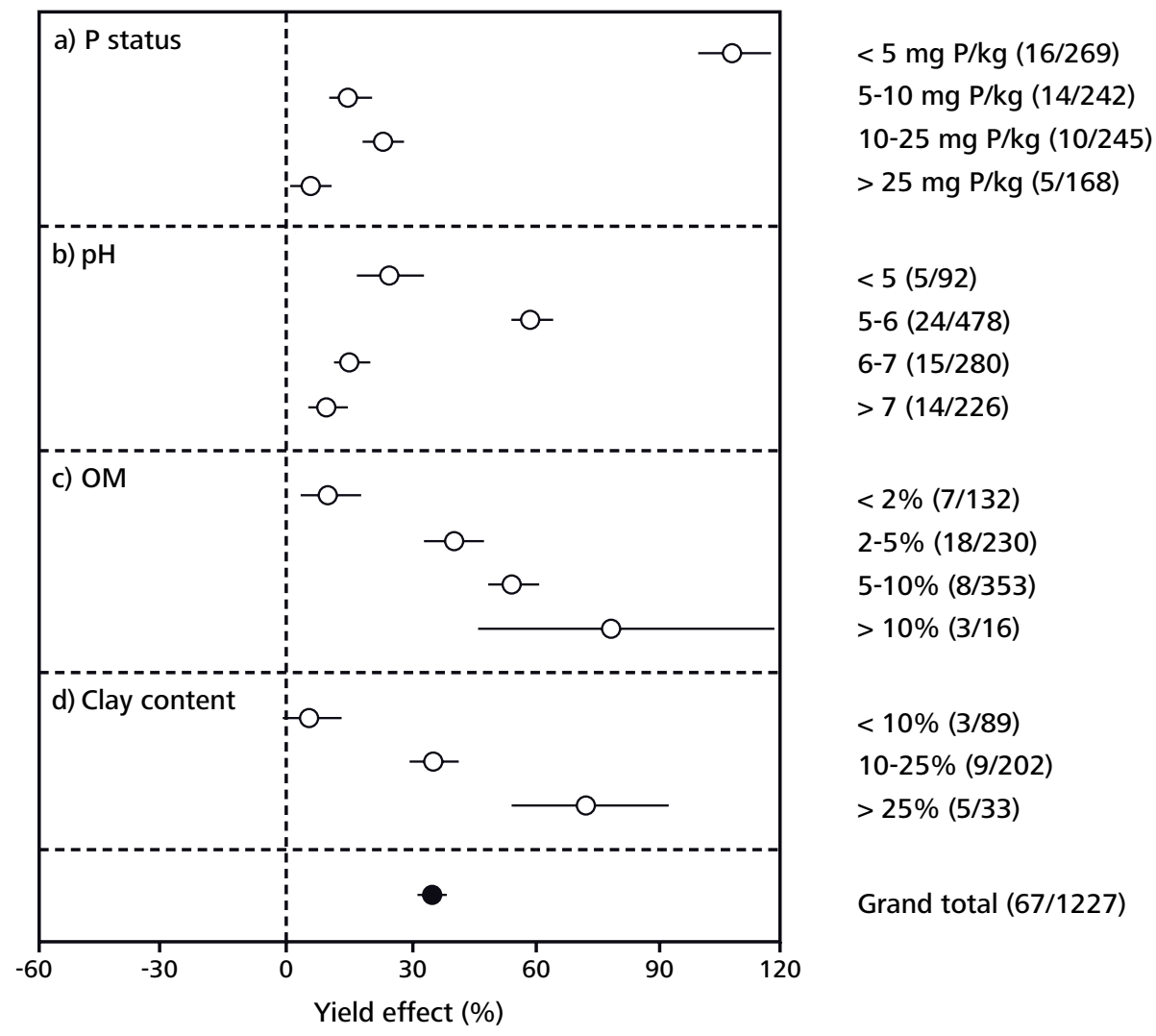

Figure 2.3. Effect of different soil characteristics on the impact of phosphorus (P) fertilisation. The effect is expressed for (a) soil P status based on Olsen P-equivalent, (b) soil pH, (c) organic matter content, and (d) clay content. Effect sizes (response ratio) were weighted by the inverse of the variance (VP). The 95\% confidence intervals are represented by the error bars, and the number of studies and observations per category are between brackets. 


\section{$5 \quad$ Managing future phosphorus inputs in grasslands}

An expansion and intensification of grassland systems during the next decades is inevitable due to the growing world population with an accompanying increasing demand for meat and dairy products (Sattari et al., 2016). Although intensification of these systems may take different forms in various parts of the world (Oenema et al., 2014), maximising production while minimising P losses to the environment will be a unifying characteristic of this intensification process. Effective use of $P$ in manure and fertilisers is essential herein. Our study provides broad and universal guidelines on where to apply $P$, and reveals that there is much to be gained from applying a limited resource more judiciously. Applying $\mathrm{P}$ to the soils with the lowest $\mathrm{P}$ status (Olsen-equivalent of $\leq 5 \mathrm{mg} \mathrm{P} \mathrm{kg}^{-1}$ ) proves most effective in terms of absolute yield increases. Additionally, grasslands on soils with a relatively high OM content and a pH between 6 and 7, as well as grasslands that include legumes represent the agricultural contexts where $P$ fertilisation may achieve its highest potential.

A spatially detailed map of the soil P status of the world's grasslands, which is currently lacking, would be an enormous step towards increasing the efficiency of $P$ fertiliser use in the face of a booming population and dwindling reserves. The development of such maps and the improvement of its spatial accuracy are ongoing (Hengl et al., 2017a, 2017b) and will be a crucial step in ensuring the sensible use of an increasingly scarce resource. Combining this with existing maps for $\mathrm{OM}$ content, $\mathrm{pH}$ and clay would allow us to locate areas with the strongest responses to $\mathrm{P}$ fertilisation. As of now, it is difficult to get a more explicit global overview of where these areas are located. Attempts have been made to compare the agronomical P status of soils across or within continents (Hengl et al., 2017a), but these attempts are often impeded by a lack of comparable and reliable data (Hengl et al., 2017a; Yang et al., 2013). Alternatively, grassland P balances or budgets are often modelled or compared (Bouwman et al., 2013; Sattari et al., 2012, 2016), as these data are more easily obtainable. Still, these data often have poor coverage or spatial resolution and do not consider soil factors, which are of paramount importance for efficient $\mathrm{P}$ use as shown in our study.

Keeping $\mathrm{P}$ budgets of grasslands small increases the possibility of sustainable intensification. This means that fertilisation strategies should not let the soil $P$ status increase to levels above the critical SPT values (Johnston et al., 2013). For soils with a P status around this critical value, application rates that replace the plant P offtake would be acceptable. Higher application rates for soils with a low P status will raise SPT levels over time, resulting in more optimal yields. However, in many intensively managed agricultural systems, application of $\mathrm{P}$ beyond the critical point occurs regularly as a result of high animal numbers per area and associated manure surpluses (Sims et al., 2013; Toor and Sims, 2015). For these regions, P input should be regulated, depending on SPT levels. 


\section{Methods}

We searched the ISI Web of Science database for peer-reviewed publications reporting the effect of $P$ fertilisation on the yield of grassland (see Supplementary Methods) with 31 December 2016 as a cut-off date. The search was limited to field studies of at least one growing season that included a control treatment (experimental treatments differing only in $\mathrm{P}$ fertilisation) and reported the $P$ fertilisation rates. This resulted in a database of 67 studies with 1227 pairwise comparisons (Supplementary Table 2.2). For the selected studies, details on the experimental conditions were collected, which included information on location, presence of legumes, fertiliser form and rates, and soil characteristics such as SPT, OM, and pH. These data were used to define the controlling factors based on which we assessed the effect of $\mathrm{P}$ fertilisation on grassland production (Table 2.1). The magnitude of the total effect and the effect of the controlling factors was determined using two effect sizes. First, we used the natural logarithm of the response ratio $R$ (Hedges and Olkin, 1985):

$\ln (R)=\ln \left(\frac{\overline{x_{e}}}{\overline{x_{c}}}\right)$

with $\overline{x_{e}}$ and $\overline{x_{c}}$ the mean yield of the experimental (P fertilised) and control treatments, respectively. Additionally, we used the $\mathrm{P}$ agronomic efficiency (PAE) to express the gain in yield per unit of $\mathrm{P}$ applied:

$P A E=\frac{\overline{x_{e}}-\overline{x_{c}}}{\text { Prate }}$

with $\mathrm{x}_{\mathrm{e}}$ and $\mathrm{x}_{\mathrm{c}}$ in $\mathrm{kg} \mathrm{ha}^{-1}$ and $\mathrm{P}$ rate in $\mathrm{kg} \mathrm{P} \mathrm{ha}{ }^{-1}$. These effect sizes were weighted by the inverse of their variance (Hedges and Olkin, 1985). For $\mathrm{R}$, we also performed three non-parametric analyses with the observations weights corrected for (i) the number of observations per study; (ii) the number of observations per study and the number of replicates within a study; and (iii) the variance and the number of observations per study (see Supplementary Methods). A significant effect of P fertilisation was assumed when the $95 \%$ confidence interval did not overlap with zero. We considered differences between subgroups significant if the two $95 \%$ confidence intervals did not overlap. All analyses were done using Meta Win 2.1 (Rosenberg et al., 2000). Because the effect of 
using different weighting factors for $\mathrm{R}$ was limited, we only present the results obtained with the conventional factor (inverse of the variance) in the main text. The complete outcomes using the other, non-parametric weighting factors can be found in Supplementary Tables 2.3 and 2.4.

\section{Acknowledgements}

This research has been made possible thanks to a donation by De Heus b.v., on the occasion of the 100th anniversary of the company. 


\section{Supplementary Information}

\section{Supplementary Methods}

\section{Data compilation}

To compile our dataset, we searched the ISI Web of Science database for published peer-reviewed papers with the topic matching the query 'phosphorus AND grass* AND (fertili*er OR fertili*ation) AND (uptake OR yield)', for all years, to a cut-off date of 31 December 2016. We selected publications from the query results that fit all of the following criteria: (i) field studies with an experimental duration of at least one growing season; (ii) studies reporting yield of grass and/or grass/legume mixtures as response variable; and (iii) studies with experimental treatments for which a suitable control treatment could be identified. Control treatments were deemed suitable if experimental factors (i.e. site, sampling time, soil characteristics, and $\mathrm{N}$ application rate) were identical to those in the experimental treatment, and the control treatment did not receive any $P$ fertilisation. This resulted in a database containing 67 studies and 1227 side-by-side comparisons of experimental and control treatments (Supplementary Table 2.2). From these studies, we collected the mean yield, the standard deviation (SD) or standard error (SE), and the number of replicates (n) for the experimental and control treatments. When SD or SE values were missing, proxy SD values were conservatively substituted using the mean of the observation and $150 \%$ of the averaged variance across the entire dataset. Figure error bars that were not labelled were assumed to represent SES, rather than $\mathrm{SDs}(S D=S E \times \sqrt{n})$.

\section{Controlling factors}

In addition to yield means and measures of variance, we extracted soil and environmental data that have been suggested to control the response of plant yield to $P$ fertilisation. For all observations the parameters crop (i.e. grass or grass/legume mixture), $\mathrm{P}$ application rate ( $\mathrm{P}$ rate), and latitude were collected. When available, we also included soil P test (SPT) data on soil P status (value and extraction procedure), soil pH (value and extraction method), soil OM content, soil clay content, and $\mathrm{N}$ application rate ( $\mathrm{N}$ rate). All these parameters were used as controlling factors to make different categorical groups (Table 2.1) which we used to analyse the data. We gathered data on additional variables, such as application rates of $\mathrm{K}$ and $\mathrm{CaCO}_{3^{\prime}}$ grass species and seeding density, and soil extractable Fe and Al. However, these values were not reported consistently enough throughout the studies in the database to be included in the analysis. 
In the included studies, we encountered a wide array of SPT procedures applied throughout the world (Supplementary Fig. 2.2). To be able to compare our response variables for grass yield (defined below) based on the soil P status, we transformed SPT values using the various extraction methods to an 'Olsen P-equivalent' with the help of conversion equations taken from peer-reviewed papers. We chose the Olsen $\mathrm{P}$ test as a reference because it was the most frequently used extraction in our database, and it is used widely across the world. We selected the equations based on largest the number of samples included $(n)$, the quality of fit of the equation $\left(R^{2}>0.7\right)$, and whether the SPT data to be converted fell within the range of SPT values used to derive the equation. Only direct conversions to Olsen $\mathrm{P}$ were used. The resulting selected equations are:

From Otabbong et al. (2009), for P-AL $\left(\mathrm{mg} \mathrm{kg}^{-1}\right)$ to P Olsen $\left(\mathrm{mg} \mathrm{kg}^{-1}\right)$ :

$P_{\text {OlsenEq }}=\left(12.678+0.599 \sqrt{P_{A L}}+0.232 \sqrt{\text { clay\% }}-1.985 \times p H_{H 2 O}\right)^{2}$

$\left(n=82 ; R^{2}=0.94\right)$

From Wolf and Baker (1985), for Bray P1 $\left(\mathrm{mg} \mathrm{kg}^{-1}\right)$, Mehlich $1\left(\mathrm{mg} \mathrm{kg}^{-1}\right)$ and Mehlich $3\left(\mathrm{mg} \mathrm{kg}^{-1}\right)$ to Olsen $\mathrm{P}\left(\mathrm{mg} \mathrm{kg}^{-1}\right)$ :

$P_{\text {OlsenEq }}=0.302 \times P_{\text {BrayP1 }}+2.915$

$\left(n=91 ; R^{2}=0.72\right)$

$P_{\text {OlsenEq }}=0.658 \times P_{\text {Mehlich } 1}-0.408$

$\left(n=91 ; R^{2}=0.87\right)$ 
$P_{\text {OlsenEq }}=0.325 \times P_{\text {Mehlich } 3}+2.010$

$\left(\mathrm{n}=91 ; \mathrm{R}^{2}=0.79\right)$

From Moody et al. (2013), for Colwell P $\left(\mathrm{mg} \mathrm{kg}^{-1}\right)$ to Olsen $\mathrm{P}\left(\mathrm{mg} \mathrm{kg}^{-1}\right)$ :

$P_{\text {olsenEq }}=0.349 \times P_{\text {Colwell }}+1.021$

$\left(n=468 ; R^{2}=0.71\right)$

From Qian et al. (1994), for Modified Kelowna P $\left(\mathrm{mg} \mathrm{kg}^{-1}\right)$ to Olsen P $\left(\mathrm{mg} \mathrm{kg}^{-1}\right)$ :

$P_{\text {OlsenEq }}=1.10 \times P_{\text {ModKelowna }}-0.90$

$\left(n=253 ; R^{2}=0.92\right)$

From Humphreys et al. (1998), for Morgan $\mathrm{P}\left(\mathrm{mg} \mathrm{L}^{-1}\right)$ to Olsen $\mathrm{P}\left(\mathrm{mg} \mathrm{L}^{-1}\right)$ :

$P_{\text {OlsenEq }}=7.14 \times P_{\text {Morgan }}-7.86$

(for values $\leq 10 \mathrm{mg} \mathrm{L}^{-1}$ )

$\left(n=236 ; R^{2}=0.76\right)$

$P_{\text {Morgan }}=5.5-0.22 \times P_{\text {OlsenEq }}+0.008 \times P_{\text {OlsenEq }}{ }^{2}$

(for values $>10 \mathrm{mg} \mathrm{L-1}$ )

$(n=368 ; R 2=0.94)$ 
More details about the SPT conversion can be found in Supplementary Table 2.1. For some studies it was necessary to convert soil $\mathrm{P}$ status from $\mathrm{mg} \mathrm{L}^{-1}$ to $\mathrm{mg} \mathrm{kg}^{-1}$ using the soil:solution ratio (SSR) employed during the extraction procedure, or from $\mathrm{kg} \mathrm{ha}^{-1}$ to $\mathrm{mg} \mathrm{kg}^{-1}$, using bulk density and sampling depth. If bulk density values $\left(\mathrm{g} \mathrm{cm}^{-3}\right)$ were unavailable, a value was calculated using an estimated mineral bulk density based on soil texture in combination with an assumed organic matter (OM) density $\left(0.224 \mathrm{~g} \mathrm{~cm}^{-3}\right.$ ) (Rawls, 1983):

Soil bulk density $=\frac{100}{\frac{\% O M}{\text { OM bulk density }}+\frac{100-\% 0 M}{\text { Mineral bulk density }}}$

Throughout the dataset soil $\mathrm{pH}$ values were measured with different extracts and SSR. Values reported as $\mathrm{pH}-\mathrm{KCl}$ and $\mathrm{pH}-\mathrm{CaCl}_{2}$ were transformed to $\mathrm{pH}-\mathrm{H}_{2} \mathrm{O}$ values using the following equations (Ahern et al., 1995; Kabala et al., 2016):

$p H_{H 2 O(1: 5)}=0.56+1.09 \times p H_{K C l(1: 2.5)}$

$p H_{H 2 O(1: 5)}=0.878+1.001 \times p H_{C a C l 2(1: 5)}$

We did not correct for a difference in SSR if the $\mathrm{pH}$ value that had to be converted was measured at a different SSR than present in the conversion equation, as the effect is expected to be minimal due to the proton buffering capacity of the soil.

Data for $\mathrm{P}$ rate and $\mathrm{N}$ rate were divided into four categories: $\leq 25 ; 25-50 ; 50-100$ and $>100$ $\mathrm{kg} \mathrm{P} \mathrm{ha}^{-1}$ for P rate; and $\leq 50$; 50-100; $100-200$ and $>200 \mathrm{~kg} \mathrm{~N} \mathrm{ha}^{-1}$ for $\mathrm{N}$ rate. Olsen-equivalent $\mathrm{P}$ values were separated into four categories: $\leq 5 ; 5-10 ; 10-25$ and $>25 \mathrm{mg} \mathrm{P} \mathrm{kg}^{-1}$. Across the world, countries use widely different Olsen $\mathrm{P}$ values to delimit the various agronomic $\mathrm{P}$ statuses. Even within a continent, the variation can be considerable: in France a value of $20 \mathrm{mg} \mathrm{kg}^{-1}$ is classified as 'low', whereas in Italy it is considered 'excessive' (Jordan-Meille et al., 2012). In Australia, optimal Olsen P levels for a legume-based pasture are considered to be $\sim 12-15 \mathrm{mg} \mathrm{P} \mathrm{kg}^{-1}$ (Simpson et al., 2014), and in China, critical yield response values have also shown to be around this range (Bai et al., 2013). Additionally, critical values of $23-25 \mathrm{mg} \mathrm{P} \mathrm{kg}^{-1}$ have been reported for grass (Johnston et 
al., 2013). Partly to ensure there would be enough observations per category, we chose to divide the Olsen-equivalent $P$ values into four categories, covering the range of these values $(\leq 5 ; 5-10 ; 10$ 25 and $>25 \mathrm{mg} \mathrm{P} \mathrm{kg}^{-1}$ ). To observe the interaction between $\mathrm{P}$ rate and soil $\mathrm{P}$ status, both controlling factors were divided into two categories ('low' $\leq 50 \mathrm{~kg} \mathrm{P} \mathrm{ha}^{-1}$ and 'high' $>50 \mathrm{~kg} \mathrm{P} \mathrm{ha}^{-1}$ for P rate and 'low' $\leq 10 \mathrm{mg} \mathrm{P} \mathrm{kg}^{-1}$ and 'high' > $10 \mathrm{mg} \mathrm{P} \mathrm{kg}^{-1}$ for SPT). A distinction was made between tropical and subtropical (latitude $\left.\leq 35^{\circ}\right)$ and temperate (latitude $>35^{\circ}$ ) climates. For soil OM content $(\leq 2$; $2-5 ; 5-10$ and $>10 \%)$ and $\mathrm{pH}(\leq 5 ; 5-6 ; 6-7$ and $>7)$, four categories were also distinguished.

\section{Meta-analysis}

The effect size chosen to assess the response of grass and grass/legume yield to $\mathrm{P}$ fertilisation was the natural logarithm of the response ratio $R$ (Hedges et al., 1999):

$$
\ln (R)=\ln \left(\frac{\overline{x_{e}}}{\overline{x_{c}}}\right)
$$

with $\overline{x_{e}}$ and $\overline{x_{c}}$ the means of the experimental (P fertilised) and control treatments respectively.

The outcome of a meta-analysis is partly determined by the weight assigned to each of the observations (Hungate et al., 2009), which can lead to an underestimation of the 95\% confidence interval size. To account for such methodological constraint, we analysed the data using four different (one parametric and three non-parametric) weighting functions:

1. Weighted by the inverse of the pooled variance. This is the conventional weighting method used in meta-analysis (Hedges and Olkin, 1985):

$$
V_{P}=1 /\left(\frac{S D_{e}^{2}}{n_{e} \times{\overline{x_{e}}}^{2}}+\frac{S D_{c}^{2}}{n_{c} \times{\overline{x_{c}}}^{2}}\right)
$$

with $S D_{e}$ and $S D_{c}$ the standard deviations of the experimental and control treatments specifically, and $n_{e}$ and $n_{t}$ the number of replicates in these treatments. 
2. Unweighted, but corrected for the amount of observations contributed per study:

$$
W_{U}=\frac{1}{\sqrt{S}}
$$

with $\mathrm{S}$ the number of observations (pairwise comparisons) by the study providing the observation.

3. Weighted by the amount of replicates and corrected for the amount of observations contributed per study:

$$
W_{R}=\frac{\left(n_{e} \times n_{c}\right)\left(n_{e}+n_{c}\right)}{\sqrt{\bar{S}}}
$$

4. Weighted by the inverse of the pooled variance and corrected for the amount of observations contributed per study:

$$
W_{V}=\frac{V_{P}}{\sqrt{S}}
$$

Additionally we did a parametric analysis to assess the phosphorus agronomic efficiency (PAE). This metric represents the yield increase per $\mathrm{kg}$ of $\mathrm{P}$ fertiliser and is defined as: 
$P A E=\frac{\overline{x_{e}}-\overline{x_{c}}}{\text { Prate }}$

with $\mathrm{x}_{\mathrm{e}}$ and $\mathrm{x}_{\mathrm{c}}$ in $\mathrm{kg} \mathrm{ha}^{-1}$ and $\mathrm{P}$ rate in $\mathrm{kg} \mathrm{P} \mathrm{ha}^{-1}$. This metric was weighted using the standard weighting function:

$$
V_{P}=1 /\left(\frac{\frac{S D_{e}^{2}}{n_{e}}+\frac{S D_{c}^{2}}{n_{c}}}{\text { Prate }^{2}}\right)
$$

For the parametric analysis (weighting function 1), a categorical meta-analysis was done, using a mixed model to calculate 95\% confidence intervals (Hedges and Olkin, 1985). Heterogeneity was separated into within-group $\left(Q_{W}\right)$ and between-group $\left(Q_{B}\right)$ heterogeneity, and controlling factors were assumed to have a significant effect on grass response to $P$ fertilisation if $Q_{B}$ was significant (Curtis and Wang, 1998). Differences between two categories within a controlling factor were considered significantly different if their $95 \%$ confidence intervals did not overlap, and the $\mathrm{Q}_{\mathrm{B}}$ value indicated significance.

For the other, non-parametric analyses, 95\% confidence intervals were calculated using a bootstrapping procedure with 9999 iterations. Data were back-transformed and subsequently reported as percentage of yield increase to allow for an easier interpretation. Effects were considered to be significant in the $95 \%$ confidence interval did not overlap zero, and differences between two categories within controlling factors were considered significantly different if their 95\% confidence intervals did not overlap. All calculations were performed using Metawin Version 2 statistical software (Rosenberg et al., 2000).

Rosenthal's Fail-safe $\mathrm{N}$ technique at $p=0.05$ was used to test the potential impact of publication bias (Rosenthal and Rosnow, 1991). The fail-safe number showed that 1649991,9 studies with null-results (i.e. with an effect size of 0 ) would be needed to make the mean yield response non-significant. This is remarkably higher than the critical value $(5 n+10=6145$, with $n$ as the number of side-by-side comparisons included in the meta-analysis) suggested by Rosenthal. Therefore, it is unlikely that publication bias existed in the literature to a sufficient extent to affect the overall statistical significance of our results.

\section{Limitations of our study}

This study presents an overview of the efficiency of $\mathrm{P}$ fertiliser applications on grassland production and explores the underlying factors and soil properties. Besides the factors shown in Table 2.1, other factors that were not taken into account in this analysis may determine the success of $P$ 
fertilisation of grasslands. Globally, a total amount of $45.9 \mathrm{Mt}_{2} \mathrm{O}_{5}$ is applied as mineral fertiliser $\mathrm{P}$ on the world's cropland (Heffer et al., 2017). Of this total, $1.8 \mathrm{Mt} \mathrm{P}_{2} \mathrm{O}_{5}$ is applied to grasslands, which amounts to $4 \%$. Most of this fertiliser is applied in China (610 kt), Australia (320 kt), New Zealand (319 kt), and the European Union (259 kt). These numbers are small compared to the amount of $\mathrm{P}$ that is applied as manure, which has been estimated to be up to 20 times as high globally in intensive grassland/livestock systems (Sattari et al., 2016). In our meta-analysis there were only three studies that used organic fertiliser as source of P. Although we found more published research on manure (or other forms of organic fertiliser) using the search query described earlier, these studies usually did not account and correct for the other nutrients applied alongside $\mathrm{P}$, and could therefore not be included in this meta-analysis. Depending on the origin, treatment, and composition of manure sources, the response of grass to manure applications may differ from that to mineral fertilisers such as triple superphosphate (Delin, 2016; Kuligowski et al., 2010). Animal manure sources usually contain a variety of organic and inorganic $P$ forms that have to be mineralised and/or dissolve before $P$ is available for plant uptake (Barnett, 1994). Besides the form in which $\mathrm{P}$ is applied, the timing and method of application of P fertiliser can greatly influence the crop response. We had no consistent information on either application method or timing, so these factors were not included in the meta-analysis. Furthermore, there are other soil factors that influence the availability of $P$ to plants, and are thus likely to affect the success of $P$ fertilisation. Most predominantly, the quantities of Al and Fe oxides in soil, which can act as an adsorbent for $\mathrm{P}$, often strongly governs the amount of $\mathrm{P}$ that is available to crops. Generally, there was a lack of information on these quantities: from the studies in our database, merely 11 studies reported some form of information on soil Al and Fe content. Lastly, although we considered differences between grass and grass/legume systems in this study, we did not distinguish between different species, or mixtures of grass species. As grass and legume species vary in their $\mathrm{P}$ requirement and root uptake characteristics, so may their response to P fertilisation (Hamel and Heckman, 2006; Paredes et al., 2011; Ros et al., 2018). 
Supplementary Tables and Figures

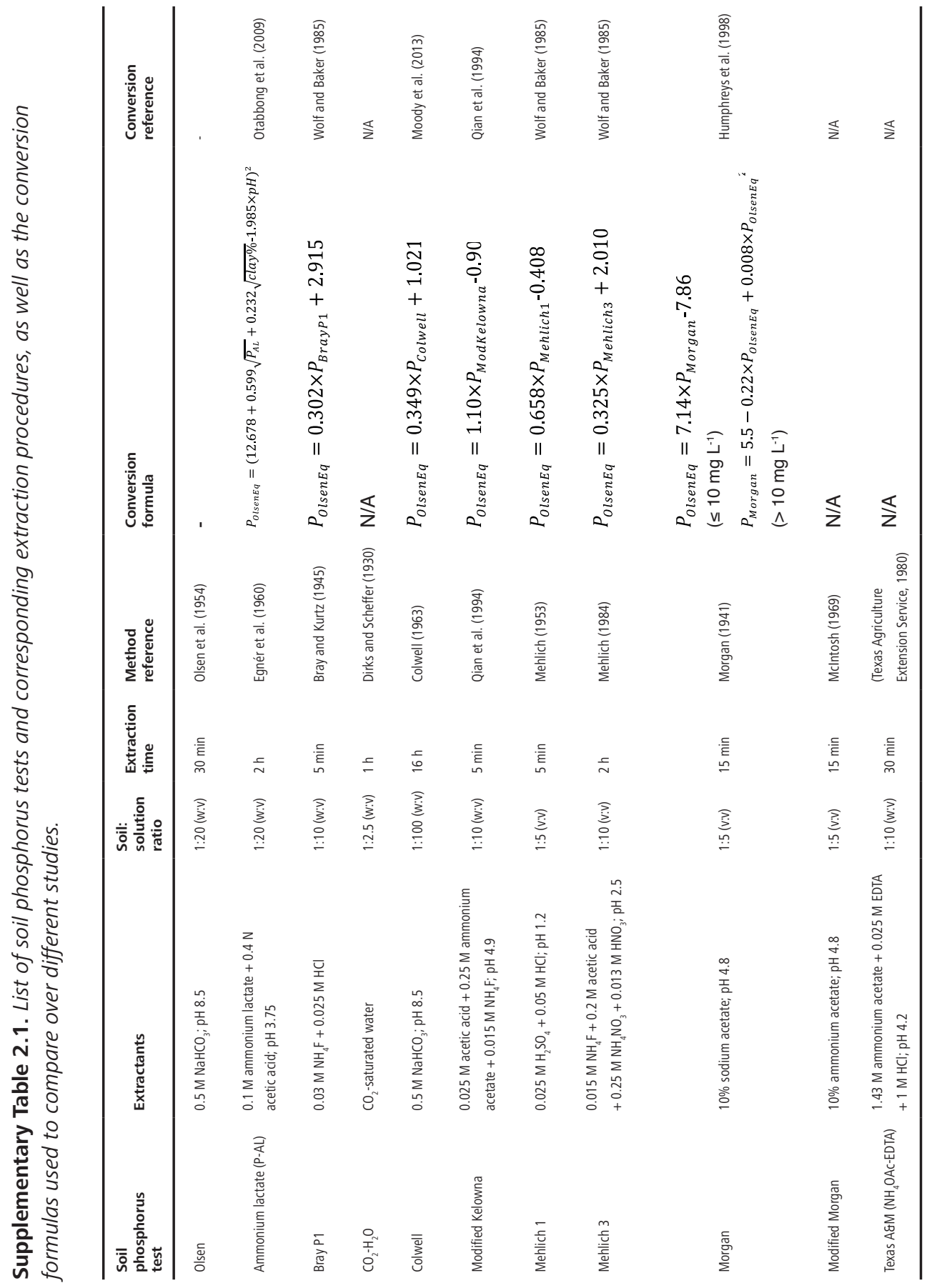


Supplementary Table 2.2. List of the 67 studies included in the meta-analysis. Given for each study are the number of observations contributed, the soil phosphorus test method used, and the inclusion of the study in different subsets to test the effect of controlling factors.

\begin{tabular}{|c|c|c|c|c|c|c|c|}
\hline \multirow[b]{2}{*}{ Study } & \multirow[b]{2}{*}{ \# Obs. } & \multirow[b]{2}{*}{ Soil P Test } & \multicolumn{4}{|c|}{ Contribution of studies to subsets ${ }^{\mathrm{a}}$} & \multirow[b]{2}{*}{$\mathrm{N}$ rate } \\
\hline & & & SPT & $\mathrm{pH}$ & $\mathrm{OM}$ & Clay & \\
\hline Alvim et al. (1992) & 3 & Unknown & & $\mathrm{x}$ & $x$ & & $x$ \\
\hline Atul-Nayyar et al. (2008) & 2 & Olsen & $x$ & $x$ & $x$ & & \\
\hline Aydin and Uzun (2005) & 8 & Olsen & $x$ & $x$ & $x$ & & $x$ \\
\hline Balabanli et al. (2010) & 6 & Olsen & $x$ & $\mathrm{x}$ & $x$ & & $x$ \\
\hline Belarmino et al. (2003) & 9 & Unknown & & $x$ & $x$ & & $x$ \\
\hline Butler and Muir (2006) & 10 & Texas A\&M & & $x$ & & & $x$ \\
\hline Calvière and Duru (1999) & 2 & None & & & & & $x$ \\
\hline Caraballo et al. (1997) & 1 & Unknown & & $x$ & & & $x$ \\
\hline Cayley et al. (1998) & 20 & None & & & & & \\
\hline Coates (1994) & 18 & Colwell & $x$ & & & & \\
\hline Coates et al. (1990) & 30 & Colwell & $x$ & & & & \\
\hline Čop et al. (2009) & 6 & Unknown & & $x$ & $x$ & & $x$ \\
\hline Covacevich et al. (2006) & 24 & Bray P1 & $x$ & $x$ & $x$ & & $x$ \\
\hline Davidson et al. (2004) & 4 & None & & $x$ & & $x$ & $x$ \\
\hline Davison et al. (1997) & 4 & Colwell & $x$ & & & & $x$ \\
\hline Erkovan et al. (2010) & 16 & Olsen & $x$ & $x$ & $x$ & & \\
\hline Griffin and Jurinak (1973) & 8 & Modified Morgan & & & & & $x$ \\
\hline Guretzky et al. (2010) & 12 & Mehlich 3 & $x$ & $x$ & $x$ & & $x$ \\
\hline Haby (2002) & 26 & Texas A\&M & & $x$ & & & $x$ \\
\hline Haynes and Williams (1992) & 2 & None & & & & & \\
\hline Hejcman et al. (2012) & 8 & Mehlich 3 & $x$ & $x$ & & & $x$ \\
\hline Hendricksen et al. (1994) & 2 & Colwell & $x$ & & & & \\
\hline Hillard et al. (1992) & 54 & Texas A\&M & & $\mathrm{x}$ & & & $x$ \\
\hline Honsová et al. (2007) & 41 & None & & $\mathrm{x}$ & & & \\
\hline Jacobsen and Surber (1995) & 6 & Olsen & $x$ & & & & $\mathrm{x}$ \\
\hline Jones and Betteridge (1994) & 2 & Unknown & & & & & \\
\hline Jones et al. (1995) & 96 & Olsen & $x$ & $\mathrm{x}$ & $x$ & $x$ & \\
\hline Junquan et al. (2007) & 3 & Bray P1 & $x$ & $\mathrm{x}$ & & & \\
\hline Kering et al. (2012) & 6 & Unknown & & $\mathrm{x}$ & $x$ & & $x$ \\
\hline Kirkham and Wilkins (1994) & 4 & None & & $x$ & & & $x$ \\
\hline Koc (2013) & 8 & Olsen & $x$ & $x$ & $x$ & & \\
\hline
\end{tabular}




\begin{tabular}{|c|c|c|c|c|c|c|c|}
\hline \multirow[b]{2}{*}{ Study } & \multirow[b]{2}{*}{ \# Obs. } & \multirow[b]{2}{*}{ Soil P Test } & \multicolumn{4}{|c|}{ Contribution of studies to subsets ${ }^{a}$} & \multirow[b]{2}{*}{$\mathrm{N}$ rate } \\
\hline & & & SPT & $\mathrm{pH}$ & OM & Clay & \\
\hline Liebisch et al. (2013) & 4 & $\mathrm{CO}_{2}-\mathrm{H}_{2} \mathrm{O}$ & & $\mathrm{x}$ & $x$ & $\mathrm{x}$ & $\mathrm{x}$ \\
\hline Liebisch et al. (2014) & 1 & None & & & & $\mathrm{x}$ & $x$ \\
\hline Lkhagvasuren et al. (2011) & 24 & Modified Kelowna & $x$ & $x$ & $x$ & & $x$ \\
\hline Loeppky et al. (1999) & 8 & Olsen & $x$ & & & & $x$ \\
\hline Martiniello and Berardo (2007) & 5 & Olsen & $x$ & $x$ & $x$ & $x$ & $x$ \\
\hline Massey et al. (2015) & 3 & Morgan & $x$ & & $x$ & $x$ & $x$ \\
\hline Mendoza et al. (2016) & 2 & Bray P1 & $x$ & $x$ & $x$ & $x$ & \\
\hline Messiga et al. (2014) & 24 & Mehlich 3 & $x$ & & & & $x$ \\
\hline Michael et al. (1991) & 6 & None & & $x$ & & & $x$ \\
\hline Michalk et al. (1998) & 12 & None & & & & & \\
\hline Morton et al. (1998) & 10 & Olsen & $x$ & $x$ & & & \\
\hline Moyer et al. (1995) & 2 & Bray P1 & $x$ & $x$ & & & $x$ \\
\hline Mullen et al. (2000) & 20 & Mehlich 3 & $\mathrm{x}$ & $\mathrm{x}$ & & & \\
\hline Obour et al. (2011) & 6 & Mehlich 1 & $\mathrm{x}$ & $\mathrm{x}$ & & & $x$ \\
\hline Paynter and Dampney (1991) & 2 & Olsen & $\mathrm{x}$ & $x$ & & & $\mathrm{x}$ \\
\hline Peters et al. (1997) & 24 & Bray P1 & $x$ & $x$ & $x$ & $x$ & \\
\hline Polat et al. (2007) & 15 & Unknown & & $x$ & $x$ & & $x$ \\
\hline Potthast et al. (2012) & 2 & Bray P1 & $x$ & & & & $x$ \\
\hline Power et al. (2005) & 120 & Olsen & $x$ & $x$ & & & $x$ \\
\hline Qi et al. (2015) & 2 & Olsen & $x$ & $x$ & $x$ & & \\
\hline Rao et al. (1996) & 80 & Olsen & $x$ & $x$ & $x$ & $x$ & $x$ \\
\hline Rasmussen (1995) & 1 & None & & & $x$ & $\mathrm{x}$ & $x$ \\
\hline Romero and Márquez (2002) & 3 & None & & $x$ & $x$ & & \\
\hline Saarela et al. (2006) & 22 & Olsen & $x$ & $x$ & $x$ & $x$ & $x$ \\
\hline Sale et al. (1997) & 204 & Colwell & $x$ & $x$ & $x$ & & \\
\hline Schellberg et al. (1999) & 6 & None & & $x$ & & & $x$ \\
\hline Schils and Snijders (2004) & 15 & P-AL & $x$ & $x$ & $x$ & & $x$ \\
\hline Scholefield et al. (1999) & 20 & None & & $x$ & & & \\
\hline Seither et al. (2014) & 4 & None & & $x$ & & & $x$ \\
\hline Sheil et al. (2016) & 96 & Morgan & $x$ & $x$ & $x$ & $x$ & $x$ \\
\hline Shi et al. (2016) & 4 & Olsen & $x$ & $x$ & $x$ & & $x$ \\
\hline Smith et al. (2012) & 6 & None & & & & & \\
\hline Stroia et al. (2007) & 2 & Olsen & $\mathrm{x}$ & $x$ & $x$ & $\mathrm{x}$ & $x$ \\
\hline Sweeney et al. (1996) & 2 & Bray P1 & $\mathrm{x}$ & $x$ & $x$ & & $x$ \\
\hline Wedderburn et al. (2005) & 2 & Olsen & $\mathrm{x}$ & $x$ & & & \\
\hline Yolcu et al. (2010) & 27 & Unknown & & $x$ & $x$ & & $x$ \\
\hline
\end{tabular}

${ }^{a}$ An ' $x$ ' indicates that a study was incorporated in a subset to test the corresponding controlling factor. 
Supplementary Table 2.3. Summary of all meta-analysis, including per weighting function: the nature of the effect, the size of the effect and significant differences between categories.

\begin{tabular}{|c|c|c|c|c|c|c|c|c|c|c|c|c|c|c|c|}
\hline Controlling factors & Categories & $\begin{array}{l}\text { Studies } \\
\text { observations }\end{array}$ & and & $V_{p}{ }^{a}$ & & & w & & & $W_{R}$ & & & $w_{v}$ & & \\
\hline Overall average & & $(67 / 1227)$ & & + & $35.9 \%$ & & + & $38.0 \%$ & & + & $28.3 \%$ & & + & $46.9 \%$ & \\
\hline \multirow[t]{2}{*}{ Crop } & Grass & (37/696) & & + & $24.7 \%$ & a & + & $28.7 \%$ & $\mathrm{a}$ & + & $23.2 \%$ & a & + & $32.4 \%$ & a \\
\hline & Grass/legume & (37/531) & & + & $53.5 \%$ & $b$ & + & $48.6 \%$ & $b$ & + & $34.5 \%$ & $b$ & + & $58.3 \%$ & $\mathrm{~b}$ \\
\hline \multirow[t]{4}{*}{ P rate } & $\leq 25 \mathrm{~kg} \mathrm{Pha}^{-1}$ & $(46 / 523)$ & & + & $39.8 \%$ & b & + & $43.2 \%$ & $\mathrm{bc}$ & + & $33.7 \%$ & $b c$ & + & $48.1 \%$ & a \\
\hline & $25-50 \mathrm{~kg} \mathrm{P} \mathrm{ha}^{-1}$ & $(46 / 500)$ & & + & $25.1 \%$ & a & + & $29.2 \%$ & $\mathrm{a}$ & + & $20.9 \%$ & a & + & $40.8 \%$ & a \\
\hline & $50-100 \mathrm{~kg} \mathrm{P} \mathrm{ha}^{-1}$ & $(21 / 133)$ & & + & $51.3 \%$ & $\mathrm{bc}$ & + & $40.6 \%$ & $a b$ & + & $28.0 \%$ & $a b$ & + & $50.5 \%$ & $a b$ \\
\hline & $>100 \mathrm{~kg} \mathrm{P} \mathrm{ha}^{-1}$ & (7/71) & & + & $63.8 \%$ & c & + & $64.6 \%$ & c & + & $51.9 \%$ & c & + & $81.5 \%$ & $\mathrm{~b}$ \\
\hline \multirow[t]{2}{*}{ Climate } & Tropical $\left(\leq 35^{\circ}\right)$ & (22/389) & & + & $51.0 \%$ & $b$ & + & $56.9 \%$ & $b$ & + & $47.7 \%$ & $b$ & + & $70.0 \%$ & $\mathrm{~b}$ \\
\hline & Temperate $\left(>35^{\circ}\right)$ & $(46 / 838)$ & & + & $29.5 \%$ & a & + & $29.9 \%$ & a & + & $21.5 \%$ & a & + & $36.1 \%$ & a \\
\hline \multirow[t]{6}{*}{ Continent } & Africa & $(1 / 24)$ & & + & $79.9 \%$ & $c d$ & + & $79.9 \%$ & $b$ & + & $79.9 \%$ & $\mathrm{~b}$ & + & $79.9 \%$ & c \\
\hline & Asia & $(10 / 177)$ & & + & $16.2 \%$ & a & + & $23.0 \%$ & a & + & $23.2 \%$ & a & + & $24.6 \%$ & $a b$ \\
\hline & Europe & $(19 / 367)$ & & + & $14.7 \%$ & a & + & $21.1 \%$ & a & + & $17.8 \%$ & a & + & $16.2 \%$ & a \\
\hline & North America & (20/327) & & + & $28.2 \%$ & $b$ & + & $24.9 \%$ & a & + & $16.9 \%$ & a & + & $19.8 \%$ & a \\
\hline & Oceania & $(11 / 300)$ & & + & $94.2 \%$ & $d$ & + & $97.6 \%$ & $b$ & + & $75.7 \%$ & $b$ & + & $75.7 \%$ & c \\
\hline & South America & $(8 / 48)$ & & + & $58.4 \%$ & c & + & $63.0 \%$ & $b$ & + & $73.8 \%$ & $b$ & + & $59.1 \%$ & $\mathrm{bc}$ \\
\hline \multirow[t]{4}{*}{ P status } & $\leq 5 \mathrm{mg} \mathrm{P} \mathrm{kg}^{-1}$ & $(16 / 269)$ & & + & $108.5 \%$ & c & + & $84.6 \%$ & c & + & $62.6 \%$ & c & + & $97.5 \%$ & c \\
\hline & $5-10 \mathrm{mg} \mathrm{P} \mathrm{kg}^{-1}$ & $(14 / 242)$ & & + & $15.8 \%$ & $a b$ & + & $15.8 \%$ & $\mathrm{~b}$ & + & $18.2 \%$ & $b$ & + & $11.6 \%$ & a \\
\hline & $10-25 \mathrm{mg} \mathrm{P} \mathrm{kg}^{-1}$ & $(10 / 245)$ & & + & $23.9 \%$ & $b$ & + & $21.7 \%$ & b & + & $10.0 \%$ & a & + & $39.9 \%$ & $b$ \\
\hline & $>25 \mathrm{mg} \mathrm{P} \mathrm{kg}^{-1}$ & $(5 / 168)$ & & + & $6.4 \%$ & a & + & $8.5 \%$ & a & + & $8.1 \%$ & a & + & $12.5 \%$ & a \\
\hline \multirow[t]{5}{*}{ P status $\times$ P rate ${ }^{b}$} & Low SPT; low P rate & $(25 / 457)$ & & + & $49.4 \%$ & $b$ & + & $44.8 \%$ & $b$ & + & $34.6 \%$ & $b$ & + & $56.5 \%$ & $b$ \\
\hline & Low SPT; high P rate & $(7 / 54)$ & & + & $127.6 \%$ & c & + & $95.4 \%$ & c & + & $91.9 \%$ & c & + & $105.9 \%$ & $b$ \\
\hline & High SPT; low P rate & $(14 / 365)$ & & + & $13.9 \%$ & a & + & $14.4 \%$ & a & + & $8.8 \%$ & a & + & $19.7 \%$ & a \\
\hline & High SPT; high P rate & $(3 / 48)$ & & + & $46.4 \%$ & $b$ & + & $31.0 \%$ & $b$ & + & $13.3 \%$ & a & + & $54.3 \%$ & $b$ \\
\hline & P status subset total & (39/924) & & + & $35.8 \%$ & & + & $34.7 \%$ & & + & $22.0 \%$ & & + & $45.7 \%$ & \\
\hline \multirow[t]{5}{*}{ Soil pH } & $\leq 5$ & (5/92) & & + & $25.7 \%$ & $b$ & + & $25.5 \%$ & a & + & $24.5 \%$ & a & + & $25.8 \%$ & $b$ \\
\hline & $5-6$ & (24/478) & & + & $59.6 \%$ & c & + & $48.3 \%$ & b & + & $46.8 \%$ & b & + & $53.3 \%$ & c \\
\hline & $6-7$ & $(15 / 280)$ & & + & $16.3 \%$ & $a b$ & + & $21.5 \%$ & a & + & $17.9 \%$ & a & + & $21.4 \%$ & $a b$ \\
\hline & $>7$ & $(14 / 226)$ & & + & $10.6 \%$ & a & + & $17.0 \%$ & a & + & $15.4 \%$ & a & + & $15.9 \%$ & a \\
\hline & pH subset total & $(49 / 1076)$ & & + & $32.4 \%$ & & + & $31.2 \%$ & & + & $27.6 \%$ & & + & $32.0 \%$ & \\
\hline \multirow[t]{5}{*}{ Soil OM content } & $\leq 2 \%$ & $(7 / 132)$ & & + & $11.0 \%$ & a & + & $26.0 \%$ & $a b$ & + & $40.9 \%$ & $a b$ & + & $19.9 \%$ & a \\
\hline & $2-5 \%$ & $(18 / 230)$ & & + & $40.8 \%$ & b & + & $33.6 \%$ & a & + & $27.6 \%$ & a & + & $27.5 \%$ & a \\
\hline & 5-10\% & $(8 / 353)$ & & + & $55.4 \%$ & c & + & $49.6 \%$ & b & + & $42.1 \%$ & $b$ & + & $67.8 \%$ & $b$ \\
\hline & $>10 \%$ & $(3 / 16)$ & & + & $79.0 \%$ & $\mathrm{bc}$ & + & $61.5 \%$ & b & + & $57.0 \%$ & b & + & $97.5 \%$ & c \\
\hline & OM subset total & (31/731) & & + & $42.6 \%$ & & + & $38.2 \%$ & & + & $35.1 \%$ & & + & $37.4 \%$ & \\
\hline
\end{tabular}




\begin{tabular}{|c|c|c|c|c|c|c|c|c|c|c|c|c|c|}
\hline Controlling factors & Categories & $\begin{array}{l}\text { Studies and } \\
\text { observations }\end{array}$ & $\mathbf{V}_{\mathrm{P}}^{\mathrm{a}}$ & & & $\mathbf{w}_{\mathrm{u}}$ & & & $\mathbf{W}_{\mathrm{R}}$ & & & $\mathrm{W}_{\mathrm{v}}$ & \\
\hline \multirow[t]{4}{*}{ Soil clay content } & $\leq 10 \%$ & $(3 / 89)$ & 0 & $6.6 \%$ & $\mathrm{a}$ & + & $8.6 \%$ & $\mathrm{a}$ & + & $9.6 \%$ & $a$ & $+\quad 7.8 \%$ & $\mathrm{a}$ \\
\hline & $10-25 \%$ & $(9 / 202)$ & + & $36.4 \%$ & $b$ & + & $50.8 \%$ & $b$ & + & $44.1 \%$ & $b$ & $+\quad 60.8 \%$ & $\mathrm{~b}$ \\
\hline & $>25 \%$ & $(5 / 33)$ & + & $73.0 \%$ & $c$ & + & $68.7 \%$ & $b$ & + & $65.3 \%$ & $b$ & $+\quad 103.9 \%$ & $\mathrm{~b}$ \\
\hline & Clay subset total & $(13 / 324)$ & + & $31.1 \%$ & & + & $44.7 \%$ & & + & $39.9 \%$ & & $+\quad 52.3 \%$ & \\
\hline \multirow[t]{5}{*}{$\mathrm{N}$ rate } & $\leq 50 \mathrm{~kg} \mathrm{~N} \mathrm{ha}^{-1}$ & $(19 / 127)$ & + & $19.6 \%$ & $\mathrm{~b}$ & + & $26.6 \%$ & $\mathrm{~b}$ & + & $25.7 \%$ & $b$ & $+\quad 22.7 \%$ & \\
\hline & $50-100 \mathrm{~kg} \mathrm{~N} \mathrm{ha}^{-1}$ & $(21 / 169)$ & + & $20.6 \%$ & $\mathrm{~b}$ & + & $26.6 \%$ & $\mathrm{~b}$ & + & $21.6 \%$ & $a b$ & $+\quad 27.6 \%$ & \\
\hline & $100-200 \mathrm{~kg} \mathrm{~N} \mathrm{ha}^{-1}$ & $(15 / 96)$ & + & $18.2 \%$ & $a b$ & + & $25.5 \%$ & $a b$ & + & $17.4 \%$ & $a b$ & $+\quad 29.7 \%$ & \\
\hline & $>200 \mathrm{~kg} \mathrm{~N} \mathrm{ha}^{-1}$ & $(11 / 275)$ & + & $11.2 \%$ & $\mathrm{a}$ & + & $14.1 \%$ & $\mathrm{a}$ & + & $12.8 \%$ & $\mathrm{a}$ & $+\quad 15.1 \%$ & \\
\hline & $\mathrm{N}$ rate Subset total & $(44 / 667)$ & + & $16.0 \%$ & & +- & $22.7 \%$ & & + & $19.1 \%$ & & $+\quad 23.2 \%$ & \\
\hline
\end{tabular}

a For each of the weighting functions and subgroups a + indicates a significant positive effect (95\% confidence interval >0) and a 0 indicates non-significance (95\% confidence interval overlaps 0 ). Letters indicate significant differences within categories. Values with the same letter per controlling factor, per weighting method, are not significantly different.

${ }^{\mathrm{b}}$ Low SPT: Olsen-equivalent $\mathrm{P}$ status $\leq 10 \mathrm{mg} \mathrm{P} \mathrm{kg}^{-1}$; High SPT: Olsen-equivalent $\mathrm{P}$ status > $10 \mathrm{mg} \mathrm{P} \mathrm{kg}^{-1}$; low $\mathrm{P}$ rate: $\leq 50 \mathrm{~kg} \mathrm{P} \mathrm{ha-1}$; high $\mathrm{P}$ rate: $>50 \mathrm{~kg} \mathrm{P} \mathrm{ha}^{-1}$. 
Supplementary Table 2.4. Averages and 95\% confidence interval limits for all analyses per weighting factor.

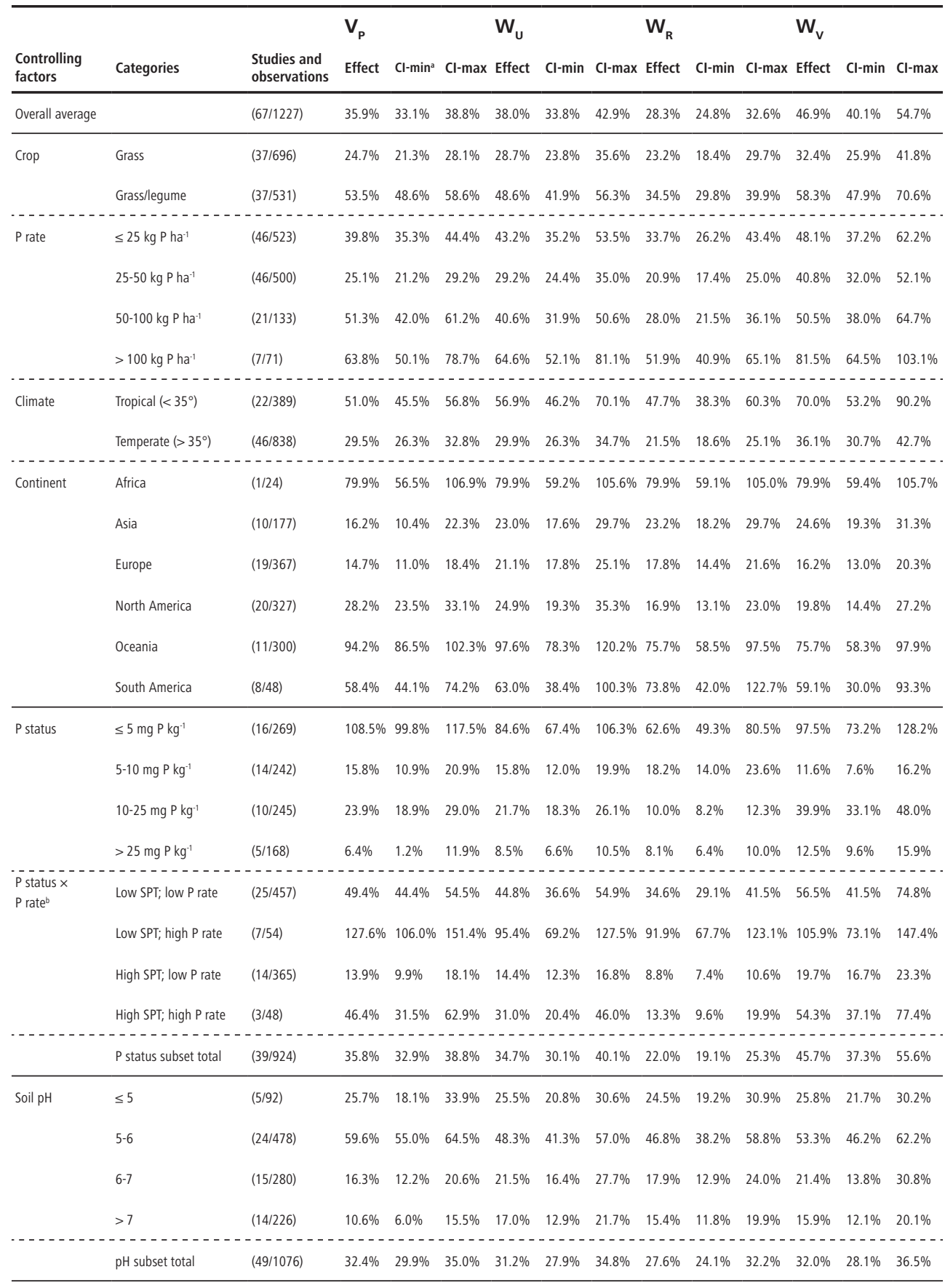




\begin{tabular}{|c|c|c|c|c|c|c|c|c|c|c|c|c|c|c|}
\hline & & & $\mathbf{V}_{\mathrm{P}}$ & & & $\mathbf{W}_{\mathrm{u}}$ & & & $W_{R}$ & & & $w_{v}$ & & \\
\hline $\begin{array}{l}\text { Controlling } \\
\text { factors }\end{array}$ & Categories & $\begin{array}{l}\text { Studies and } \\
\text { observations }\end{array}$ & Effect & $\mathrm{Cl}-\mathrm{min}^{\mathrm{a}}$ & Cl-max & Effect & $\mathrm{Cl}-\mathrm{min}$ & $\mathrm{Cl}-\max$ & Effect & $\mathrm{Cl}-\mathrm{min}$ & Cl-max & Effect & $\mathrm{Cl}-\min$ & $\mathrm{Cl}-\max$ \\
\hline Overall average & & $(67 / 1227)$ & $35.9 \%$ & $33.1 \%$ & $38.8 \%$ & $38.0 \%$ & $33.8 \%$ & $42.9 \%$ & $28.3 \%$ & $24.8 \%$ & $32.6 \%$ & $46.9 \%$ & $40.1 \%$ & $54.7 \%$ \\
\hline \multirow[t]{6}{*}{ Soil OM content } & $\leq 2 \%$ & $(7 / 132)$ & $11.0 \%$ & $3.9 \%$ & $18.7 \%$ & $26.0 \%$ & $9.8 \%$ & $55.2 \%$ & $40.9 \%$ & $14.0 \%$ & $80.4 \%$ & $19.9 \%$ & $7.3 \%$ & $40.4 \%$ \\
\hline & $2-5 \%$ & $(18 / 230)$ & $40.8 \%$ & $34.0 \%$ & $48.1 \%$ & $33.6 \%$ & $28.9 \%$ & $38.8 \%$ & $27.6 \%$ & $22.8 \%$ & $33.2 \%$ & $27.5 \%$ & $21.6 \%$ & $33.5 \%$ \\
\hline & $5-10 \%$ & $(8 / 353)$ & $55.4 \%$ & $49.4 \%$ & $61.7 \%$ & $49.6 \%$ & $42.8 \%$ & $57.4 \%$ & $42.1 \%$ & $36.1 \%$ & $49.5 \%$ & $67.8 \%$ & $58.5 \%$ & $78.3 \%$ \\
\hline & $>10 \%$ & $(3 / 16)$ & $79.0 \%$ & $46.6 \%$ & $118.5 \%$ & $61.5 \%$ & $42.4 \%$ & $88.5 \%$ & $57.0 \%$ & $38.6 \%$ & $85.7 \%$ & $97.5 \%$ & $78.4 \%$ & $116.7 \%$ \\
\hline & ---------- & ----- & ----- & ---- & ----- & ---- & ---- & ---- & ---- & ---- & ----- & ---- & ---- & ---- \\
\hline & OM subset total & $(31 / 731)$ & $42.6 \%$ & $38.7 \%$ & $46.6 \%$ & $38.2 \%$ & $33.4 \%$ & $45.0 \%$ & $35.1 \%$ & $29.2 \%$ & $42.8 \%$ & $37.4 \%$ & $31.8 \%$ & $45.2 \%$ \\
\hline \multirow[t]{3}{*}{ Soil clay content } & $\leq 10 \%$ & $(3 / 89)$ & $6.6 \%$ & $-0.3 \%$ & $13.9 \%$ & $8.6 \%$ & $3.1 \%$ & $15.7 \%$ & $9.6 \%$ & $3.6 \%$ & $17.5 \%$ & $7.8 \%$ & $2.5 \%$ & $14.2 \%$ \\
\hline & $10-25 \%$ & $(9 / 202)$ & $36.4 \%$ & $30.9 \%$ & $42.1 \%$ & $50.8 \%$ & $38.5 \%$ & $75.1 \%$ & $44.1 \%$ & $33.4 \%$ & $63.6 \%$ & $60.8 \%$ & $37.8 \%$ & $93.6 \%$ \\
\hline & $>25 \%$ & $(5 / 33)$ & $73.0 \%$ & $55.0 \%$ & $93.1 \%$ & $68.7 \%$ & $43.1 \%$ & $136.3 \%$ & $65.3 \%$ & $35.1 \%$ & $113.8 \%$ & $103.9 \%$ & $57.4 \%$ & $171.2 \%$ \\
\hline \multicolumn{15}{|l|}{ - - - - - - } \\
\hline & Clay subset total & $(13 / 324)$ & $31.1 \%$ & $26.9 \%$ & $35.5 \%$ & $44.7 \%$ & $34.4 \%$ & $59.8 \%$ & $39.9 \%$ & $30.8 \%$ & $52.9 \%$ & $52.3 \%$ & $37.1 \%$ & $72.4 \%$ \\
\hline \multirow[t]{4}{*}{$\mathrm{N}$ rate } & $\leq 50 \mathrm{~kg} \mathrm{~N} \mathrm{ha}^{-1}$ & $(19 / 127)$ & $19.6 \%$ & $14.4 \%$ & $25.1 \%$ & $26.6 \%$ & $19.2 \%$ & $34.7 \%$ & $25.7 \%$ & $18.5 \%$ & $34.2 \%$ & $22.7 \%$ & $15.0 \%$ & $31.9 \%$ \\
\hline & $50-100 \mathrm{~kg} \mathrm{~N} \mathrm{ha}^{-1}$ & $(21 / 169)$ & $20.6 \%$ & $16.5 \%$ & $24.8 \%$ & $26.6 \%$ & $18.4 \%$ & $38.4 \%$ & $21.6 \%$ & $14.8 \%$ & $31.9 \%$ & $27.6 \%$ & $17.1 \%$ & $45.6 \%$ \\
\hline & $100-200 \mathrm{~kg} \mathrm{~N} \mathrm{ha}^{-1}$ & $(15 / 96)$ & $18.2 \%$ & $12.6 \%$ & $24.0 \%$ & $25.5 \%$ & $14.5 \%$ & $50.4 \%$ & $17.4 \%$ & $10.8 \%$ & $31.7 \%$ & $29.7 \%$ & $14.3 \%$ & $67.4 \%$ \\
\hline & $>200 \mathrm{~kg} \mathrm{~N} \mathrm{ha}^{-1}$ & $(11 / 275)$ & $11.2 \%$ & $8.2 \%$ & $14.3 \%$ & $14.1 \%$ & $11.7 \%$ & $16.8 \%$ & $12.8 \%$ & $9.8 \%$ & $15.9 \%$ & $15.1 \%$ & $12.3 \%$ & $18.3 \%$ \\
\hline \multicolumn{15}{|c|}{ - - - - - - - - - - - - - - - - - - - - - - - - - - - - - - - - - - - - - - - - - - - - - - - - - - - - - - - - - - - - - - - - - - - - - - - - - - - - - } \\
\hline & $\mathrm{N}$ rate subset total & $(44 / 667)$ & $16.0 \%$ & $14.0 \%$ & $18.1 \%$ & $22.7 \%$ & $18.8 \%$ & $28.2 \%$ & $19.1 \%$ & $15.6 \%$ & $23.6 \%$ & $23.2 \%$ & $18.0 \%$ & $30.9 \%$ \\
\hline
\end{tabular}

a $\mathrm{Cl}$-min indicates the lower limit of the 95\% confidence interval; $\mathrm{Cl}$-max indicates the upper limit of the $95 \%$ confidence interval.

${ }^{\mathrm{b}}$ Low SPT: Olsen-equivalent $\mathrm{P}$ status $\leq 10 \mathrm{mg} \mathrm{P} \mathrm{kg}{ }^{-1}$; High SPT: Olsen-equivalent $\mathrm{P}$ status > $10 \mathrm{mg} \mathrm{P} \mathrm{kg}^{-1}$; low $\mathrm{P}$ rate: $\leq 50 \mathrm{~kg} \mathrm{P} \mathrm{ha-1}$; high $\mathrm{P}$ rate: $>50 \mathrm{~kg} \mathrm{P} \mathrm{ha-1.}$ 
Supplementary Table 2.5. Summary of the results for the phosphorus agronomic efficiency (PAE; $\mathrm{kg} \mathrm{kg}^{-1}$ ), including the nature of the effect, the size of the effect, significant differences between categories, and the confidence interval.

\begin{tabular}{|c|c|c|c|c|c|c|c|}
\hline Controlling factors & Categories & $\begin{array}{l}\text { Studies and } \\
\text { observations }\end{array}$ & PA & & & $\mathrm{Cl}-\mathrm{min}^{\mathrm{b}}$ & Cl-max \\
\hline Overall average & & $(67 / 1227)$ & + & 23.0 & & 21.7 & 24.4 \\
\hline \multirow[t]{2}{*}{ Crop } & Grass & $(37 / 696)$ & + & 16.8 & a & 15.1 & 18.4 \\
\hline & Grass/legume & $(37 / 531)$ & + & 33.3 & b & 31.0 & 35.6 \\
\hline \multirow[t]{4}{*}{$P$ rate } & $\leq 25 \mathrm{~kg} \mathrm{P} \mathrm{ha}^{-1}$ & $(46 / 523)$ & + & 40.6 & c & 37.4 & 43.9 \\
\hline & $25-50 \mathrm{~kg} \mathrm{P} \mathrm{ha}^{-1}$ & $(46 / 500)$ & + & 20.2 & $\mathrm{~b}$ & 18.1 & 22.3 \\
\hline & $50-100 \mathrm{~kg} \mathrm{P} \mathrm{ha}^{-1}$ & $(21 / 133)$ & + & 25.1 & $b$ & 21.8 & 28.3 \\
\hline & $>100 \mathrm{~kg} \mathrm{P} \mathrm{ha}^{-1}$ & $(7 / 71)$ & + & 11.2 & a & 7.9 & 14.5 \\
\hline \multirow[t]{2}{*}{ Climate } & Tropical $\left(\leq 35^{\circ}\right)$ & $(22 / 389)$ & + & 20.7 & & 18.6 & 22.8 \\
\hline & Temperate $\left(>35^{\circ}\right)$ & $(46 / 838)$ & + & 23.8 & & 22.1 & 25.5 \\
\hline \multirow[t]{6}{*}{ Continent } & Africa & $(1 / 24)$ & + & 106.7 & $d$ & 89.2 & 124.3 \\
\hline & Asia & $(10 / 177)$ & + & 10.6 & a & 7.9 & 13.3 \\
\hline & Europe & $(19 / 367)$ & + & 20.3 & b & 17.7 & 23.0 \\
\hline & North America & $(20 / 327)$ & + & 13.7 & a & 11.6 & 15.8 \\
\hline & Oceania & $(11 / 300)$ & + & 54.7 & c & 51.2 & 58.3 \\
\hline & South America & $(8 / 48)$ & + & 51.3 & c & 44.8 & 57.8 \\
\hline \multirow[t]{4}{*}{ P status } & $\leq 5 \mathrm{mg} \mathrm{P} \mathrm{kg}^{-1}$ & $(16 / 269)$ & + & 49.0 & c & 45.7 & 52.3 \\
\hline & $5-10 \mathrm{mg} \mathrm{P} \mathrm{kg}^{-1}$ & $(14 / 242)$ & + & 12.4 & $\mathrm{a}$ & 9.5 & 15.3 \\
\hline & $10-25 \mathrm{mg} \mathrm{P} \mathrm{kg}^{-1}$ & $(10 / 245)$ & + & 20.2 & $\mathrm{~b}$ & 17.3 & 23.1 \\
\hline & $>25 \mathrm{mg} \mathrm{P} \mathrm{kg}^{-1}$ & $(5 / 168)$ & + & 7.8 & a & 3.9 & 11.6 \\
\hline \multirow[t]{5}{*}{$P$ status $\times P$ rate $^{c}$} & Low SPT; low P rate & $(25 / 457)$ & + & 26.3 & c & 23.9 & 28.8 \\
\hline & Low SPT; high P rate & $(7 / 54)$ & + & 35.4 & $d$ & 30.5 & 40.2 \\
\hline & High SPT; low P rate & $(14 / 365)$ & + & 18.5 & $\mathrm{~b}$ & 15.6 & 21.3 \\
\hline & High SPT; high $\mathrm{P}$ rate & $(3 / 48)$ & + & 10.4 & a & 6.3 & 14.5 \\
\hline & $P$ status subset total & (39/924) & + & 22.2 & & 20.6 & 23.8 \\
\hline \multirow[t]{5}{*}{ Soil pH } & $\leq 5$ & $(5 / 92)$ & + & 13.0 & $a$ & 9.3 & 16.7 \\
\hline & $5-6$ & $(24 / 478)$ & + & 37.0 & c & 34.7 & 39.2 \\
\hline & $6-7$ & $(15 / 280)$ & + & 20.3 & $\mathrm{~b}$ & 17.4 & 23.2 \\
\hline & $>7$ & $(14 / 226)$ & + & 8.6 & a & 6.0 & 11.2 \\
\hline & pH subset total & (49/1076) & + & 22.1 & & 20.7 & 23.4 \\
\hline
\end{tabular}




\begin{tabular}{|c|c|c|c|c|c|c|}
\hline Controlling factors & Categories & $\begin{array}{l}\text { Studies and } \\
\text { observations }\end{array}$ & $\mathrm{PAE}^{\mathrm{a}}$ & & $\mathrm{Cl}-\min ^{\mathrm{b}}$ & Cl-max \\
\hline Overall average & & $(67 / 1227)$ & +23.0 & & 21.7 & 24.4 \\
\hline \multirow[t]{5}{*}{ Soil OM content } & $\leq 2 \%$ & $(7 / 132)$ & +5.4 & a & 2.0 & 8.8 \\
\hline & $2-5 \%$ & $(18 / 230)$ & +29.6 & $\mathrm{~b}$ & 26.5 & 32.6 \\
\hline & $5-10 \%$ & $(8 / 353)$ & +44.7 & c & 41.6 & 47.7 \\
\hline & $>10 \%$ & $(3 / 16)$ & +44.9 & c & 35.1 & 54.7 \\
\hline & OM subset total & $(31 / 731)$ & +28.7 & & 26.9 & 30.5 \\
\hline \multirow[t]{4}{*}{ Soil clay content } & $\leq 10 \%$ & $(3 / 89)$ & $0 \quad 2.4$ & $a$ & -0.1 & 4.9 \\
\hline & $10-25 \%$ & $(9 / 202)$ & +20.0 & $\mathrm{~b}$ & 17.6 & 22.3 \\
\hline & $>25 \%$ & $(5 / 33)$ & +24.1 & $\mathrm{~b}$ & 19.3 & 28.9 \\
\hline & Clay subset total & $(13 / 324)$ & +13.1 & & 11.5 & 14.7 \\
\hline \multirow[t]{5}{*}{$\mathrm{N}$ rate } & $\leq 50 \mathrm{~kg} \mathrm{~N} \mathrm{ha}^{-1}$ & $(19 / 127)$ & $+\quad 10.1$ & $a$ & 7.5 & 12.7 \\
\hline & $50-100 \mathrm{~kg} \mathrm{~N} \mathrm{ha}^{-1}$ & $(21 / 169)$ & +13.2 & a & 11.0 & 15.4 \\
\hline & $100-200 \mathrm{~kg} \mathrm{~N} \mathrm{ha}^{-1}$ & $(15 / 96)$ & +23.1 & $\mathrm{~b}$ & 18.4 & 27.8 \\
\hline & $>200 \mathrm{~kg} \mathrm{~N} \mathrm{ha}^{-1}$ & $(11 / 275)$ & +14.8 & a & 11.9 & 17.8 \\
\hline & $N$ rate Subset total & $(44 / 667)$ & +13.6 & & 12.2 & 15.0 \\
\hline
\end{tabular}

a For each of the subgroups a + indicates a significant positive effect ( $95 \%$ confidence interval > 0 ) and a 0 indicates non-significance (95\% confidence interval overlaps 0 ). Letters indicate significant differences within categories. Values with the same letter per controlling factor, per weighting method, are not significantly different.

${ }^{b} \mathrm{Cl}$-min indicates the lower limit of the 95\% confidence interval; $\mathrm{Cl}$-max indicates the upper limit of the $95 \%$ confidence interval.

c Low SPT: Olsen-equivalent P status $\leq 10 \mathrm{mg} \mathrm{P} \mathrm{kg}^{-1}$; High SPT: Olsen-equivalent P status $>10 \mathrm{mg} \mathrm{P}$ $\mathrm{kg}^{-1}$; low $\mathrm{P}$ rate: $\leq 50 \mathrm{~kg} \mathrm{P} \mathrm{ha-1}$; high $\mathrm{P}$ rate: $>50 \mathrm{~kg} \mathrm{P} \mathrm{ha}^{-1}$. 
Supplementary Table 2.6. Between group heterogeneity $\left(Q_{B}\right)$ and within group heterogeneity $\left(Q_{w}\right)$ per controlling factor for the response ratio (RR) and phosphorus agronomic efficiency (PAE) as effect sizes. Significance is indicated as follows: n.s. not significant; ${ }^{*} p<0.05 ;{ }^{* *} p<0.01$;

${ }^{* * *} p<0.001$.

\begin{tabular}{|c|c|c|c|c|c|c|c|c|}
\hline \multirow{3}{*}{$\begin{array}{l}\text { Controlling factors } \\
\text { Crop }\end{array}$} & \multicolumn{4}{|l|}{ RR } & \multicolumn{4}{|l|}{ PAE } \\
\hline & $\mathrm{Q}_{\mathrm{B}}$ & & $\mathrm{Q}_{\mathrm{w}}$ & & $\mathbf{Q}_{\mathrm{B}}$ & & $\mathrm{Q}_{\mathrm{w}}$ & \\
\hline & 93 & $* * *$ & 1748 & $* * *$ & 135 & $* * *$ & 2911 & $* * *$ \\
\hline$P$ rate & 58 & $* * *$ & 1802 & $* * *$ & 173 & $* * *$ & 2771 & $* * *$ \\
\hline Climate & 46 & $* * *$ & 1833 & $* * *$ & 5 & * & 3036 & $* * *$ \\
\hline P status & 561 & $* * *$ & 1386 & $* * *$ & 355 & $* * *$ & 2031 & $* * *$ \\
\hline $\mathrm{P}$ status $\times \mathrm{P}$ rate & 234 & $* * *$ & 1502 & $* * *$ & 80 & $* * *$ & 2288 & $* * *$ \\
\hline Soil pH & 276 & $* * *$ & 1337 & $* * *$ & 301 & $* * *$ & 2253 & $* * *$ \\
\hline Soil OM content & 79 & $* * *$ & 913 & $* * *$ & 304 & $* * *$ & 1835 & $* * *$ \\
\hline Soil clay content & 68 & $* * *$ & 434 & $* * *$ & 129 & $* * *$ & 654 & $* * *$ \\
\hline $\mathrm{N}$ rate & 17 & $* * *$ & 621 & n.s. & 24 & $* * *$ & 1125 & $* * *$ \\
\hline
\end{tabular}

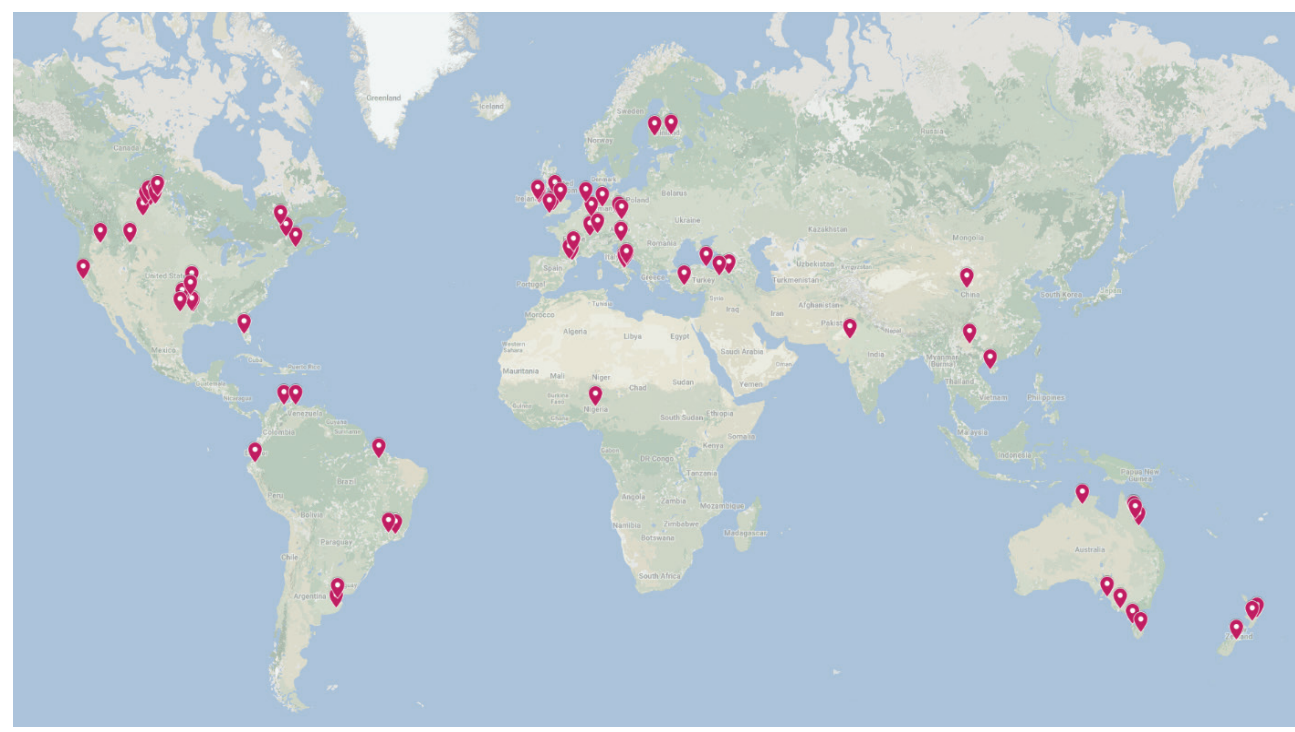

Supplementary Figure 2.1. Map with the distribution and approximate locations of the 77 experimental sites used in the 67 studies incorporated in this meta-analysis. Note that several studies had more than one study site, and that some locations were used by multiple studies. 


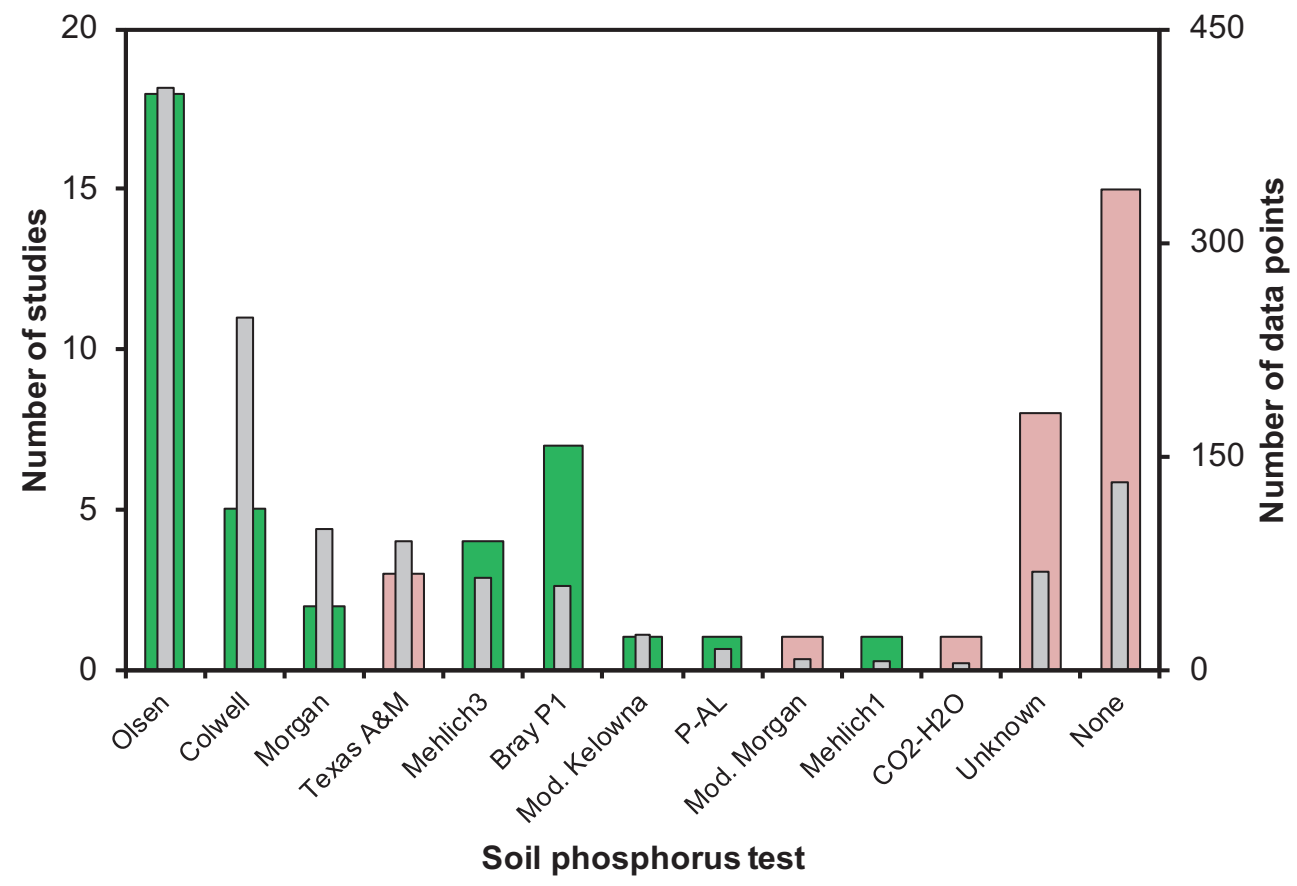

Supplementary Figure 2.2. Distribution of different soil phosphorus test methods used to measure initial soil phosphorus status over the studies included in this meta-analysis. The study count is represented by the broad bars, whereas the narrow bars show the corresponding number of data points. For methods with a green bar, the data were transformed to Olsen-equivalent values and subsequently incorporated in the Soil P subset. Short summaries of the different SPT methods can be found in Supplementary Table 2.1. 

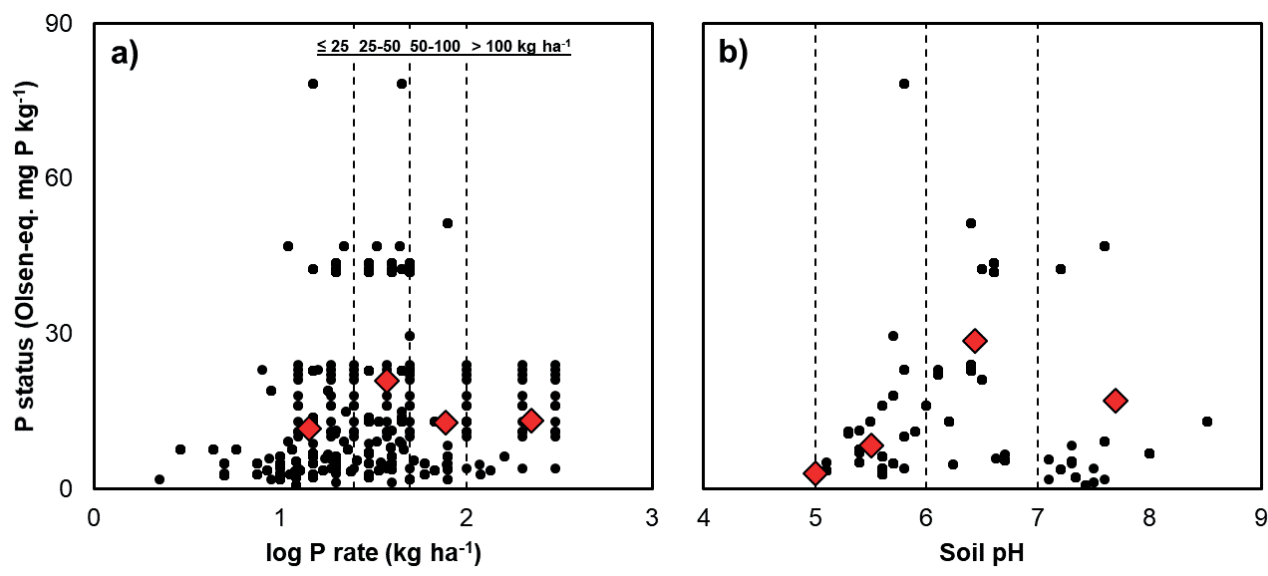

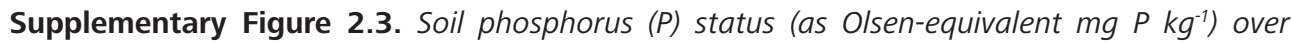
different categories of $P$ application rate (a) and soil $\mathrm{pH}$ (b). The black dots represent the $P$ status of the soils at the start of the $P$ fertilisation experiments underlying the calculated yield effects and the red diamonds indicate the averages (for both $x$ and $y$ variables) per defined category. The dotted lines indicate category limits for $P$ application rate ( $\left.\leq 25 ; 25-50 ; 50-100 ;>100 \mathrm{~kg} P \mathrm{ha}^{-1}\right)$ and $\mathrm{pH}(\leq 5 ; 5-6 ; 6-7 ;>7)$. 


\section{Chapter 3}

\section{What root traits determine grass resistance to phosphorus deficiency in production grassland?}

Mart B.H. Ros, Gerlinde B. De Deyn, Gerwin F. Koopmans,

Oene Oenema, Jan Willem van Groenigen

This chapter is published as:

Ros, M.B.H., De Deyn, G.B., Koopmans, G.F., Oenema, O., van Groenigen, J.W., 2018.

What root traits determine grass resistance to phosphorus deficiency in production grassland?

J. Plant Nutr. Soil Sci. 181, 323-335. https://doi.org/10.1002/jpln.201700093 


\begin{abstract}
Grasslands are a major form of agricultural land use worldwide. Current and future declines of phosphorus $(\mathrm{P})$ inputs into production grasslands necessitate a shift towards selecting grass species based on high efficiency under suboptimal, rather than optimal P conditions. It is therefore imperative to identify key root traits that determine $\mathrm{P}$ acquisition of grasses in soils with a low $\mathrm{P}$ status. In a 9-month greenhouse experiment, we grew eight common grass species and cultivars on a soil with a low P status and related root morphological traits to their performance under P-limiting conditions. We applied (P1) or withheld (P0) P fertilisation while providing adequate amounts of all other nutrients. Omitting $P$ fertilisation greatly reduced yield and nutrient acquisition for the various grass species. Biomass production differed significantly $(p<0.001)$ amongst species and $P$ fertilisation treatments, varying from 17.1 to $72.1 \mathrm{~g} \mathrm{pot}^{-1}$ in the P0 treatment and from 33.4 to 85.8 $\mathrm{g} \mathrm{pot}^{-1}$ in the P1 treatment. Root traits were species-specific and unresponsive to P fertilisation, but overall we observed a trade-off between root biomass and specific root length. Structural equation modelling identified total root length as key factor with respect to resistance to $P$ deficiency, especially when roots explored the subsoil. Optimising root length and subsoil exploration could be the key to maintaining high productivity of production grasslands with decreasing P availability. This is relevant for both plant breeding programmes and for composing seed mixtures.
\end{abstract}




\section{Introduction}

Phosphorus $(\mathrm{P})$ is one of the main nutrients for plant growth. Due to its immobile nature in soil, a low $P$ availability is frequently limiting growth of crops in agricultural systems (Hinsinger, 2001). In agriculture, grasslands are a major form of land use across the world, covering approximately $26 \%$ of the Earth's ice-free surface (Foley et al., 2011), and accounting for 34\% of Europe's agricultural land (Eurostat, 2016). Worldwide, grassland systems vary widely in their P inputs, P balances and yield outputs (Sattari et al., 2016; Simpson et al., 2014). Generally, production grasslands in temperate areas such as Europe and parts of North America are intensively managed, receive high $P$ inputs in the form of manure and/or mineral fertiliser, and have high yields. Over the past decades however, $\mathrm{P}$ inputs in European grasslands have been decreasing (Sattari et al., 2016). A possible further reduction of $P$ inputs in the future (due to stricter environmental legislation, or increased fertiliser costs), may result in sub-optimal $\mathrm{P}$ conditions and pose a challenge to maintaining high crop yields.

Maintaining high crop yields under reduced $P$ inputs requires improvement of the $P$ use efficiency in these grassland systems. One way to achieve this is the use of plants that are efficient in acquiring P. Plants have various strategies to increase P acquisition. They may for instance increase the volume of soil that is explored by the roots by increasing root : shoot ratios, alter their root distribution, increase the specific root length (SRL; root length per unit of weight), or increase topsoil foraging (Lynch, 2007). Additionally, plants may form mycorrhizal symbioses, or secrete protons, organic anions, and phosphatases to acquire P (Richardson et al., 2009b). Sometimes several of these strategies can be combined, although trade-offs are also often observed (Eissenstat, 1992).

Studies on the differences in $\mathrm{P}$ acquisition amongst various grass species and varieties have previously been published, but the large majority focused on natural or semi-natural grasslands in which nutrients are far more scarce (e.g. Hill et al., 2006; Fujita et al., 2010). Studies focusing on the acquisition of $\mathrm{P}$ by grass species used in intensively managed systems are limited. Caradus (1980) screened biomass production of a range of grass and legume species under two different $P$ conditions (one of which was growth-limiting), but the study was carried out with small amounts of soil, making it difficult to translate these results to grassland systems. Liu et al. (1995) found significant differences in $\mathrm{P}$ acquisition and shoot $\mathrm{P}$ concentrations amongst various cultivars of $P$ oa pratensis (Kentucky bluegrass), Lolium perenne (perennial ryegrass) and Festuca arundinacea (tall fescue) under moderate $P$ fertilisation. They showed that on average $F$. arundinacea had lower shoot $\mathrm{P}$ concentration than $P$. pratensis and L. perenne, but its total $\mathrm{P}$ acquisition was higher due to a higher yield. Hamel and Heckman (2006) found in their study that $P$. pratensis was more sensitive to $\mathrm{P}$ deficiency than F. arundinacea and L. perenne, and Paredes et al. (2011) reported a lower sensitivity of $F$. arundinacea to $P$ deficiency compared to $L$. perenne. These studies indicate that differences exist amongst grass species in $\mathrm{P}$ acquisition, but it remains unclear which plant traits are underlying these differences. 
Variation of root traits amongst grass species may be driving these differences in plant $\mathrm{P}$ acquisition. For example, Elberse and Berendse (1993) reported variation amongst eight grass species in responsiveness to nutrient availability. They found that species from nutrient-poor environments such as Anthoxanthum odoratum and Festuca rubra tend to have a higher SRL compared to those from nutrient-richer environments such as $L$. perenne and Arrhenatherum elatius. This may indicate that species with higher SRL are better accustomed to retrieving P in a P-limiting environment. Many studies have reported differences in rooting depth, SRL and other root morphological traits amongst grass species and cultivars (e.g. Crush et al., 2007; Deru et al., 2014). These characteristics may change with the presence or absence of P fertilisation (Hill et al., 2006). Also, grass species may be affected differently by the presence of arbuscular mycorrhizal fungi (Unger et al., 2016; Wilson and Hartnett, 1998) or may secrete different quantities of phosphatases at low P availability (Olde Venterink and Güsewell, 2010).

Due to crop selection under well-fertilised conditions, grass species and varieties used in production grasslands have not been selected based on their root traits. They are selected based on yield potential under optimal nutrient conditions (Smit et al., 2005; Whitehead, 2000), rather than their root characteristics. With a further movement towards reduced $\mathrm{P}$ inputs, and a possible decrease of the soil $\mathrm{P}$ status, yield of grass species under suboptimal conditions will become increasingly important. This may lead to a greater role for species and genotypic differences in root traits and $\mathrm{P}$ acquisition strategies amongst plants as seed selection criteria for farmers and plant breeders.

In the current study, we aim to link the performance of commonly seeded grass species, in the absence and presence of $\mathrm{P}$ fertilisation, to root morphological traits. We hypothesize that, when comparing P-limited and P-sufficient conditions experimentally, (i) species with a relatively high yield and $\mathrm{P}$ uptake under P-sufficient conditions, will be affected to a greater extent when $\mathrm{P}$ is withheld and (ii) differences in root biomass distribution and SRL are the main drivers for the differences in performance amongst species in the absence of $P$ fertilisation. We tested these hypotheses in a nine-month pot experiment where grass species were grown on a low-P non-calcareous sandy soil, and $\mathrm{P}$ fertilisation was either applied or withheld. 
Table 3.1. Physico-chemical characteristics of the soil.

\begin{tabular}{ll}
\hline Characteristics & Bulk soil \\
\hline Sand (\%) & 67 \\
Silt (\%) & 22 \\
Clay (\%) & 11 \\
Organic matter $\left(\mathrm{g} \mathrm{kg}^{-1}\right)^{\mathrm{a}}$ & 85 \\
$\mathrm{pH}_{\text {H20 }}$ & 5.6 \\
Water-extractable DIP $\left(\mathrm{mg} \mathrm{L}^{-1}\right)^{\mathrm{b}}$ & 0.02 \\
$\left.\mathrm{P}-\mathrm{AL}(\mathrm{mg} \mathrm{P} \mathrm{kg})^{-1}\right)$ & 26 \\
Total P $\left(\mathrm{mg} \mathrm{kg}^{-1}\right)$ & 823 \\
Organic P $\left(\mathrm{mg} \mathrm{kg}^{-1}\right)$ & 439 \\
$\mathrm{Al}$ & $\left(\mathrm{mmol} \mathrm{kg}^{-1}\right)$ \\
$\mathrm{Fe}_{\text {ox }}\left(\mathrm{mmol} \mathrm{kg}^{-1}\right)$ & 16.9 \\
$\left.\mathrm{P}_{\text {ox }}(\mathrm{mg} \mathrm{kg})^{-1}\right)$ & 169.9 \\
$\alpha^{\mathrm{c}}$ & 334 \\
\hline
\end{tabular}

${ }^{a}$ Loss on ignition with the loss of water from the crystalline structure of clay taken into account.

${ }^{b}$ Concentration of dissolved inorganic phosphorus (DIP) measured in a 1:10 (w:v) water extract (see Material and Methods for details).

${ }^{\mathrm{C}}$ Degree of $\mathrm{P}$ saturation of a soil with respect to its content of reactive metal oxides calculated according to Equation 3.1.

\section{Materials and Methods}

\subsection{Soil collection and physico-chemical characteristics}

In our greenhouse experiment, we used the same soil as in a previous study (Vos et al., 2014). The soil (Umbric Gleysol; FAO, 2006) was collected from the $0-20 \mathrm{~cm}$ soil layer of a pasture near the village of Joppe, the Netherlands $\left(52^{\circ} 20^{\prime} \mathrm{N}, 6^{\circ} 23^{\prime} \mathrm{E}\right)$ in April 2013. Prior to the experiment, the soil was air-dried and sieved to pass $5 \mathrm{~mm}$. Physico-chemical soil properties (Table 3.1) were taken from Vos et al. (2014). Before determining these properties, the soil was oven-dried $\left(40^{\circ} \mathrm{C}\right)$ and sieved (2 mm). In short, particle size distribution was determined using the pipette method and organic matter (OM) content was estimated from loss-on-ignition (Houba et al., 1997). In this study, waterextractable dissolved inorganic phosphorus (DIP) was measured as described in Vos et al. (2014): A soil sample was extracted at a solid to solution ratio of 1:10 (W:v) for $24 \mathrm{~h}$ at 75 strokes $\mathrm{min}^{-1}$, centrifuged for $15 \mathrm{~min}$ at $10000 \mathrm{rpm}$, and filtered (0.45 $\mu \mathrm{m}$; Aqua 30/0.45 CA Whatman). The 
DIP concentration was subsequently determined using the molybdenum blue method (Murphy and Riley, 1962) and segmented flow analysis (SFA; Skalar, SAN ${ }^{++}$). Before centrifugation and filtration of the same water extracts, the $\mathrm{pH}_{\mathrm{H} 2 \mathrm{O}}$ was measured in a subsample of the suspension. Organic soil $\mathrm{P}$ was calculated as the difference between the amounts of $\mathrm{P}$ extracted with $0.5 \mathrm{M} \mathrm{H}_{2} \mathrm{SO}_{4}$ from an ignited soil sample $\left(550^{\circ} \mathrm{C}\right.$; total soil P) and an unignited sample (inorganic soil P; Kuo, 1996). The pool of $\mathrm{P}$ reversibly bound to reactive metal (hydr)oxides $\left(\mathrm{P}_{\text {ox }}\right)$ was determined using the acid ammonium oxalate extraction method (Schwertmann, 1964). Concentrations of $\mathrm{P}, \mathrm{Al}\left(\mathrm{Al} \mathrm{ox}_{\mathrm{x}}\right.$ ) and $\mathrm{Fe}$ $\left(\mathrm{Fe}_{\mathrm{ox}}\right)$ in the acid ammonium oxalate extracts were measured using inductively coupled plasma atomic emission spectroscopy (ICP-AES; Varian Vista Pro). From these results, the P saturation index $(\alpha)$ was calculated:

$\alpha=\frac{P_{o x}}{[A l+F e]_{o x}}$

with $\mathrm{P}_{\text {ox }}$ and $[\mathrm{Fe}+\mathrm{Al}]_{\mathrm{ox}}$ in $\mathrm{mmol} \mathrm{kg}^{-1}$ (Van der Zee and Van Riemsdijk, 1988). Ammonium lactateextractable $\mathrm{P}(\mathrm{P}-\mathrm{AL}$ ) was used to determine the agronomic $\mathrm{P}$ status of our soil for grassland (Egnér et al., 1960).

\subsection{Experimental design}

We examined the growth and acquisition of eight commonly used grass species/cultivars in the presence and absence of $P$ fertilisation in a 9-month greenhouse experiment. The experiment was set up as a full-factorial, completely randomised block design, with two $\mathrm{P}$ fertilisation treatments ( $\mathrm{P}$ fertilisation absent or present: P0 and P1) aimed at either creating P-limiting or optimal growth conditions, and eight grass species/cultivars (hereafter referred to as 'grass species') as the two independent factors. Each treatment was replicated six times, resulting in a total of 96 pots at the start of the experiment. The replicates were evenly distributed over three blocks, resulting in two replicates per block, one of which was destructively harvested after 118 days and the other after 275 days. Conditions in the greenhouse were semi-controlled: Temperature was kept above $15{ }^{\circ} \mathrm{C}$ at all times and during winter a 16-h day was maintained by using artificial light as a supplement to natural light. Additionally, relative air humidity was kept at $65 \%$.

For the experiment, the 96 polyvinylchloride pots $(15 \mathrm{~cm}$ in diameter and $40 \mathrm{~cm}$ in height) were filled with $8 \mathrm{~kg}$ air-dried, sieved $(5 \mathrm{~mm})$, and homogenised soil, mixed with fertiliser solution, and water. All pots were fertilised with nitrogen $\left(\mathrm{N} ; 27 \mathrm{mg} \mathrm{kg}^{-1}\right.$, supplied in equal molar amounts of ammonium and nitrate), potassium ( $\left.\mathrm{K} ; 24 \mathrm{mg} \mathrm{kg}^{-1}\right)$, calcium $\left(\mathrm{Ca} ; 11 \mathrm{mg} \mathrm{kg}^{-1}\right)$, sulfur $\left(\mathrm{S} ; 3.3 \mathrm{mg} \mathrm{kg}^{-1}\right)$, and sodium ( $\left.\mathrm{Na} ; 2.4 \mathrm{mg} \mathrm{kg}^{-1}\right)$. The pots of the P1 treatment received additional $\mathrm{P}\left(9.7 \mathrm{mg} \mathrm{kg}^{-1}\right.$, in 
the form of $\mathrm{K}_{2} \mathrm{HPO}_{4}$ ). The composition of the nutrient solution can be found in Table 3.2. The water (up to a total of $1130 \mathrm{~mL}$ per pot) was added to bring the soil moisture up to $60 \%$ of the maximum water-holding capacity (WHC). On top of this mixture, an unfertilised germination layer was added using $250 \mathrm{~g}$ of dry soil and $36 \mathrm{~mL}$ water.

At the start of the experiment, per pot $1 \mathrm{~g}$ of grass seeds of one of the following eight species was sown in the germination layer of the pots: a diploid cultivar of L. perenne (LP2; CV. Barforma), a tetraploid cultivar of L. perenne (LP4; CV. Bealey), Lolium multiflorum (LM; annual ryegrass; CV. Barelli), F. arundinacea (FA; cv. Bardoux), Poa trivialis (PT; rough bluegrass; cv. Bartalon), Poa pratensis (PP; cv. Bariris), Phleum pratense (PHP; Timothy-grass; cv. Barpenta), and Holcus lanatus (HL; velvet grass; cv. Barlatus). Seeds from all these grasses were obtained from Barenbrug Holland b.v., Nijmegen, the Netherlands. For the first 3 days, pots were covered with plastic to keep the soil moist and stimulate seed germination. Soil moisture was kept at $60 \%$ of maximum WHC throughout the rest of the experiment. This was done by gravimetrically checking moisture loss in five to six randomly selected pots, and watering accordingly with tap water once every $2 \mathrm{~d}$. Once per week, all pots were weighed individually and both the setup of the pots within the blocks and the location of the blocks were randomised.

Table 3.2. Fertiliser application throughout the experiment. The elements were supplied using a mixture of the following salts: $\mathrm{NH}_{4} \mathrm{NO}_{3^{\prime}} \mathrm{NH}_{4} \mathrm{Cl} ;\left(\mathrm{NH}_{4}\right)_{2} \mathrm{SO}_{4^{\prime}} \mathrm{KNO}_{3^{\prime}} \mathrm{KCl}_{2} \mathrm{KH}_{2} \mathrm{PO}_{4^{\prime}} ; \mathrm{CaCl}_{2^{\prime}} ; \mathrm{NaCl}$ and $\mathrm{MgSO}_{4}$. Fertiliser solutions for the PO and P1 treatments had the same ionic strength and equal amounts of $\mathrm{NH}_{4}^{+}$and $\mathrm{NO}_{3}$.

\begin{tabular}{lccccccc}
\hline & \multicolumn{7}{c}{ Fertiliser applied (kg ha-1) } \\
Time in the experiment & N & Pa & S & K & Ca & Na & Mg \\
\hline Start of the experiment & 120 & 44 & 15 & 108 & 50 & 11 & \\
Cut 1 (25 days) & 70 & 11 & 15 & 83 & & 11 & \\
Cut 2 (46 days) & 70 & 11 & & 83 & & & \\
Cut 3 (74 days) & 70 & 11 & & 83 & & \\
Cut 4 (95 days) & 70 & 11 & & 83 & & \\
Cut 5 (118 days) & 70 & 44 & & 83 & & & \\
Cut 6 (145 days) & 70 & 44 & & 83 & & & \\
Cut 7 (170 days) & 250 & 44 & 76 & 279 & 239 & & 58 \\
Cut 8 (194 days) & 250 & 44 & 76 & 279 & 239 & & 58 \\
Cut 9 (221 days) & 250 & 44 & 76 & 279 & 239 & & 58 \\
Cut 10 (248 days) & 250 & 44 & 76 & 279 & 239 & & 58 \\
\hline
\end{tabular}

a Phosphorus was only fertilised to pots of the P1 treatment. 
During the experiment, eleven grass cuts were collected, with $25 \pm 4$ days between each cut. In every pot, grass was cut at $4 \mathrm{~cm}$ above the soil surface. These cuttings were then dried at $70{ }^{\circ} \mathrm{C}$ for $24 \mathrm{~h}$ and weighed. The material was milled $(1 \mathrm{~mm})$ and $\mathrm{N}$ and $\mathrm{P}$ concentrations $\left(\mathrm{mg} \mathrm{g}^{-1}\right)$ in the grass were determined using a digestion with $\mathrm{H}_{2} \mathrm{SO}_{4^{\prime}}$ salicylic acid, $\mathrm{H}_{2} \mathrm{O}_{2}$, and selenium as a catalyst (Temminghoff and Houba, 2004). Shoot $\mathrm{N}$ and $\mathrm{P}$ uptake (mg pot ${ }^{-1}$ ) were subsequently derived per cut from yield and shoot $\mathrm{N}$ and $\mathrm{P}$ content. After every cut, pots were fertilised again by broadcasting nutrient solution at the soil surface so that only $\mathrm{P}$ was limiting growth in the PO treatment and so that optimal growth was achieved in the P1 treatment (see Table 3.1 for fertiliser rates and composition). As we suspected the initial fertiliser regime to be inadequate, fertilisation rates were increased after the fifth cut to ensure these conditions were maintained.

\subsection{Root and soil collection and analysis}

After the fifth cut (118 days) and after the last and eleventh cut (275 days), the two halves of the experiment were destructively sampled and root samples were collected. More specifically, 3 pots from every treatment were sampled during the first sampling, with one pot from each block. The remaining three pots of each treatment were sampled during the second sampling. For the destructive sampling, the pots were removed from the experiment after cutting the grass, and the topsoil $(0-10 \mathrm{~cm})$ was separated from the subsoil $(10-40 \mathrm{~cm})$ using a knife to enable collection of roots from both soil layers. Roots were removed from the soil by hand over a sieve and subsequently rinsed with water until visually free of soil particles. At this point, root subsamples from the topsoil and subsoil were taken for root scanning and mycorrhizal colonisation measurements and these samples (approximately the equivalent of 0.05-0.10 g dry weight) were stored in 50\% ethanol until further analysis (Pérez-Harguindeguy et al., 2013). The remainder of the roots was dried at $70^{\circ} \mathrm{C}$ for $24 \mathrm{~h}$ and weighed. After the roots had been taken out, the remaining soil was mixed and samples were taken from both topsoil and subsoil. These samples were dried at $40^{\circ} \mathrm{C}$ and stored.

For the topsoil samples from the pots in one block taken after the eleventh cut, a water extraction (1:10, w:v) was used, following the procedure of Vos et al. (2014) as described above, to obtain an indication of the amount of readily available $P$ at the end of the experiment. In these water extracts, we measured total dissolved P (TDP) using ICP-AES, and DIP, total dissolved N (TDN), nitrate- $\mathrm{N}\left(\mathrm{N}-\mathrm{NO}_{3}\right)$, and ammonium- $\mathrm{N}\left(\mathrm{N}-\mathrm{NH}_{4}\right)$ using SFA. Dissolved organic $\mathrm{N}(\mathrm{DON})$ was calculated as the remaining pool when subtracting $\mathrm{N}-\mathrm{NO}_{3}$ and $\mathrm{N}-\mathrm{NH}_{4}$ from TDN. Additionally, we measured the $\mathrm{pH}$ in the water extracts.

To assess the degree of mycorrhizal colonisation, the root samples were removed from the ethanol, rinsed, and cut into $1 \mathrm{~cm}$ segments. These segments were washed and stained with Trypan Blue dye (Phillips and Hayman, 1970). The degree of root colonisation was assessed microscopically (Giovannetti and Mosse, 1980). For the root scanning, subsamples were dyed with $0.5 \mathrm{~g} \mathrm{~L}^{-1}$ Natural 
Red dye for $24 \mathrm{~h}$ (Bouma et al., 2000). Images were acquired using an Epson Perfection V700 Photo scanner at $600 \mathrm{dpi}$ and analysed for root length and root diameter using the WinRhizo Pro 2013e software (Regent Instruments Inc., Quebec City, QC, Canada). After scanning, the root subsamples used were dried at $70^{\circ} \mathrm{C}$ for $24 \mathrm{~h}$ and weighed to calculate SRL. The root mass of these subsamples was added to the biomass of the remainder of the roots to calculate total root biomass and shoot/ root ratio. From this, subsoil exploration was calculated as the root biomass found in the subsoil $(10-40 \mathrm{~cm})$ divided by the total root biomass.

\subsection{Data analyses}

We used two-way analysis of variance (ANOVA) in GenStat $17^{\text {th }}$ edition (VSN International Ltd, Hemel Hempstead, UK) to analyse whether there were significant effects of the factors $P$ treatment and grass species on different response variables $(p<0.05)$. If necessary, data were transformed prior to analysis to conform to assumptions on normality and homogeneity of variances. We used power transformations (shoot yield, $\mathrm{N}$ acquisition, shoot N/P ratio, root mass in both top- and subsoil, SRL of topsoil roots, root length in top- and subsoil), log transformations (shoot/root ratio, $\mathrm{SRL}$ of subsoil roots) and double log transformations (relative subsoil exploration, mycorrhizal colonisation in subsoil roots). As a post-hoc test, Tukey's honest significant difference test was applied to differentiate between treatments.

We assessed the correlation between different response variables and their importance for explaining the variation amongst species with redundancy analysis (RDA; Rao, 1964). The factor grass species was used as an environmental factor, whereas the shoot and root traits were the response variables. The significance of the canonical axes was tested using a Monte Carlo permutation test using 999 permutations. The analysis was done separately for both P treatments, and was performed in Canoco 5 for Windows.

Structural equation modelling (SEM) was applied to identify the most important pathways determining yield of the grass. This method is used to determine whether our proposed causal relationships based on a priori knowledge match with the empirical results of our experiment (Grace, 2006). We used the Lavaan package (Rosseel, 2012) in R version 3.2.2 to execute the analysis. Values of the predicting and dependent variables used in the SEM were transformed beforehand to achieve comparability of parameters. We defined our conceptual model a priori based on knowledge from literature, and tested the quality of this model separately for the two $P$ treatments. For the root characteristics in the model, we did not make a distinction between topsoil and subsoil. Hence, for root length and root mass, the values for topsoil and subsoil were added, and for SRL and mycorrhizal colonisation we used a weighted average based on root mass in both soil layers. After the model was run, we used the modification index function to find omitted pathways that might improve the model. The quality of the conceptual models was concluded from 
the $X^{2}$ statistic (with good model fits providing insignificant results, $p>0.05$ ), and any alterations made to the model were evaluated using the Akaike (AIC) and Bayesian (BIC) information criteria, which are mainly used to compare different models and penalise for model complexity. Within the tested models, pathways with a p-value lower than 0.05 were assumed to be significant.

Table 3.3. Composition of the water extracts $(1: 10, w: v)$ performed on the top soil of the pots in block 1 after 11 cuts.

\begin{tabular}{|c|c|c|c|c|c|c|c|}
\hline Grass species & P treatment $\mathrm{t}^{\mathrm{a}}$ & $\begin{array}{c}\text { TDP } \\
\left(\mathrm{mg} \mathrm{L}^{-1}\right)\end{array}$ & $\begin{array}{c}\text { DIP } \\
\left(\mathrm{mg} \mathrm{L}^{-1}\right)\end{array}$ & $\begin{array}{l}\mathrm{N}-\mathrm{NH}_{4} \\
\left(\mathrm{mg} \mathrm{L}^{-1}\right)\end{array}$ & $\begin{array}{l}\mathrm{N}-\mathrm{NO}_{3} \\
\left(\mathrm{mg} \mathrm{L}^{-1}\right)\end{array}$ & $\begin{array}{c}\text { DON } \\
\left(\mathrm{mg} \mathrm{L}^{-1}\right)\end{array}$ & $\mathrm{pH}$ \\
\hline L. perenne $(2 p ; \mathrm{LP} 2)$ & P0 & 0.0 & 0.00 & 3.0 & 17.1 & 0.1 & 4.9 \\
\hline L. perenne (4p; LP4) & P0 & 0.0 & 0.00 & 2.7 & 14.6 & 0.0 & 4.9 \\
\hline L. multiflorum (LM) & P0 & 0.1 & 0.01 & 1.0 & 3.8 & 0.9 & 5.0 \\
\hline F. arundinacea (FA) & P0 & 0.0 & 0.00 & 0.3 & 11.9 & 0.5 & 4.8 \\
\hline P. trivialis (PT) & P0 & 0.0 & 0.00 & 5.4 & 40.4 & 0.0 & 4.9 \\
\hline P. pratensis (PP) & P0 & 0.0 & 0.00 & 4.7 & 40.1 & 0.0 & 4.9 \\
\hline P. pratense (PHP) & P0 & 0.0 & 0.00 & 5.2 & 28.5 & 0.0 & 4.9 \\
\hline H. Lanatus (HL) & PO & 0.0 & 0.00 & 0.7 & 10.1 & 0.4 & 5.3 \\
\hline L. perenne $(2 p ;$ LP2) & P1 & 0.2 & 0.05 & 0.6 & 11.5 & 0.8 & 5.4 \\
\hline L. perenne (4p; LP4) & P1 & 0.2 & 0.06 & 0.3 & 6.7 & 0.9 & 4.9 \\
\hline L. multiflorum (LM) & P1 & 0.2 & 0.05 & 0.4 & 2.8 & 1.5 & 5.3 \\
\hline F. arundinacea (FA) & P1 & 0.1 & 0.05 & 0.2 & 9.2 & 0.3 & 5.1 \\
\hline P. trivialis (PT) & P1 & 0.1 & 0.04 & 2.2 & 35.8 & 0.0 & 4.9 \\
\hline P. pratensis (PP) & P1 & 0.1 & 0.06 & 3.6 & 38.8 & 0.0 & 4.9 \\
\hline P. pratense (PHP) & P1 & 0.1 & 0.04 & 2.4 & 40.3 & 0.0 & 5.0 \\
\hline H. Lanatus (HL) & P1 & 0.1 & 0.05 & 0.6 & 4.5 & 0.8 & 5.3 \\
\hline
\end{tabular}

${ }^{\mathrm{a}} \mathrm{PO}=$ absence of $\mathrm{P}$ fertilisation; $\mathrm{P} 1$ = presence of $\mathrm{P}$ fertilisation 


\section{Results}

\subsection{Soil characteristics}

Table 3.2 shows the physico-chemical characteristics of the soil used in the pot experiment. Based on the P-AL value of $26 \mathrm{mg} \mathrm{P} \mathrm{kg}^{-1}$, the P status of this soil in the Netherlands is considered low (Tunney et al., 1997). More than $50 \%$ of the total soil $P$ content was organic $P$. The remainder of the total soil $\mathrm{P}$ content, i.e. inorganic $\mathrm{P}$, was mostly adsorbed to metal (hydr)oxide surfaces, as indicated by the low $\alpha$. In Table 3.3 the amounts of water-extractable (1:10, w:v) P and N species in the top soil of the pots at the end of the experiment are given. In the soil samples from the treatment without $P$ fertilisation, DIP and TDP concentrations remained below detection limits. With $P$ fertilisation, DIP and TDP concentrations were detectable but still rather low (0.04-0.06 mg $\mathrm{L}^{-1}$ for DIP and 0.1-0.2 $\mathrm{mg} \mathrm{L}^{-1}$ for TDP), even though they were slightly above the DIP concentration of $0.02 \mathrm{mg} \mathrm{L}^{-1}$ for the initial soil (Table 3.2). Concentrations of $\mathrm{N}-\mathrm{NH}_{4}$ and $\mathrm{N}-\mathrm{NO}_{3}$ at the end of the experiment ranged from $0.2-5.4 \mathrm{mg} \mathrm{L}^{-1}$ and $2.8-40.4 \mathrm{mg} \mathrm{L}^{-1}$ respectively (Table 3.3). 

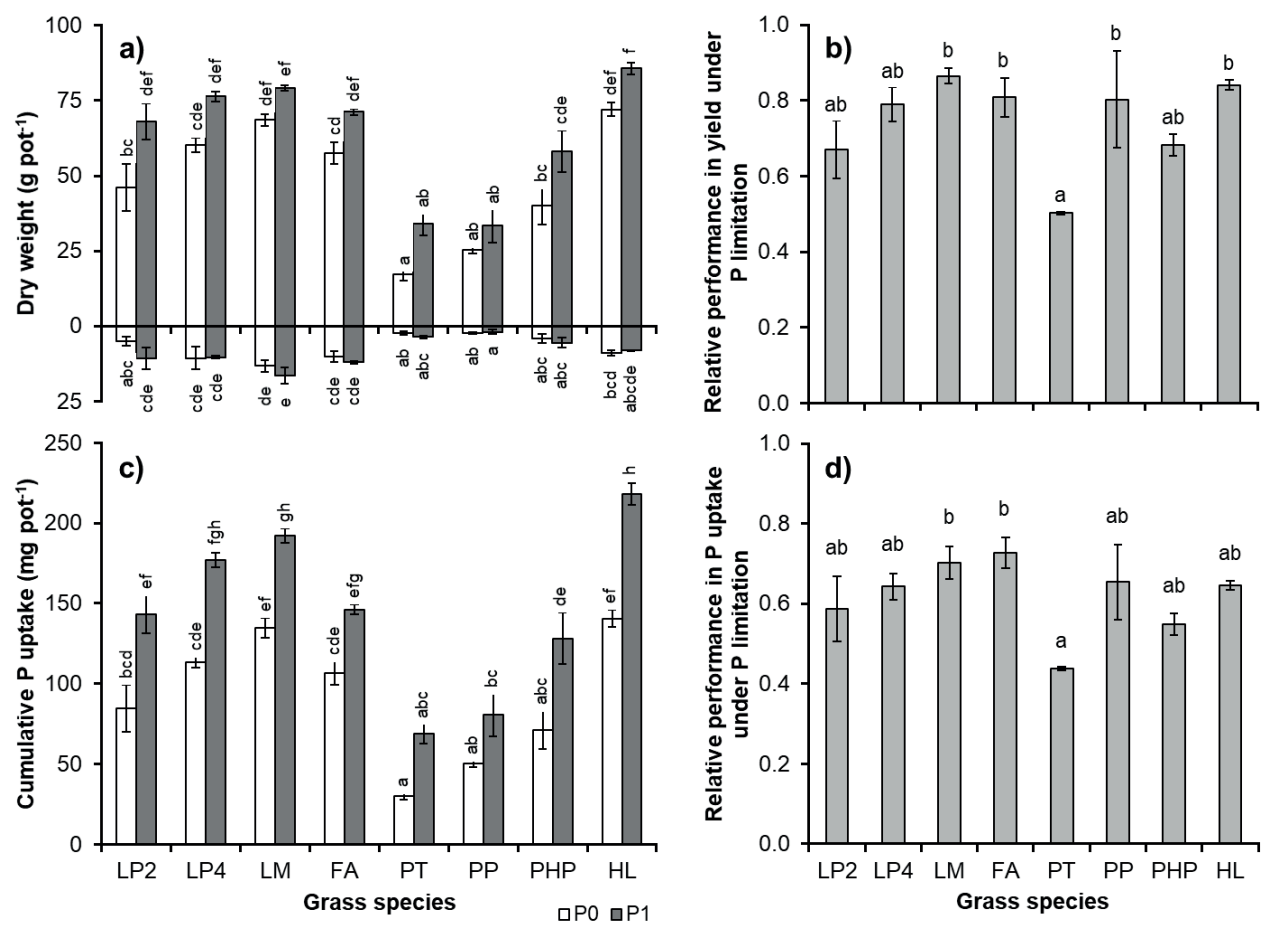

Figure 3.1. Results of (a) the shoot yield (above the $x$ axis) and the root biomass (below the $x$ axis) per species $(L P 2=$ diploid cultivar of $L$. perenne; $L P 4=$ tetraploid cultivar of $L$. perenne; $L M$ $=L$. multiflorum; $F A=F$. arundinacea; $P T=P$. trivialis; $P P=P$. pratensis; $P H P=P$. pratense; $H L=$ $H$. lanatus) and $P$ treatment (white bars for $P 0$; grey bars for $P 1$ ) after eleven cuts; $(b)$ the relative shoot yield obtained per species in the absence of $P$ fertilisation, compared to the presence of $P$ fertilisation; $(c)$, the $P$ uptake per species and $P$ treatment; and $(d)$, the relative $P$ uptake obtained per species in the absence of $P$ fertilisation, compared to $P$ uptake in the presence of $P$ fertilisation. Within each graph, treatments with the same letter are not significantly different $(\alpha=0.05)$.

\subsection{Yield and nutrient acquisition}

Results after five cuts (118 d) showed almost identical, albeit slightly less pronounced patterns to those obtained after eleven cuts, for yield and nutrient uptake as well as root traits. We will therefore limit the discussion of the results to those obtained at the end of the experiment ( $275 \mathrm{~d}$ ). After eleven cuts, cumulative yields ranged from $17.1 \mathrm{~g} \mathrm{pot}^{-1}$ (PT, P0) to $85.8 \mathrm{~g} \mathrm{pot}^{-1}$ (HL, P1) (Fig. 3.1a; Table 3.4). Biomass yield was significantly affected by $P$ treatment as well as grass species, 
and there was no interaction between these factors (Table 3.4). Relative yield performance in the absence of $\mathrm{P}$ fertilisation (the yield in the P0 treatment divided by the yield in the P1 treatment) differed significantly per species and was lowest for PT, whereas LM, FA, HL and PP showed the smallest relative yield decline when $\mathrm{P}$ fertilisation was withheld (Fig. 3.1b). Similar results were observed for $\mathrm{P}$ and $\mathrm{N}$ uptake throughout the experiment (Table 3.4, Fig. 3.1c and 3.1d). Cumulative P uptake ranged from $30 \mathrm{mg} \mathrm{pot}^{-1}$ (PT, P0) to $218 \mathrm{mg} \mathrm{pot}^{-1}$ (HL, P1) (Fig. 3.1C; Table 3.4). As for yield, relative $P$ uptake in the absence of $P$ fertilisation (the $P$ uptake in the $P 0$ treatment divided by the $\mathrm{P}$ uptake in the P1 treatment) was lowest for PT, differing significantly from FA and LM, which had a high relative $P$ uptake. The average N/P ratio in the shoots harvested throughout the experiment was the only response variable that showed an interaction between $\mathrm{P}$ fertilisation and grass species (Table 3.4). They varied from 19.8 (HL) to 33.4 (PT) in the P0 treatment and from 14.5 (LM) to 22.1 (PT) in the P1 treatment. All species had their N/P ratio reduced as a result of $\mathrm{P}$ fertilisation, but PT in particular was more affected than other grass species. Overall, the highest N/P ratios were found for PT, while LM and $\mathrm{HL}$ had the lowest N/P ratios.

\subsection{Root traits}

Table 3.5 shows the different root parameters per $\mathrm{P}$ treatment and grass species. All root traits differed significantly amongst grass species in both the topsoil and subsoil layers, except for SRL in the topsoil, whereas the P treatment generally did not significantly affect the root traits. Overall, the largest root mass was observed for LM, whereas PP had the smallest biomass (Table 3.5), and species with large root mass also had a high shoot yield (Fig. 3.1a). The relative subsoil exploration also differed per species: FA and $\mathrm{HL}$ had a relatively high fraction of their root mass in the subsoil $(10-40 \mathrm{~cm})$, whereas for PT almost all roots were allocated in the topsoil. For SRL we found high values (up to $1280 \mathrm{~m} \mathrm{~g}^{-1}$ ) for PT, PP, and PHP, while FA and LM had low SRL (Table 3.5). Additionally, a trade-off was observed between root mass and SRL in both $\mathrm{P}$ treatments, with SRL declining as root mass increased (Fig. 3.2).

The degree of mycorrhizal colonisation was the only root trait that was significantly affected by $\mathrm{P}$ treatment (Table 3.5). In both $\mathrm{P}$ treatments, the average mycorrhizal colonisation in grass roots ranged from $8 \%$ to $74 \%$ in the topsoil and $11 \%$ to $77 \%$ in the subsoil; P fertilisation decreased colonisation. Mycorrhizal colonisation and SRL in the subsoil were affected by the interaction of $P$ treatment and grass species. 


\subsection{Redundancy analysis and structural equation modelling}

Results of the RDA are shown in Fig. 3.3. The canonical axes were significant for both PO $(p=0.002)$ and P1 $(p=0.002)$ treatments, and the first two canonical axes cumulatively explained $70 \%$ and $66 \%$ of the variation for $\mathrm{PO}$ and $\mathrm{P} 1$, respectively. Plant yield and nutrient uptake were highly positively correlated with root mass, root length and relative subsoil exploration, and negatively related to SRL, shoot N content and N/P ratio. Mycorrhizal colonisation showed no or little correlation with the aforementioned plant traits. In both P treatments, LM was correlated with variables such as root mass and root length, whereas PHP and PP were mostly related to SRL and shoot/root ratio. 
Table 3.4. Summary of the cumulative shoot yield, $N$ and $P$ uptake, and N/P ratio after eleven cuts. Per experimental treatment the mean and standard deviation are given. ANOVA results for the two treatment factors as well as their interaction are presented per response variable.

\begin{tabular}{|c|c|c|c|c|c|}
\hline Grass species & $\begin{array}{l}\mathrm{P} \\
\text { treatment }^{\mathrm{a}}\end{array}$ & $\begin{array}{c}\text { Yield } \\
\left(\mathrm{g} \mathrm{pot}^{-1}\right)\end{array}$ & $\begin{array}{l}\text { N uptake } \\
\left(\text { mg pot }^{-1}\right)\end{array}$ & $\begin{array}{c}\text { P uptake } \\
\left(\mathrm{mg} \mathrm{pot}^{-1}\right)\end{array}$ & $\begin{array}{l}\text { N/P ratio } \\
\left(\mathrm{mg} \mathrm{mg}^{-1}\right)\end{array}$ \\
\hline L. perenne ( $2 p ; \mathrm{LP} 2)$ & P0 & $46.2 \pm 13.6$ & $1938 \pm 518$ & $85 \pm 26$ & $23.9 \pm 1.5$ \\
\hline L. perenne (4p; LP4) & PO & $60.1 \pm 4.2$ & $2459 \pm 136$ & $114 \pm 6$ & $22.8 \pm 0.8$ \\
\hline L. multiflorum (LM) & PO & $68.6 \pm 3.4$ & $2578 \pm 159$ & $134 \pm 11$ & $20.3 \pm 0.4$ \\
\hline F. arundinacea (FA) & PO & $57.6 \pm 6.3$ & $2309 \pm 152$ & $107 \pm 13$ & $23.7 \pm 1.6$ \\
\hline P. trivialis (PT) & PO & $17.1 \pm 3.6$ & $807 \pm 146$ & $30 \pm 5$ & $33.4 \pm 1.0$ \\
\hline P. pratensis (PP) & PO & $25.4 \pm 2.5$ & $969 \pm 92$ & $50 \pm 4$ & $22.7 \pm 0.5$ \\
\hline P. pratense (PHP) & PO & $40.0 \pm 10.7$ & $1518 \pm 390$ & $71 \pm 21$ & $22.6 \pm 1.0$ \\
\hline H. lanatus (HL) & PO & $72.1 \pm 3.8$ & $2680 \pm 80$ & $141 \pm 9$ & $19.8 \pm 1.1$ \\
\hline L. perenne $(2 p ; L P 2)$ & P1 & $68.1 \pm 10.3$ & $2609 \pm 253$ & $143 \pm 21$ & $18.5 \pm 0.8$ \\
\hline L. perenne ( $4 p ; L P 4)$ & P1 & $76.4 \pm 2.9$ & $2909 \pm 46$ & $177 \pm 8$ & $17.8 \pm 0.8$ \\
\hline L. multiflorum (LM) & P1 & $79.3 \pm 1.6$ & $2777 \pm 58$ & $192 \pm 8$ & $14.5 \pm 0.5$ \\
\hline F. arundinacea (FA) & P1 & $71.2 \pm 2.0$ & $2635 \pm 40$ & $146 \pm 6$ & $19.8 \pm 0.9$ \\
\hline P. trivialis (PT) & P1 & $34.0 \pm 6.6$ & $1200 \pm 360$ & $69 \pm 11$ & $22.1 \pm 0.6$ \\
\hline P. pratensis (PP) & P1 & $33.4 \pm 9.8$ & $1245 \pm 352$ & $80 \pm 23$ & $16.4 \pm 0.8$ \\
\hline P. pratense (PHP) & P1 & $58.1 \pm 11.9$ & $2158 \pm 369$ & $128 \pm 28$ & $17.5 \pm 1.1$ \\
\hline H. lanatus (HL) & P1 & $85.8 \pm 3.4$ & $3106 \pm 79$ & $218 \pm 12$ & $15.1 \pm 0.8$ \\
\hline \multicolumn{6}{|l|}{ 2-way ANOVA results ${ }^{b}$} \\
\hline \multicolumn{2}{|l|}{$P$ treatment } & $* * *$ & $* * *$ & *** & *** \\
\hline \multicolumn{2}{|l|}{ Grass species } & $* * *$ & $\star \star \star *$ & *** & *** \\
\hline \multicolumn{2}{|c|}{ P treatment $\times$ Grass species } & NS & NS & NS & $* * *$ \\
\hline
\end{tabular}

a $\mathrm{PO}=$ absence of $\mathrm{P}$ fertilisation; $\mathrm{P} 1$ = presence of $\mathrm{P}$ fertilisation

${ }^{b}$ Levels of significance for the ANOVA results: ${ }^{*} p<0.05 ;{ }^{* *} p<0.01 ;{ }^{* * *} p<0.001$ 


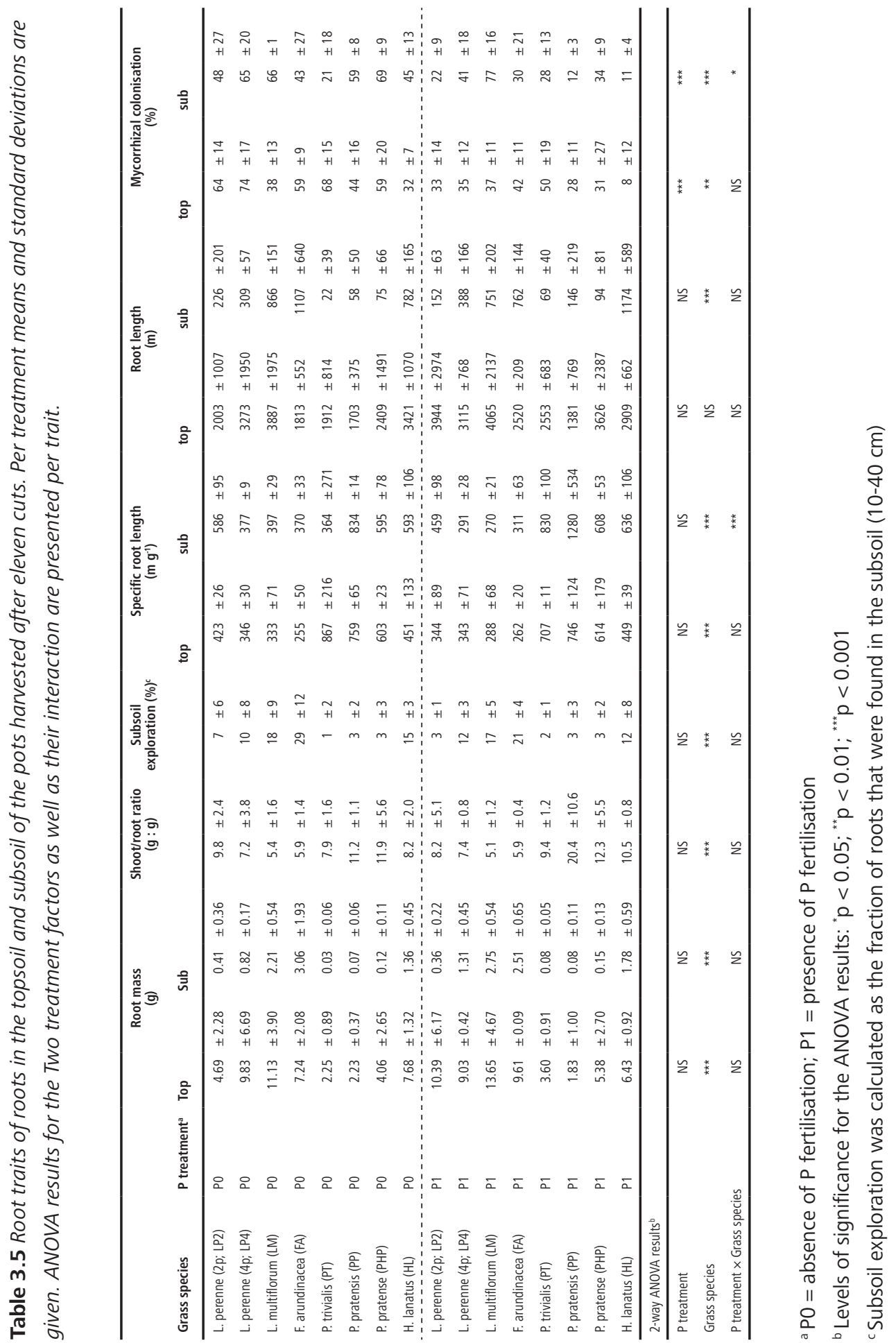



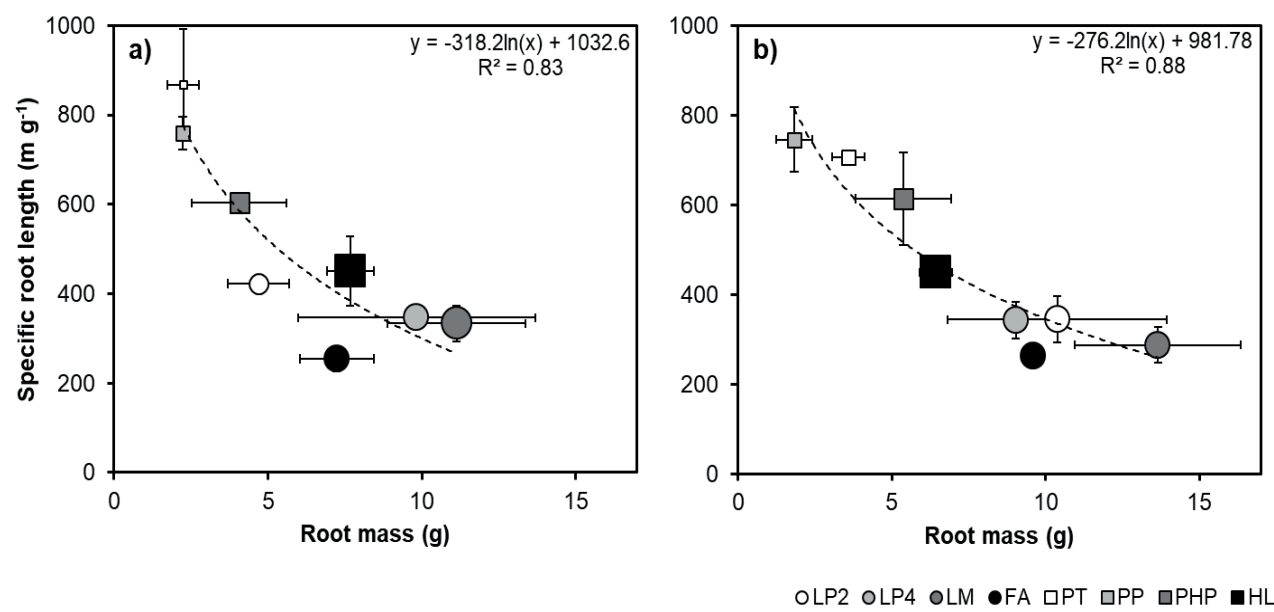

Figure 3.2. Trade-off relationship between root mass and specific root length in the absence (a) and presence (b) of $P$ fertilisation after eleven cuts. The symbols represent the means for the different grass species $(L P 2=$ diploid cultivar of $L$. perenne; $L P 4=$ tetraploid cultivar of $L$. perenne; $L M=L$. multiflorum; $F A=F$. arundinacea; $P T=P$. trivialis; $P P=P$. pratensis; $P H P=P$. pratense; $H L=$ $H$. lanatus). The symbol size indicates the relative performance of the species in terms of shoot yield (larger symbols represent species with higher yield; see Table 3.2). The error bars represent standard errors $(n=3)$.

In the SEM analysis, the conceptual model defined a priori (Fig. 3.4c) was not significant ( $p>0.05$ ) for either P treatment. However, based on the RDA results (Fig. 3.3), the relationship between mycorrhizal colonisation of roots and yield was omitted from the conceptual model. Additionally, the modification index function suggested the inclusion of a pathway between SRL and shoot yield. The resulting final model matched the data well and performed the best in explaining the data for both the PO (model fit $X^{2}$ statistic $p=0.37$, RMSEA $=0.05$; Fig. $\left.3.4 a\right)$ and the P1 $(p=0.35$, RMSEA $=0.07$; Fig. 3.4b) treatments. The strongest relationships were found between root mass and root length, as well as root length and yield, indicated by the standardised relationship coefficients (Fig. 3.4a and 3.4b). Besides total root length and root mass, relative subsoil exploration and SRL also directly influenced shoot yield. Positive relationships between mycorrhizal colonisation and root mass, and between subsoil exploration and root mass, were found in the presence of P fertilisation, but not in its absence. There was no significant relationship between SRL and mycorrhizal colonisation for either $\mathrm{P}$ treatment. 


\section{Discussion}

\subsection{Yield and nutrient uptake}

Grass yield and nutrient uptake over the entire experiment were significantly lower when $P$ fertilisation was omitted. All eight grasses showed decreases for shoot yield, P uptake and $N$ uptake in the PO treatment as compared to the P1 treatment (Table 3.4; Fig. 3.1). Although in general these effects were highly significant and omitting $P$ fertilisation resulted in large reductions of yield and $P$ uptake (with decreases ranging from 13\% to 50\% for yield and from 27\% to 57\% for $P$ uptake), differences between PO and P1 within individual species were often not significant. Only LP2 showed a significant yield increase when fertilised with P (Fig. 3.1a). The influence of $P$ fertilisation was more pronounced with respect to $P$ uptake, for which we found a significant increase for five out of eight grass species (Fig. 3.1c and 3.1d). This is to be expected, as plants may respond to $P$ deficiency with lower $P$ concentration in shoots and a reduction in shoot development (Ha and Tran, 2014; Richardson et al., 2009b) and P uptake is a combined effect of these two responses.
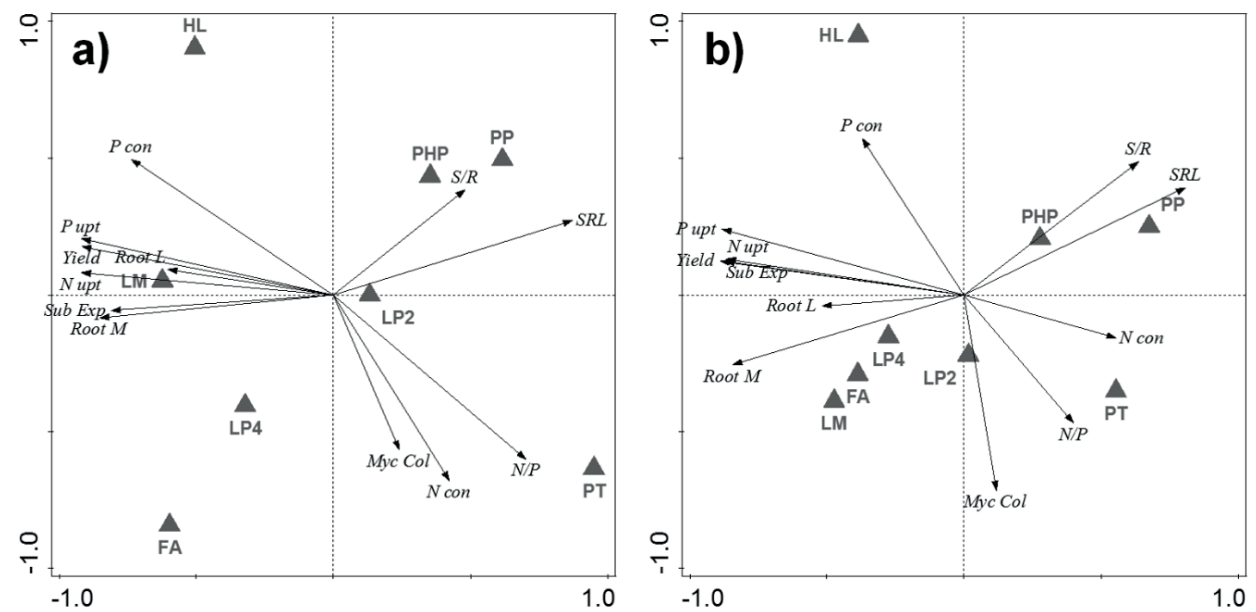

Figure 3.3. Results of the redundancy analysis of the pots without (a) and with (b) P fertilisation after eleven cuts ( $n=24$ in both cases). Triangles indicate the different grass species (LP2 = diploid cultivar of $L$. perenne; $L P 4=$ tetraploid cultivar of $L$. perenne; $L M=L$. multiflorum; $F A=$ F. arundinacea; $P T=P$. trivialis; $P P=P$. pratensis; $P H P=P$. pratense; $H L=H$. lanatus) and arrows represent the different response variables for yield, $P$ uptake ( $P$ upt), $N$ uptake ( $N$ upt), $P$ content ( $P$ con), $N$ content ( $N$ con), N/P ratio (N/P), total root mass (Root $M)$, total root length (Root $L)$, relative subsoil exploration (Sub Exp), specific root length $(S R L)$, shoot/root ratio $(S / R)$, and percentage of mycorrhizal colonisation (Myc Col). 
We hypothesised that species with a relatively high yield and $\mathrm{P}$ uptake under $\mathrm{P}$-sufficient conditions would be affected to a greater extent when $P$ is withheld. However, the lack of interactions between grass species and $P$ treatment for yield and nutrient uptake (Table 3.4) indicates that withholding $P$ fertilisation resulted in similar decreases (in absolute sense) in both yield and $\mathrm{P}$ uptake. Moreover, the species that performed best in the PO treatment in terms of biomass production ( $\mathrm{HL}$ and $\mathrm{LM}$ ) also tended to have high yield under P fertilisation, and both these species lost relatively little biomass when P fertilisation was withheld (Fig. 3.1b). Grass species that had a lower yield and nutrient uptake were relatively more affected by the lack of $\mathrm{P}$ fertilisation. The only exception to this pattern was PP, which had low yield and nutrient uptake compared to other grass species, but showed only small decrease when $\mathrm{P}$ fertilisation was witheld. Overall however, higher-yielding species were more resistant to a reduction in $\mathrm{P}$ availability. Contrary to our expectations, our first hypothesis is therefore rejected by our data. Possible reasons for this will be discussed below. 


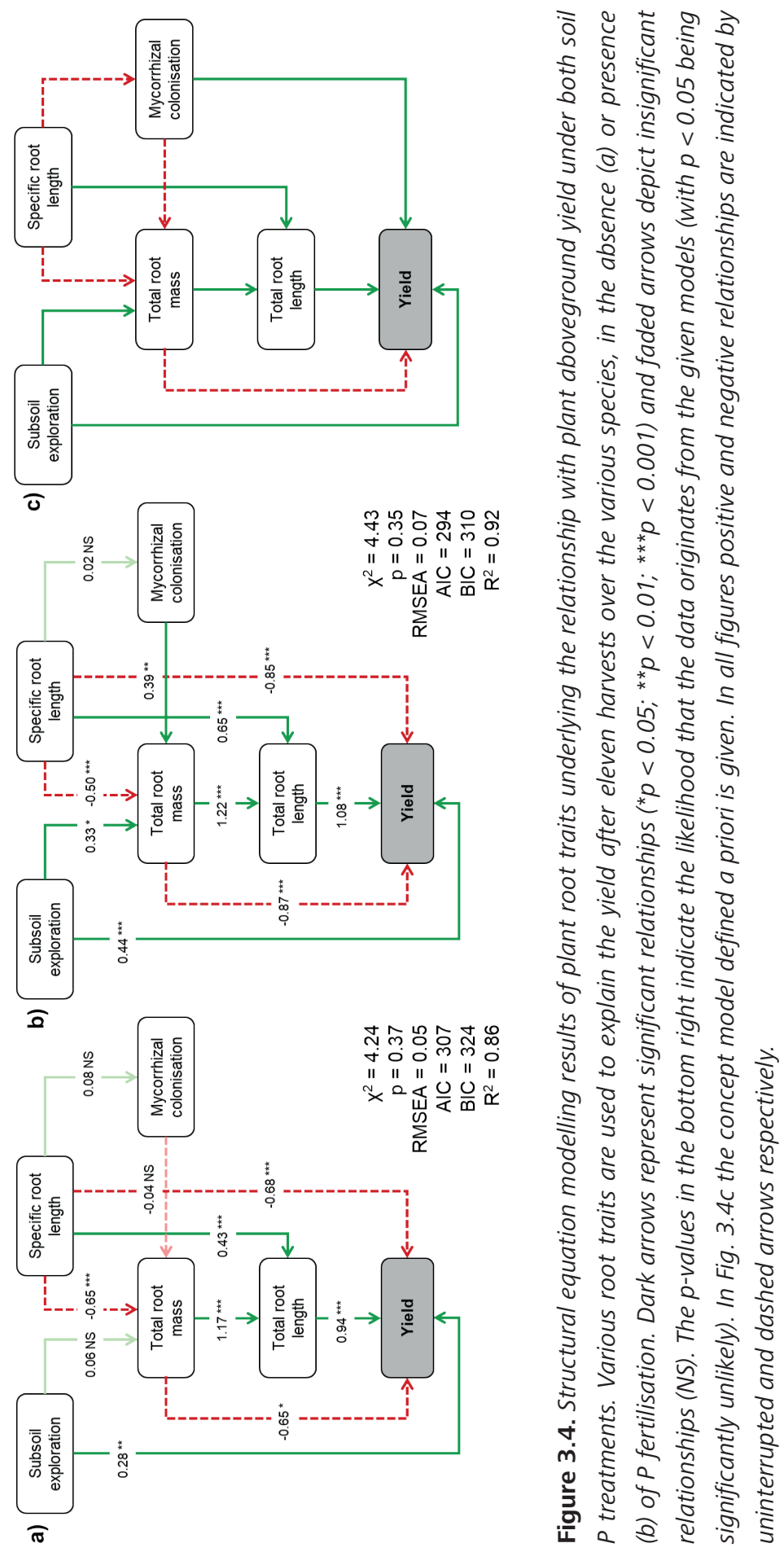




\subsection{Root traits}

Root traits in our experiment varied significantly amongst species, but were not affected by $\mathrm{P}$ treatment (Table 3.5). Only mycorrhizal colonisation was significantly decreased in the presence of P fertilisation; this is in line with earlier observations (Hill et al., 2010; Mendoza et al., 2016). Despite pronounced differences for root mass and SRL, total root length in the top $10 \mathrm{~cm}$ of the soil was the one trait that did not significantly differ amongst grass species. This is likely due to the dense rooting in the top soil of grass species in general, a common feature that might have been further stimulated in this experiment by applying nutrients on the soil surface after every cut. Overall, a finer resolution of the root distribution analysis across the soil profile (for instance by taking an additional sample from the top few $\mathrm{cm}$ ), might have been able to capture this effect and to show clearer differences amongst species. The large root mass found for LM in both P treatments indicates a fast growing species that roots very thoroughly. This is in agreement with results found earlier (Crush et al., 2005; Moir et al., 2013). Many of the higher-yielding species that performed relatively well both in presence and absence of $\mathrm{P}$ fertilisation ( $\mathrm{LM}, \mathrm{FA}$, and $\mathrm{HL}$ ) had a relatively large part of their roots in the subsoil $(10-40 \mathrm{~cm})$. In contrast, the two Poa species had the largest SRL of all species, but had lower root biomass and yield. The differences in root traits amongst the grass species point towards different below-ground strategies to increase the amount of explored soil and nutrient uptake by increasing SRL, root mass and/or subsoil exploration. The lack of effect of $P$ fertilisation on the measured root traits suggests that the plasticity of these traits (i.e. the capacity to adapt to changes in $\mathrm{P}$ availability) in the grass species used in our pot experiment is limited. The ability of these species to acquire $\mathrm{P}$ in P-limiting environments would therefore be based on intrinsic root characteristics, rather than the phenotypic plasticity of these characteristics (Fransen et al., 1999; Hill et al., 2006). Freschet et al. (2015) did find phenotypic plasticity in herbaceous species as a response to nutrient treatments, but these treatments did not include P limitation. Alternatively, the grasses in our experiment may have responded by changing root characteristics we did not measure such as the speed of root system development or rooting depth. The different grass species may furthermore have increased the production of organic compounds or phosphatases (Olde Venterink and Güsewell, 2010; Richardson et al., 2009b), which would have resulted in root physiological plasticity, rather than root structural plasticity.

Another factor that is likely to have contributed to the absence of a P effect on the different root traits is the soil, which was very low in readily available $\mathrm{P}$ (Table 3.1). Despite our efforts to create a pronounced difference in readily available $\mathrm{P}$ by using presence/absence of $\mathrm{P}$ fertilisation, other soil characteristics might have reduced this effect. The amounts of water-extractable $P$ found in the topsoil at the end of the experiment indicate that $P$ fertilisation only slightly increased readily available $P$ in the soil during our experiment (Table 3.1; Table 3.3). This increase was barely detectable by our measurements and consisted mostly of organic or unreactive P (TDP-DIP). The large amounts of $\mathrm{Fe}_{\text {ox }}$ and $\mathrm{Al}_{\text {ox }}$ in our soil indicate a high content of amorphous metal (hydr)oxides (Koopmans et al., 2006). This leads to a low P loading of the metal (hydr)oxides as evidenced by 
the low $\alpha$ value of 0.06 (Table 3.2). If we take into account all additions of fertiliser $\mathrm{P}$ supplied throughout the experiment, the average $\alpha$ would increase to 0.07 . The maximum value of $\alpha$ varies between 0.4 and 0.6 (Van der Zee et al., 1988; Van der Zee and Van Riemsdijk, 1988), meaning that our soil still has the capacity to adsorb additional P. A large part of the P that was introduced to the soil through $\mathrm{P}$ fertiliser application in the P1 treatment may therefore have been adsorbed by metal (hydr)oxides, resulting in P-limiting conditions despite the addition of P. More evidence for the mild $P$ deficiency can be found in the N/P ratios of the shoots (Table 3.4). Koerselman and Meuleman (1996) found wet grasslands to be P-limited for N/P ratios above 16 and N-limited for ratios below 14. Slightly larger ranges (below 10 for $N$ limitation and above 20 for $P$ limitation) for N/P ratios have also been reported (Güsewell, 2004). The average values for N/P ratios in the PO treatment are close to, or higher than 20 for all grass species, which indicates a substantial P deficiency. For the P1 treatment, most ratios were above 16 (all except LM and $\mathrm{HL}$ ), suggesting a milder P deficiency. The combination of these data provides indirect evidence that grass growth in both the P0 and P1 treatment might have been P-limited. Overall, the difference in P availability between P0 and P1 treatments seemed to be large enough to cause differences in yield and nutrient uptake, but not to significantly affect root traits of the different grass species under the current experimental setup.

\subsection{Interactions between root traits and yield}

We observed a trade-off between SRL and root mass for both $P$ treatments (Fig. 3.2). The grass species with higher yields and nutrient uptake balanced these two properties $(\mathrm{HL})$ or had higher root mass (LM), whereas the lower-yielding species (PT, PP) prioritised SRL. This trade-off is also supported by the results of the RDA, which indicate that SRL correlates positively with shoot/root ratio and negatively with root mass (Fig. 3.3). Trade-offs like this have been reported before, not only between SRL and root mass (Eissenstat, 1992; Freschet et al., 2015), but also for example between SRL and mycorrhizal colonisation (Cortois et al., 2016; Smith and Read, 2008). Our SEM analysis was aimed at testing whether these trade-offs were present and at finding the most influential pathway through which the grass species in our experiment acquired P. To do so we included relationships between root mass, SRL and mycorrhizal colonisation in our conceptual model, next to those between these root traits and yield (Fig. 3.4c). Many of the defined relationships between different root traits and yield in our conceptual model were significant (Fig. 3.4a and 3.4b). The relationships between root mass and root length, and root length and yield were strongly positive, as expected, and seemed to have the largest impact. Total root length over the entire soil profile appears to explain the variation in yield to a significant extent.

A priori we expected SRL to be an important discriminator amongst our grass species in their susceptibility to P deficiency. However, the SEM showed that the relation between SRL and yield in our system was complex. Next to the earlier observed trade-off between SRL and root mass, we found an indirect relation of SRL with yield through total root length, as well as a direct 
negative relationship between SRL and yield. The latter is an effect we did not include in our conceptual model, but was suggested by the modification index function. We do not have a clear explanation for this significant negative relation between SRL and yield. However, it does indicate that there are other, yet un-quantified, underlying traits associated or correlated with high SRL that constrain plant biomass production. These may be plant physiological properties, such as a tradeoff between phosphatase activity and SRL. The expected trade-off between SRL and mycorrhizal colonisation was not significant for either P treatment. Overall, the coefficients of the SEM show that SRL is negatively correlated with yield (which is further supported by the RDA; Fig. 3.3). Subsoil exploration appeared to affect yield positively, either directly (by exploring a larger volume of soil), and indirectly (by allowing for more total root biomass). However, total root length rather than SRL or subsoil exploration was the determining factor for yield, in both P treatments. This means our second hypothesis was not confirmed.

Although our model explains a large proportion of our data $\left(R^{2}\right.$ values of 0.86 and 0.92 for $\mathrm{PO}$ and $\mathrm{P} 1$ respectively), and performs well on the $\mathrm{X}^{2}$ and RMSEA statistics for both $\mathrm{P}$ treatments, there is still room for improvement. In particular, by adding other factors and strategies of plants that we did not take into account. Most prominently, we did not measure phosphatase activity or $\mathrm{P}$ mineralisation rates from $\mathrm{OM}$ in this experiment. In a study on $\mathrm{N}$ and $\mathrm{P}$ stoichiometry in grasslands, Fujita et al. (2010) reported differences of a factor three in relative phosphatase activity amongst grass species. Moreover, root surface phosphatase activity was correlated with grass $\mathrm{P}$ uptake (Fujita et al., 2010). Root surface phosphatase activity may thus differ amongst various grass species, and could have contributed to grass $\mathrm{P}$ uptake in a soil with a relatively high OM content like ours (Table 3.1). Furthermore, root hairs might increase $P$ acquisition by exploring a larger volume of soil. The length and density of these root hairs may differ for grass species, and are often affected by environmental conditions such as nutrient availability or acidity (Haling et al., 2011; Robinson and Rorison, 1987; Yang et al., 2017). These are examples of properties that could be included in further studies towards the importance of different root traits for $\mathrm{P}$ acquisition. Finally, the ratio between shoot and root biomass was not explicitly included in the model as a predictor. However, this effect is indirectly taken into account by including a negative relationship between root mass and yield (Fig. 3.4).

\subsection{Implications}

For natural or semi-natural grasslands, differences in $\mathrm{P}$ acquisition amongst various grass species and varieties have received considerable attention. However, this has not been the case for $P$ acquisition by grass species in intensively managed production grasslands. Our study shows that root traits such as root length and subsoil exploration can be important characteristics in determining yield and $\mathrm{P}$ uptake of grass species commonly grown in production grassland under P-limiting conditions, and thus their resistance to $\mathrm{P}$ deficiency. Translating results from pot experiments to 
field conditions is always a challenge, as growth rate and rooting characteristics of plants in the greenhouse generally differ from those in the field (De Vries, 1980). Additionally, the nutrient management in our experiment was aimed at creating $\mathrm{P}$ limitation or removing nutrient limitation. To ensure this, large quantities of inorganic nutrients were applied, which is not representative for nutrient management in grassland systems in practice, where application rates are lower and often include organic sources such as manures. Different root traits might be beneficial for acquiring $P$ from organic sources. The fact that we used a mixed topsoil, instead of an intact soil core with a $P$ stratification or nutrient gradient that usually occurs in the field (Whitehead, 2000), may also have affected nutrient distribution and the rooting pattern of the grasses. The results we obtained for subsoil exploration should be regarded with this in mind, as it is not certain that this trait will be as important in the field as it was in this pot experiment. Rather, the root development of grasses in the top few $\mathrm{cm}$ of the soil might be a key root trait, as this is where most of the P will end up after application.

Finally, the limited pot volume may have impaired root growth and with that limited root morphological plasticity over the duration of the experiment. However, the large depth of our pots provided a closer approximation to realistic rooting conditions than most pot experiments, as most often shallower pots are used. Additionally, the long duration of this experiment, in combination with the relatively stable climate in the greenhouse, provides unique conditions for studying fundamental relations between rooting patterns and $P$ acquisition of grass that are not easily obtained in the field. The results of our experiment suggest that selecting (combinations of) grass species based on root length and soil exploration might be a key to maintaining high grass yields and $\mathrm{P}$ uptake in production grasslands. However, this needs further confirmation in the field and on different soil types. Future research should also focus on grass species that have complementary root traits (for instance a combination of deep-rooting and shallow-rooting species). This might provide useful information for plant breeding programs or composing seed mixtures.

\section{Conclusions}

In this experiment, omitting $\mathrm{P}$ fertilisation to grass species commonly occurring in intensively managed grasslands resulted in large reductions of both yield and nutrient acquisition. We showed that grass species differ in their resistance to $\mathrm{P}$ deficiency, with biomass production and nutrient acquisition differing significantly amongst species in the absence or presence of $\mathrm{P}$ fertilisation. Root traits generally varied amongst species, but were not affected by $\mathrm{P}$ treatment, which indicates limited plasticity of these traits under the current experimental setup. We observed a trade-off between SRL and root biomass, but SEM showed that total root length and subsoil exploration were the root traits that explained most of the variation in our yield data. Selecting grass species based on these root traits for plant breeding programs or use in grass seed mixtures may be a key to maintaining optimal yields under declining soil P status, as a result of lower P inputs. 


\section{Acknowledgments}

This research has been made possible thanks to a donation by De Heus b.v., on the occasion of the $100^{\text {th }}$ anniversary of the company. We are grateful to Barenbrug b.v. for supplying the grass seeds used in the experiment and we would like to thank Jakia Sultana, Anupol Chareesri, Hannah Vos, Wim Joost van Hoek, Simon Jeffery, Ilse Memelink, Ingrid Lubbers, Walter Andriuzzi, Jingmeng Wang and Jaap Nelemans for their help with the pot experiment. We are indebted to Tamás Salanki for his expertise and invaluable help with assessing mycorrhizal colonisation, and to Ron de Goede for his assistance with the structural equation modelling. Additionally, we would like to thank René Knook, Arjan Reijneveld, Guus van Laarhoven, Piet Aerts and Stefan van der Heijden for useful comments and insights on the experimental setup and the results, and Thom Kuyper for proofreading an earlier version of this manuscript. 


\section{Chapter 4}

\section{Do earthworms affect phosphorus availability to grass? A pot experiment}

Hannah M.J. Vos, Mart B.H. Ros, Gerwin F. Koopmans,

Jan Willem van Groenigen

This chapter is published as:

Vos, H.M.J., Ros, M.B.H., Koopmans, G.F., Van Groenigen, J.W., 2014. Do earthworms affect phosphorus availability to grass? A pot experiment. Soil Biol. Biochem. 79, 34-42.

https://doi.org/10.1016/j.soilbio.2014.08.018 


\section{Abstract}

The largest part of phosphorus $(P)$ in soil is bound by the soil solid phase; its release to the soil solution therefore often does not meet the demand of plants. Since global P fertiliser reserves are declining, it becomes increasingly important to better utilise soil P. We tested whether earthworm activity can increase $\mathrm{P}$ availability to grass (Lolium perenne L.) in a 75-day greenhouse pot experiment in a soil with low $\mathrm{P}$ availability. The full factorial design included two factors: P fertilisation (control, no P; phytate; and inorganic P fertilisation) and earthworm population (control, no earthworms; Lumbricus rubellus Hoffmeister, Lr; Aporrectodea caliginosa Savigny, Ac; and L. terrestris L., Lt). At four times during the experiment, aboveground plant growth and $\mathrm{P}$ uptake were determined. In a separate incubation experiment, earthworm casts and bulk soil were analysed for inorganic and organic $P$ in water extracts. We observed higher levels of dissolved $P$ pools $(p<0.001)$ in the water extracts of earthworm casts compared to those of the bulk soil. The magnitude of the difference differed between earthworm species, with the largest levels for $L r$ : from $<0.02$ to $8.56 \mathrm{mg} \mathrm{L}^{-1}$ for inorganic $P$ $(p=0.007)$ and from 0.18 to $1.30 \mathrm{mg} \mathrm{L}^{-1}$ for organic $P(p=0.007)$. After three harvests, presence of $L t$ significantly increased $\mathrm{P}$ uptake by grass to $44.1 \mathrm{mg} \mathrm{pot}^{-1}$ compared to $41.8 \mathrm{mg} \mathrm{pot}^{-1}$ for the control

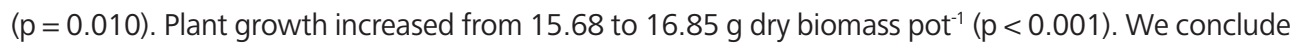
that earthworms casts contain higher levels of plant available $P$ than the bulk soil, and that this might translate into increased plant $\mathrm{P}$ uptake. It is well-known that maintaining soil faunal biodiversity is important for a variety of ecosystem services; our results show that these ecosystem services may include improving the utilisation of soil $\mathrm{P}$ in a world with rapidly declining $\mathrm{P}$ stocks. 
Phosphorus (P) is an essential nutrient for plant growth and it is taken up by plants from the soil solution in the form of orthophosphate (ortho-P) (Hawkesford et al., 2012). The quantity of ortho-P in soil solution usually represents $<1 \%$ of annual $\mathrm{P}$ uptake by crops, while the remaining $>99 \%$ is supplied by the soil solid phase over the growing season (Hesterberg, 2010; Morel et al., 2000). Desorption of ortho-P bound to reactive metal oxides within the soil solid phase to soil solution and subsequent diffusion to the surface of the plant roots are important processes in determining the rate by which ortho-P is taken up (Jungk and Claassen, 1997; Koopmans et al., 2004; Morel et al., 2000; Van Noordwijk et al., 1990). Additionally, the release of ortho-P to soil solution through mineralisation of soil organic P can contribute to P nutrition of plants (Richardson, 2001). On the other hand, plants themselves have developed strategies to enhance $P$ uptake, especially by adapting their root morphology, entering symbiosis with mycorrhizal fungi (Lynch and Brown, 2001; Raghothama, 1999), or by excretion of organic acids and phosphatases (Bieleski, 1973; Tarafdar and Jungk, 1987). Hence, $\mathrm{P}$ uptake by plants is the result of a complex interplay between physical, chemical, and biological processes.

Most agricultural soils are unable to supply sufficient amounts of $P$ to plants to realise an optimal crop yield, due to their low native soil $\mathrm{P}$ contents and strong $\mathrm{P}$ binding to the soil solid phase (Hinsinger, 2001). In such soils, the low availability of P leads to a P-limited growth of plants and this is often ameliorated through application of inorganic $P$ fertiliser or animal manure. The application of microbial inoculants (Richardson, 2001) or the use of new crop genotypes (Lynch and Brown, 2001) have been suggested as an alternative for inorganic $P$ fertiliser application to alleviate low $P$ availability.

A hitherto little studied topic is the role of soil macrofauna in the soil $\mathrm{P}$ cycle in relation to plant growth. Especially earthworms may play an important role in this respect, as they are considered "ecosystem engineers". They can to a large extent affect soil carbon (C) and nitrogen (N) cycles as well as physical-chemical properties of soils (e.g. soil aggregation and aeration) (Darwin, 1881; Jones et al., 1994). Earthworms ingest their food selectively and especially feed on fresh organic matter or further decomposed organic matter associated with the soil solid phase (Curry and Schmidt, 2007; Doube et al., 1997). When earthworms burrow through the soil, they create macro-pores (Schrader et al., 2007), mix organic matter and soil particles, and disperse soil micro-organisms (Devliegher and Verstraete, 1997; Le Bayon and Milleret, 2009). Consequently, earthworms stimulate mineralisation of soil organic matter (SOM) and increase soil fertility (Postma-Blaauw et al., 2006). Excretion of casts, enzymes, and mucus are other examples of how earthworms can modify microbial activity and SOM dynamics (Bernard et al., 2012; LopezHernandez et al., 1993; Tiunov and Scheu, 2000).

The effects earthworms can have on soil properties differ between earthworm species. Observed differences are often attributed to variation in their feeding and burrowing behaviour (Lattaud et al., 1997; Suárez et al., 2004). Earthworms are typically classified in three ecological 
categories: (i) epigeic (feed on surface litter and live in the litter layer and top centimeters of soil); (ii) endogeic (feed on soil and associated organic matter and live in non-permanent burrows deeper in the soil); and (iii) anecic species (feed on surface litter and make permanent vertical burrows) (Bouché, 1977). However, some species show characteristics belonging to multiple groups and can, therefore, not be fully classified within one functional group. For instance, Lumbricus rubellus, a common earthworm in temperate regions, is often classified as epi-endogeic, whereas the behaviour of $L$. terrestris, an earthworm that used to be classified as anecic, is recently more often described as epi-anecic.

In many studies, positive effects of earthworm presence on plant growth have been observed (Scheu, 2003), and different mechanisms have been suggested for this (Brown et al., 2004). However, relatively little attention has been paid to effects of earthworms on the soil P cycle (Le Bayon and Milleret, 2009). Higher levels of available $P$ for plant uptake have been measured in earthworm casts compared to the bulk soil (Kuczak et al., 2006; Lopez-Hernandez et al., 1993; Sharpley and Syers, 1976) and increased plant growth as a result of a higher P availability has been documented before (Mackay et al., 1982). Hypothesised pathways for this effect include selective feeding behaviour of earthworms, (thereby concentrating SOM, clay and nutrients), as well as processes taking place in the earthworm gut and cast (Brown et al., 2004). Furthermore, earthworms have recently been reported to be able to modify $\mathrm{P}$ dynamics and plant interactions in an intercropping system (Coulis et al., 2014). However, it is still largely unknown to what extent earthworms can beneficially affect $P$ uptake and plant growth in agricultural systems, and through which mechanisms they influence the plant availability of $P$.

The objective of the present study was to examine whether earthworm activity can improve the utilisation of soil $\mathrm{P}$ by grass, through increasing the fraction of ortho-P in the soil solution. Our hypotheses are: $\mathrm{P}$ availability in soil water extracts, which are used as a proxy for soil pore water (Koopmans et al., 2006; Torrent and Delgado, 2001) are elevated for earthworm casts compared to those for the bulk soil $(\mathrm{H} 1)$; under $\mathrm{P}$ limiting conditions earthworm presence will increase $\mathrm{P}$ availability in water extracts of the bulk soil $(\mathrm{H} 2)$; as well as $P$ uptake and aboveground grass biomass production $(\mathrm{H} 3)$. Furthermore, as we expect stimulation of the microbial community and elevated mineralisation of organic $P$ to be the main pathway through which earthworms affect $P$ uptake by plants and plant growth, observed effects are expected to be largest for soil fertilised with myo-inositol hexakisphosphate (phytate), which is a major form of organic $\mathrm{P}$ in soils (Turner et al., 2002) (H4). Finally, the effects on $P$ uptake and aboveground grass biomass are hypothesised to be larger for epi-endogeic earthworms than for endogeic and anecic earthworms (H5), as epiendogeic earthworms are active throughout the rooting zone. 


\section{Materials and Methods}

\subsection{Soil characteristics}

The topsoil $(0-20 \mathrm{~cm}$ ) of a Umbric Gleysol (FAO, 2006) was collected from an agricultural pasture in April 2013 in Joppe, the Netherlands $\left(52^{\circ} 20^{\prime} \mathrm{N}, 6^{\circ} 23^{\prime} \mathrm{E}\right)$. For physico-chemical characterisation, the soil was dried at $40{ }^{\circ} \mathrm{C}$ and sieved $(2 \mathrm{~mm})$. The particle size distribution was determined with a sieve and pipette and SOM was estimated from loss-on-ignition in a muffle furnace $\left(550{ }^{\circ} \mathrm{C}\right)$. Loss of water from the crystalline structure of clay particles was taken into account (Houba et al., 1997). The $\mathrm{pH}$ was measured with a combined glass electrode in a $1: 10$ (w:v) suspension of soil in ultra-pure water (UPW). The availability of $\mathrm{P}$ for plant uptake was determined using an extraction with acetic acid and ammonium lactate (P-AL) (Egnér et al., 1960). In the Netherlands, P-AL is used as a soil test in agricultural practice for $P$ fertiliser recommendation of grassland. The amount of $\mathrm{P}$ adsorbed to reactive metal oxides $\left(\mathrm{P}_{\mathrm{ox}}\right)$ as well as the amounts of reactive aluminium and iron oxides $\left(\mathrm{Al}_{\mathrm{ox}}\right.$ and $\mathrm{Fe}_{\mathrm{ox}}$ ) were determined by the extraction of soil with acid ammonium oxalate (Schwertmann, 1964). Based on these results, the degree of $\mathrm{P}$ saturation of the soil with respect to its content of reactive metal oxides was calculated:

$\alpha=\frac{P_{o x}}{[A l+F e]_{o x}}$

where $\mathrm{P}_{\mathrm{ox}}$ and $[\mathrm{Al}+\mathrm{Fe}]_{\mathrm{ox}}$ are expressed in $\mathrm{mmol} \mathrm{kg}^{-1}$ (Van der Zee and Van Riemsdijk, 1988). The soil organic $\mathrm{P}$ content was calculated as the difference between total inorganic $\mathrm{P}$ measured after combustion of organic matter in a muffle furnace $\left(550^{\circ} \mathrm{C}\right)$ and subsequent digestion of soil with $0.5 \mathrm{M} \mathrm{H}_{2} \mathrm{SO}_{4}$ and inorganic $\mathrm{P}$ measured after digestion of soil with $0.5 \mathrm{M} \mathrm{H}_{2} \mathrm{SO}_{4}$ (Kuo, 1996).

\subsection{Experimental design}

We set up a 75-day pot experiment consisting of 48 pots (plant experiment) in the greenhouse. The experiment was laid out as a fully factorial design with three $P$ fertilisation treatments and four earthworm treatments as independent factors. The replicates were distributed over four blocks, and both the location of the block and the setup within the block was randomised weekly. A separate experiment (cast experiment) was performed simultaneously. This consisted of six pots, with two replicates of all three earthworm treatments on the same non-P-fertilised soil as in the 
plant experiment. In both experiments, Mitscherlich pots with a diameter of $20 \mathrm{~cm}$ and a depth of $23 \mathrm{~cm}$ were used.

Each pot was filled with $6 \mathrm{~kg}$ of air-dried, sieved $(5 \mathrm{~mm})$, and homogenised soil. All pots were fertilised with $133 \mathrm{~kg} \mathrm{~N} \mathrm{ha}^{-1}$ (with equal amounts of $\mathrm{NH}^{+}$and $\mathrm{NO}^{-}$), $108 \mathrm{~kg} \mathrm{~K} \mathrm{ha}^{-1}, 12 \mathrm{~kg} \mathrm{~S} \mathrm{ha}^{-1}$, $50 \mathrm{~kg} \mathrm{Ca} \mathrm{ha}{ }^{-1}$, and micro-nutrients. The $\mathrm{P}$ fertilisation treatments included: (i) control without $\mathrm{P}$ fertilisation; (ii) fertilisation with phytate $\left(\mathrm{C}_{6} \mathrm{H}_{18} \mathrm{O}_{24} \mathrm{P}_{6} . x \mathrm{Na}\right.$.yH2O); and (iii) fertilisation with inorganic $\mathrm{P}\left(\mathrm{KH}_{2} \mathrm{PO}_{4}\right)$. The $\mathrm{P}$ application rate in treatments (ii) and (iii) was $65 \mathrm{~kg} \mathrm{P} \mathrm{ha}^{-1}$, based on the measured $\mathrm{P}-\mathrm{AL}$ value of the initial soil and the Dutch $\mathrm{P}$ fertilisation recommendation for grassland (Commissie Bemesting Grasland en Voedergewassen, 2012). Water was added to obtain $60 \%$ of the water holding capacity.

For both the plant and cast experiments, $4 \mathrm{~g} \mathrm{pot}^{-1}$ of perennial ryegrass (Lolium perenne) seeds were sown in a $0.5 \mathrm{~kg}$ unfertilised seedbed. After a pre-growing period of 28 days, earthworms were added. The four earthworm treatments included: (i) control; (ii) L. rubellus Hoffmeister (epiendogeic; Lr); (iii) Aporrectodea caliginosa Savigny (endogeic; Ac); and (iv) L. terrestris L (anecic, Lt). Earthworm densities were $5.0(\mathrm{Lr}), 6.1(\mathrm{Ac})$, and $14.2(\mathrm{Lt}) \mathrm{g}$ earthworm pot ${ }^{-1}$, respectively, corresponding to 159, 223 and 95 earthworms $\mathrm{m}^{-2}$, which is in correspondence with values found in Dutch pastures (Didden, 2001). Earthworms were collected in May 2013 in park areas in Wageningen, the Netherlands ( $\mathrm{Lr}$ and $\mathrm{Ac}$ ) or purchased from a supplying company (Star Food Holland b.v., Barneveld, the Netherlands; Lt). Before addition of the earthworms, they were kept for a minimum of 1.5 week in separate containers filled with the same soil as used in both pot experiments, with poplar (Populus spp L.) leaves as feed. The containers were placed in the dark at $15{ }^{\circ} \mathrm{C}$. All earthworms were adults or large juveniles and their intestines were voided for $48 \mathrm{~h}$ according to the wet filter paper method of (Dalby et al., 1996) before they were weighed and added to the pots.

Pots were watered every 1 or 2 days, depending on the weather conditions. Once a week, the water content of each pot was gravimetrically adjusted. During the pre-growing phase, water was applied through a watering tube placed in the middle of each pot. After earthworm addition, water was applied to the entire surface of the pots to simulate rainfall, in order to allow surface casts to deconstruct and let the nutrients they contained leach into the soil.

Grass was cut five times and after each grass cut, all the pots were fertilised with $\mathrm{N}\left(86 \mathrm{~kg} \mathrm{ha}^{-1}\right.$ as $\left.\mathrm{NO}_{3} \mathrm{NH}_{4}\right), \mathrm{K}\left(42 \mathrm{~kg} \mathrm{ha}^{-1}\right.$ as $\left.\mathrm{KCl}\right)$, and trace elements. Additional trace elements were added after the fourth cut. These fertiliser applications were applied in a $50 \mathrm{~mL}$ solution through the watering tube, after which $200 \mathrm{~mL}$ water was used to flush the salts into the soil.

In order to keep soil temperature optimal for temperate earthworms (Curry, 2004), all pots were cooled after the start of the earthworm treatments by placing them in a layer of $10 \mathrm{~cm}$ gently flowing water of approximately $15^{\circ} \mathrm{C}$. Soil temperature was monitored daily and fluctuated between 15 and $19{ }^{\circ} \mathrm{C}$ during the entire period of both experiments. To prevent entry of water into the pots and earthworm escaping, the pots were placed in plastic bags before they were put in the water. 


\subsection{Sample collection}

In the plant experiment, grass was harvested five times, i.e. 28, 46, 64, 82, and 103 days after sowing (T0, T1, T2, T3, and T4 respectively). The first harvest was prior to the actual start of the pot experiment, just before addition of the earthworms. The data of T0 are therefore not reported here. At T0-T3, the grass was cut approximately $5 \mathrm{~cm}$ above the soil surface to facilitate rapid regrowth, dried for $48 \mathrm{~h}$ at $70{ }^{\circ} \mathrm{C}$, and weighed. At day 103 after sowing the final harvest (T4) was cut. At this harvest, the grass was cut close to the soil surface, including stubbles. Earthworms were collected and rinsed with tap water to remove any adhering soil particles. The moist bulk soil was homogenised, sieved $(2 \mathrm{~mm})$, and stored at $4{ }^{\circ} \mathrm{C}$ until further chemical analysis. Earthworm casts were collected by leaving the earthworms for $48 \mathrm{~h}$ in $100 \mathrm{~mL}$ polyethylene cups with an inert glass fibre filter (GF92, Schleicher and Schuell) at the bottom, pre-wetted with UPW. The cups were gently shaken by hand every day to activate the earthworms. Since the amount of collected cast was limited, cast samples collected from the 4 replicates of each treatment of the plant experiment were pooled for chemical analysis.

The cast experiment started at the same date as the plant experiment, but the earthworms were collected 71 days after sowing. Earthworm densities of the 6 pots in this experiment were increased 8 days prior to the final harvest by a factor 10 ( $\mathrm{Lr}$ and $\mathrm{AC}$ ) or 5 (Lt) to generate a sufficient amount of cast for chemical analysis. In the cast experiment, collection of the cast and bulk soil samples was carried out similar to the methods described for the plant experiment.

\subsection{Chemical analyses}

The dry weight of the cast and bulk soil samples from the plant and cast experiments was determined by drying subsamples for $24 \mathrm{~h}$ at $40^{\circ} \mathrm{C}$. The remaining material was sealed and stored at $4{ }^{\circ} \mathrm{C}$ to prevent the samples from desiccation. The moist cast and bulk soil samples were used to generate water extracts as a proxy for soil pore water (Koopmans et al., 2006; Torrent and Delgado, 2001) to determine the amount of readily available $P$ for plant uptake. These samples were not dried before the extraction with water as drying and subsequent rewetting of soil is known to enhance the release of dissolved ortho-P, organic $\mathrm{P}$, and dissolved organic carbon (DOC) to solution (Koopmans et al., 2006; Koopmans and Groenenberg, 2011).

For the cast and bulk soil samples from both experiments, moist material was suspended in UPW in 50-mL polypropylene tubes at a solid to solution ratio of 1:10 (w:v) based on the dry weight of the material. The suspensions were gently shaken for $24 \mathrm{~h}$ in a horizontal position on a reciprocating shaking machine with 75 strokes $\mathrm{min}^{-1}$ at $20^{\circ} \mathrm{C}$ in the dark. Subsequently, the suspensions were centrifuged for $15 \mathrm{~min}$ at $10000 \mathrm{rpm}$ and the supernatants were filtered through a $0.45 \mu \mathrm{m}$ filter (Aqua 30, Schleicher and Schuell). In the filtrates, $\mathrm{pH}$ and electrical conductivity 
(EC; Consort K810) were measured. The EC values were converted to ionic strength according to (Griffin and Jurinak, 1973):

$I=0.0127 \times E C$

where $I$ is ionic strength in $\mathrm{mol} \mathrm{L}^{-1}$ and $\mathrm{EC}$ is in $\mathrm{dS} \mathrm{m}^{-1}$. DOC was measured with a fully automated segmented flow analyser (SFA; Skalar, $\mathrm{SAN}^{++}$) by persulphate and tetraborate oxidation under ultraviolet (UV) light and infrared detection. Total dissolved Al, Ca, and Fe were analysed using inductively coupled plasma - atomic emission spectroscopy (ICP-AES; Varian Vista Pro), while total dissolved P (TDP) and Si were measured using high resolution - inductively coupled plasma - mass spectrometry (HR-ICP-MS; Thermo Scientific Element 2). Ortho-P, which is referred to here as dissolved inorganic $P$ (DIP), was measured according to the molybdenum blue method of Murphy and Riley (1962) using a SFA. Dissolved organic P (DOP) was calculated as the difference between the concentrations of TDP and DIP (Koopmans et al., 2006; Koopmans and Groenenberg, 2011). The absorbance at $254 \mathrm{~nm}\left(\mathrm{~A}_{254}\right)$ was measured using a Genesys 10S UV-Vis spectrophotometer (Thermo Scientific) when the volume of remaining filtrate was sufficient to perform this analysis. Based on the $A_{254^{\prime}}$ the Specific UV Absorbance (SUVA) value was calculated:

$S U V A_{254}=100 \times \frac{A_{254}}{D O C}$

with SUVA ${ }_{254}$ in $\mathrm{L} \mathrm{mg}^{-1}$ and DOC in $\mathrm{mg} \mathrm{L}^{-1}$. The SUVA ${ }_{254}$ is used to estimate the degree of DOC aromaticity according to Weishaar et al. (2003):

Aromaticity $=6.52 \times S U V A_{254}+3.63$

where the aromaticity is expressed as a percentage and SUVA ${ }_{254}$ is in $\mathrm{L} \mathrm{mg} \mathrm{C}^{-1} \mathrm{~m}^{-1}$. For the water extracts of the cast samples collected from the plant experiment, only ortho- $\mathrm{P}, \mathrm{pH}$, and for some samples, EC were measured because the volume of filtrate was insufficient to perform the other analyses. 
Total $\mathrm{P}$ and $\mathrm{N}$ contents of the shoots was measured after drying of the shoots at $70{ }^{\circ} \mathrm{C}$ and grinding and homogenisation of the dried material. Digestion was done using a mixture of $\mathrm{H}_{2} \mathrm{SO}_{4^{\prime}}$ $\mathrm{H}_{2} \mathrm{O}_{2}$ and salicylic acid with Se as a catalyst (Houba et al., 1997). The $\mathrm{N}$ and $\mathrm{P}$ concentrations in the digest were measured with a SFA. The final harvest (T4) was analysed separately, while composite samples were made for the harvests collected at T1, T2, and T3. The contribution of each of these harvests to the composite sample was weighted in accordance with grass biomass.

\subsection{Statistical analyses}

Statistical analyses were carried out in SPSS version 20. Analysis of variance (ANOVA) with earthworm species, $\mathrm{P}$ treatment, and block as independent factors was used to determine significance. For all analyses, $p$-values of $p<0.05$ were considered significant. Tukey's honest significant difference test was used as post-hoc test.

\section{Results and discussion}

\subsection{Soil characteristics}

The soil used for the plant and cast experiments had a P-AL value of $26 \mathrm{mg} \mathrm{P} \mathrm{kg}^{-1}$ (Table 4.1), which is considered a low P status in the Netherlands (Tunney et al., 1997). Organic P contributed 53\% to the total soil $\mathrm{P}$ content, meaning more than half of soil $\mathrm{P}$ is organic in nature. The amount of reactive metal oxides $[\mathrm{Al}+\mathrm{Fe}]_{\mathrm{ox}}$ is much larger than the amounts typically found in Dutch noncalcareous sandy soils $\left(<100 \mathrm{mmol} \mathrm{kg}^{-1}\right)$ or in noncalcareous clay soils $\left(<133 \mathrm{mmol} \mathrm{kg}^{-1}\right)$ with an agricultural land use (Koopmans et al., 2006). This is due to the large amount of Fe oxides in our soil, which dominates the composition of reactive metal oxides (Table 4.1). The degree of $\mathrm{P}$ saturation of the reactive metal oxides was low, with an $\alpha$ of 0.06 whereas maximum values of $\alpha$ have been found to range from 0.4 to 0.6 (Freese et al., 1992; Maguire et al., 2001; Van der Zee et al., 1988; Van der Zee and Van Riemsdijk, 1988). 
Table 4.1. Physico-chemical characteristics of the soil used in the cast and plant experiments.

\begin{tabular}{|c|c|}
\hline & Bulk soil \\
\hline Sand (\%) & 67 \\
\hline Silt (\%) & 22 \\
\hline Clay (\%) & 11 \\
\hline Organic matter $\left(\mathrm{g} \mathrm{kg}^{-1}\right)^{\text {a }}$ & 85 \\
\hline $\mathrm{pH}_{\mathrm{H} 20}$ & 5.6 \\
\hline P-AL (mg P kg $\left.{ }^{-1}\right)$ & 26 \\
\hline Total P $\left(\mathrm{mg} \mathrm{kg}^{-1}\right)$ & 823 \\
\hline Organic $\mathrm{P}\left(\mathrm{mg} \mathrm{kg}^{-1}\right)$ & 439 \\
\hline $\mathrm{Al}_{\mathrm{ox}}\left(\mathrm{mmol} \mathrm{kg}{ }^{-1}\right)$ & 16.9 \\
\hline $\mathrm{Fe}_{\mathrm{ox}}\left(\mathrm{mmol} \mathrm{kg}^{-1}\right)$ & 169.9 \\
\hline$P_{o x}(m g ~ k g-1)$ & 334 \\
\hline$\alpha^{\mathrm{b}}$ & 0.06 \\
\hline
\end{tabular}

a Loss on ignition with the loss of water from the crystalline structure of clay taken into account

${ }^{b}$ Degree of $\mathrm{P}$ saturation of a soil with respect to its content of reactive metal oxides calculated according to Equation 4.1

\subsection{Cast experiment}

\subsubsection{Composition of water extracts}

For all earthworm species, the DIP concentrations in the water extracts of the earthworm casts were significantly higher than those in the water extracts of the bulk soil $(p<0.001$; Fig. 4.1, Table 4.2). For the casts, the average DIP concentrations were 8.56, 3.59, and $0.44 \mathrm{mg} \mathrm{L}^{-1}$ for $\mathrm{Lr}$, Lt and Ac respectively, whereas the DIP concentrations in the water extracts of the bulk soil remained below the detection limit of $0.02 \mathrm{mg} \mathrm{L}^{-1}$. Our data, therefore, confirm $\mathrm{H} 1$. These results are in line with those found in previous studies (Chapuis-Lardy et al., 2009, 1998; Kuczak et al., 2006; Lopez-Hernandez et al., 1993; Sharpley and Syers, 1976). The levels of DOP in the water extracts of the casts were also significantly elevated for all three species $(p<0.001$, Table 4.2$)$, reaching a concentration of $1.3 \mathrm{mg} \mathrm{L}^{-1}$ for the casts of Lr compared to less than $0.2 \mathrm{mg} \mathrm{L}^{-1}$ for the bulk soil samples. Although the difference between TDP and DIP is often taken as a proxy for DOP (e.g. Koopmans et al., 2006; Koopmans and Groenenberg, 2011), this fraction most likely does not consist solely of organic P compounds, but may include P-containing colloidal particles in the form of P-metal-humic complexes, calcium phosphate minerals, and P bound to clay minerals and metal oxides (Gerke, 2010; Regelink et al., 2013; Turner et al., 2004). These colloids are able to pass 
the $0.45 \mu \mathrm{m}$-filter, which is used as a standard to remove particulates from environmental water samples. The contribution of DIP and DOP to TDP in the water extracts differed between the bulk soil and the cast of the different earthworm species: DIP contributed $<1 \%$ to TDP for the bulk soil, whereas TDP consisted for more than $75 \%$ of DIP for the Lr and Lt casts (results not shown). However, the contribution of DIP to TDP was lower for the Ac casts (33\%).

Table 4.2. Chemical characteristics of the 1:10 (w:v) water extracts generated from the earthworm casts and the bulk soil of the pots from the cast experiment where these earthworms were present. Data are averages of two measurements, standard errors are given between brackets ${ }^{\text {. }}$

\begin{tabular}{|c|c|c|c|c|c|c|}
\hline & \multicolumn{3}{|c|}{ Earthworm casts } & \multicolumn{3}{|c|}{ Bulk soil } \\
\hline & $\operatorname{Lr}$ & $\mathrm{Ac}$ & Lt & Lr & Ac & Lt \\
\hline $\operatorname{DIP}\left(m g L^{-1}\right)^{b}$ & $8.56(0.725)^{* *}$ & $0.44(0.119)^{\mathrm{ns}}$ & $3.59(0.630)$ * & $<0.02(0.008)$ & $<0.02(0.012)$ & $<0.02(0.004)$ \\
\hline $\operatorname{DOP}\left(\mathrm{mg} \mathrm{L}^{-1}\right)^{\mathrm{b}}$ & $1.30(0.113)^{* *}$ & $0.68(0.019)^{* * *}$ & $1.16(0.228)$ * & $0.18(0.008)$ & $0.18(0.012)$ & $0.15(0.004)$ \\
\hline $\operatorname{TDP}\left(\mathrm{mg} \mathrm{L}^{-1}\right)^{\mathrm{b}}$ & $9.85(0.838)$ ** & $1.12(0.138)$ * & $4.75(0.858)$ * & $0.18(0.009)$ & $0.18(0.012)$ & $0.15(0.004)$ \\
\hline pH & $7.8(0.03)^{* * *}$ & $7.8(0.07)^{* * *}$ & $7.8(0.05)^{* \star *}$ & $6.1(0.04)$ & $6.1(0.01)$ & $6.1(0.06)$ \\
\hline $\mathrm{Al}\left(\mathrm{mg} \mathrm{L}^{-1}\right)$ & $14.2(1.30)^{* \star}$ & $5.1(0.66)$ * & $11.7(2.99)^{\mathrm{ns}}$ & $2.2(0.07)$ & $2.2(0.15)$ & $1.9(0.01)$ \\
\hline $\mathrm{Fe}\left(\mathrm{mg} \mathrm{L}^{-1}\right)$ & $62.5(5.20) * *$ & $22.6(3.25)$ * & $51.0(11.85)^{*}$ & $10.7(0.60)$ & $10.2(0.60)$ & $8.9(0.30)$ \\
\hline $\mathrm{Si}\left(\mathrm{mg} \mathrm{L}^{-1}\right)$ & $32.2(2.72)^{* *}$ & $13.0(1.28)$ ** & $27.0(5.95)$ * & $5.7(0.23)$ & $5.6(0.26)$ & $4.8(0.16)$ \\
\hline $\mathrm{DOC}\left(\mathrm{mg} \mathrm{L}^{-1}\right)$ & $113(14.2)$ * & $51(1.8) * *$ & $101(15.4)$ * & $11(0.3)$ & $10(0.6)$ & $10(0.0)$ \\
\hline Aromaticity DOC (\%) & $28.9(3.15)^{* \star}$ & $41.5(3.90)$ ** & $32.5(3.90)$ ** & $71.0(0.85)$ & $69.7(0.00)$ & $68.0(1.25)$ \\
\hline Ionic strength (mM) & $4.23(0.380) * *$ & $3.20(0.220) * *$ & $3.96(0.165)$ * & $0.23(0.005)$ & $0.22(0.010)$ & $0.26(0.060)$ \\
\hline
\end{tabular}

a Levels of significance between values in earthworm casts and bulk soil for each specific earthworm species (one-way-ANOVA): ${ }^{*} p<0.05,{ }^{* *} p<0.01,{ }^{* * *} p<0.001$, ns $=$ not significant

${ }^{\mathrm{b}}$ Dissolved inorganic P (DIP), dissolved organic $\mathrm{P}$ (DOP), and total dissolved P (TDP)

For all earthworm species, the Al, Fe, and Si concentrations in the water extracts of the casts were higher than those in the water extracts of the bulk soil (Table 4.2). This difference can be explained by dispersion of colloidal clay minerals and metal oxides in the water extracts of the earthworm casts. Earthworm casts are known to contain a larger amount of clay minerals than the surrounding bulk soil (Sharpley and Syers, 1976), which may disperse when the cast is suspended in water. These clay colloids can act as a carrier for ortho-P (Regelink et al., 2013; Turner et al., 2004) and as such, contribute to the elevated DOP and DIP concentrations in the water extracts of the earthworm casts. Also, the high DOC levels in the casts, which will be discussed below, may contribute to the elevated $\mathrm{Al}$ and Fe concentrations, because DOC has a strong ability to form soluble complexes with these metals (Tipping et al., 2002). 
Earthworms are often reported to accumulate OM, fine soil fractions and nutrients in their casts by selective feeding (Brown et al., 2004). Besides this, several pathways for elevated concentrations of DIP in earthworm casts have been postulated by Kuczak et al. (2006). Below, we will discuss pathways involving $\mathrm{pH}$, mineralisation of organic $\mathrm{P}$, and the $\mathrm{DOC}$ concentration that could have led to the elevated dissolved $\mathrm{P}$ concentrations that we measured in the water extracts of the earthworm casts.

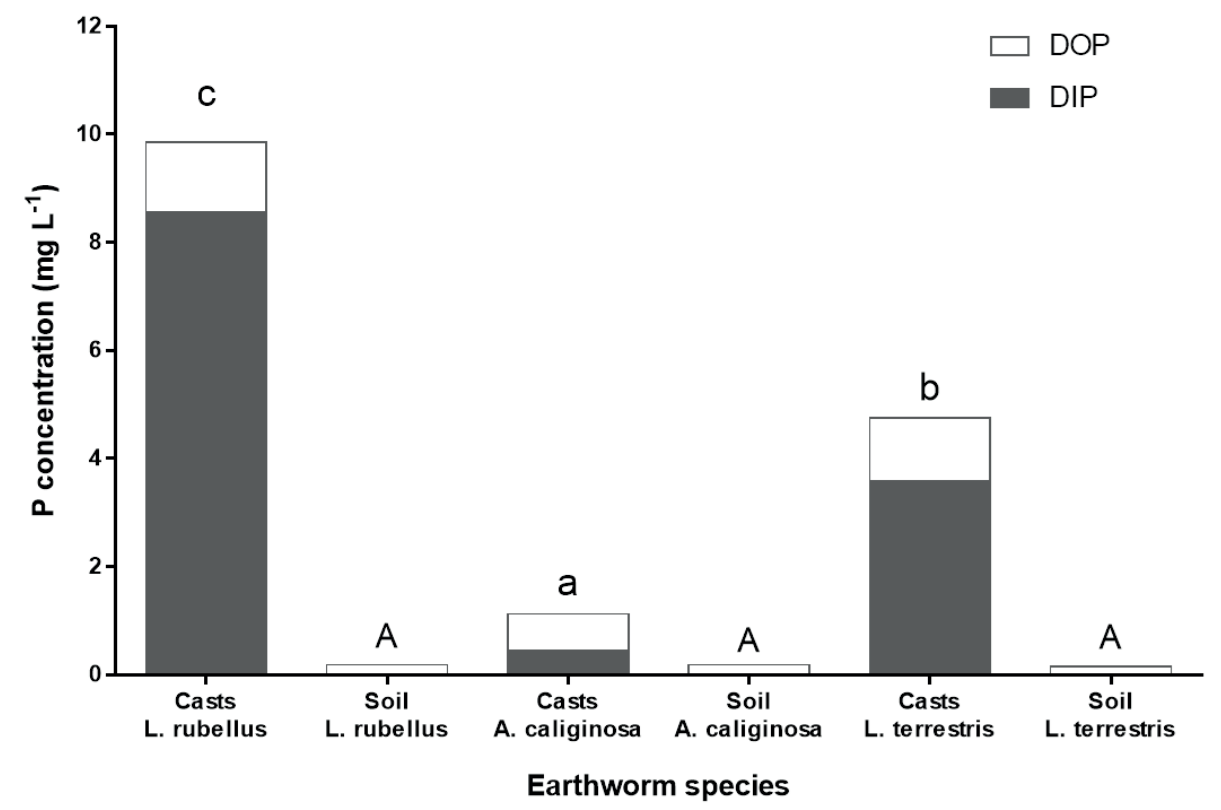

Figure 4.1. Dissolved inorganic $P(D I P)$ and dissolved organic $P(D O P)$ concentrations $\left(m g L^{-1}\right)$ in 1:10 (w:v) water extracts of earthworm casts and bulk soil collected in the cast experiment. Different letters indicate significant differences between DIP concentrations in the different treatments.

\section{$3.2 .2 p H$}

For all earthworm species, the pH levels in the water extracts of the casts were on average 1.7 units higher than those for the bulk soil $(p<0.001$; Table 4.2). Similar findings have been reported in previous studies (Barois and Lavelle, 1986; Basker et al., 1994; Kuczak et al., 2006; Sharpley and Syers, 1976). A conclusive explanation for this $\mathrm{pH}$ increase remains elusive, although the excretion of $\mathrm{CaCO}_{3}$ particles from the calciferous glands of earthworms has been suggested to buffer the $\mathrm{pH}$ at these elevated values (Briones et al., 2008; Lambkin et al., 2011). In another study, the increased 
$\mathrm{pH}$ for earthworm casts was attributed to mineralisation of organic $\mathrm{N}$ to $\mathrm{NH}^{+}$, which leads to the consumption of protons and a subsequent increase in $\mathrm{pH}$ (Basker et al., 1994).

The increase in $\mathrm{pH}$ may have contributed to the elevated levels of DIP in the water extracts of the earthworm casts. Adsorption of ortho-P to reactive metal oxides is known to be $\mathrm{pH}$-dependent, with adsorption decreasing with an increase in $\mathrm{pH}$ due to a decrease in the positive charge of metal oxides (Hesterberg, 2010; Weng et al., 2011). A higher pH of the casts is, therefore, expected to lead to high ortho-P concentrations in the water extracts. Although the increase in $\mathrm{pH}$ was similar for all earthworm species, the high DIP values for the casts varied considerably between species (Table 4.2). Consequently, the increase in $\mathrm{pH}$ in the earthworm casts is unlikely to be the sole explanation for the elevated DIP levels in the water extracts of the casts.

\subsubsection{Mineralisation of organic $P$}

Enhanced mineralisation of organic matter may have contributed to the elevated DIP levels measured in the water extracts of the casts. The conditions in the earthworm gut are known to be favourable for microbial activity (Aira et al., 2008; Lopez-Hernandez et al., 1993; Tiunov and Scheu, 2000). Increases in microbial activity, in turn, are associated with an increased enzyme activity (e.g. Tiwari et al., 1989), which may lead to an increased mineralisation rate of organic $P$, causing higher DIP concentrations in solution. The mineralisation process may help to understand the differences found in DIP concentration between the earthworm species. The concentrations of DIP in the water extracts of the casts were clearly higher for $L r$ and $L t$ than for AC (Tables 4.2 and 4.3). Since the first two species are known to feed mainly on fresh organic material, whereas the latter ingests mainly soil particles and associated organic matter, this specific feeding behaviour of Lr and Lt may have led to more mineralisable material in their casts and subsequent higher DIP concentrations in the water extracts. This is supported by the lower aromaticity of the DOC in the water extracts of the earthworm casts of $\mathrm{Lr}$ and $\mathrm{Lt}$ than for the ones of Ac (Table 4.2). This lower degree of aromaticity is associated with DOC exhibiting a more hydrophilic character with a lower molecular weight and a higher susceptibility towards mineralisation than humic substances including humic and fulvic acids (Swietlik and Sikorska, 2006).

Increased mineralisation of organic $\mathrm{P}$ has been reported before for casts by Satchell and Martin (1984), who measured higher activities of phosphatase enzymes in casts as compared to the bulk soil. In some studies, however, no difference (Don et al., 2008) or even a decrease (Jiménez et al., 2003) in phosphatase enzyme activity in cast material as compared to bulk soil was reported. It is therefore difficult to assess to which extent a higher mineralisation rate may have contributed to the elevated DIP levels in our cast experiment. 
Table 4.3. The $p$ values of the two experimental factors (earthworm species and matrix) on dissolved $P$ concentrations in the 1:10 (w:v) water extracts collected in the cast experiment (twoway-ANOVA).

\begin{tabular}{lccc}
\hline Factor & DIP $^{\text {a }}$ & DOP $^{\text {a }}$ & TDP $^{\text {a }}$ \\
\hline Earthworm species & $<0.001$ & 0.057 & $<0.001$ \\
Matrix & $<0.001$ & $<0.001$ & $<0.001$ \\
Earthworm species $\times$ Matrix & $<0.001$ & 0.053 & $<0.001$ \\
\hline
\end{tabular}

a Dissolved inorganic $\mathrm{P}$ (DIP), dissolved organic $\mathrm{P}$ (DOP), and total dissolved P (TDP)

\subsubsection{DOC}

The DOC concentrations in the water extracts of the earthworm casts were much higher than those for the bulk soil (Table 4.2). This might be explained by a combination of enhanced mineralisation of organic matter, and by excretion of DOC-rich mucus by earthworms (Lopez-Hernandez et al., 1993).

The difference in DOC concentrations between the water extracts of the casts and those of the bulk soils can have an important consequence for DIP. Since negatively charged DOC compounds can compete with ortho-P for the same binding sites on reactive metal oxides, the higher DOC levels can possibly explain the elevated DIP concentrations in the water extracts of the casts (Lopez-Hernandez et al., 1993). However, since the loading of reactive metal oxides in our bulk soil with ortho-P $(\boxplus)$ was relatively low (Table 4.1), it is unclear to which extent such a competition contributed to the elevated DIP concentrations. Determining the relevance and importance of each of the three aforementioned pathways requires further investigation, but this falls beyond the scope of our current study.

\subsection{Plant experiment}

\subsubsection{Phosphorus in bulk soil}

Earthworm survival in the plant experiment was on average $90 \%$, with no differences between earthworm or P fertilisation treatments (results not shown). In contrast to the cast experiment, the plant experiment contained treatments with and without earthworms, which allowed us to test whether earthworms affect P availability in the bulk soil (H2). However, the DIP concentrations in the water extracts of the bulk soils with and without earthworms remained below the detection limit 
for all treatments (Table S4.1). Even though earthworms had a dramatic effect on the availability of DIP in the water extracts of their fresh casts (Fig. 4.1 and Table 4.2), this effect clearly did not translate into an increase in the DIP concentrations for the bulk soil samples taken from the plant experiment. For this reason, we reject $\mathrm{H} 2$. The absence of any effect of the presence of earthworms on DIP concentrations in the water extracts of the bulk soils may be attributed to the strong $P$ binding properties of our soil, which is reflected in the large amount of amorphous Fe-oxides and the low $\oplus$ value of the reactive metal oxides (Table 4.1). Any ortho-P released from the earthworm casts to the surrounding bulk soil was probably retained by reactive metal oxides.
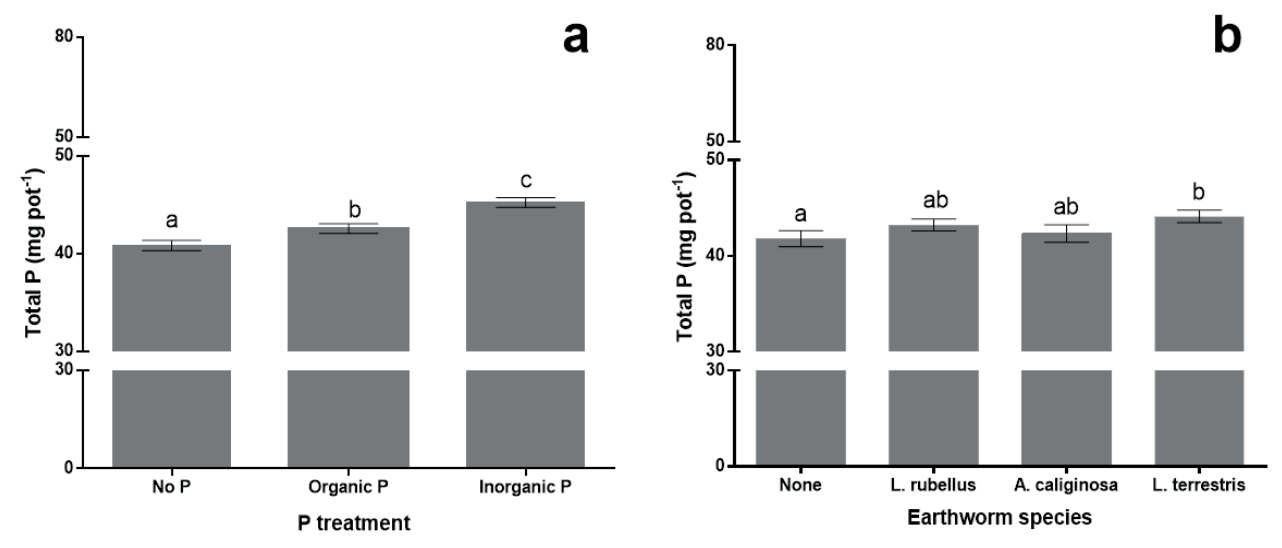

C
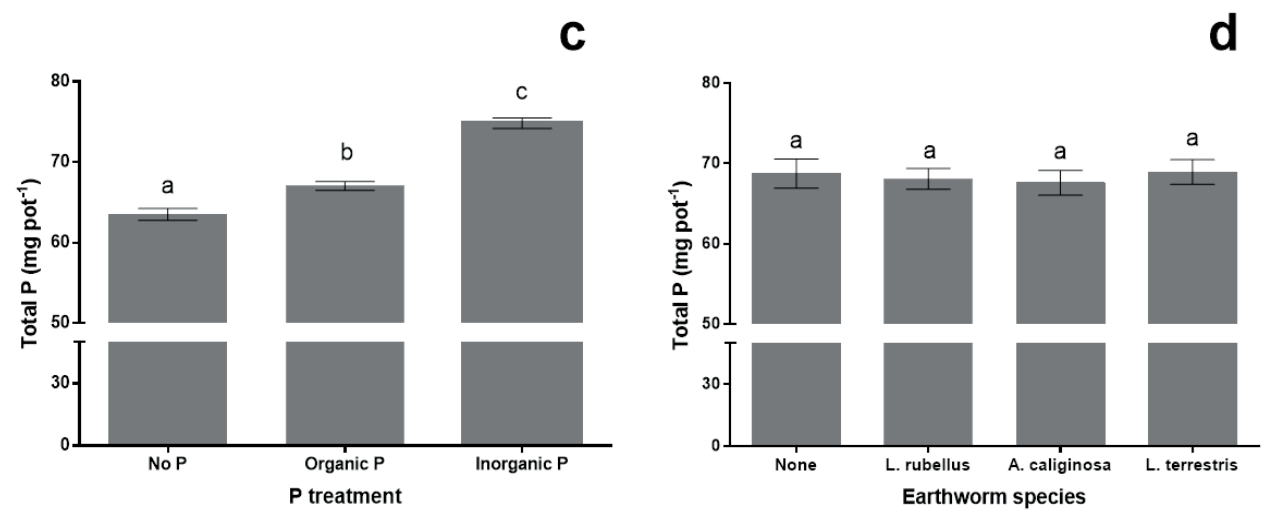

Figure 4.2. Total $P$ uptake by the grass for the different $P$ fertilisation treatments and earthworm species for harvests collected at T1-T3 ( $a$ and b) and T1-T4 ( $c$ and $d$ ) in the plant experiment. Error bars denote SE and different letters indicate significant differences $(p<0.05), n=16$ for $a$ and $c$, $n=12$ for $b$ and $d$. 


\subsubsection{Effects of $P$ treatment on $P$ and $N$ uptake by the grass}

Total P uptake was lowest for the control treatment and highest for the pots fertilised with inorganic P (Fig. 4.2a and 2c, Table 4.4), despite the fact that crop yield was highest in the treatment without added $\mathrm{P}$. Although plants are unable to directly take up organic $\mathrm{P}$ from the soil solution, the total $\mathrm{P}$ uptake in the treatment with phytate as a $P$ fertiliser was larger than for the treatment not receiving any $\mathrm{P}$ fertiliser. Phytate is known to compete with ortho-P for binding sites on reactive metal oxides (Celi et al., 1999; Ognalaga et al., 1994), but considering the application rate in this experiment and the rather low $\oplus$ of the soil (Table 4.1), desorption of ortho-P as a result of competition with phytate seems to be unlikely. Hence, phytate may have been mineralised during the plant experiment, leading to the release of ortho-P to soil solution and causing an increase in uptake of $\mathrm{P}$ by the grass.

Table 4.4. Plant growth and $P$ uptake for the harvests at T1-T3 (cumulative) and for the harvest at T4. Averages of four replicates are expressed for the different fertilization and earthworm treatments. Standard errors are given between brackets.

\begin{tabular}{|c|c|c|c|c|c|}
\hline \multirow{2}{*}{$\begin{array}{l}\text { Treatments } \\
\text { P treatment }\end{array}$} & \multirow[b]{2}{*}{$\begin{array}{l}\text { Worm } \\
\text { treatment }\end{array}$} & \multicolumn{2}{|c|}{ Harvest T1-T3 } & \multicolumn{2}{|c|}{ Harvest T4 } \\
\hline & & $\begin{array}{l}\text { Plant growth } \\
\qquad\left(\text { g pot }^{-1}\right)\end{array}$ & $\begin{array}{l}\text { Plant P } \\
\text { uptake } \\
\left(\mathrm{mg} \mathrm{pot}^{-1}\right)\end{array}$ & $\begin{array}{l}\text { Plant growth } \\
\qquad\left(\text { g pot }^{-1}\right)\end{array}$ & $\begin{array}{l}\text { Plant P } \\
\text { uptake } \\
\left(\mathrm{mg} \mathrm{pot}^{-1}\right)\end{array}$ \\
\hline No $P$ & No worms & $16.16(0.26)$ & $39.09(1.09)$ & $9.06(0.31)$ & $23.51(1.11)$ \\
\hline No $P$ & L. rubellus & $16.87(0.21)$ & $42.94(0.31)$ & $8.67(0.30)$ & $22.88(0.94)$ \\
\hline No $P$ & A.caliginosa & $15.80(0.22)$ & $39.76(0.66)$ & $8.84(0.16)$ & $22.99(0.71)$ \\
\hline No $P$ & L. terrestris & $17.02(0.29)$ & $42.07(0.96)$ & $8.26(0.41)$ & $21.96(0.80)$ \\
\hline Organic P & No worms & $16.03(0.14)$ & $42.00(0.82)$ & $9.47(0.21)$ & $26.40(0.20)$ \\
\hline Organic P & L. rubellus & $16.26(0.22)$ & $41.95(0.82)$ & $8.62(0.23)$ & $23.65(0.48)$ \\
\hline Organic $P$ & A.caliginosa & $16.58(0.12)$ & $42.51(1.09)$ & $9.06(0.23)$ & $24.76(0.35)$ \\
\hline Organic $P$ & L. terrestris & $17.59(0.44)$ & $44.53(0.82)$ & $8.77(0.03)$ & $24.47(0.33)$ \\
\hline Inorganic P & No worms & $14.86(0.15)$ & $44.83(1.22)$ & $9.39(0.20)$ & $31.77(0.44)$ \\
\hline Inorganic $\mathrm{P}$ & L. rubellus & $15.02(0.17)$ & $45.57(1.07)$ & $8.77(0.23)$ & $28.80(0.62)$ \\
\hline Inorganic P & A.caliginosa & $14.92(0.25)$ & $45.46(1.32)$ & $9.18(0.26)$ & $29.99(0.95)$ \\
\hline Inorganic P & L. terrestris & $15.94(0.17)$ & $46.28(0.41)$ & $8.45(0.21)$ & $28.76(1.23)$ \\
\hline \multicolumn{6}{|c|}{ 2-way-ANOVA results a } \\
\hline \multicolumn{2}{|l|}{$P$ treatment } & $* * *$ & $* * *$ & ns & $* * *$ \\
\hline \multicolumn{2}{|c|}{ Worm treatment } & $* * *$ & * & $* *$ & ** \\
\hline \multicolumn{2}{|c|}{$\mathrm{P}$ treatment $\times$ Worm treatment } & ns & ns & ns & ns \\
\hline
\end{tabular}

a Levels of significance for the experimental factors (two-way-ANOVA): ${ }^{*}<<0.05,{ }^{* *} p<0.01$, $* * * p<0.001$, ns $=$ not significant 
Alhough significant, the differences in crop yield and total $\mathrm{P}$ uptake were relatively small. This indicates a limited difference in plant available $\mathrm{P}$ between $\mathrm{P}$ treatments, which could possibly be attributed to the strong binding character of the soil. Since $P$ was supplied only before the start of the experiment, a major part of the available $P$ in the inorganic and organic $P$ treatments might have been immobilised before plants could have fully benefited from it. An additional explanation could be that, while levels of ortho-P measured in bulk soil samples were very low, the replenishment rate of the soil was high enough to sustain plant growth to some extent.

The averages for the calculated N/P ratios of the grass for the different $P$ treatments in the plant experiment are shown in Fig. S4.1. An N/P ratio above 16 suggests P-limited plant growth, while an N/P ratio below 14 signifies $N$ limitation (Koerselman and Meuleman, 1996). For the harvests taken at $\mathrm{T} 1-\mathrm{T} 3$, the average shoot N/P ratio for the treatment receiving no $\mathrm{P}$ fertilisation was 17.2, indicating a P-limited growth of the grass. For the treatment receiving phytate as a $\mathrm{P}$ fertiliser, the average N/P ratio was lower (16.0), resulting from the higher $P$ uptake by the grass, as discussed above. Nevertheless, this N/P is still indicative of a P-limited growth. The grass harvested from the treatment with inorganic $P$ as a fertiliser had an average N/P ratio of 13.7, which was, therefore, slightly $\mathrm{N}$ limited. The average N/P ratios of the grass in these $\mathrm{P}$ fertilisation treatments were lower when the data of the final harvest (T4) were included in the calculation of the N/P ratio (Fig. S4.1 b). Nevertheless, the differences between $\mathrm{P}$ treatments remained similar when the final harvest was included.

\subsubsection{Effects of earthworm species on grass growth and $P$ uptake}

In T1-T3, total $\mathrm{P}$ uptake by the grass in the treatment with $\mathrm{Lt}\left(44.3 \mathrm{mg} \mathrm{P} \mathrm{pot}^{-1}\right)$ was significantly higher than the total $\mathrm{P}$ uptake in the treatment without earthworms $\left(42.0 \mathrm{mg} \mathrm{P} \mathrm{pot}^{-1}\right.$; Fig. $4.2 \mathrm{~b}$, Table 4.4). The presence of $L r$ and Ac caused intermediate levels of total $P$ uptake (43.5 and 42.6 mg P pot ${ }^{-1}$, respectively). A similar effect was observed for the grass growth over T1-T3, with the presence of Lt leading to a significantly larger plant growth $\left(16.85 \mathrm{~g} \mathrm{pot}^{-1} ; \mathrm{p}<0.001\right)$ than for the other three earthworm treatments. For the latter three treatments, no significant differences were found $\left(16.05,15.77\right.$ and $15.68 \mathrm{~g} \mathrm{pot}^{-1}$ for the $\mathrm{Lr}$, Ac, and no earthworm treatments, respectively; Table 4.4). Therefore, we reject $\mathrm{H} 5$. The increase in plant growth for the Lt is probably linked to the high dissolved P concentration in the water extracts of the Lt casts (Fig. 4.1). Although the chemical analysis of the bulk soil samples did not reveal any increase in plant available $\mathrm{P}$ levels, the grass roots were able to effectively exploit earthworm-induced $P$ "hot-spots". However, it is unclear whether the significant effects of $L t$ on total $P$ uptake and plant growth are specific for this earthworm species or whether these effects result from an earthworm biomass effect. Species-specific traits of $L t$ are not necessarily the explanation for the increased total $P$ uptake and plant growth. Lt had 
the largest biomass of the earthworm species used in this pot experiment and produced the largest amount of cast (results not shown). The exact explanation for the effects of Lt on total P uptake and plant growth, therefore, remains elusive based on this plant experiment. For example, the relative short duration of the plant experiment may have prevented the other two earthworm species from affecting total P uptake and plant growth. According to a review of Feller et al. (2003), earthworm cast production in temperate ecosystems ranges from 2.2 to $91.6 \mathrm{t} \mathrm{ha}^{-1} \mathrm{yr}^{-1}$. Based upon these numbers, cast production during the 75-day experimental period would be approximately two orders of magnitude smaller than the total amount of soil present in each pot. Although earthworm casts clearly have higher levels of dissolved $\mathrm{P}$ in casts, for an effect on the availability of $\mathrm{P}$ in the bulk soil a significant portion of the soil needs to pass through the earthworm gut, which would require a longer duration of the plant experiment.Another important factor when considering the effects of earthworms on total $\mathrm{P}$ uptake and plant growth is the ageing of the earthworm casts. The availability of $\mathrm{P}$ in earthworm casts has been demonstrated to change over time; after initial high levels of plant available $P$, the $P$ availability in earthworm casts decreased with time (Le Bayon and Binet, 2006; Lopez-Hernandez et al., 1993; Scheu, 1987; Sharpley and Syers, 1976). As this will affect access of plants to available $P$, these $P$ dynamics should be included in future studies on the effects of earthworms on $\mathrm{P}$ availability in soil for uptake by plants.

The earthworm effect on total $\mathrm{P}$ uptake and plant growth described above disappeared when the final harvest taken at T4 was included (Fig. 4.2d). The disappearance of the earthworm effect when the harvests taken at T1-T4 were combined may be due to the different harvesting protocol used for the final harvest taken at T4. For the harvests taken at T1-T3, the grass was cut $5 \mathrm{~cm}$ above the surface to ensure a rapid regrowth of the grass. However, at T4, all plant parts were cut directly above the soil surface, which included the stubbles, so as to harvest all aboveground biomass produced over the entire course of the plant experiment. The stubbles consist of grass grown during the entire course of the plant experiment, including the pre-growing phase, prior to introduction of the earthworms. As grass growth in this initial growth stage relies for an important part on the availability of nutrients provided by the seeds, no differences in P content due to $P$ treatment are expected. Because of the relatively high contribution of the stubbles to the total weight of the biomass collected at the final harvest, earthworm-induced differences on total $\mathrm{P}$ uptake and plant growth might have been obscured. Consequently, we cannot fully confirm H3, although it is consistent with results from harvests T1-T3.

In order to test $\mathrm{H} 4$, we assessed the effect of earthworm presence on total $\mathrm{P}$ uptake and plant growth separately for each $\mathrm{P}$ fertiliser treatment for the harvests taken at T1-T3. For the treatment with phytate, there was no significant increase in total P uptake by the grass in the pots with earthworms (Table 4.4). For the plant growth, however, a significant increase was observed for Lt in the treatments with inorganic $P$ and phytate as compared to the treatments with the same $P$ fertilisers but without earthworms. This difference was larger in the treatment with phytate than in the treatment with inorganic $P$ (average increases of $1.56 \mathrm{~g} \mathrm{pot}^{-1}$ and $1.08 \mathrm{~g} \mathrm{pot}^{-1}$, respectively). Therefore, we can confirm $\mathrm{H} 4$ for the plant growth, but not for total $\mathrm{P}$ uptake. 


\section{Conclusions}

Both DIP and DOP concentrations were significantly higher in the water extracts of earthworm casts than in those of the bulk soil. These results differed for the three earthworm species, with the largest differences observed for Lr. In the bulk soil, no significant effects of the presence of earthworms on P availability were observed. After three harvests, the presence of Lt significantly increased total $\mathrm{P}$ uptake by the grass as well as the plant growth as compared to the control treatment, but an earthworm effect was not present for Lr and Ac. For plant growth, the effect of Lt was larger for the treatment with phytate than for the treatment with inorganic P. Inclusion of grass stubbles at the fourth and final harvest is likely to have contributed to the absence of a significant effect on grass $\mathrm{P}$ uptake and plant growth after the final harvest. More research is needed to further understand and quantify the processes which are responsible for these earthworm-induced effects. Such research should focus on (i) unravelling the mechanisms through which earthworms influence $\mathrm{P}$ availability, and (ii) assessing the spatio-temporal dynamics of these effects on a bulk soil level, and the accompanying implications for plant uptake. Maintaining soil faunal biodiversity is known to be important for a variety of ecosystem services (Blouin et al., 2013). Our results show that these ecosystem services may include improving the utilisation of P stored in agricultural soils, which is promising in a world with rapidly declining P stocks.

\section{Acknowledgements}

This research has been made possible thanks to a donation by De Heus b.v., on the occasion of the 100th anniversary of the company. We are grateful to Arjan Reijneveld for his assistance in the location and collection of the used soil, and to Jaap Nelemans, Willeke van Tintelen and Gerlinde Vink for their assistance with laboratory work. We would further like to thank Bastiaan Molleman for helpful discussions on data interpretation, and Lucas Pecci Canisares, Maartje Vos, Klaas De Jong, Anupol Chareesri and Ingrid Lubbers for their assistance with harvesting the experiments. Finally, we gratefully acknowledge suggestions by Lijbert Brussaard on an earlier version of this manuscript, and thank two anonymous reviewers for their useful comments. 


\section{Supplementary Information}

Table S4.1. Chemical characteristics of the 1:10 (w:v) water extracts generated from the earthworm casts and the bulk soil of the pots from the plant experiment where these earthworms were present. Data are averages of 3 measurements for the casts and of 12 measurements for the bulk soil.

\begin{tabular}{|c|c|c|c|c|c|c|c|}
\hline & \multicolumn{3}{|c|}{ Earthworm casts } & \multicolumn{4}{|c|}{ Bulk soil } \\
\hline & Lr & Ac & Lt & None & $\mathrm{Lr}$ & Ac & Lt \\
\hline $\operatorname{DIP}\left(m g L^{-1}\right)^{a}$ & 4.98 & 0.32 & 2.10 & $<0.02$ & $<0.02$ & $<0.02$ & $<0.02$ \\
\hline $\mathrm{DOP}\left(\mathrm{mg} \mathrm{L}^{-1}\right)^{\mathrm{a}}$ & - & - & - & 0.15 & 0.15 & 0.17 & 0.18 \\
\hline $\operatorname{TDP}\left(m g L^{-1}\right)^{a}$ & - & - & - & 0.16 & 0.16 & 0.17 & 0.18 \\
\hline $\mathrm{pH}$ & 8.3 & 8.2 & 7.9 & 6.2 & 6.1 & 6.1 & 6.1 \\
\hline $\mathrm{Al}\left(\mathrm{mg} \mathrm{L}^{-1}\right)$ & - & - & - & 1.6 & 1.6 & 1.7 & 1.8 \\
\hline $\mathrm{Fe}\left(\mathrm{mg} \mathrm{L}^{-1}\right)$ & - & - & - & 7.3 & 7.4 & 7.9 & 8.5 \\
\hline Si $\left(\mathrm{mg} \mathrm{L}^{-1}\right)$ & - & - & - & 4.7 & 4.8 & 5.2 & 5.4 \\
\hline $\mathrm{DOC}\left(\mathrm{mg} \mathrm{L}^{-1}\right)$ & - & - & - & 8 & 8 & 9 & 9 \\
\hline Aromaticity DOC (\%) & - & - & - & 72.3 & 68.6 & 68.5 & 65.5 \\
\hline Ionic strength (mM) & - & - & 3.37 & 0.33 & 0.38 & 0.39 & 0.40 \\
\hline
\end{tabular}

a Dissolved inorganic P (DIP), dissolved organic P (DOP), and total dissolved P (TDP) 

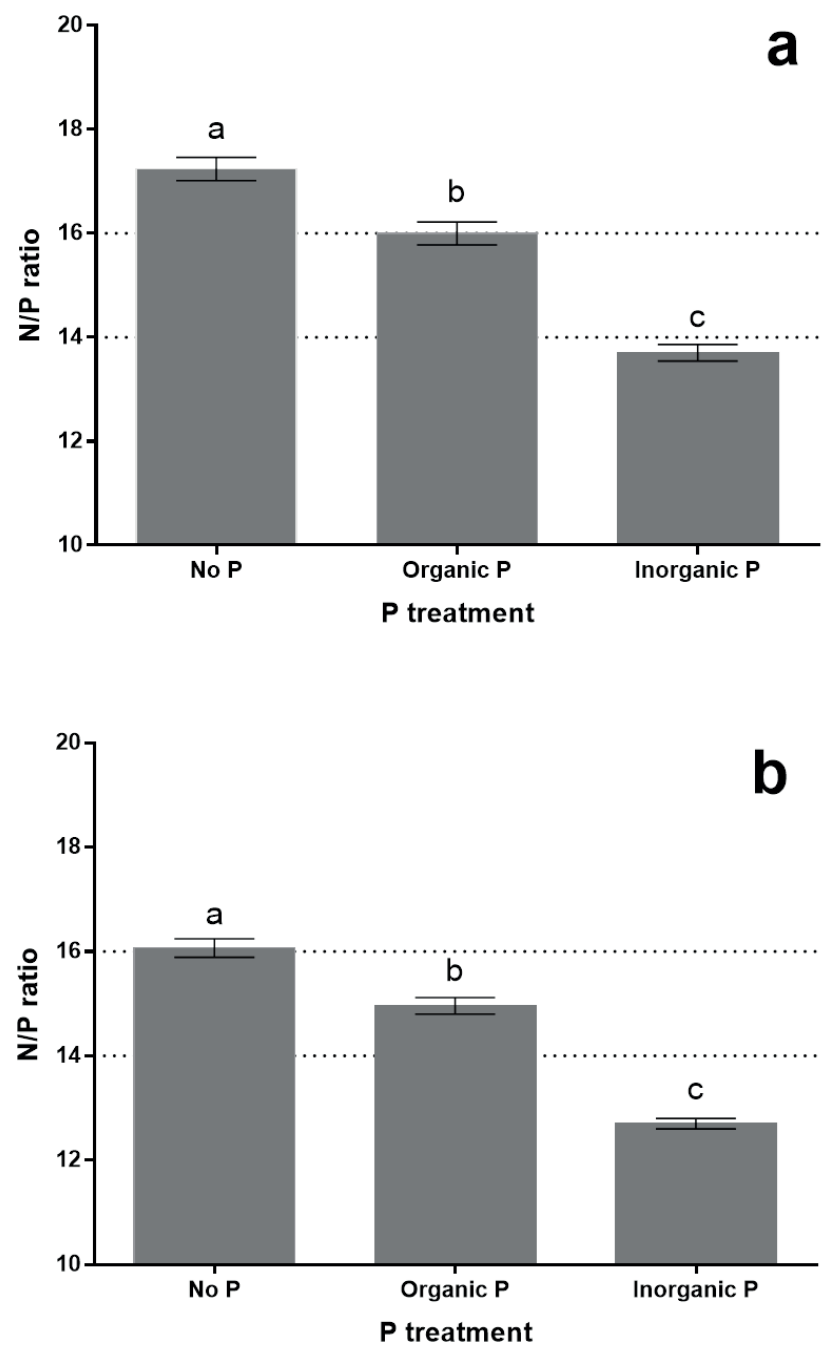

Figure S4.1. The N/P ratio of the grass for the different $P$ fertilisation treatments for harvests collected at T1-T3 (a) and T1-T4 (b) in the plant experiment. Above the upper dotted line, growth of grass is considered to be P-limited, while below the lower dotted line it is considered to be $N$-limited. Error bars denote SE and different letters indicate significant differences $(p<0.05)$, $n=16$. 


\section{Chapter 5}

\section{Exploring the pathways of earthworm- induced phosphorus availability}

Mart B.H. Ros, Tjisse Hiemstra, Jan Willem van Groenigen,

Anupol Chareesri, Gerwin F. Koopmans

This chapter is published as:

Ros, M.B.H., Hiemstra, T., van Groenigen, J.W., Chareesri, A., Koopmans, G.F., 2017.

Exploring the pathways of earthworm-induced phosphorus availability. Geoderma 303,

99-109. doi:10.1016/j.geoderma.2017.05.012 


\section{Abstract}

As many soils are unable to supply sufficient amounts of phosphorus $(P)$ to plants, $P$ availability is often a growth-limiting factor. Literature shows that levels of readily available $\mathrm{P}$ can be considerably higher in earthworm casts than in the surrounding bulk soil, possibly resulting in increased plant $\mathrm{P}$ uptake. However, the underlying mechanisms through which this increase of readily available $\mathrm{P}$ occurs are unclear. In a greenhouse pot experiment with annual ryegrass (Lolium multiflorum) on a soil with low $\mathrm{P}$ availability, we tested whether the presence of the anecic earthworm Lumbricus terrestris resulted in increased grass growth and $\mathrm{P}$ uptake and explored the possible mechanisms behind such an effect. During the pot experiment, earthworm casts were collected and analysed for water-extractable $\mathrm{P}$ as well as for most other relevant ions. The earthworm's presence significantly increased grass yield from 9.80 to $10.80 \mathrm{~g}$ dry matter $\operatorname{pot}^{-1}(p=0.044)$ and $P$ uptake from 6.32 to $8.04 \mathrm{mg} \mathrm{pot}^{-1}(p=0.002)$. Due to increased microbial activity, the solution chemistry in the water extracts of the casts was dramatically changed compared to the bulk soil samples. The concentrations of dissolved inorganic $\mathrm{P}$ in cast were enhanced by a factor $\sim 30-1000$ compared to the levels found in bulk soil. The $\mathrm{pH}$ in earthworm casts increased from 5.9 to values between 7.4 and 9.0 and the Ca concentrations decreased by about a factor $\sim 2-3$ compared to bulk soil samples. In addition, there was an increase in dissolved organic carbon (35 mg L-1 in casts versus $3 \mathrm{mg} \mathrm{L}^{-1}$ in soil). Surface complexation modelling, using the Charge Distribution model, suggests that, besides an increase in $\mathrm{pH}$, particularly an enhanced interaction of dissolved organic matter with reactive surface of metal (hydr)oxides is likely to be a major driving force for the augmented release of orthophosphate $\left(\mathrm{PO}_{4}\right)$ via competitive adsorption and desorption. This competition for adsorption sites is an alternative pathway, next to mineralisation of organic matter, through which earthworms can increase soil fertility. 


\section{Introduction}

Phosphorus $(\mathrm{P})$ is one of the macronutrients that are essential for plant growth; it is a structural element in biomolecules like nucleic acids, and is crucial in energy transfer processes (Hawkesford et al., 2012). Plants take up $P$ from the soil solution in the form of orthophosphate $\left(\mathrm{PO}_{4}\right)$, which, depending on the soil $\mathrm{pH}$, is most commonly present as $\mathrm{HPO}_{4}{ }^{2-}$ or $\mathrm{H}_{2} \mathrm{PO}$. In most soils, the amount of $\mathrm{PO}_{4}$ in the soil solution is limited and represents $<1 \%$ of the typical $\mathrm{P}$ uptake by crops (around $50 \mathrm{~kg} \mathrm{P} \mathrm{ha}^{-1}$ ) over a growing season (Morel et al., 2000). The remaining $\mathrm{P}$ is provided by the release of $\mathrm{PO}_{4}$ from the soil solid phase to the soil solution throughout the growing season. The rate at which $\mathrm{PO}_{4}$ in soil solution is replenished is governed by an intricate interplay between various soil chemical and biological processes. Among these, desorption of $\mathrm{PO}_{4}$ to the soil solution from reactive surfaces of metal (hydr)oxides and edges of clay minerals, or dissolution of calciumphosphate and magnesium-phosphate minerals, as well as subsequent diffusion of $\mathrm{PO}_{4}$ towards the plant root surface where uptake occurs, are the dominant processes affecting $P$ uptake by crops in many agricultural soils (Gérard, 2016; Hinsinger, 2001; Koopmans et al., 2004; Kovar and Claassen, 2005; Van Noordwijk et al., 1990). Moreover, mineralisation of soil organic matter (OM), microbial biomass, and plant residues can contribute substantially to $\mathrm{P}$ availability and subsequent plant $\mathrm{P}$ uptake, especially in soils with high OM content and microbial activity (Richardson et al., 2011, 2009a). These processes, in turn, are affected by abiotic factors like $\mathrm{pH}$, soil moisture, temperature, soil texture, as well as metal (hydr)oxide content.

As a result of a low $\mathrm{P}$ content and strong binding of $\mathrm{PO}_{4}$ to mineral surfaces, most soils are unable to supply $P$ to plants at sufficient rates for sustaining optimal growth. This is especially the case in highly weathered tropical soils, but also frequently occurs in non P-fertilised soils in temperate climates (Hinsinger, 2001). Application of P fertiliser is often used to avoid P deficiency in plants. In large parts of Europe and North America, however, application rates of $P$ in the form of animal manure and mineral $P$ fertiliser well above $P$ crop removal have led to an accumulation of $P$ in a so-called soil "legacy" P pool (Kleinman et al., 2011). This has increased the accompanying risk of $P$ losses to ground- and surface waters that contribute to eutrophication (Csathó and Radimszky, 2009; Jarvie et al., 2015; Koopmans et al., 2007; MacDonald et al., 2011). In intensively managed soils with excessive $\mathrm{P}$ application rates, the legacy $\mathrm{P}$ pool can reach a substantial size. In the Netherlands, the average size of this pool has been estimated to be $2050 \mathrm{~kg} \mathrm{P} \mathrm{ha}^{-1}$ in the upper $0.5 \mathrm{~m}$ of agricultural land (Schoumans and Chardon, 2015). Since global $P$ reserves might be depleted within a century and prices of mineral P fertiliser will increase over the coming decades (Cordell et al., 2009), unsustainable $\mathrm{P}$ management has been identified as a key planetary boundary that has been crossed and needs to be addressed (Steffen et al., 2015). There is therefore an increasing need for alternative, sustainable ways that facilitate plants to acquire $P$ from this legacy $P$ pool.

Increasing plant $\mathrm{P}$ acquisition can possibly be achieved through adapting plants or their environment. Many plants have developed their own strategies to enhance $P$ uptake, such as adaptation of their root morphology, excretion of organic acids and phosphatases, or forming 
mycorrhizal associations (Milleret et al., 2008; Shen et al., 2011). Using new plant genotypes (Lynch and Brown, 2001) or inoculating the soil with microbes (Richardson, 2001) may be effective strategies to increase plant $\mathrm{P}$ uptake. In a different line of research, recent studies have shown that earthworms might also increase $P$ acquisition by plants. Earthworms are ecosystem engineers that can strongly alter physico-chemical soil properties. They create burrows and feed on litter and OM associated with soil particles (Doube et al., 1997). By doing so, earthworms affect soil structure, microbial activity, decomposition of OM, and nutrient cycling. Earthworms have been shown to increase yield of grasses and grain crops by $25 \%$ on average, and this effect has been linked to increased nitrogen (N) availability (Van Groenigen et al., 2014). Additionally, they stimulate microbial activity in their casts and can increase the amount of readily available P (Kuczak et al., 2006; Lopez-Hernandez et al., 1993; Sharpley and Syers, 1976; Vos et al., 2014). Although a variety of pathways through which earthworms might affect plant growth have been suggested (Brown et al., 2004), the relative importance of the mechanisms responsible for the increase in readily available $P$ in earthworm casts still remains largely unclear (Le Bayon and Milleret, 2009).

In an earlier study (Vos et al., 2014), we established that earthworm species with different feeding strategies produced casts with different amounts of water-extractable P (a proxy for plantavailable $P$ ), and that $P$ uptake by grass was enhanced by earthworm presence when other nutrients were sufficiently supplied. Three possible mechanisms were hypothesised for this earthworminduced increase in readily available $\mathrm{P}$ in casts: a) desorption of $\mathrm{PO}_{4}$ from mineral surfaces due to the elevated $\mathrm{pH}$ in earthworm casts; b) increased mineralisation of organic $\mathrm{P}$ due to enhanced microbial activity; and c) desorption of $\mathrm{PO}_{4}$ from mineral surfaces due to competitive adsorption of elevated dissolved organic matter (DOM) concentrations in casts (Vos et al., 2014). To facilitate plant uptake from the legacy P pool in the presence of earthworms, it is important to develop our understanding of how the cast environment enhances $P$ availability. Additionally, the temporal dynamics of readily available $P$ in earthworm casts are still unclear and may affect $P$ uptake by plants. The objectives of this study are (i) to determine the effect of earthworm presence on grass growth and $\mathrm{P}$ uptake in relation to the increase of the amount of readily available $\mathrm{P}$ in their casts; (ii) to quantitatively distinguish between the main pathways for earthworm-induced elevated $\mathrm{P}$ availability; and (iii) to assess the persistence of the amount of readily available $\mathrm{P}$ in earthworm casts over time.

\section{Materials and Methods}

In the present study, we addressed two of the proposed pathways for the increase of readily available $P$ in earthworm casts, as well as the temporal dynamics of this increase. We used a combination of pot and incubation experiments with a soil that is low in readily available P. In the pot experiment, we tested whether earthworms can increase the growth of grass through increased levels of readily available $\mathrm{P}$ in their casts. In a separate incubation experiment, we compared incubated cast and bulk soil material and quantify the temporal dynamics of elevated levels of readily available $\mathrm{P}$ in 
the casts. In a third experiment, we assessed the effect of $\mathrm{pH}$ on readily available $\mathrm{P}$ by adjusting the $\mathrm{pH}$ of bulk soil samples. Finally, for gaining insight in the complex chemical P dynamics of the earthworm casts, we used surface complexation modelling applying the Charge Distribution (CD) model (Hiemstra and Van Riemsdijk, 1996). This advanced mechanistic approach has been used to successfully predict the adsorption and desorption behaviour of $\mathrm{PO}_{4}$ to metal (hydr)oxide surfaces in mono- and multiple component synthetic systems (Rietra et al., 2001; Weng et al., 2012, 2008) and soil samples (Hiemstra et al., 2013). The mechanistic nature of the model enables the prediction of the change in $\mathrm{PO}_{4}$ adsorption as a result of variation in $\mathrm{pH}$, concentrations of interacting cat- and anions, and the amount of OM adsorbed to metal (hydr)oxides. The CD model has not yet been used for analysing the role of these factors on the solubility of $\mathrm{PO}_{4}$ in earthworm casts. This modelling approach will allow us to unravel the pathways through which earthworms influence the solubility of $\mathrm{PO}_{4}$ in their casts.

\subsection{Soil collection and physico-chemical characteristics}

For the pot experiment, we used a non-calcareous sandy soil from the subsoil $(30-60 \mathrm{~cm})$ of an arable field of the Droevendaal experimental farm in Wageningen, the Netherlands $\left(51^{\circ} 59^{\prime} 32^{\prime \prime} \mathrm{N}\right.$ $5^{\circ} 39^{\prime} 45^{\prime \prime} \mathrm{E}$ ). This soil can be classified as a typic endoaquoll (USDA, 1999). The soil was air-dried and sieved $(5 \mathrm{~mm})$ prior to the experiment. For determination of relevant soil physico-chemical characteristics, a soil subsample was dried at $40{ }^{\circ} \mathrm{C}$ for $24 \mathrm{~h}$ and sieved $(2 \mathrm{~mm})$. Soil particle size distribution and $\mathrm{OM}$ content were determined using standard analytical methods (Houba et al., 1997). Soil particle size distribution was determined using the sieve and pipette method and $\mathrm{OM}$ content by loss-on-ignition. Soil $\mathrm{pH}-\mathrm{H}_{2} \mathrm{O}$ was measured in water extracts obtained at a solid to solution ratio (SSR) of 1:10 ( $\mathrm{W}: \mathrm{V}$; based on dry weight). Total and inorganic soil $\mathrm{P}$ contents were measured according to Kuo (1996). In short, inorganic soil P was determined by digestion of soil with $0.5 \mathrm{M} \mathrm{H}_{2} \mathrm{SO}_{4}$, followed by measuring P colourimetrically using the molybdenum blue method (Murphy and Riley, 1962) and segmented flow analysis (SFA; Skalar, SAN ${ }^{++}$); total soil P was determined by measuring $\mathrm{P}$ in a $0.5 \mathrm{M} \mathrm{H}_{2} \mathrm{SO}_{4}$ soil digest after $\mathrm{OM}$ combustion in a muffle furnace $\left(550^{\circ} \mathrm{C}\right)$. Organic $P$ was calculated as the difference between total and inorganic soil $P$. The amounts of short-range ordered iron and aluminium oxides $\left(\mathrm{Fe}_{\mathrm{ox}}\right.$ and $\mathrm{Al}_{\mathrm{ox}}$ ) as well as $\mathrm{P}$ bound to these mineral oxides $\left(\mathrm{P}_{\mathrm{ox}}\right)$ were determined by acid ammonium oxalate extraction (Schwertmann, 1964). Concentrations of $\mathrm{P}, \mathrm{Fe}$, and $\mathrm{Al}$ in the acid ammonium oxalate extracts were measured using inductively coupled plasma - atomic emission spectroscopy (ICP-AES; Varian Vista Pro). From these data, the P-saturation index $(\alpha)$ was calculated according to: 
$\alpha=\frac{P_{o x}}{[A l+F e]_{o x}}$

with $\mathrm{P}_{\text {ox }}$ and $[\mathrm{Fe}+\mathrm{Al}]_{\text {ox }}$ in $\mathrm{mmol} \mathrm{kg}^{-1}$. Additionally, $\mathrm{P}$ was measured in an ammonium lactate extract of the soil (P-AL; Egnér et al., 1960). This method is routinely used in the P fertiliser recommendation system of the Netherlands to assess the P status of grassland soils.

\subsection{Experimental setup and chemical analyses}

\subsubsection{Pot experiment}

For the 42-day greenhouse pot experiment, a full factorial, completely randomised block design was set up, with P fertilisation (present or absent: P1 and P0) and earthworms (present or absent: EW1 and EWO) as two independent factors. Every treatment was repeated 8 times, resulting in a total of 32 pots. Temperature was controlled and kept above $15^{\circ} \mathrm{C}$ at all times. In the winter, a 16 -h day was provided through the use of artificial light to supplement natural light. Relative humidity was maintained at $65 \%$. We used Mitscherlich pots (20 cm in diameter and $23 \mathrm{~cm}$ in height) filled with a mixture of $8.5 \mathrm{~kg}$ air-dried soil, water, and nutrient solution. The nutrient solution included $\mathrm{N}$ (in equal molar amounts of $\mathrm{NH}_{4}^{+}$and $\mathrm{NO}_{3}^{-}$), potassium (K), calcium (Ca), magnesium (Mg), and sulphur (S). In addition, the pots belonging to the P1EW0 and P1EW1 treatments received adequate $\mathrm{P}$ fertilisation, which was also mixed through the soil. In the Supplementary information (Table S5.1), the application rates of these nutrients are given. The moisture content of the soil was brought up to $60 \%$ of the maximum water holding capacity (WHC), equal to $240 \mathrm{~g}$ water per kg dry soil, before it was added to the pots. After filling all pots, a small tube ( $3 \mathrm{~cm}$ diameter) was installed in the middle of every pot for watering and further fertilisation. Throughout the pot experiment, soil moisture content was maintained at $60 \%$ of the maximum WHC by adjusting the weight of the pots gravimetrically with de-ionised water every two or three days: pots were weighed individually and the water was added accordingly using a watering can.

Before the introduction of earthworms, grass was pre-grown in all pots for five weeks: $4.0 \mathrm{~g}$ of annual ryegrass seeds (Lolium multiflorum, cultivar Barelli; Barenbrug Holland B.V., Nijmegen, the Netherlands) was sown in every pot. Pots were kept moist and covered with plastic sheets for the first three days to stimulate germination. After five weeks, the grass was cut at $4 \mathrm{~cm}$ above the soil surface and the pots were re-fertilised with N, P, K, Ca, Mg, and S (Table S5.1). One day later (T0), 5 healthy individuals (on average $26 \mathrm{~g}$ fresh weight per pot) of the anecic earthworm Lumbricus terrestris were added to every pot of the P0EW1 and P1EW1 treatments. This corresponds to $\sim 160$ 
individuals $\mathrm{m}^{-2}$ and $\sim 830 \mathrm{~g} \mathrm{~m}^{-2}$. The earthworms were purchased from Starfood B.V. (Barneveld, the Netherlands). Prior to weighing, the earthworms were kept in plastic cups at $16^{\circ} \mathrm{C}$ for $48 \mathrm{~h}$ to empty their guts, as described by Dalby et al. (1996). Similar to an earlier pot experiment (Vos et al., 2014), the pots were placed in a water bath to maintain the soil temperature at $15{ }^{\circ} \mathrm{C}$ during the pot experiment to increase earthworm survival. To prevent entry of water into the pots and earthworm escaping, the pots were placed in plastic bags before they were put in the water.

After 21 days (T1) and 42 days (T2), grass was cut at $4 \mathrm{~cm}$ above the soil surface. The cuttings were dried at $70{ }^{\circ} \mathrm{C}$ and weighed. The dry material was milled $(1 \mathrm{~mm})$ and analysed for $\mathrm{N}$ and $\mathrm{P}$ content using a digestion with a mixture of $\mathrm{H}_{2} \mathrm{SO}_{4}$, salicylic acid, $\mathrm{H}_{2} \mathrm{O}_{2}$, and selenium as a catalyst (Temminghoff and Houba, 2004). At T2, all 32 pots were destructively harvested, bulk soil samples were taken, and surviving earthworms were collected. Earthworms were hand-sorted and weighed using the procedure described above. Moist bulk soil samples were sieved $(2 \mathrm{~mm})$ and for each soil sample, moisture content was determined by drying a subsample at $40{ }^{\circ} \mathrm{C}$. Readily available $P$ was determined by suspending moist soil in ultrapure water (UPW) at a SSR of 1:10 (w:v; based on dry weight), as described by Vos et al. (2014). The UPW was obtained from a Milli-Q gradient

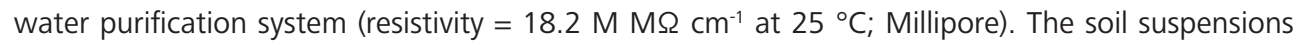
(hereafter referred to as 'water extracts') were gently shaken for $24 \mathrm{~h}$, centrifuged for $15 \mathrm{~min}$ at $10,000 \mathrm{rpm}$, and the supernatants were filtered through a $0.45 \mu \mathrm{m}$ filter (Aqua 30, Schleicher and Schuell). Subsequently, dissolved inorganic P (DIP) in the filtrates was measured colourimetrically, as described above. We decided to use moist soil samples instead of dried soil samples to prevent augmented release of P by drying and rewetting processes (Koopmans and Groenenberg, 2011; Koopmans et al., 2006).

\subsubsection{Incubation experiment}

For the incubation experiment with earthworm casts and bulk soil samples, an extra four pots were included for both the P0EW1 and P1EW1 treatments of the pot experiment with grass, as described above. At T0, 10 healthy individuals of $L$. terrestris (on average $49 \mathrm{~g}$ fresh weight per pot) were introduced to each of these additional pots, which were otherwise prepared identically to those in the pot experiment. After 10 days, the pots of the incubation experiments were harvested for earthworms and cast material deposited at the soil surface of the pots (surface casts) and bulk soil samples were collected. The surface casts (around $15 \mathrm{~g}$ per $\mathrm{P}$ treatment) were pooled and carefully mixed per P treatment (P0 and P1), and subsequently dried at $40{ }^{\circ} \mathrm{C}$. Bulk soil samples were pooled and mixed per $\mathrm{P}$ treatment. A subsample of the pooled moist bulk soil samples was used in the incubation experiment (this section) whereas another subsample was stored in sealed plastic bags at $4{ }^{\circ} \mathrm{C}$ for later use in the $\mathrm{pH}$-adaptation experiment, (Section 2.2.3). The remaining bulk soil material was dried at $40{ }^{\circ} \mathrm{C}$, similar to the surface casts. In the dried surface cast and bulk 
soil samples, $\mathrm{OM}$ and $\mathrm{P}_{\mathrm{ox}} \mathrm{Fe}_{\mathrm{ox}^{\prime}}$ and $\mathrm{Al}_{\text {ox }}$ were determined following the same analytical methods as described in Section 2.1.

The harvested earthworms were used to collect fresh cast material. For this purpose, the earthworms were first rinsed with water to remove adhering soil particles, and then put in closed polyethylene cups at $16{ }^{\circ} \mathrm{C}$ with pre-wetted glass microfiber filters (GF92, Schleicher and Schuell; Vos et al., 2014). The cups were briefly opened after $24 \mathrm{~h}$ to refresh the headspace and to check the vitality of the earthworms. After $48 \mathrm{~h}$, the excreted fresh cast material was collected, pooled per $\mathrm{P}$ treatment (around $12 \mathrm{~g}$ per treatment), and carefully mixed. In the mixed bulk soil and fresh cast samples, moisture content was determined by drying small subsamples at $40^{\circ} \mathrm{C}$. To assess the effects of earthworm cast ageing on the chemical composition of water extracts, the remainder of the fresh cast samples from the P0 and P1 treatments was divided in three equal portions and incubated in closed poly-ethylene bags $(0.1 \mathrm{~mm})$, which allowed gas exchange, but minimised loss of water (Gordon et al., 1987). The same was done for the moist bulk soil samples. The two types of matrices (cast and bulk soil), the two P treatments (P0 and P1), and three incubated samples to be sampled at three different times resulted in a total of 12 bags. The bags were incubated in the dark at $16{ }^{\circ} \mathrm{C}$. After 1,7 , and 28 days, one bag per matrix per $\mathrm{P}$ treatment was destructively sampled for chemical analysis. Due to the small quantity of cast material available, no replicate bags could be included in this incubation experiment.

The harvested moist cast and bulk soil samples were extracted with UPW at a SSR of 1:10 (w:v; based on dry weight), as described above. In the filtrates of the water extracts $(0.45 \mu \mathrm{m})$, the $\mathrm{pH}$ and electrical conductivity (EC; Consort K810) were measured. The EC values were converted to ionic strength (I) according to Griffin and Jurinak (1973). Nitrogen present in ammonium $\left(\mathrm{N}-\mathrm{NH}_{4}\right)$ and nitrate $\left(\mathrm{N}-\mathrm{NO}_{2}+\mathrm{NO}_{3}\right)$ as well as DIP were measured colourimetrically using SFA. Concentrations of total dissolved P (TDP), Ca, Mg, sodium ( $\mathrm{Na}$ ), $\mathrm{K}$, aluminium (Al), iron (Fe), silicon (Si), K, and manganese $(\mathrm{Mn})$ were analysed with ICP-AES. Dissolved organic $P$ (DOP) was calculated as the difference between TDP and DIP (Koopmans et al., 2006). Dissolved organic carbon (DOC) concentrations were calculated from the difference between total carbon (TC) and inorganic carbon (IC), both of which were measured using a Shimadzu C-analyser.

\subsection{3 pH-Adaptation experiment}

To assess the effect of $\mathrm{pH}$ in the earthworm casts on the chemical composition and $\mathrm{P}$ solubility in the 1:10 (w:v) water extracts of the casts, a pH-adaptation experiment was executed with moist bulk soil samples that were stored from the PO and P1 treatments of the incubation experiment (Section 2.2.2). Another extraction was carried out with an $\mathrm{NH}_{4} \mathrm{OH}$ solution in UPW at a SSR of 1:10 (w:v, based on dry weight), with a varying $\mathrm{NH}_{4} \mathrm{OH}$ concentration in order to mimic the $\mathrm{pH}$ increase induced by the earthworms. We have chosen to use $\mathrm{NH}_{4} \mathrm{OH}$ as a base since analysis of the water extracts of the earthworm casts from the incubation experiment (Section 2.2.2) showed 
an increased $\mathrm{pH}$ and a release of $\mathrm{NH}_{4}$. Filtrates $(0.45 \mu \mathrm{m})$ from the water extracts of the bulk soil samples with $\mathrm{pH}$ values that matched almost exactly with those found in the water extracts of the earthworm casts from the incubation experiment were submitted to the same chemical analyses as those mentioned above for the water extracts from the incubation experiment (Section 2.2.2). Additionally, chlorine $(\mathrm{Cl})$ and S concentrations were determined using ICP-AES.

\subsection{Statistics}

Statistical analyses on the results of the pot experiment and incubation experiment, as well as on the properties of the surface casts were performed using GenStat $17^{\text {th }}$ edition (VSN International Ltd, Hemel Hempstead, UK). For the pot experiment we used analysis of variance (ANOVA) with $P$ treatment, earthworm presence and block as independent factors to determine whether there was significant difference between treatments (assumed at $p$-values of $p<0.05$ ). Tukey's honest significant difference test was used as post-hoc test. We also used ANOVA to analyse the difference in composition of bulk soil and surface casts, with matrix and $\mathrm{P}$ treatment as independent factors. To analyse the chemical composition of the water extracts of the cast and bulk soil samples in the incubation experiment, we averaged the values of the samples (analysed after 1, 7 and 28 days) over time and over $P$ treatment. The non-parametric Mann-Whitney $U$ test was used to assess whether the average values found in the water extracts of the cast samples were different from those found in water extracts of the bulk soil. We used a one-sided test for $\mathrm{pH}, \mathrm{I}, \mathrm{NH}_{4^{\prime}} \mathrm{Ca}, \mathrm{Mg}$, DIP and DOC as our hypothesis based on previous studies was that values would be increased in the casts. We used a two-sided test for the other properties. 
Table 5.1. Physico-chemical characteristics of the soil used in the plant and cast experiments.

\begin{tabular}{|c|c|}
\hline Characteristics & Bulk soil \\
\hline Sand $(\%)$ & 92.6 \\
\hline Silt (\%) & 3.6 \\
\hline Clay (\%) & 3.8 \\
\hline Organic matter $\left(\mathrm{g} \mathrm{kg}^{-1}\right)^{\mathrm{a}}$ & 6.4 \\
\hline $\mathrm{pH}_{\mathrm{H} 2 \mathrm{O}}$ & 5.9 \\
\hline P-AL (mg P kg $\left.{ }^{-1}\right)$ & 19 \\
\hline Total P $\left(\mathrm{mg} \mathrm{kg}^{-1}\right)$ & 110 \\
\hline Organic $\mathrm{P}\left(\mathrm{mg} \mathrm{kg}^{-1}\right)$ & 30 \\
\hline $\left.\mathrm{Fe}_{\mathrm{ox}}(\mathrm{mmol} \mathrm{kg})^{-1}\right)$ & 14.8 \\
\hline $\mathrm{Al}_{\mathrm{ox}}\left(\mathrm{mmol} \mathrm{kg}{ }^{-1}\right)$ & 6.3 \\
\hline$P_{o x}(m g ~ k g-1)$ & 54.1 \\
\hline$\alpha^{\mathrm{b}}$ & 0.08 \\
\hline
\end{tabular}

${ }^{a}$ Loss on ignition with correction for the loss of water from the crystalline structure of clay (7\%).

${ }^{b}$ Molar ratio of $\mathrm{P}$ and $\mathrm{Fe}+\mathrm{Al}$ in the oxalate extract.

\subsection{Modelling}

The CD model (Hiemstra and Van Riemsdijk, 1996) was used to simulate the $\mathrm{PO}_{4}$ concentrations in the water extracts of the cast and bulk soil samples from the incubation experiment, as well as those of the soil samples from the pH-adaptation experiment. In this study, goethite is used as reference oxide for which a consistent CD parameter set is available (Hiemstra et al., 2010a). In our study, the competitive effect of adsorbed $\mathrm{OM}$ on $\mathrm{PO}_{4}$ solubility was modelled, using an adapted approach that has been tested successfully for soil samples (Hiemstra et al., 2013) using data of Weng et al. (2008). The formation reactions of the surface species used in the CD model have been summarised in Table S5.2.

The total reactive surface area of metal (hydr)oxides in the earthworm cast and bulk soil samples was estimated using the measured amounts of $\mathrm{Fe}_{\mathrm{ox}}$ and $\mathrm{Al}_{\mathrm{ox}}$. These values were transformed into the amounts of representative goethite and gibbsite using a molar mass of 89 and $78 \mathrm{~g} \mathrm{~mol}^{-1}$, respectively, and were subsequently summed to calculate the equivalent amount of reactive metal (hydr)oxides. The corresponding specific surface area (SSA) of these oxides was set at $650 \mathrm{~m}^{2} \mathrm{~g}^{-1}$ oxide (Hiemstra and Van Riemsdijk, 2009). In our experiments, adsorption of $\mathrm{PO}_{4}$ is expected to be controlled by metal (hydr)oxides. In our non-calcareous sandy soil, the clay mass fraction is dominant: clay / $\left(\mathrm{Fe}_{\mathrm{ox}}+\mathrm{Al}_{\mathrm{ox}}\right)=38 \mathrm{~g} \mathrm{~kg}^{-1} /\left(1.32 \mathrm{~g} \mathrm{~kg}^{-1}+0.49 \mathrm{~g} \mathrm{~kg}^{-1}\right) \approx 21$, where $\mathrm{Fe}_{\text {ox }}$ and $\mathrm{Al}_{\text {ox }}$ are converted into the mass fractions of goethite and gibbsite, respectively. However, because illite as the dominant type of clay (Van der Salm et al., 1998) may bind 100 times less $\mathrm{PO}_{4}$ than metal 
(hydr)oxides at same mass of the adsorbents (Manning and Goldberg, 1996a, 1996b), we estimate the clay contribution to $\mathrm{PO}_{4}$ adsorption to be around $17 \%$ at maximum. We used $\mathrm{P}_{\text {ox }}$ as a measure for the total amount of reversibly bound $\mathrm{PO}_{4}$ (Hiemstra et al., 2010a) in the earthworm cast and bulk soil samples.

Besides the total reactive surface area of the metal (hydr)oxides and the total amount of reversibly bound $\mathrm{PO}_{4^{\prime}}$ the $\mathrm{CD}$ model requires as input the $\mathrm{pH}$, the $I$, and the concentrations of the major cations and anions that have been measured in the various water extracts. Based on the $\mathrm{pH}$, the measured values of the total dissolved $\mathrm{Na}, \mathrm{K}, \mathrm{NH}_{4^{\prime}} \mathrm{Ca}, \mathrm{Mg}, \mathrm{Cl}, \mathrm{SO}_{4^{\prime}}, \mathrm{CO}_{3^{\prime}}$ and $\mathrm{NO}_{3}$ concentrations were recalculated with the ECOSAT software (Keizer and Van Riemsdijk, 1998) to free ion concentrations to account for any complexation of Ca and $\mathrm{Mg}$ ions by DOM (Hiemstra et al., 2013; Weng et al., 2012), using the NICA-Donnan model with generic model parameters (Milne et al., 2003). In these calculations, DOM was assumed to consist of fulvic acid (FA), and FA concentrations were calculated from the measured DOC concentrations assuming a carbon content of $50 \%$. In addition, the partial $\mathrm{CO}_{2}$ pressures $\left(\mathrm{CO}_{2}\right)$ in the different water extracts were calculated from the $\mathrm{pH}$ and $\mathrm{HCO}_{3}$ concentrations. The resulting free ion concentrations and $p \mathrm{CO}_{2}$ values have been used as input for our $\mathrm{PO}_{4}$ adsorption modelling. For the incubation experiment, $\mathrm{NH}_{4}$ was only measured after 28 days. For days 1 and 7 of this experiment, $\mathrm{NH}_{4}$ concentrations are likely to be similar considering the electroneutrality of the charge balance of the water extracts.

In our modelling study, the formation of aqueous complexes and competitive effects of specifically adsorbed inorganic cations $(\mathrm{Ca}$ and $\mathrm{Mg})$ as well as anions $\left(\mathrm{CO}_{3}\right.$ and $\left.\mathrm{SO}_{4}\right)$ on the $\mathrm{PO}_{4}$ adsorption to metal (hydr)oxides were taken into account. Competition of adsorbed OM was introduced according to Hiemstra et al. (2013). In this model, it is assumed that OM competes with $\mathrm{PO}_{4}$ via occupying reactive sites and by introducing interfacial charge. These processes are mimicked by defining an amount of adsorbed organic surface ligands that interact with singly coordinated surface groups. In this approach, three OM surface species are defined (Table S5.2), representing outersphere complexation ( $\left.\equiv \mathrm{FeOH}_{2}-\mathrm{OM}\right)$, and innersphere complex formation without ( $\equiv \mathrm{FeOM}$ ) and with additional protonation $(\equiv \mathrm{FeOMH})$. The effect of $\mathrm{OM}$ as competitor on $\mathrm{PO}_{4}$ solubility was evaluated in two steps. First, by defining the appropriate amount of organic surface ligands, we derived the mean $\mathrm{OM}$ surface loading that explains the $\mathrm{PO}_{4}$ concentrations in the water extracts of the bulk soil samples from the incubation and $\mathrm{pH}$-adaptation experiments at the various $\mathrm{pH}$ values using an average of the measured ion compositions as input for the two different $\mathrm{P}$ treatments (POEW1 and P1EW1). In the second step, this OM loading was used to evaluate the $\mathrm{PO}_{4}$ solubility in the water extracts of the cast samples from the incubation experiment, using the corresponding $\mathrm{pH}, l$, free ion concentrations, and $p \mathrm{CO}_{2}$ of the individual casts as input. In addition to this, we have assessed the sensitivity of the predicted $\mathrm{PO}_{4}$ concentrations to variations in this OM loading. In both steps, the sensitivity of the predicted $\mathrm{PO}_{4}$ solubility to variations in the SSA of the metal (hydr)oxides was evaluated. All model calculations were done using the ECOSAT software (Keizer and Van Riemsdijk, 1998). 


\section{Results and discussion}

\subsection{Soil characteristics}

The physico-chemical properties of the soil used in the pot and incubation experiments are summarised in Table 5.1. Overall, the soil was very poor in minerals, OM, and P. The P-AL value of the soil (19 $\mathrm{mg} \mathrm{P} \mathrm{kg}^{-1}$ ) indicates a very low ability of the soil to supply $\mathrm{P}$ to the grass and points to a very low soil P status (Tunney et al., 1997). Considering that we used a subsoil for our experiments, the low $\mathrm{P}$ and $\mathrm{OM}$ contents are unsurprising. Most of the $\mathrm{P}$ is present in inorganic form (79\%), which agrees with the low $\mathrm{OM}$ content. Values for $\mathrm{P}_{\mathrm{ox}^{\prime}} \mathrm{Fe}_{\text {ox }}$ and $\mathrm{Al}_{\mathrm{ox}^{\prime}}$ were well below normal contents usually found in topsoils of Dutch non-calcareous sandy soils (Koopmans et al., 2006). The $\mathrm{P}$ loading of metal (hydr)oxides $(\alpha)$ amounted to 0.08 , which is relatively low, considering the maximum loading that may be as high as 0.4-0.6 in P-saturated soils (Freese et al., 1992; Maguire et al., 2001; Van der Zee et al., 1988; Van der Zee and Van Riemsdijk, 1988).

Table 5.2. Averages, standard deviations and ANOVA results for cumulative plant dry weight over the two harvests (T2), and for nutrient uptake and N/P ratio over the final harvest of the pot experiment per treatments. Within a column, results with different letters were significantly different.

\begin{tabular}{|c|c|c|c|c|}
\hline Treatment & $\begin{array}{c}\text { Cumulative dry } \\
\text { weight yield } \\
\left(\text { g pot }^{-1}\right)\end{array}$ & $\begin{array}{l}\text { P-uptake } \\
\left(\mathrm{mg} \mathrm{pot}^{-1}\right)\end{array}$ & $\begin{array}{l}\text { N-uptake } \\
\left(\mathrm{mg} \mathrm{pot}^{-1}\right)\end{array}$ & $\begin{array}{l}\text { N/P ratio } \\
\left(\mathrm{mg} \mathrm{mg}^{-1}\right)\end{array}$ \\
\hline POEWO & $9.80 \pm 0.98 \mathrm{a}$ & $6.32 \pm 1.20 a$ & $234.0 \pm 28.4 a$ & $37.45 \pm 2.59 \mathrm{~d}$ \\
\hline P0EW1 & $10.80 \pm 0.71 \mathrm{~b}$ & $8.04 \pm 0.44 b$ & $266.9 \pm 12.2 b$ & $33.23 \pm 1.16 c$ \\
\hline P1EW0 & $22.56 \pm 1.11 c$ & $60.78 \pm 5.39 c$ & $593.3 \pm 18.0 c$ & $9.81 \pm 0.63 \mathrm{a}$ \\
\hline P1EW1 & $21.98 \pm 0.65 c$ & $59.92 \pm 2.34 c$ & $649.7 \pm 18.2 \mathrm{~d}$ & $10.85 \pm 0.25 b$ \\
\hline \multicolumn{5}{|c|}{ 2-way ANOVA results ${ }^{a}$} \\
\hline $\mathrm{P}$ treatment & $* * *$ & *** & $* * *$ & *** \\
\hline EW treatment & n.s. & n.s. & $* * *$ & ** \\
\hline$P \times E W$ & * & n.s. & * & *** \\
\hline
\end{tabular}

a Significance levels: ${ }^{*} p<0.05 ;{ }^{* *} p<0.01 ;{ }^{* * *} p<0.001$ 


\subsection{Pot experiment}

In the pot experiment, we observed, besides the expected effect of $\mathrm{P}$ fertilisation on grass growth and nutrient uptake, earthworm-induced increases in grass yield and $\mathrm{P}$ and $\mathrm{N}$ uptake in the POEW1 treatment (Fig. 5.1 and Table 5.2). Although there was no earthworm effect apparent at T1 (data not shown), cumulative yield and $P$ uptake were increased by the presence of $L$. terrestris after two harvests (T1 plus T2) in the POEW1 treatment. The presence of earthworms caused the grass yield to increase by $10 \%$, from 9.8 in the POEWO treatment to $10.8 \mathrm{~g} \mathrm{pot}^{-1}$ in POEW1 ( $p=0.044$ ), and P uptake to increase by $27 \%$, from 6.3 to $8.0 \mathrm{mg} \mathrm{pot}^{-1}(p=0.002)$. No such effect was apparent in the P1EW0 and P1EW1 treatments, indicating that earthworms can indeed increase grass growth by facilitating additional P uptake in soils with a low P status, but not in soils fertilised with P (Vos et al., 2014). Total $N$ uptake was augmented in the presence of earthworms in both $P$ fertilisation treatments, although the relative effect was larger in the POEW1 treatment (14\%) than in the P1EW1 treatment (9.5\%). The enhanced $\mathrm{N}$ uptake was most likely a stoichiometric result of the elevated $\mathrm{P}$ uptake in the presence of earthworms, since all pots were amply fertilised with mineral $\mathrm{N}$, and N/P ratios of the grass cuttings indicated a severe P deficiency in the plants rather than any $\mathrm{N}$ deficiency (Koerselman and Meuleman, 1996).

In contrast to the results found for grass $\mathrm{P}$ uptake, the addition of earthworms did not increase the amount of water-extractable $P$ in the bulk soil (data not shown). The DIP concentrations in the water extracts from the bulk soil samples taken at T2 were only affected by P fertilisation: in samples belonging to the P1EW0 and P1EW1 treatments, the measured DIP concentrations were $5.7 \pm 1.6 \mu \mathrm{M}$, whereas they were well below detection limits $(<0.65 \mu \mathrm{M})$ in the P0EW0 and P1EW1 treatment. The lack of an earthworm effect on DIP levels in water extracts from a bulk soil is in agreement with previous findings (Vos et al., 2014). Although earthworms did not seem to increase readily available $\mathrm{P}$ at the bulk soil level, their presence could still provide the grass with additional $\mathrm{P}$ and thereby increase yield (Fig. 5.1 and Table 5.2).
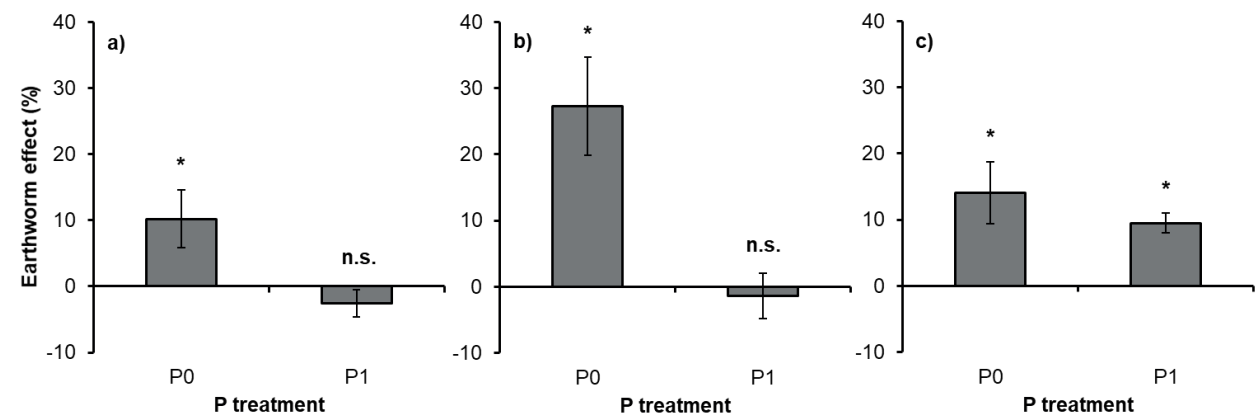

Figure 5.1. Relative effects of earthworms on grass yield (a), P uptake (b) and $N$ uptake (c) of grass for treatments without (PO) and with (P1) P fertilisation after two harvests (T2). Asterisks indicate significant effects $(p<0.05)$, error bars represent standard errors. 
Earthworm survival at T2 averaged $28 \%$ and was positively correlated $\left(R^{2}=0.83\right.$ for P0EW1 and $\mathrm{R}^{2}=0.73$ for P1EW1) with grass yield for both $\mathrm{P}$ treatments (data not shown). Although the mortality of $L$. terrestris was high compared to other pot experiments (Paul et al., 2012; Vos et al., 2014), the positive correlation between earthworm survival rate and plant growth indicates that increases in biomass production and P uptake in the POEW1 treatment are earthworm-induced, and not a consequence of the decay of the earthworms themselves. We are unsure what caused the high death rate of earthworms in this experiment. One of the causes for the low survival rate in this pot experiment could be a shortage of food. Anecic earthworms like L. terrestris are known to feed on plant residues which they gather from the soil surface (Lee, 1985). In our pot experiment, most of the aboveground biomass was removed when the grass was cut, leaving little fresh residue for the earthworms to feed on. The very low soil OM content did not provide much additional food, resulting in a stressful environment for the worms to survive in.

It remains difficult to scale the results of our pot experiment to the field. The high number of $L$. terrestris used compared to the abundance of anecic species in field systems (Didden, 2001; Van Eekeren et al., 2008), in combination with the short duration of the pot experiment, leaves questions about what these findings imply for agro-ecosystems. Cast production may widely differ between systems, but usually amounts to a layer of several mm of soil per year (Feller et al., 2003). However, the total earthworm density (independent of species) is rather realistic for Dutch managed grasslands (Didden, 2001) and also the effect on P availability varies between species (Vos et al., 2014), all species seem to increase $P$ availability in the casts. It is therefore likely that an effect such as the one we found will be relevant under field conditions. However, species abundance, feeding behaviour and cast production are factors that will indirectly and locally influence $\mathrm{P}$ availability in the field. We expect that the effect of earthworms on P supply is most likely to be applicable for low-tillage systems like grasslands or organic agriculture, since both of these provide relatively undisturbed habitats for earthworms. Future research should therefore focus on field studies assessing the effect of earthworm communities, rather than the impact of individual species.

\subsection{Incubation experiment}

Table 5.3 presents the data from the water extracts of the cast and bulk soil samples with different $\mathrm{P}$ treatments ( $\mathrm{PO}$ and $\mathrm{P} 1$ ) over time. One day after the start of the incubation experiment, the water extracts of the cast samples contained elevated $(p=0.002)$ DIP concentrations $(0.31$ and $0.24 \mathrm{mM}$ for the P0 and P1 treatments respectively), whereas the concentrations for the bulk soil remained low $(<0.01 \mathrm{mM})$. For both cast and bulk soil samples, levels of DOP were close to zero throughout the incubation period, as TDP consisted almost exclusively of DIP. Significant increases $(p=0.002)$ were also observed for $\mathrm{pH}$ and $\mathrm{DOC}$ (Table 5.3). The $\mathrm{pH}$ in the water extracts increased from 5.9 for the bulk soils to an average of 8.1 for the casts, while the DOC concentrations increased from 
around $3 \mathrm{mg} \mathrm{L}^{-1}$ for the bulk soils to approximately $37 \mathrm{mg} \mathrm{L}^{-1}$ for the casts.

The concentrations of DIP and DOC as well as the $\mathrm{pH}$ in the water extracts of the bulk soil samples remained mostly stable during the incubation experiment. In contrast, the DIP and DOC concentrations and the $\mathrm{pH}$ for the casts increased over time, except for one sample harvested after 28 days with $\mathrm{P}$ fertilisation (P1). The differences between the cast and bulk soil samples persisted during the entire incubation period. The averaged values of $\mathrm{pH}$, DIP, and $\mathrm{DOC}$ found for both $\mathrm{P}$ treatments are given in Fig. 5.2. These results clearly illustrate the increase in $\mathrm{pH}$ and the elevated concentrations of DIP and DOC in the water extracts of the casts, which is in line with earlier studies (Barois and Lavelle, 1986; Chapuis-Lardy et al., 2009, 1998; Kuczak et al., 2006; Lopez-Hernandez et al., 1993; Sharpley and Syers, 1976; Sizmur et al., 2011; Vos et al., 2014). Remarkably, the DIP concentrations were slightly higher in the water extracts of the casts without P fertilisation (PO; Fig. $5.2 \mathrm{~b}$ ), which is probably related to the difference in $\mathrm{pH}$ (Fig. 5.2a). The higher $\mathrm{pH}$ of the casts from the PO treatment might have led to an increased P solubility (Weng et al., 2011). The enhanced DOC concentrations in the water extracts of the casts (Fig. 5.2c) may be due to a higher dissolution and desorption of $\mathrm{OM}$ at high $\mathrm{pH}$, but are likely to also be the result of the production of newly dissolved organic molecules as a by-product of mineralisation (Kalbitz et al., 2000).

Alongside the differences for $\mathrm{pH}, \mathrm{DIP}$, and DOC, we found an increase in the I of the water extracts of the casts, showing input of additional cations and anions. Levels of $\mathrm{HCO}_{3}, \mathrm{Na}$, and $\mathrm{K}$, were significantly $(p=0.002)$ elevated in the water extracts of the casts compared to the bulk soil samples (Table 5.3). For $\mathrm{NH}_{4}$, this trend was not significant due to limited number of observations, although the average of the $\mathrm{NH}_{4}$ concentrations in the casts was almost 100 times the average of those in the bulk soil. This increase in monovalent ions in the casts might be due to mineralisation of $\mathrm{OM}$ that can induce an increase in $\mathrm{pH}$, as protons are consumed during this process (Basker et al., 1994), producing alkalinity as we can illustrate with the following representative reaction:

$$
\left(\mathrm{CH}_{2} \mathrm{O}\right)_{m} \mathrm{NH}_{3}+m \mathrm{O}_{2} \Leftrightarrow \mathrm{NH}_{4}^{+}+\mathrm{HCO}_{3}^{-}+(m-1) \mathrm{CO}_{2}+(m-1) \mathrm{H}_{2} \mathrm{O}
$$

Electroneutrality requires an equal release of $\mathrm{NH}_{4}$ and $\mathrm{HCO}_{3}$ ions. $\mathrm{A} \mathrm{pH}$ increase is clearly shown in Fig. 5.2a. At the same time, the high $\mathrm{NH}_{4}$ concentrations in the water extracts of the bulk soil after 28 days, as well as the elevated $\mathrm{HCO}_{3}$ levels in the water extracts of the casts, can be explained by assuming a significant mineralisation of $\mathrm{OM}$ in the cast. The $\mathrm{NH}_{4}$ ions released will mainly exchange against the monovalent cations present at the cation exchange capacity (CEC) complex of the soil, leading to enhanced concentrations $\mathrm{K}$ and $\mathrm{Na}$ ions in the water extracts (Table 5.3). 

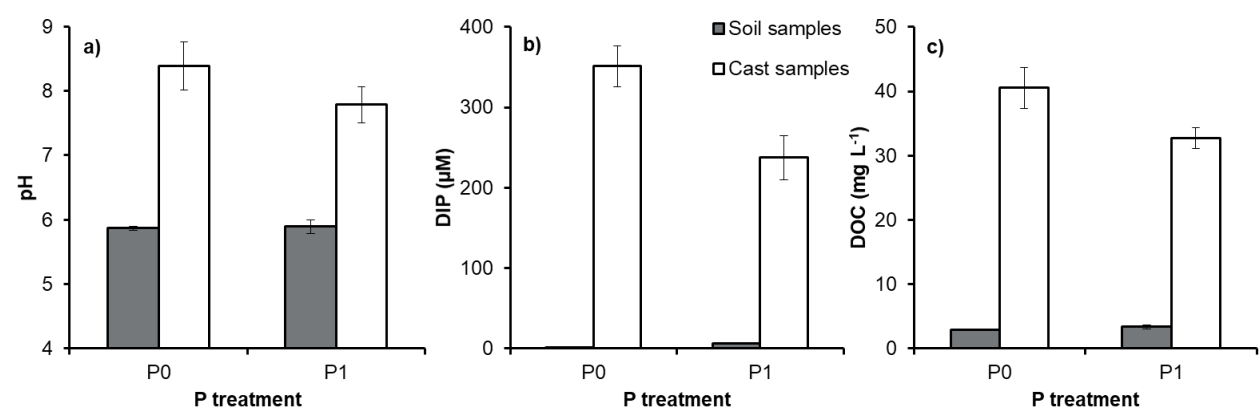

Figure 5.2. Dissolved inorganic phosphorus (DIP) concentrations (a), $\mathrm{pH}(\mathrm{b})$ and dissolved organic carbon (DOC) concentrations (c) measured in the water extracts of the incubated soil (grey bars) and cast (white bars) samples for the two $P$ treatments. The shown values are averages of the three sampling times (1, 7 and 28 days). The error bars represent standard errors $(n=3)$.

In contrast to the monovalent cations, we found lower averages $(p=0.032)$ for divalent cation concentrations ( $\mathrm{Ca}$ and $\mathrm{Mg}$ ) in the water extracts of the casts than for the bulk soils (Table 5.3). Calcium concentrations in the casts were a factor $\sim 2-3$ lower than in the bulk soil. For Mg, the effect was smaller. One sample deviates from the pattern ( $\mathrm{P} 1$, after 28 days), but we are unsure why. This decrease in the $\mathrm{Ca}$ and $\mathrm{Mg}$ concentrations can be related to the higher $\mathrm{pH}$ values in the casts. Earthworms are known to produce $\mathrm{CaCO}_{3}$ mineral particles in their glands (Briones et al., 2008; García-Montero et al., 2013). However, according to our equilibrium calculations based on the solubility of $\mathrm{CaCO}_{3}(\mathrm{~s})$, the water extracts are undersaturated with respect to this mineral. The lower $\mathrm{Ca}$ and $\mathrm{Mg}$ concentrations in the water extracts of the casts are likely to be the result of an increase in the CEC of OM with an increase of the $\mathrm{pH}$. Additionally, $\mathrm{Ca}$ and $\mathrm{Mg}$ ions will adsorb better to metal (hydr)oxides at a high $\mathrm{pH}$.

Nitrate concentrations in the water extracts were lower for casts than for bulk soil. Similar to the results for the $\mathrm{Ca}$ and $\mathrm{Mg}$ concentrations, this trend did not apply to one sample. Nevertheless, the low $\mathrm{NO}_{3}$ concentrations for the casts overall can be the result of an increased denitrification and/or decreased nitrification of $\mathrm{NH}_{4}$. The protons released during nitrification $\left(\mathrm{NH}_{4}^{+}+\mathrm{O}_{2} \Leftrightarrow 2 \mathrm{H}^{+}\right.$ $+\mathrm{NO}_{3}^{-}$) may in turn be consumed again during denitrification (Knowles, 1982). Denitrification would point to slight anaerobic conditions during the incubation of the casts. However, anaerobic conditions are unlikely since, by calculation, we found low values for the $p \mathrm{CO}_{2}\left(\sim 10^{-3}-10^{-4} \mathrm{bar}\right)$, which points to a high rate of exchange of gases $\left(\mathrm{O}_{2}\right.$ included) through the poly-ethylene material of the incubation bags, meaning that aerobic conditions prevailed during incubation (Greenway et al., 2006). 


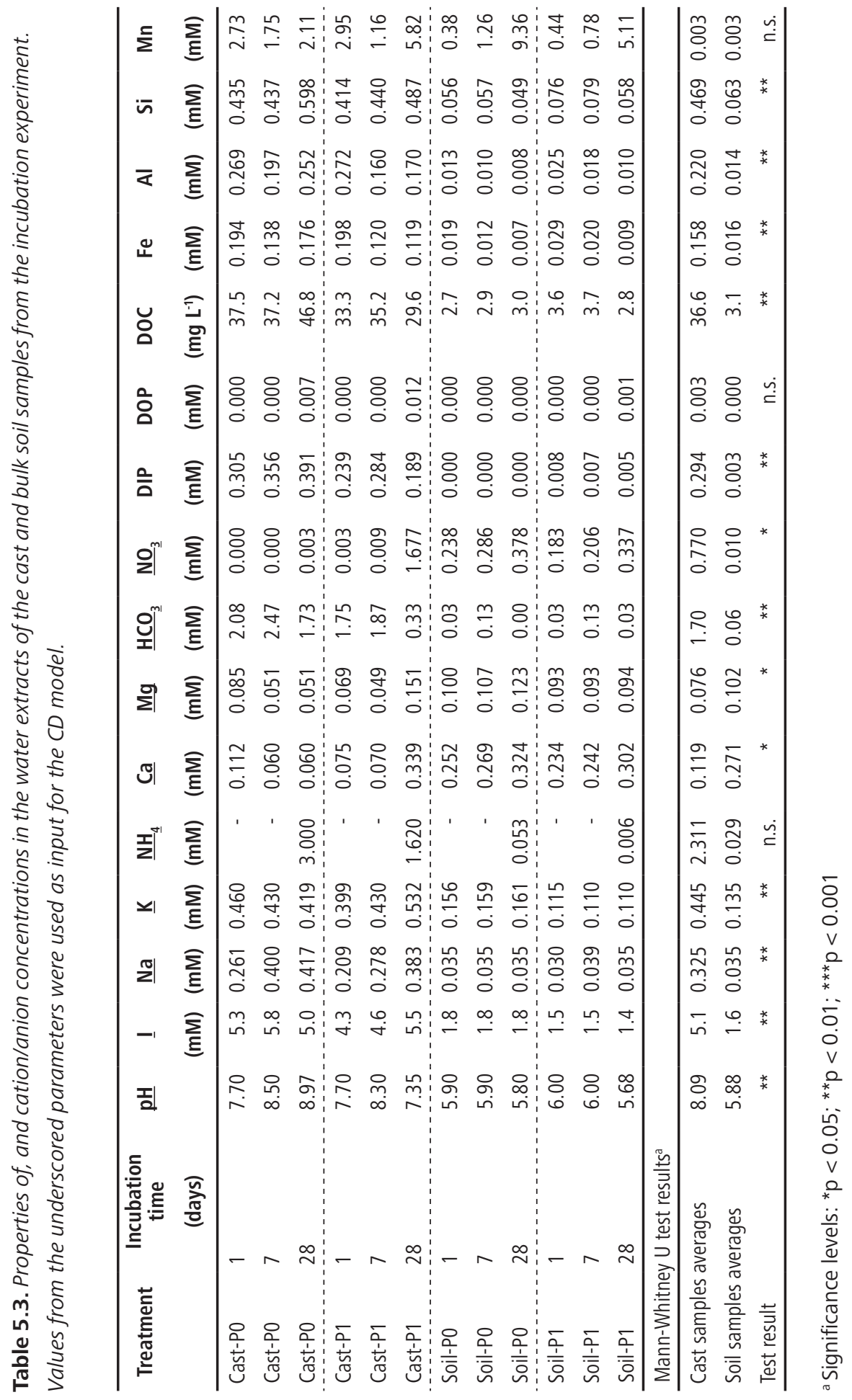




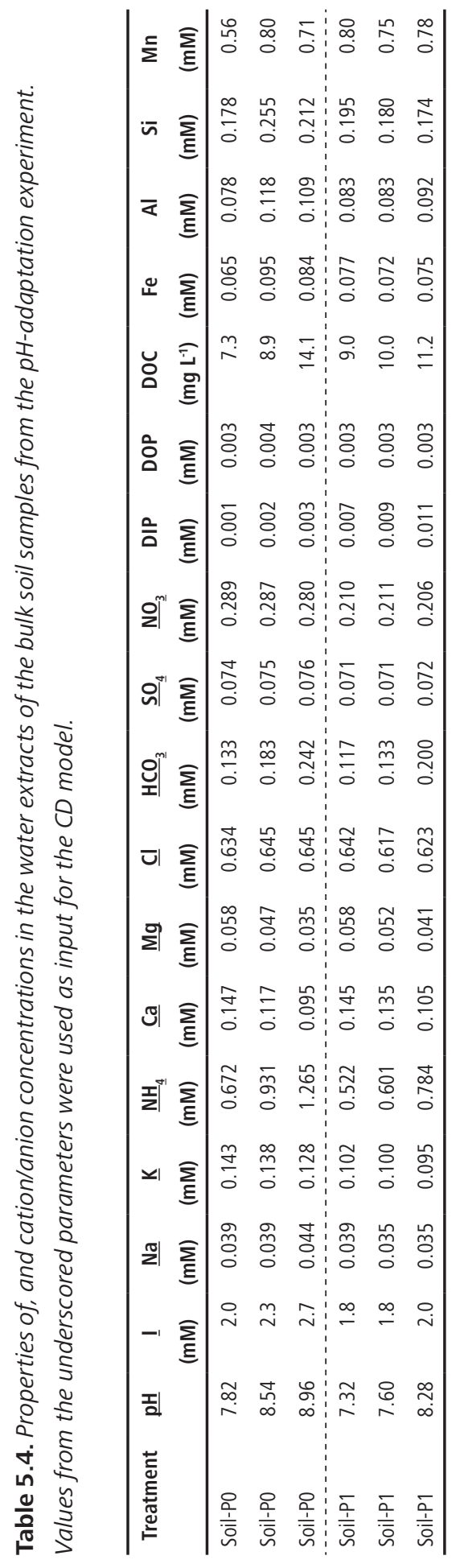


Denitrification might thus have occurred before the incubation, i.e. within the earthworm gut, where conditions are known to be anaerobic (Drake and Horn, 2006).

In conclusion, it is likely that microbial processes like decomposition of OM are a major driver for the increases in $\mathrm{pH}$ and $\mathrm{DOC}$ in the water extracts of the earthworm casts. In turn, this will affect the $\mathrm{P}$ chemistry. In the next section, we will assess the effect of $\mathrm{pH}$ on $\mathrm{P}$ solubility.

\section{$3.4 \quad p H$-adaptation experiment}

In the incubation experiment, we found a much higher concentrations of DIP in the water extracts of the casts than for the bulk soil (Fig. 5.2b). Simultaneously, we observed an increase of pH (Fig. 5.2a). In this $\mathrm{pH}$-adaptation experiment, we tested whether $\mathrm{pH}$ is the ruling factor that explains the difference in $\mathrm{P}$ solubility between the casts and bulk soil samples. Figure 5.3 and Table 5.4 show that increasing the $\mathrm{pH}$ of the water extracts of the bulk soil by adding $\mathrm{NH}_{4} \mathrm{OH}$ led to an increase in the DIP concentrations in the water extracts. However, the DIP levels found for the bulk soil with the augmented $\mathrm{pH}$ are still much lower than those of the casts at the same pH; the DIP concentrations remain one to two orders of magnitude lower than in the water extracts of casts (Fig. 5.3a). This points to the presence of an additional factor that increases the $\mathrm{PO}_{4}$ solubility in the water extracts of the casts. Another remarkable difference between the bulk soil samples and the casts is the concentration of DOC. The DOC concentrations in the water extracts of the casts are about 10 times higher and this increase is probably due to microbial decomposition of organic matter, producing organic molecules as an intermediate by-product (Kalbitz et al., 2000). These molecules may bind to metal (hydr)oxide surface and may act as competitor of $\mathrm{PO}_{4}$. In the modelling Section 3.6, the latter possibility will be analysed. 

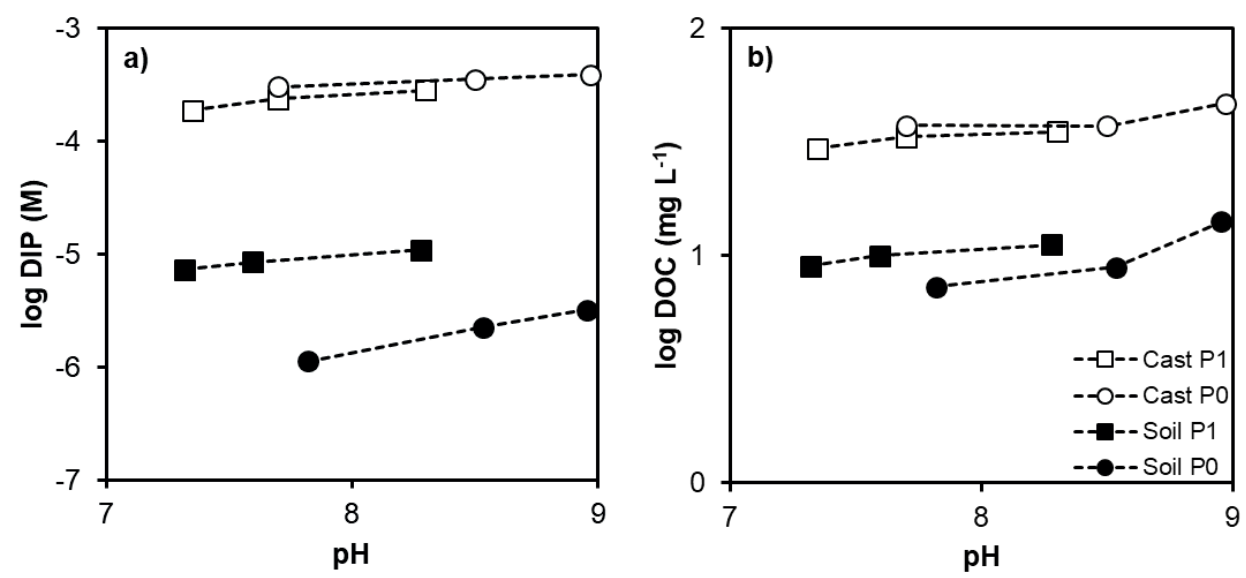

Figure 5.3. $\mathrm{pH}$ dependency of dissolved inorganic $P$ (DIP in $M ;$ a) and dissolved organic carbon (DOC; b) in the water extracts of the cast samples (white symbols) and the $\mathrm{NH}_{4} \mathrm{OH}$-amended bulk soil samples (black symbols). Circles represent PO treatment samples whereas squares indicate P1 treatment samples. Values can be found in Tables 5.3 and 5.4 .

\subsection{Surface cast properties}

The OM content in the surface casts $\left(6.2 \mathrm{~g} \mathrm{~kg}^{-1}\right)$ was not significantly higher $(\mathrm{p}=0.087)$ than in the bulk soils (4.7 $\mathrm{g} \mathrm{kg}^{-1}$; Table 5.5). However, the slight differences in OM content between earthworm cast and bulk soil suggest some preferential feeding by the earthworms. The earthworm may have accumulated OM associated with soil particles or scavenged some residue left-over from cutting of the grass. The amounts of $\mathrm{Al}_{\text {ox }}$ are essentially the same in the cast and bulk soil samples, whereas casts had higher amounts of $\mathrm{Fe}_{\text {ox }}$ than the bulk soil (Table 5.5). However, in the earthworm casts, $\mathrm{P}_{\text {ox }}$ is elevated as well, resulting in higher $\alpha$ values. The $\mathrm{P}_{\text {ox }}$ may have increased due to mineralisation of organic $P$ in the surface casts (Le Bayon and Milleret, 2009). Another possibility is that the metal (hydr)oxide particles in soil ingested by the earthworms (the casts) are substantially smaller. Earthworms are known to feed selectively on smaller texture fractions in the soil (Brown et al., 2004; Sharpley and Syers, 1976). Smaller metal (hydr)oxide particles have a higher SSA per unit of mass than larger particles, meaning that they are capable of adsorbing more $\mathrm{PO}_{4}$ per unit of mass than larger particles, leading to a higher $\alpha$ of the surface casts. At the same time, this would explain why the OM content in the casts is slightly higher, because smaller metal oxide particles are not only able to adsorb more $\mathrm{PO}_{4}$ but they can bind more OM as well (Hiemstra et al., 2010a). The interaction between $\mathrm{PO}_{4}$ and $\mathrm{OM}$ binding at the surface of metal (hydr)oxides in the casts and 
the effect thereof on $\mathrm{PO}_{4}$ solubility will be further analysed by the $\mathrm{CD}$ modelling in the next section (Section 3.6). In addition to this, the sensitivity of the assumed SSA of metal (hydr)oxides on the model predictions of the $\mathrm{PO}_{4}$ concentrations will be evaluated.

Table 5.5. Properties of surface cast and bulk soil samples taken at the end of the earthworm experiment. Given are the averages of 2 measurements and the analytical standard deviation. Oxalate $\left(P_{o x^{\prime}}, \mathrm{Il}_{\text {ox }}\right.$ and $\left.\mathrm{Fe} \mathrm{ox}_{\mathrm{x}}\right)$ values were used as input for the $\mathrm{CD}$ model.

\begin{tabular}{lccccc}
\hline Treatment & $\begin{array}{c}\text { Organic matter } \\
\left(\mathbf{g ~ k g}^{-1}\right)\end{array}$ & $\begin{array}{c}\mathrm{P}_{\text {ox }} \\
\left(\mathbf{m g ~ k g}^{-1}\right)\end{array}$ & $\begin{array}{c}\mathrm{Fe}_{\text {ox }} \\
\left(\mathrm{mmol} \mathrm{kg}^{-1}\right)\end{array}$ & $\begin{array}{c}\mathrm{Al}_{\mathrm{ox}} \\
\left(\mathrm{mmol} \mathrm{kg}^{-1}\right)\end{array}$ & $\begin{array}{c}\alpha^{\mathrm{b}} \\
(-)\end{array}$ \\
\hline SurfCast-P0 & $8.3 \pm 2.3$ & $76 \pm 0$ & $14.0 \pm 0.6$ & $5.5 \pm 0.2$ & $0.13 \pm 0.01$ \\
SurfCast-P1 & $5.8 \pm 1.1$ & $97 \pm 4$ & $17.6 \pm 0.1$ & $6.4 \pm 0.1$ & $0.13 \pm 0.01$ \\
Bulk-P0 & $4.5 \pm 0.8$ & $45 \pm 1$ & $13.1 \pm 0.2$ & $5.8 \pm 0.0$ & $0.08 \pm 0.00$ \\
Bulk-P1 & $4.8 \pm 0.3$ & $63 \pm 4$ & $15.1 \pm 1.1$ & $6.3 \pm 0.2$ & $0.10 \pm 0.00$ \\
\hline 2-way ANOVA results & & & & & \\
\hline Matrix & $\dagger$ & $* * *$ & $*$ & n.s. & $* * *$ \\
P treatment & n.s. & $* * *$ & $* *$ & $* *$ & $*$ \\
$M{ }^{*} P$ & n.s. & n.s. & n.s. & n.s. & n.s. \\
\hline
\end{tabular}

${ }^{a}$ Loss on ignition with the loss of water from the crystalline structure of clay taken into account.

${ }^{b}$ Degree of $\mathrm{P}$ saturation with respect to the content of reactive metal oxides calculated according to the aforementioned equation (5.1).

c Significance levels: $\mathrm{tp}<0.1 ;{ }^{*} p<0.05 ;{ }^{* *} \mathrm{p}<0.01 ;{ }^{* * *} \mathrm{p}<0.001$

\subsection{Modelling study}

The above shows that the elevated solubility of DIP in the casts may be due to a number of factors, such as a higher $\mathrm{PO}_{4}$ surface loading or reactive surface area of the metal (hydr)oxides, $\mathrm{pH}$, or enhanced levels of adsorbed OM. The influence of these factors will be quantified with surface complexation modelling.

In our modelling study, we included OM as a competitor, since we found elevated levels of OM in the surface casts (Section 3.5) and higher DOC concentrations in the water extracts of the casts (Section 3.3). Moreover, it has been shown that models without the presence of OM underestimate the $\mathrm{PO}_{4}$ solubility in agricultural topsoils (Hiemstra et al., 2010b). Since the $\mathrm{P}_{\text {ox }}$ levels in the surface casts and bulk soil samples were different (Table 5.5), the measured $P_{\text {ox }}$ values in these matrices have been used as a measure for the amount of total reversibly bound $\mathrm{P}$ to model the $\mathrm{PO}_{4}$ solubility in the water extracts of the cast and bulk soil samples. Similarly, we used the $\mathrm{Fe}_{\text {ox }}$ and $\mathrm{Al}_{\text {ox }}$ values of the surface casts and bulk soil samples (Table 5.5) to account for the difference in total 
reactive surface area between these matrices. When comparing model predictions of $\mathrm{PO}_{4}$ solubility to the DIP concentrations measured in the water extracts, we assumed all DIP to be dissolved $\mathrm{PO}_{4}$. As explained in Section 2.4, we have modelled the $\mathrm{PO}_{4}$ solubility in two steps. In the first step, the $\mathrm{PO}_{4}$ concentrations in the water extracts of the bulk soil samples that had a variable $\mathrm{pH}(6-9)$ were modelled, by estimating the apparent surface loading of the OM competitor that is able to describe the data using the acid ammonium oxalate extraction data as input together with averages of the experimental equilibrium concentrations of the various cat- and anions. The results are shown in Fig. 5.4a. For the $\mathrm{pH}$ range 5-7, the model predicts an increased adsorption of $\mathrm{PO}_{4}$ to metal (hydr)oxides with $\mathrm{pH}$ and thus a decrease in the dissolved $\mathrm{PO}_{4}$ concentration. This is the result of increased $\mathrm{Ca}$ adsorption with increasing $\mathrm{pH}$ facilitating additional adsorption of $\mathrm{PO}_{4}$. The adsorbed Ca ions reduce the negative charge created by the adsorption of $\mathrm{PO}_{4}$ at the surface of metal (hydr) oxides enabling additional $\mathrm{PO}_{4}$ adsorption (Weng et al., 2011). In the $\mathrm{pH}$ range 7-9, the model shows an increase in the dissolved $\mathrm{PO}_{4}$ concentration, and thus a decrease of the $\mathrm{PO}_{4}$ adsorption. The change in $\mathrm{pH}$ dependency of $\mathrm{PO}_{4}$ adsorption is largely the result of deprotonation of the $\mathrm{H}_{2} \mathrm{PO}_{4}$ species, forming $\mathrm{HPO}_{4}{ }^{2-}$, which due to its divalent negative charge is less likely to adsorb to (hydr) oxide surfaces (Rietra et al., 2001). The variation in Ca levels in our systems is too small to explain the increased $\mathrm{PO}_{4}$ solubility. Despite a slight overestimation in the predicted $\mathrm{PO}_{4}$ concentrations for the bulk soil samples from the PO treatment and an underestimation for the bulk soil samples from the $\mathrm{P} 1$ treatment, the model was able to explain the $\mathrm{PO}_{4}$ solubility in the incubated and $\mathrm{pH}$-treated bulk soil samples well, using a single value for the OM surface loading $\left(0.8 \mu \mathrm{mol} \mathrm{OM} \mathrm{m}{ }^{-2}\right)$. This OM loading falls within the range of values found by Hiemstra et al. (2010b) for a set of different agricultural topsoils.

In the second step, we extended the CD modelling to predict the $\mathrm{PO}_{4}$ solubility in the water extracts of the casts. We used unique input values of the individual water extracts of both cast and bulk soil samples (Table 5.3 and 4), in combination with different loadings of the OM competitor to predict the $\mathrm{PO}_{4}$ solubility in these extracts. Figure $5.4 \mathrm{~b}$ shows that, as predicted in the first step, a loading of $0.8 \mu \mathrm{mol} \mathrm{OM} \mathrm{m}{ }^{-2}$ is adequate to model the $\mathrm{PO}_{4}$ solubility in the water extracts of the bulk soils well, as the data points representing these samples are close to the 1:1 line. For the water extracts of the casts, we find that the $\mathrm{PO}_{4}$ solubility is greatly underestimated in the absence of an OM competitor, as expected from earlier results (Hiemstra et al., 2010b). Assuming the same loading of $0.8 \mu \mathrm{mol} \mathrm{OM} \mathrm{m}{ }^{-2}$ that was used for the bulk soils resulted in an increase in $\mathrm{PO}_{4}$ solubility because of the higher initial $\mathrm{PO}_{4}$ loading of the metal (hydr)oxides, as suggested by the higher measured $\mathrm{P}_{\text {ox }}$ values. However, the predicted $\mathrm{PO}_{4}$ concentrations still remain below the 1:1 line, implying that the predicted $\mathrm{PO}_{4}$ concentrations are lower than the measured DIP concentrations.

A possible explanation for this underestimation of the $\mathrm{PO}_{4}$ concentrations in the water extracts of the casts is a stronger competition of $\mathrm{PO}_{4}$ with adsorbed $\mathrm{OM}$ as result of enhanced levels of $\mathrm{DOC}$ in the casts as shown in Section 3.3. With an OM loading of 2 instead of $0.8 \mu \mathrm{mol} \mathrm{m} \mathrm{m}^{-2}$, predictions approached the measured DIP values within $0.5 \mathrm{log}$ unit (Fig. 5.4b). When increasing the OM loading beyond $2 \mu \mathrm{mol} \mathrm{m}{ }^{-2}$, the further increase in predicted $\mathrm{PO}_{4}$ concentrations was only minimal. 
This OM loading of $2 \mu \mathrm{mol} \mathrm{m} \mathrm{m}^{-2}$ is in the upper part of the range in OM loading of metal (hydr)oxides reported for a set of soils with different physico-chemical properties (Hiemstra et al., 2010b, 2013) in which loadings up to $\sim 2.1 \mu \mathrm{mol} \mathrm{m}{ }^{-2}$ were found. Even though the exact OM loading of metal (hydr)oxides in casts remains uncertain, our modelling results suggest that the role of OM in casts with respect to competition with $\mathrm{PO}_{4}$ for adsorption to metal (hydr)oxides is important.
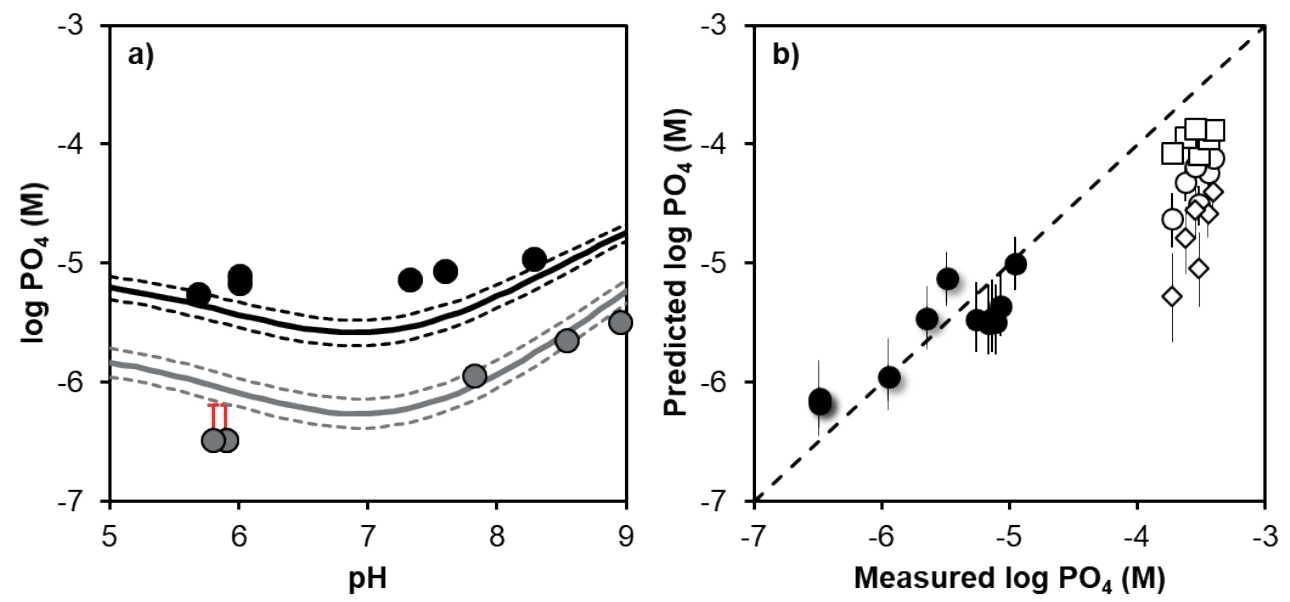

Figure 5.4. Main results of the modelling study. Figure a) shows modelled and observed $\mathrm{PO}_{4}$ concentrations as a function of $\mathrm{pH}$, with the observed values for the soil samples of the $P O$ and $P 1$ treatments represented by the grey and black circles respectively. The continuous grey and black lines indicate modelling results for the soil samples of the PO and P1treatments, with the model input based on averages of cation and anion concentrations (Tables 5.3 and 5.4) found for these samples and at a fitted OM loading of $0.8 \mu \mathrm{mol} \mathrm{m} \mathrm{m}^{-2}$. Sensitivity to an increase and decrease in OM loading of $0.1 \mu \mathrm{mol} \mathrm{m} \mathrm{m}^{-2}$ is indicated by the dotted lines. The concentrations of the three lowest points were below the detection limit, which is indicated by the red error bars. In Figure b) the observed (measured) versus predicted (modelled) values for dissolved inorganic $P(D I P)$ concentrations in water extracts of incubated cast samples (white symbols) and soil samples (black symbols). Diamonds represent concentrations obtained in the absence of an OM competitor. Circles represent concentrations obtained with an OM loading input of $0.8 \mu \mathrm{mol} \mathrm{m} \mathrm{m}^{-2}$, whereas for the squares a density of $2 \mu \mathrm{mol} \mathrm{m} \mathrm{m}^{-2}$ was used. The dotted line indicates the 1:1 line and the error bars represent the error induced by a 10\% over- or underestimation of the specific surface area (set at $650 \mathrm{~m}^{2} \mathrm{~g}^{-1}$; Hiemstra and Van Riemsdijk, 2009) 
As mentioned before, the input of total reversibly bound $P$ in the $C D$ model was derived from $P_{\text {ox }}$ values measured in surface casts and bulk soil samples. Ideally, $\mathrm{P}_{\text {ox }}$ would have been measured in the same cast and bulk soil samples that were used in the incubation experiment. Since it was difficult to obtain a sufficient amount of cast material, this was not possible, meaning that we had to measure $P_{\text {ox }}$ in surface casts collected from the extra four pots with grass for the incubation experiment. The surface casts were collected 10 days after earthworm addition. However, $P$ leaching from these surface casts may have occurred while watering the grass, thereby lowering the amount of $P_{\text {ox }}$. Consequently, the exact $P_{o x}$ values in the incubated casts might have been higher than those of the surface casts that we used in the CD model. The exact magnitude of this effect is unknown, but our model calculations show that when the input of total reversibly bound $\mathrm{P}$ is increased by $50 \%$, the predicted $\mathrm{PO}_{4}$ concentrations approach the measured DIP values within 0.1 log unit. At the same time, the true nature of the measured DIP concentrations in the water extracts of the casts is subject to debate. We made the assumption that all the P measured as DIP using the molybdenum blue method (Murphy and Riley, 1962) was present as $\mathrm{PO}_{4}$. However, it has been shown that this value can be overestimated due to the interference of colloidal $\mathrm{P}$ particles that dissolve at low pH (Van Moorleghem et al., 2011). We cannot be certain if or to what extent this was the case in our study, but this will require attention in further studies. Lastly, it is important to note that the modelled $\mathrm{PO}_{4}$ concentrations may be subject to uncertainty due to the assumption of a SSA of the metal (hydr)oxide particles that was set at $650 \mathrm{~m}^{2} \mathrm{~g}^{-1}$ (Hiemstra and Van Riemsdijk, 2009). As discussed in Section 3.5, smaller particles with a higher SSA may be present in casts, due to selective feeding. For this reason we assessed the sensitivity of the assumed SSA. The error bars in Fig. 5.4b indicate the effect on the predicted $\mathrm{PO}_{4}$ concentrations of a $10 \%$ change in the assumed SSA. It is clear that with increasing $\mathrm{PO}_{4}$ concentration, the variation in prediction becomes less dependent on the assumed SSA. Despite these uncertainties, our modelling study suggests that competition for adsorption sites on metal (hydr)oxide surfaces between $\mathrm{PO}_{4}$ and $\mathrm{OM}$, might be an important process in determining the plant availability of $\mathrm{P}$ in casts.

\section{Conclusion}

Our combination of experimental and modelling exercises leads to the conclusion that a previously unstudied pathway is important with respect to earthworm-induced elevated $\mathrm{P}$ availability in soil. Whereas the increase in $\mathrm{pH}$ has only a minor effect on $\mathrm{P}$ availability, our modelling exercises show that competition between $\mathrm{OM}$ and $\mathrm{PO}_{4}$ for adsorption sites on metal (hydr)oxide surfaces is an important mechanism determining levels of readily available P in earthworm casts. Surface complexation models can be used to gain insight in these processes. For more accurate predictions, however, OM loading in the casts, as well as the SSA of the metal (hydr)oxides in the casts should be investigated further. All in all, our results suggest an alternative pathway, next to mineralisation of organic matter, through which earthworms can increase soil fertility. 


\section{Acknowledgements}

This research has been made possible thanks to a donation by De Heus b.v., on the occasion of the $100^{\text {th }}$ anniversary of the company. We are grateful to Barenbrug b.v. for supplying the grass seeds used in the pot experiment and to Jaap Nelemans, Willeke van Tintelen, Gerlinde Vink, Arie Brader, Tamás Salanki, André Maassen, Pornpipat Kasemsap and Surachet Chamontri for their help during the experiments. We would like to thank four anonymous reviewers for their time and efforts to help improve this manuscript. Additionally, we would like to thank Oene Oenema, René Knook, Arjan Reijneveld, Guus van Laarhoven, Piet Arts and Stefan van der Heijden for their support. 


\section{Supplementary Information}

Table S5.1. Fertiliser application for the plant and cast experiments.

\begin{tabular}{lllll}
\hline & \multicolumn{2}{l}{ Start of the experiment } & \multicolumn{2}{l}{ At earthworm addition (T0) } \\
Nutrients & P0 treatments & P1 treatments & P0 treatments & P1 treatments \\
\hline $\mathrm{N}\left(\mathrm{kg} \mathrm{ha}^{-1}\right)$ & 100 & 100 & 250 & 250 \\
$\mathrm{P}\left(\mathrm{kg} \mathrm{ha}{ }^{-1}\right)$ & 0 & 48 & 0 & 100 \\
$\mathrm{~K}\left(\mathrm{~kg} \mathrm{ha} \mathrm{-}^{-1}\right)$ & 55 & 55 & 336 & 336 \\
$\mathrm{Ca}\left(\mathrm{kg} \mathrm{ha}^{-1}\right)$ & 40 & 40 & 334 & 334 \\
$\mathrm{Mg}\left(\mathrm{kg} \mathrm{ha}^{-1}\right)$ & 0 & 0 & 58 & 58 \\
$\mathrm{~S}\left(\mathrm{~kg} \mathrm{ha}^{-1}\right)$ & 30 & 30 & 76 & 76 \\
\hline
\end{tabular}




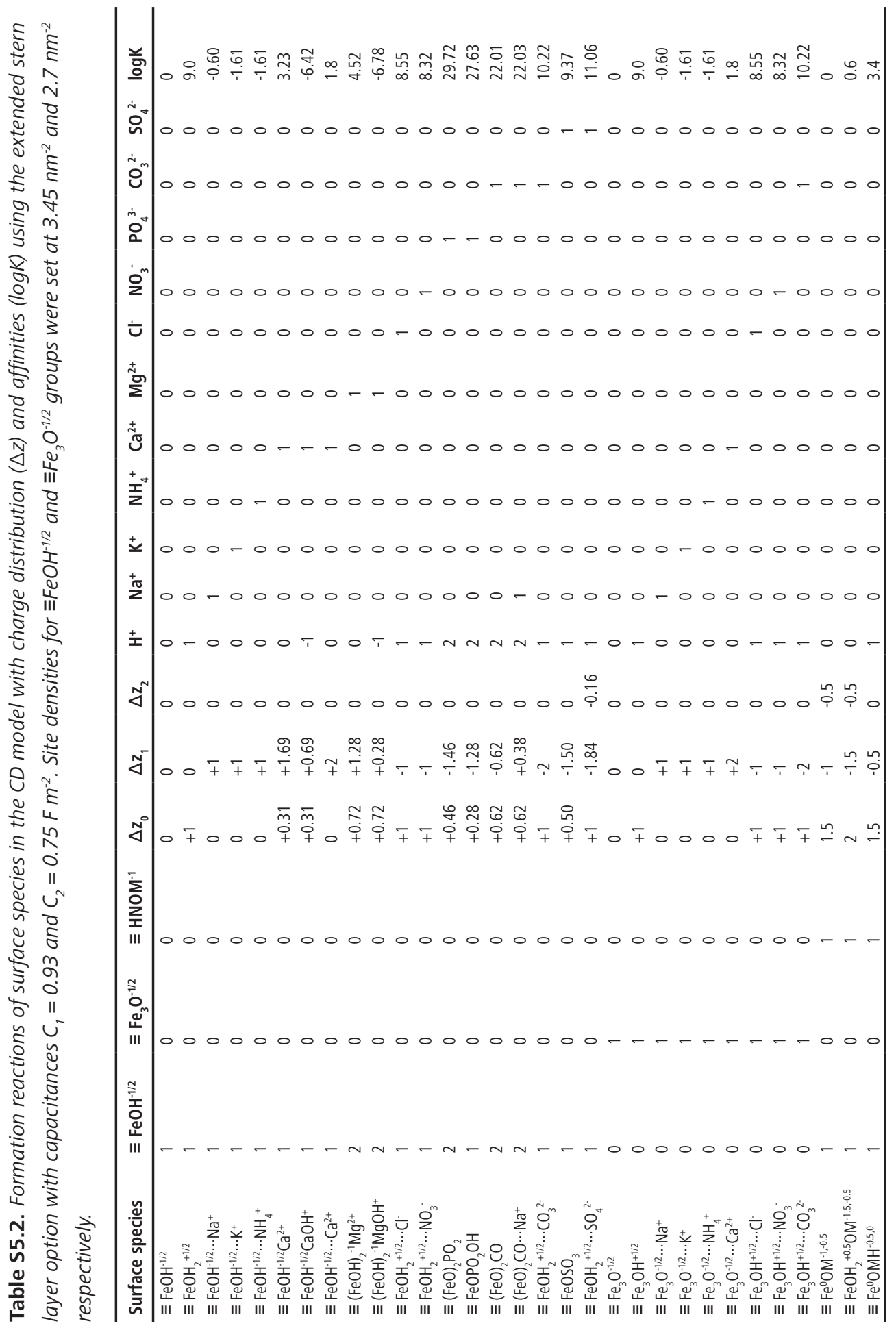


Chapter 6

\section{General discussion}




\section{Introduction}

The world population and global food consumption are growing rapidly, putting large pressure on agriculture to increase its production and resource use efficiency (Tilman et al., 2011, 2002). Dairy farming is a major agricultural system across the world, and grasslands are an integral part of these dairy farming systems, providing a feed source for the cattle. To meet the projected increase in the demand for dairy and beef, these grasslands will have to become more productive and will need to be managed more efficiently over the coming decades.

Phosphorus $(P)$ is one of the essential nutrients for plant growth, and its availability often limits grass yield. Efficient management of $\mathrm{P}$ inputs into dairy systems will be critical to sustainably intensify the use and production of grasslands. Globally, there are large differences with respect to the soil P balance and its $\mathrm{P}$ status: areas with aged, weathered soils usually struggle to provide sufficient $\mathrm{P}$ to sustain optimal crop yield, whereas $\mathrm{P}$ has become a pollutant in some other regions, due to long-term excessive applications of $P$ in mineral fertiliser and manure. Overall, $P$ inputs in grasslands may decrease in the future, partly due to increased scarcity and higher prices of phosphate rock (Cordell et al., 2009), and partly because of $\mathrm{P}$ application limits in some countries (e.g., Van Middelkoop et al., 2016). Increasing productivity without increasing P inputs requires, amongst others, a more efficient use of the P present in soil and manure. Discovering ways to access $\mathrm{P}$ pools in soils that were previously less available to plants, by using improved management of crop, soil, and manure can help to achieve this goal.

The research in this thesis aims to investigate mechanisms and factors that affect $P$ availability in grassland soils, and to explore options to increase the P utilisation in managed grasslands. The specific objectives of this research are:

- to identify the (soil) factors that drive the success of $P$ fertilisation of grassland on a global scale (Chapter 2);

- to assess the ability of various grass species to take up P from soils with a low P status and to link this ability to morphological root traits (Chapter 3);

- to quantify the effects of different earthworm species on $P$ availability and grass yield and $\mathrm{P}$ uptake (Chapters 4 and 5); and

- to examine the availability of $P$ in earthworm casts and model the mechanisms that affect the $\mathrm{P}$ availability in these casts (Chapter 5).

In the current chapter (Chapter 6), I will summarise and discuss the main findings of my research and place these into a broader scientific and societal perspective. At the end of this chapter, main conclusions and suggestions for future research are provided. 


\section{Main findings}

- An inventory and statistical meta-analysis of results from field experiments published in peer-reviewed literature showed that $P$ fertilisation of grasslands increased grass yields by an average 36\% (Chapter 2). This corresponded to an average yield increase of $23 \mathrm{~kg}$ dry matter per kg of $\mathrm{P}$ applied. The effect was most pronounced for studies in Africa and Oceania, whereas field trials in North America, Asia, and Europe were least responsive to $P$ fertilisation.

- Fertiliser application rate and soil P status were two factors that strongly determined the success of $\mathrm{P}$ fertilisation. Soils with an Olsen $\mathrm{P}$ status below $5 \mathrm{mg} \mathrm{P} \mathrm{kg}^{-1}$ responded disproportionately strong to $\mathrm{P}$ fertilisation, compared to soils with a higher P status, yielding on average $109 \%$ more than the control treatment (49 kg dry matter increase per $\mathrm{kg} P$ applied). Higher $\mathrm{P}$ application rates increased the relative yield response, but decreased the efficiency of $P$ fertilisation. Phosphorus applications should thus be focused on the soils with low P availability, and $\mathrm{P}$ applications on soils with a high $\mathrm{P}$ status should be minimal. Additionally, $\mathrm{P}$ inputs have the highest efficiency on soils with a pH between 5 and 6 and on grasslands with high levels of soil organic matter (SOM), although the meta-analysis does not provide a thorough evaluation of the responsible mechanisms.

- In a 9-month greenhouse experiment (Chapter 3), I showed that omitting P fertilisation resulted in a $13-50 \%$ yield penalty for eight different grass species used in managed grasslands. Although grass yield and nutrient uptake were significantly affected by both grass species and $P$ fertilisation treatments, a statistically significant interaction between the two experimental factors was not observed in the experiment.

- Root traits of the different grass species were measured and linked to grass yield and nutrient acquisition. The measured root traits differed strongly amongst species, but were unaffected by $\mathrm{P}$ treatment. In general, there was a trade-off between root mass and specific root length, indicating a difference in nutrient acquisition strategies amongst the species. Structural equation modelling showed that total root length and subsoil exploration were important root characteristics in explaining variation in yield. Focussing on these characteristics when selecting grass species may provide a promising strategy to maintain high yields under decreasing soil $\mathrm{P}$ availability.

- Earthworms excrete casts with high levels of available P (Chapters 4 and 5). Water-extractable orthophosphate (ortho-P) concentrations in earthworm casts (up to $10 \mathrm{mg} \mathrm{L}^{-1}$ ) were orders of magnitude higher than those of the bulk soil $\left(0.02 \mathrm{mg} \mathrm{L}^{-1}\right)$. The magnitude of the P effect in earthworm casts strongly depends on species: the epi-endogeic Lumbricus rubellus showed larger increases in readily available $\mathrm{P}$ than did the anecic $L$. terrestris and the endogeic Aporrectodea caliginosa. Although the effect of introducing earthworms in soil on P availability 
was not detectable at the bulk soil level, grass plants were able (in the case of $L$. terrestris) to capitalise on these local increases in $\mathrm{P}$ availability and increased yield and $\mathrm{P}$ uptake compared to the control treatment without earthworms.

- Several mechanisms were proposed to explain the substantial difference between waterextractable ortho-P concentrations in earthworm cast and those in the bulk soil: i) a higher $\mathrm{pH}$ observed in the earthworm casts, compared to the bulk soil, may induce desorption of ortho-P; ii) selective feeding and accumulation of P-rich material, such as plant litter or a clay fraction with a higher $\mathrm{P}$ loading and SOM content may cause an increased $\mathrm{P}$ content in casts; iii) increased mineralisation rates can result in an elevated $\mathrm{P}$ concentration in casts; and iv) higher concentrations of dissolved organic matter (DOM) in casts, resulting from increased mineralisation rates, may compete for adsorption sites and cause desorption of ortho-P.

- The elevated P concentrations in the casts were sustained over a 28-day incubation period. Incubation of earthworm cast and bulk soil material showed that, while a pH increase of the bulk soil slightly elevated water-extractable ortho-P concentrations, the magnitude of increase in ortho-P in casts cannot solely be attributed to a pH-effect (Chapter 5).

- With the help of standard model parameters, I was able to simulate the ortho-P concentrations in the water extracts of the bulk soil with relatively good accuracy, using surface complexation modelling in the Charge Distribution (CD) model. This was the first time this model was used to simulate the chemical conditions in earthworm casts. These modelling exercises additionally demonstrated that competition between (higher levels of) DOM and ortho-P in earthworm casts can contribute significantly to the elevated levels of dissolved ortho-P observed and should thus be considered as major factor moderating the readily available P levels in earthworm casts.

\section{$3 \quad$ Managing phosphorus inputs of grasslands}

\subsection{The importance of proper fertilisation}

Although the major part of my research focused on the possible pathways to improve the utilisation of the existing soil $\mathrm{P}$ pools, adequate use of mineral $\mathrm{P}$ fertilisers and animal manures is a key component of improving the $P$ use efficiency of managed grasslands, especially since $P$ inputs in grasslands are needed to support a sustainable intensification of grasslands globally (Sattari et al., 2016). The effectiveness by which $P$ sources, such as $P$ fertilisers and manures, are used on grasslands to increase yield strongly depends on climate, P application rate, and soil properties, as illustrated in Chapter 2. The response of grass to $P$ fertilisation was strongest (109\%) on soils with the lowest soil $\mathrm{P}$ test (SPT) values. Furthermore, $\mathrm{pH}$ and SOM content had significant effects on the 
success of $\mathrm{P}$ fertilisation, with the strongest responses for soils with a pH between 5 and 6 (60\%) and a large response for soils with high levels of SOM. It is well known that $\mathrm{pH}$ affects the solubility of $\mathrm{P}$, and thus its availability to plants (Hinsinger, 2001). At low pH, ortho-P adsorbs to iron (Fe) and aluminium (Al) (hydr)oxide surfaces or can precipitate as Fe-P and Al-P minerals, whereas at higher $\mathrm{pH}$ levels $\mathrm{P}$ is more likely to precipitate as $\mathrm{Ca}-\mathrm{P}$ minerals. The optimum $\mathrm{pH}$ for $\mathrm{P}$ fertilisation to become effective would therefore be around the level where P solubility is the highest. This optimum is often considered to reside around the neutral region (between 5.5 and 7; e.g. Tisdale et al., 1985; Price, 2006), which suggests that liming low-pH soils is a possible strategy to increase the availability of $\mathrm{P}$ for uptake by plants. However, Barrow (2017) recently argued that this view on $\mathrm{pH}$ and optimal $\mathrm{P}$ uptake is outdated and that the true $\mathrm{pH}$ optimum is lower than previously assumed. In addition to $\mathrm{pH}$, the SOM content of soil has been shown to affect $\mathrm{P}$ availability. Orthophosphate can compete with humic substances such as humic or fulvic acids for adsorption sites on $\mathrm{Al}$ and Fe (hydr)oxide surfaces (Antelo et al., 2007; Weng et al., 2008). Regelink et al. (2015) showed that the ortho-P concentration increases in soils with an increasing SOM content, at a similar $\mathrm{P}$ loading and $\mathrm{pH}$. Grassland soils with a high SOM content may hence show a stronger response to $P$ fertilisation than soils with a low SOM content. As also demonstrated for earthworm casts in the surface complexation modelling exercise in Chapter 5 , this competition between organic matter (OM) and ortho-P effect can potentially have a large effect on the solubility of ortho-P, and thus on the success of $P$ fertilisation. Other soil factors may also affect the adsorption behaviour of ortho- $P$ and thereby determine the success of $\mathrm{P}$ fertilisation. For example, large amounts of acid ammonium oxalate-extractable $\mathrm{Al}$ and $\mathrm{Fe}$ in soil can indicate an increased potential of a soil to bind ortho-P through adsorption or precipitation processes.

Aside from soil factors, grassland management choices can influence the result of $P$ fertilisation and the potential for $\mathrm{P}$ uptake by grass as well. The response to $\mathrm{P}$ fertilisation may for instance differ amongst selected grassland species. There were too few studies in the meta-analysis to test for this effect, but there was a clear effect of the inclusion of legumes in grasslands. In studies with grass/legume mixtures, P fertilisation resulted in $16.5 \mathrm{~kg}$ more yield per $\mathrm{kg} P$ applied than in studies without legumes. As for individual species, the results of Chapter 3 illustrate that grass species may show differences in relative response to $P$ fertilisation (Fig. 3.1; Table 3.4). Although the lack of a statistical significant interaction between grass species and $\mathrm{P}$ fertilisation indicates that there was no difference between species in yield response to $P$ fertilisation, other studies have shown that the $P$ response to $P$ fertilisation can differ amongst grass species (Hamel and Heckman, 2006; Paredes et al., 2011; Waddell et al., 2016).

Proper management of $\mathrm{P}$ inputs is crucial to the success of fertilisation. Application method and timing, and the availability and application of other essential nutrients such as nitrogen $(\mathrm{N})$ and potassium $(K)$ can have a strong effect on the effectiveness of $P$ application. Proper timing of $P$ applications and use of methods to incorporate $\mathrm{P}$ into the soil via injection or subsurface banding of animal manures may prevent losses of $P$ through runoff and erosion and thereby increase the $P$ fertilisation efficiency (e.g. Kleinman and Sharpley, 2003; Maguire et al., 2011; Rotz et al., 2011). A 
significant fraction of the $\mathrm{P}$ input of managed grasslands is generally in the form of animal manure (Sattari et al., 2016). Especially dairy systems with a relatively high animal density or stocking rate, and thus a high manure production per land area, can be expected to supply most nutrients to the crops through manure applications. However, there is often a discrepancy between the N/P ratio required by crops and the N/P ratio found in animal manures. The relatively low N/P ratio of manure commonly results from higher $\mathrm{N}$ losses than $\mathrm{P}$ losses throughout the manure management chain, predominantly through ammonia volatilisation and denitrification (Bai et al., 2013; Hristov et al., 2011). This relative high $N$ loss can result in over-application of $P$ when applying manure based on the $\mathrm{N}$ requirements of crops (which is often the higher priority). Evidently, this is in conflict with efficient and sustainable $\mathrm{P}$ use. Additional application of mineral $\mathrm{N}$ fertilisers or manure treatment practices, such as solid-liquid separation, can help to overcome this problem. In solid-liquid separation, manure (often a mixture of faeces, urine and water) is separated into a solid fraction, rich in $\mathrm{P}$ and $\mathrm{OM}$, and a relatively $\mathrm{N}$ - and $\mathrm{K}$-rich liquid fraction (Foged et al., 2011; Hou, 2016; Schröder et al., 2009). The liquid fraction often has a much higher N/P ratio than the solid fraction and may thus be more suitable as a $\mathrm{N}$ fertiliser product, allowing application based on the crop's $\mathrm{N}$ need without applying excessive amounts of $\mathrm{P}$. On the other hand, the solid fraction has a lower moisture content, a higher nutrient content, and lower N/P ratio (relatively P rich), making it more suitable product for the export of $\mathrm{P}$ to other farms, in case of farms with little land and P-rich soils.

\section{Overcoming global phosphorus imbalances}

Phosphorus applications and input-output $\mathrm{P}$ balances of agricultural land vary widely across the world (Liu et al., 2017; MacDonald et al., 2011; Sattari et al., 2016, 2012). One way towards a more sustainable use of $\mathrm{P}$ resources and towards closing the large differences in $\mathrm{P}$ use efficiency and $P$ balances would be a redistribution of $P$ inputs (MacDonald et al., 2011; Steffen et al., 2015). In this redistribution, $P$ sources would be moved from areas where $P$ has become an environmental pollutant to regions where soil $P$ status is low and can be used most effectively. Although this may seem like a straightforward idea, there are some major hurdles to overcome.

One particular issue revolves around identifying the areas where $P$ can be used most effectively. The results of Chapter 2 give an indication of the characteristics of grasslands that are likely to be the most responsive to $\mathrm{P}$ fertilisation: those on soils with a low $\mathrm{P}$ status, a $\mathrm{pH}$ between 5 and 6 , and a relatively high SOM content. Combining maps of these soil properties at global, regional, or national levels (e.g. Meersmans et al., 2012; Hengl et al., 2017a; Chen et al., 2019; Liang et al., 2019) into one map that indicates the likelihood of $P$ fertilisation success may aid in achieving better global use of $P$ resources. Although the generation of such maps is currently in progress (Hengl et al., 2017b, 2017a), data availability, spatial resolution, and global differences in soil test methods (for instance for $\mathrm{P}$, soil texture, or $\mathrm{pH}$ ) complicate the generation, usefulness, 
and reliability of these maps. Of the soil properties to consider, soil P status is the most important to incorporate in such maps. Studies analysed in Chapter 2 showed a mean yield increase of 23 $\mathrm{kg}$ dry biomass per $\mathrm{kg} \mathrm{P}$ applied, but this was more than doubled (49 $\mathrm{kg}$ dry biomass per $\mathrm{kg} \mathrm{P}$ ) when the grasslands with low P status ( $\leq 5 \mathrm{mg} \mathrm{P} \mathrm{kg}^{-1}$ Olsen-equivalent) were considered. Obtaining information on soil $\mathrm{P}$ availability of grassland soils worldwide may not be easy. The differences in soil P test (SPT) methods in the analysed studies (Fig. S2.2; Table S2.1) induce a degree of uncertainty when they are transformed to Olsen-equivalent $\mathrm{P}$ using empirical conversion equations. Additionally, information on the extracted P pool is lost; for example, 'intensity' SPT methods extract a relatively small fraction of the soil P pool that resembles the directly available P fraction (Fig 1.2), whereas 'quantity' SPT methods extract a fraction of soil P that includes strongly adsorbed P, which can be accessed by plants only over a long time period. Translating these different methods into one number means that information on what fraction of $\mathrm{P}$ was actually extracted is lost. This does then not allow for a distinction between soils that have a low $P$ status as a result of a small total soil $\mathrm{P}$ content (low $\mathrm{P}$ quantity) and those with a low $\mathrm{P}$ status as a result of a low $\mathrm{P}$ intensity (in $\mathrm{P}$ fixing soils for example). Although I was not able to disentangle these differences in Chapter two, they may be important for the success of P fertilisation. For the purpose of creating a global map, adopting a universal SPT methodology for soil testing would thus be desirable. A methodology that uses a combination of quantity and intensity SPT methods could provide information on the supply potential of a soil to when assessing the P status (Van Rotterdam et al., 2012). However, soils may respond differently to various SPT methods when it comes to bioavailability of P. Nawara et al. (2017) showed that quantity methods such as Olsen P and intensity methods, such as $0.01 \mathrm{M}$ $\mathrm{CaCl}_{2}$-extractable $\mathrm{P}$, were equally successful at predicting crop response to $\mathrm{P}$ fertilisation, whereas for tropical soils intensity methods have been documented to be better predictors (Six et al., 2013; Speirs et al., 2013). Although a universal SPT test could thus improve the comparability amongst regions, adopting one method may increase uncertainty of crop response in certain areas. Moreover, the proposal of a common SPT may be practically infeasible, as most existing methods to determine recommendations for $\mathrm{P}$ application rates are based on local fertilisation trials, yield response curves, and corresponding local STP methods, which are all carefully calibrated for the regions in which they are used (Jordan-Meille et al., 2012). Adopting a new SPT method only to improve comparability with other regions, may thus meet objections from areas where this method is not practiced. However, developing countries without SPT-based P fertilisation recommendation systems yet, may find a universal method and a corresponding map indicating the P fertilisation efficiency useful.

Another issue that may obstruct a possible re-allocation of $\mathrm{P}$ sources are the costs involved with the transportation of manure P. In areas with intensive dairy management and high stocking rates, such as the Netherlands, dairy farms are not able to produce all feed on their own land base. A portion of concentrates and sometimes roughage is imported from outside the farm. On these high-livestock density farms, nutrients often accumulate in soil and manure (Cela et al., 2014). Manure export is then needed to relieve the environmental pressure and lower the $\mathrm{P}$ accumulation 
on the farm. In the Netherlands, for example, manure export and processing has been incorporated into the legislation and is mandatory for farms that produce more than a given amount of manure (CDM, 2018; Klootwijk et al., 2016). Exporting and transporting manure is costly, and it is thus unlikely that exported $\mathrm{P}$ in manure can be moved far from the source. Manure treatment options, such as the solid-liquid separation mentioned earlier, and drying of the solid fraction may be key to solving this problem. If these techniques can be developed to extract a P-rich bio-fertiliser product that can match the efficiency of mineral fertilisers, processing and exporting manure products may become increasingly attractive (Case et al., 2017). Currently, economic costs and technological limitations are often still constraints for farmers to adopt manure treatment practices (Hou et al., 2018).

\section{The role of grass species selection in improving $P$ utilisation}

With decreasing $\mathrm{P}$ inputs into grasslands and/or a decreasing soil $\mathrm{P}$ status, careful selection of grass species that are adapted to a lower $P$ availability may become essential to increase the $P$ use efficiency in managed grasslands. The results of Chapter 3 showed that there was a large variability in yield, nutrient uptake, and relative responses to withholding $P$ fertilisation amongst grass species used in managed temperate grasslands. Particularly the species Holcus lanatus and Lolium multiflorum showed a relatively high yield and high $\mathrm{N}$ and $\mathrm{P}$ acquisition under both $P$ fertilisation treatments. They also had the lowest N/P ratios in both $P$ treatments (Table 3.4), which indicates that the degree of $P$ limitation was lowest for these species. The differences in yield and nutrient uptake observed amongst species were much larger than those induced by the $\mathrm{P}$ fertilisation treatments. Furthermore, there was no significant interaction between the two treatments on yield and nutrient uptake, which indicates that the effect of $\mathrm{P}$ fertilisation was similar for all species. There are strong indications that the two $P$ treatments may not have resulted in a pronounced difference in $\mathrm{P}$ availability, as discussed in Chapter 3, Section 4.2: the relatively high $\mathrm{N} / \mathrm{P}$ ratios of the grass species in both $\mathrm{P}$ treatments, the low water-extractable $\mathrm{P}$ concentrations in all pots, and the minor effect of $\mathrm{P}$ fertilisation on the $\mathrm{P}$ saturation index $\alpha$ provide circumstantial evidence for this hypothesis. Furthermore, this could explain why no specific effects of $P$ fertilisation on structural root traits were observed. Alternatively, root plasticity may have been limited for the species used in our experiment, which would mean that the ability of a species to acquire $P$ in P-limiting conditions would be based on intrinsic root characteristics, rather than on the adaptability of said characteristics (Fransen et al., 1999; Hill et al., 2006). In a recent experiment, Waddell et al. (2017) did record root plasticity of various wallaby grass species (well-adapted to an environment of low $\mathrm{P}$ availability), but all species responded similarly to $\mathrm{P}$ addition. Coinciding with the results from Chapter 3, they reported distinct relationships between $P$ uptake, root length, and root mass.

To properly test whether the presumed lack of difference in soil $P$ availability between the two $P$ treatments of the experiment described in Chapter 3 has concealed root trait plasticity for any of the species, a similar experiment with $\mathrm{P}$ fertilisation treatments could be run on a P soil with 
not just a low $\mathrm{P}$ intensity, but also a low $\mathrm{P}$ quantity. Additionally, there are several root traits that I did not consider, but might cause differences in $\mathrm{P}$ acquisition ability of the grass species and thus be important in P-limiting environments:

- Species with a strong root proliferation may be able to react quicker to temporary hotspots of nutrients, like those created by deposition of earthworm casts (as demonstrated in Chapters 4 and 5). This can give such species a competitive advantage over other species; root proliferation has been shown to differ amongst grass species (Fransen et al., 1999; Hodge et al., 1999). The species in Chapter 3 may have reacted by increasing their root density in the top soil in response to fertilisation being applied at the soil surface, but as root characteristics were only measured after 5 and 11 harvests, this does not give specific information on the speed at which roots develop in relatively nutrient-rich areas.

- Development of root hairs is a relatively carbon-efficient way in which species can increase the volume of soil explored by their roots (Richardson et al., 2011; Simpson et al., 2014). Root hair length and density varies for pasture species and can be altered in response to nutrient limitation (Haling et al., 2011; Robinson and Rorison, 1987; Waddell et al., 2017; Yang et al., 2017). Long root hairs may help grasses perform better under P-deficient conditions.

- Some plant species, such as white lupine (Lupinus albus) are known to exude organic anions such as citrate and oxalate under low P availability (Hinsinger, 2001; Richardson et al., 2009b; Vance et al., 2003). These anions can increase P solubility by competing with ortho-P for adsorption sites on reactive surfaces in soil. Although this mechanism could potentially lead to an increase in P use efficiency, conclusive evidence for yield benefits to agricultural grasslands has not been demonstrated yet and this topic requires further attention (Richardson et al., 2011; Simpson et al., 2014).

- In addition to organic anions, some grassland species (or associated mycorrhizal fungi) can exude phosphatase enzymes (Fujita et al., 2010; Hayes et al., 1999; Olde Venterink and Güsewell, 2010; Richardson et al., 2011). These enzymes can facilitate and stimulate the mineralisation of organic $P$ compounds such as P-esters (Fig. 1.3), which potentially opens up a previously unavailable soil $\mathrm{P}$ pool. Better utilisation of the organic soil P pool has long since been of interest, as this pool is generally difficult to access by plants. Regularly fertilised agricultural soils have a higher turnover of inorganic than organic $P$, which means that it is likely that the (relative) importance of the organic P pool will increase when $\mathrm{P}$ inputs to these soils decline. This is illustrated by Van der Salm et al. (2017), who quantified various soil P pools during 17 years of balanced P fertilisation and saw a decrease in available and total $P$ pools, but an increase in organic $P$. 
As (agricultural) grasslands, even intensively managed ones, are rarely composed of monocultures and usually contain a variety of species, yield and $P$ uptake of different combinations of grass species should be studied in relation to their $\mathrm{P}$ acquisition strategies. This is especially of interest if the involved species harness different strategies or can access different $\mathrm{P}$ pools. In this case, $\mathrm{P}$ resource partitioning can in theory lead to better utilisation of the soil $\mathrm{P}$ pools and ultimately to higher yields (Turner, 2008). This hypothesis has received some attention lately (Ceulemans et al., 2017; Li et al., 2018), but it is a difficult principle to prove (Li et al., 2018). Nevertheless, studying combinations of different grass species may be worthwhile not only because they may access different $\mathrm{P}$ sources, but also because their root structures allow these species to access $\mathrm{P}$ at different places in the soil. For instance, I observed a difference in rooting depth between grass species; through structural equation modelling, I identified the relative amount of roots in the subsoil as one of the predictors for grass yield. Next to species combinations, legumes should also be considered in further studies on grasslands. Legumes are often included in grasslands to provide extra $\mathrm{N}$ inputs through fixation of atmospheric N. Additionally, grasslands with legumes often have a higher protein content, which improves their value as a forage. The results from Chapter 2 show that the response of grasslands to $\mathrm{P}$ fertilisation is more than twice as strong when legumes are included. This is likely due to the higher $\mathrm{P}$ requirement of legumes and their courser roots and shorter root hairs (Hill et al., 2006; Simpson et al., 2014). These characteristics could introduce an interesting management choice for farmers in situations of a low soil $\mathrm{P}$ availability: including legumes in a grassland may increase the feed quality of grassland and provide extra $\mathrm{N}$ inputs. Additionally, the $\mathrm{N}$ and $\mathrm{P}$ contents of the resulting manure may be higher compared to that of manure derived from grass-only feed, but the higher $\mathrm{P}$ requirements of legumes may require larger $\mathrm{P}$ inputs in these grasslands.

Although I specifically focused on establishing a link between sensitivity to $P$ deficiency of different grass species and root characteristics, in practice grass species are usually selected for other reasons. Yield production under optimal conditions and grass quality parameters, such as crude protein, digestible fibre content, energy level, and nutrient concentrations are important variables that are taken into account (Whitehead, 2000) as these may differ amongst species (Čop et al., 2009a; JanĐík et al., 2010). Valk and Šebek (1999) established that a concentration of $2.8 \mathrm{mg}$ $\mathrm{P}$ per kg of dry matter feed intake is sufficient to sustain milk production in highly productive dairy cows without apparent complications. Grass P concentrations just above this value would thus be ideal for sustainable $\mathrm{P}$ use in dairy farming, as it decreases the need for feed (concentrate) imports with higher $\mathrm{P}$ concentrations to compensate for lack of $\mathrm{P}$ in home-grown forage. The average shoot $\mathrm{P}$ concentrations observed in the grass species throughout the pot experiment of Chapter 3 ranged from 1.52 to $2.02 \mathrm{mg} \mathrm{P} \mathrm{kg}^{-1}$ in the absence of $\mathrm{P}$ fertilisation and from 2.05 to $2.63 \mathrm{mg} \mathrm{P} \mathrm{kg}^{-1}$ when fertilised with $\mathrm{P}$ mineral fertiliser (dissolved $\mathrm{K}_{2} \mathrm{HPO}_{4}$ ). Lolium multiflorum and $\mathrm{H}$. lanatus had the highest $\mathrm{P}$ concentrations throughout the experiment, but were mostly still below $2.8 \mathrm{mg} \mathrm{P} \mathrm{kg}^{-1}$, indicating that $P$ limitation can decrease the nutritional value of the grass. 


\section{$5 \quad$ Employing earthworms to increase soil $\mathbf{P}$ utilisation}

\subsection{Assessing the effect of earthworms on P availability}

Earthworms dramatically increase the amount of water-extractable $\mathrm{P}$ of the soil ingested and excreted as casts. In Chapter 4, I showed that grasses can utilise this P; introduction of earthworms increased yield and $\mathrm{P}$ uptake under exclusively P-limiting conditions, both on a soil with a low $\mathrm{P}$ intensity (Chapter 4) and one with both a low P intensity and quantity (Chapter 5). This means that the plant roots were able to reach and access the cast and drilosphere (i.e. the area of soil affected by earthworms) before the earthworm effect on $\mathrm{P}$ availability had subsided. This effect was studied under controlled conditions and in strongly P-limited systems. The latter is suggested by the low water-extractable levels of soil $\mathrm{P}$ and the low yield and $\mathrm{P}$ uptake of the grass. The earthworm-induced increases in yield and $P$ uptake (Chapter 4: 7-15\% for yield and $2-6 \%$ for $P$ uptake after 3 harvests; Chapter 5: 10\% for yield and 27\% for $\mathrm{P}$ uptake) were also relatively modest compared to the average effect (25\% yield increase) of earthworms on crop yield calculated in a recent meta-analysis (Van Groenigen et al., 2014). The results from this meta-analysis were not specific to $\mathrm{P}$ limited environments, however, and these results may come from a variety of other earthworm-induced effects, especially an improvement in soil structure or a higher $\mathrm{N}$ supply. After including a fourth harvest in Chapter 4, the earthworm effect disappeared, although this can most likely be attributed to the inclusion of the stubble material, which was a relatively large contributor to the harvested biomass. In Chapter 5 only two harvests were considered. Future studies should thus focus on longer lasting experiments to investigate whether this effect persists over longer time periods, such as the length of an entire growing season. For managed grasslands, this usually includes four or five cuts or harvests, obtained throughout several months, which is considerably longer than the 42 days of the greenhouse study in Chapter 4. Additionally, it is important to check whether the observed earthworm effects extend beyond the controlled environment of a greenhouse, and if they persist under field conditions and for different soil types. Both these steps are currently explored in the PhD research work of Hannah Vos, which is currently ongoing at Wageningen University.

In Chapters 4 and 5, readily available $P$ was estimated by a 1:10 (w:v) extraction with deionized water. This is not a commonly used method to measure $\mathrm{P}$ intensity in soils, like for instance an extraction with $0.01 \mathrm{M}$ calcium chloride $\left(\mathrm{CaCl}_{2}\right)$ (Houba et al., 2000). The $\mathrm{CaCl}_{2}$ method is designed to mimic the ionic strength of many agricultural soil solutions ( $30 \mathrm{mM})$ and uses $\mathrm{Ca}$ as this is the primary cation on the adsorption complex of soils (Houba et al., 2000). Unlike the $\mathrm{CaCl}_{2}$ method, the ultrapure water used in the extraction of soil does not approach the ionic strength of the soil solution. The absence of $\mathrm{Ca}$ in the extraction solution may also lead to a greater desorption of $\mathrm{P}$ (Koopmans et al., 2001), as Ca can facilitate the adsorption of $\mathrm{P}$ to metal (hydr)oxides in soil and therefore reduce the extracted amount (Weng et al., 2011). In preliminary tests, the dissolved inorganic $\mathrm{P}$ concentration in $0.01 \mathrm{M} \mathrm{CaCl}_{2}$ extracts of the soils used in Chapters 3 and 4 were 
below the detection limit of the Segmented Flow Analyser (results not shown), which is why I have used a water extraction at 1:10 (w:v) as a measure of P intensity in soil and earthworm casts. As the water extraction method is an intensity SPT, it does not provide information on the P quantity that buffers the water-extractable $P$ in soil. Hence, this measure of directly available $P$ does not give information about how long this earthworm effect will last. In Chapter 5 we measured acid ammonium oxalate-extractable $\mathrm{P}\left(\mathrm{P}_{\text {ox }}\right)$ as a quantity measure of the total pool of reversibly adsorbed $P$ in earthworm casts, but this analysis was done on surface casts rather than fresh casts. The age of this cast material was uncertain and therefore provides little information on the persistence of the earthworm effect on $\mathrm{P}$ availability in casts.

Research on the temporal dynamics on the P availability in earthworm casts has been scarce so far, but studies have showed that elevated concentrations of available $P$ in earthworm casts can persist on time scales from days to weeks (Le Bayon and Binet, 2006; Sharpley and Syers, 1976). Results from the incubation experiment in Chapter 5 showed that water-extractable $P$ levels remained elevated compared to the bulk soil, even after 28 days. This suggests that the grass roots would have the opportunity, at least during this time frame, to capitalise on such elevated available $P$ levels. Nevertheless, this incubation was done in an isolated environment, meaning there were no chemical or biological interactions between the cast material and the bulk soil. To estimate the temporal dynamics and persistence of an earthworm effect on P availability more accurately, this experiment would have to be repeated in the presence of bulk soil, so that physico-chemical processes such as diffusion of $\mathrm{P}$ into the soil, and transformation of $\mathrm{P}$ to less available forms can be taken into account more realistically.

I proposed several pathways that may explain the elevated water-extractable P concentrations in earthworm casts: i) a higher pH observed in the earthworm casts, compared to the bulk soil, may induce desorption of ortho-P; ii) selective feeding and accumulation of P-rich material, such as plant litter or a clay fraction with a higher $\mathrm{P}$ loading and SOM content may cause an increased $\mathrm{P}$ content in casts; iii) increased mineralisation rates can result in an elevated P concentration in casts; and iv) higher concentrations of DOM in casts, resulting from increased mineralisation rates, may compete with ortho-P for adsorption sites and cause desorption of ortho-P. The incubation of soil samples with a modified $\mathrm{pH}$ showed that an increase in $\mathrm{pH}$ slightly elevated water-extractable P levels, but the elevated $\mathrm{pH}$ was not solely responsible for the increase in ortho-P concentrations found in earthworm casts. The modelling exercise described in Chapter 5 was the first instance where the $C D$ model was used to simulate the chemical environment of earthworm casts to get fundamental insight in the P dynamics in casts. However, the results showed that even when a high OM loading of reactive surfaces of the metal (hydr)oxides in the earthworm casts was assumed, the model still underestimated the observed ortho-P concentrations found in the water extracts of the casts. This high OM loading of $2 \mu \mathrm{mol} \mathrm{m} \mathrm{m}^{-2}$ is in the upper range for the OM loading of metal (hydr)oxides reported for a set of soils with different physico-chemical properties (Hiemstra et al., 2013, 2010b). My modelling results seem to indicate that competition for adsorption sites between ortho-P and OM may be a major factor influencing the readily available amount of $\mathrm{P}$ in earthworm casts, as has 
been observed before for a series of Dutch agricultural topsoils by Hiemstra et al. (2010b) and for forest and cropland sites by Regelink et al. (2015).

Regarding the CD modelling, I had to make several assumptions regarding input parameters that may affect the P solubility in earthworm casts and need to be discussed:

- In the CD model calculations, all oxide surfaces from both Fe and Al (hydr)oxides were interpreted as goethite for which this model has been extensively calibrated (Hiemstra et al., 2010a). However, other types of Fe (hydr)oxides such as ferrihydrite may be more common in soil (e.g. Jambor and Dutrizac, 1998). Based on the recently developed probe ion method, Hiemstra et al. (2010a) found a high specific surface area (SSA) for a series of agricultural topsoils that corresponds with the presence of very small Fe oxide nanoparticles of about 1 to $10 \mathrm{~nm}$ in size. This particle size is typical for synthetic ferrihydrites rather than goethite (Hiemstra et al., 2010a). For synthetic ferrihydrites, a maximum P adsorption density of 3.9 to $4.6 \mu \mathrm{mol} \mathrm{m} \mathrm{m}^{-2}$ has been found (Celi et al., 2003; Wang et al., 2013), whereas for goethite adsorption is usually limited to 2.5 to 3.5 $\mu \mathrm{mol} \mathrm{m} \mathrm{m}^{-2}$ (Hiemstra and Van Riemsdijk, 1996). This difference is due to the much higher reactive site density of ferrihydrite (Hiemstra and Zhao, 2016). It remains to be seen, however, whether this higher site density of ferrihydrite in combination with the model parameters of ortho- $P$ for this oxide mineral in the $C D$ model will lead to an improvement in the predictions of the ortho-P solubility for earthworm casts, as the adsorption behaviour of ortho-P at the elevated $\mathrm{pH}$ of the earthworm casts for ferrihydrite and goethite is rather similar (Mendez and Hiemstra, 2018). Moreover, in the current modelling exercise, the amount of oxides in soil and casts was estimated based on an acid ammonium oxalate extraction, assuming that all extracted Fe and Al originated from goethite and gibbsite, respectively. The molar quantities of Fe and Al were converted into an amount of oxides, using a molar mass of $89 \mathrm{~g} \mathrm{~mol}^{-1}$ for goethite and $78 \mathrm{~g} \mathrm{~mol}^{-1}$ for gibbsite, respectively. A specific surface area (SSA) of $650 \mathrm{~m}^{2} \mathrm{~g}^{-1}$ oxide was assumed for the oxides in the earthworm casts, which appears to be a reasonable estimate for ferrihydrite (Hiemstra, 2013; Mendez and Hiemstra, 2018). As this type of research on casts is novel, there is no information available yet on the type and SSA of the oxides occurring in earthworm casts. For future studies, the SSA of oxides in earthworm casts could be measured using the recently developed probed ion method of Hiemstra et al. (2010a).

- The input data for the earthworm cast properties in the CD model were partially derived from surface casts and partially from fresh casts. The solution composition was mimicked using data from the water extracts of the fresh casts (Table 5.3). The aim was to model fresh earthworm casts, but there was not enough fresh material to do all the required chemical analyses to obtain the model parameters. Therefore, as mentioned before, values for the total pool of reversibly adsorbed P and Fe and Al (hydr)oxides of the system 
were estimated using an acid ammonium oxalate extraction (Table 5.5), which in this case was done on aged surface casts. The uncertainty about the age of the surface casts and how these parameters may have changed over time may have led to an underestimation of the total reversibly adsorbed P pool and metal (hydr)oxide contents in the modelling exercise.

- Additionally, it is remarkable that the amount of ortho-P found in the water extracts of the harvested earthworm casts is of a similar order as the amount of reversibly adsorbed $\mathrm{P}$ in the form of $\mathrm{P}_{\text {ox }}$. It suggests that the $\mathrm{P}$ present in the casts is completely dissolved. This is unexpected and it is difficult to explain the strong increase in water-extractable ortho-P by adsorption-desorption processes only. Moreover, the increases in $\mathrm{pH}$ and ortho-P concentration measured in the water extracts of earthworm casts reported in Chapter 5 (0.35 mM P and pH 7.7-9.0 for P0 casts) are much more extreme than those observed in Chapter 4 (0.11 mM P and pH 7.8 for the casts of L. terrestris), especially as the water extracts of the casts in Chapter 5 contain $>100 \%$ of the $P_{\text {ox }}$ of the soil as ortho-P compared to $1-26 \%$ for the casts in Chapter 4. Although the sampling and collection of the earthworm casts was nearly identical in both studies, the casts collected in Chapter 5 were incubated in polyethylene bags for at least $24 \mathrm{~h}$. This material is known to allow for gas exchange (Gordon et al., 1987), but the supply of oxygen through the plastic may still have been lower than the consumption rate of oxygen due to microbial activity, leading to the persistence or augmentation of anaerobic conditions in the incubated fresh casts. The extremely high ortho-P levels in the water extracts may suggest that surfaces of Fe (hydr)oxides are no longer active, which might be resulting from, for example, reductive dissolution of these (hydr)oxides. Although this process would lead to a large release of $\mathrm{Fe}(\mathrm{II})$, which is at most only partly observed in the water extracts $\left(\sim 11 \%\right.$ of the $\mathrm{Fe}_{\text {ox }}$ is extracted as dissolved $\left.\mathrm{Fe}\right)$, no conclusive explanation can be given presently. Hence, this remarkable observation needs more attention in further studies.

\subsection{Managing earthworms in grasslands}

Assuming the effect of earthworms on soil $\mathrm{P}$ availability is transferable to field conditions, an interesting question is how these fields can be managed to optimise the effect of earthworms on P cycling. In my thesis, I focused mostly on the effect of single species. Species with different feeding strategies may however have a complementary effect on nutrient cycling (Giannopoulos et al., 2011), and should therefore be studied in combinations and in their natural environment. Didden (2001) found that grasslands in the Netherlands contain roughly 380 individuals per $\mathrm{m}^{2}$. The majority of these are endogeic species; epigeic and anecic earthworms occur at a density of about 60 individuals per $\mathrm{m}^{2}$. The species A. caliginosa and L. rubellus, which were used in the experiments 
described in this thesis, were amongst the most common earthworms in Dutch grasslands (Didden, 2001). Lumbricus terrestris was less common, although that may partly have been the result of the used sampling method. Earthworm abundance and community composition may vary largely with location and climate and higher abundances have been observed in grasslands elsewhere (e.g. Cluzeau et al., 2012; Rutgers et al., 2016; Sechi et al., 2015). In the experiments described in Chapters 4 and 5, the earthworm densities used were higher than those reported by Didden (2001). The effects might thus have been augmented by a higher density, although in Chapter 5 a significant portion of the earthworms died during the pot experiment, which could point towards an underestimation of the earthworm effect instead.

Results of my thesis suggest that stimulating earthworm activity in managed grasslands may increase soil P utilisation by grass species. Although earthworms are sometimes sown or inoculated into grasslands to increase the population, the results of these practices are likely to be limited if the target soil is not suitable as a habitat. The most important step towards increasing earthworm abundance is thus to create a good living environment, which includes a sufficient supply of fresh OM from plant litter, a lack of disturbance caused by heavy tillage practices, a well-drained soil that can retain water, and sufficient shelter from predators (Briones and Schmidt, 2017; Curry, 2004). Compared to arable soils, grasslands are more likely to meet this requirement as they usually have a relatively high $\mathrm{OM}$ content and are not regularly tilled. Indeed, earthworm populations are often higher in grasslands than in arable soils (Didden, 2001; Rutgers et al., 2009). Management practices that increase the aforementioned conditions could contribute to higher earthworm densities. Applications of animal manure may provide OM (Koopmans et al., 2007), whereas the cutting height of the grass may affect the vulnerability of earthworms to predators. Practices such as these could be investigated in the light of their effect on the earthworm population. Despite their generally positive effect on soil quality and carbon and nutrient cycling, instances have been reported in which earthworms can increase nutrient losses from fields. Earthworms have been shown to increase greenhouse-gas emissions (Lubbers et al., 2013). Additionally, the permanent burrows of anecic earthworms can act as preferential flow pathways for water and dissolved nutrients (Allaire et al., 2011; Shipitalo et al., 2004; Shipitalo and Gibbs, 2000).

\section{Outlook}

There is a clear need for improvement of the use efficiency of soil $\mathrm{P}$ in agricultural grasslands across the world. Grassland productivity needs to increase globally to be able to meet the increasing demand for forage by the increasing dairy and beef cattle herds over the coming decades. Current areas with $\mathrm{P}$ scarcity and those with $\mathrm{P}$ excess will face a similar challenge of maximising production with restricted $P$ inputs.

Grasslands in the Netherlands have been fertilised with animal manure for decades and have sufficient amounts of $\mathrm{P}$ to sustain high levels of grass production for the years to come (Reijneveld 
et al., 2010; Schoumans and Chardon, 2015). Additionally, the Dutch animal production sector produces more manure than is allowed to apply on all agricultural land, according to the current $P$ application limits (CDM, 2018). It is therefore unlikely that $\mathrm{P}$ scarcity will be a pressing issue in the Netherlands over the coming decade. Still, these issues are likely to be relevant in the future as a result of lower P inputs (Van Middelkoop et al., 2016). The current system of manure P quota limits the number of dairy cows and production of dairy manure at the farm and national levels, mainly to prevent a further increase in the number of cows and hence in manure production (Klootwijk et al., 2016). Furthermore, enforcing P-equilibrium fertilisation is likely to bring down SPT levels, although it is uncertain how this will affect grassland production in the coming years. Nawara et al. (2018) calculated that Belgian agricultural soils would start to be P deficient after 3 to 8 years without $\mathrm{P}$ application, depending on soil $\mathrm{P}$ level and biomass production. This period will be longer when equilibrium $P$ fertilisation is adopted, but nevertheless a drawdown of the soil $P$ status can be expected eventually (Van der Salm et al., 2017). This mining effect on the plant available $P$ pool may be aggravated by the hysteretic nature of $\mathrm{P}$ adsorption-desorption processes (Barrow, 1983; Okajima et al., 1983; Schoumans and Chardon, 2015), which implies that during desorption (extraction of $\mathrm{P}$ from the soil) the $\mathrm{P}$ intensity is lower than during adsorption (addition of $\mathrm{P}$ to the soil), at a similar $P$ quantity.

In the end, most $\mathrm{P}$ fertilisation recommendations are designed to bring soils to the 'adequate' status. It is unclear what exactly this means for the Dutch dairy farms. Should the soil P status of grasslands drop to a level where farmers may need to consider P-based management practices, my thesis points towards several directions with the potential to improve P use efficiency:

- Apply manure and mineral fertiliser on the most effective places (low P status; pH 5-6; high OM content; grasslands with legumes)

- Use deep-rooting grass species that have high root length and mass

- Manage grasslands as a suitable habitat for earthworms and adopt practices that stimulate their activity

To give further content and detail to these directions, more research is needed. In my opinion, the key towards successful and useful agricultural science, in this case to improve the utilisation of soil $P$ in grasslands, is threefold:

1. There is always a need for confined research, i.e. controlled and fundamental experiments such as pot and lab experiments or modelling exercises with the main goal of increasing fundamental and mechanistic insight in processes that affect (and can be used to manipulate) $\mathrm{P}$ availability in soil and uptake of $\mathrm{P}$ by grass. The controlled conditions of a 
laboratory or a greenhouse allow for the isolation of factors of interest and ensure that unwanted variables do not play into the results. These experiments can often be designed to have a relatively simple setup. Extrapolation of the obtained results to a more practical scale, however, is very difficult if not impossible.

2. The principles and mechanisms investigated in the confined settings have to be studied and tested in a field trial context under semi-controlled conditions, to see whether similar results are obtained and hypotheses hold. In these settings, other geospatial and temporal factors such as the weather but also field elevation or slope might play a role. Long term research farms like experimental farm 'De Marke' (Aarts, 2000; Verloop et al., 2010), which act as field sites, provide a controlled environment that is excellent for this step. These sites could also provide suitable locations to run mesocosm or lysimeter trials on the effect of different earthworm species on P uptake of grass under field conditions. Hannah Vos is currently running such an experiment at experimental fields of Wageningen University. Additionally, for farms like 'De Marke', large amounts of data, for example on soil characteristics or nutrient flows on the farm, are usually available from previous experiments.

3. If the results from the confined research and from field trials are consistent, they can be translated into management strategies to be adopted by farmers. At this point, on-farm research is vital to confirm the results from the previous steps and discover if the previously obtained results are applicable to a broader set of parameters (different soil types, locations, management, etc.). In this step, it is thus important to find a broad subset of farms that are willing to collaborate in the final research step. A network of farmers that work together with researchers, like the 'Cows \& Opportunities' network (Koeien \& Kansen; Oenema et al., 2001, 2011) in the Netherlands would be ideal to involve in this last step.

The research in my thesis has mostly focussed on the first step. Drawing far-reaching conclusions on management practices that improve $P$ utilisation from the results presented in this thesis is therefore premature. The next step is to design field trials to test whether the results presented here are sustained under less controlled conditions. Throughout this chapter, I have given examples on the directions these efforts should take. In general, the results and discovered mechanisms should be verified under a range of soils and with a diversity of grassland species, as is common in agricultural grasslands. 


\section{References}

Aarts, H.F.M., 2000. Resource management in a "De Marke" dairy farming system. Wageningen University, Wageningen, the Netherlands.

Ahern, C.R., Baker, D.E., Aitken, R.L., 1995. Models for relating pH measurements in water and calcium chloride for a wide range of $\mathrm{pH}$, soil types and depths. Plant Soil 171, 47-52. doi:10.1007/BF00009563

Aira, M., McNamara, N.P., Piearce, T.G., Domínguez, J., 2008. Microbial communities of Lumbricus terrestris L. middens: structure, activity, and changes through time in relation to earthworm presence. J. Soils Sediments 9, 54-61. doi:10.1007/s11368-008-0055-8

Alexandratos, N., Bruinsma, J., 2012. World agriculture towards 2030/2050: The 2012 revision. Rome.

Allaire, S.E., Van Bochove, E., Denault, J.-T., Dadfar, H., Thériault, G., Charles, A., De Jong, R., 2011. Preferential pathways of phosphorus movement from agricultural land to water bodies in the Canadian Great Lakes basin: A predictive tool. Can. J. Soil Sci. 91, 361-374. doi:10.4141/ cjss09121

Alvim, M.J., Carvalho, M.M., Botrel, M. de A., 1992. NPK fertilization to establish setaria on a lowland soil (in Portuguese). Pesqui. Agropecuária Bras. 27, 79-85.

Annaheim, K.E., Doolette, A.L., Smernik, R.J., Mayer, J., Oberson, A., Frossard, E., Bünemann, E.K., 2015. Long-term addition of organic fertilizers has little effect on soil organic phosphorus as characterized by ${ }^{31} \mathrm{P}$ NMR spectroscopy and enzyme additions. Geoderma 257-258, 67-77. doi:10.1016/j.geoderma.2015.01.014

Anonymous, 2013. Fifth Dutch action programme nitrate directive (2014-2017) (in Dutch).

Antelo, J., Arce, F., Avena, M., Fiol, S., López, R., Macías, F., 2007. Adsorption of a soil humic acid at the surface of goethite and its competitive interaction with phosphate. Geoderma 138, 12-19. doi:10.1016/J.GEODERMA.2006.10.011

Atul-Nayyar, Hamel, C., Forge, T., Selles, F., Jefferson, P.G., Hanson, K., Germida, J., 2008. Arbuscular mycorrhizal fungi and nematodes are involved in negative feedback on a dual culture of alfalfa and Russian wildrye. Appl. Soil Ecol. 40, 30-36. doi:10.1016/j.apsoil.2008.03.004 
Aydin, I., Uzun, F., 2005. Nitrogen and phosphorus fertilization of rangelands affects yield, forage quality and the botanical composition. Eur. J. Agron. 23, 8-14. doi:10.1016/j.eja.2004.08.001

Bai, Z., Li, H., Yang, X., Zhou, B., Shi, X., Wang, B., Li, D., Shen, J., Chen, Q., Qin, W., Oenema, O., Zhang, F., 2013. The critical soil P levels for crop yield, soil fertility and environmental safety in different soil types. Plant Soil 372, 27-37. doi:10.1007/s11104-013-1696-y

Bai, Z.H., Ma, L., Oenema, O., Chen, Q., Zhang, F.S., 2013. Nitrogen and phosphorus use efficiencies in dairy production in China. J. Environ. Qual. 42, 990-1001. doi:10.2134/jeq2012.0464

Balabanli, C., Albayrak, S., Yuksel, O., 2010. Effects of nitrogen, phosphorus and potassium fertilization on the quality and yield of native rangeland. Turkish J. F. Crop. 15, 164-168.

Barnett, G.M., 1994. Phosphorus forms in animal manure. Bioresour. Technol. 49, 139-147. doi:10.1016/0960-8524(94)90077-9

Barois, I., Lavelle, P., 1986. Changes in respiration rate and some physicochemical properties of a tropical soil during transit through Pontoscolex corethrurus (glossoscolecidae, oligochaeta). Soil Biol. Biochem. 18, 539-541. doi:10.1016/0038-0717(86)90012-X

Barrow, N.J., 1983. On the reversibility of phosphate sorption by soils. J. Soil Sci. 34, 751-758. doi:10.1111/j.1365-2389.1983.tb01069.x

Barrow, N.J., 2017. The effects of pH on phosphate uptake from the soil. Plant Soil 410, 401-410. doi:10.1007/s11104-016-3008-9

Barrow, N.J., 1983. A mechanistic model for describing the sorption and desorption of phosphate by soil. Eur. J. Soil Sci. 34, 733-750. doi:10.1111/ejss.12198

Basker, A., Kirkman, J.H., Macgregor, A.N., 1994. Changes in potassium availability and other soil properties due to soil ingestion by earthworms. Biol. Fertil. Soils 17, 154-158. doi:10.1007/BF00337748

Beek, J., 1979. Phosphate retention by soil in relation to waste disposal. Wageningen University.

Belarmino, M.C.J., Pinto, J.C., Rocha, G.P., Furtini Neto, A.E., De Morais, A.R., 2003. Tanzania grass tiller height and dry matter production under different doses of simple superphosphate and ammonium sulfate (in Portuguese). Ciência e Agrotecnologia 27, 879-885. 
Bernard, L., Chapuis-Lardy, L., Razafimbelo, T., Razafindrakoto, M., Pablo, A.-L., Legname, E., Poulain, J., Brüls, T., O’Donohue, M., Brauman, A., Chotte, J.-L., Blanchart, E., 2012. Endogeic earthworms shape bacterial functional communities and affect organic matter mineralization in a tropical soil. ISME J. 6, 213-22. doi:10.1038/ismej.2011.87

Beusen, A.H.W., Bouwman, A.F., Van Beek, L.P.H., Mogollón, J.M., Middelburg, J.J., 2016. Global riverine $\mathrm{N}$ and $\mathrm{P}$ transport to ocean increased during the 20th century despite increased retention along the aquatic continuum. Biogeosciences 13, 2441-2451. doi:10.5194/ bg-13-2441-2016

Bieleski, R.L., 1973. Phosphate pools, phosphate transport, and phosphate availability. Annu. Rev. Plant Physiol. 24, 225-252. doi:10.1146/annurev.pp.24.060173.001301

Blouin, M., Hodson, M.E., Delgado, E.A., Baker, G., Brussaard, L., Butt, K.R., Dai, J., Dendooven, L., Peres, G., Tondoh, J.E., Cluzeau, D., Brun, J.-J., 2013. A review of earthworm impact on soil function and ecosystem services. Eur. J. Soil Sci. 64, 161-182. doi:10.1111/ejss.12025

Bouché, M.B., 1977. Stratégies lombriciennes, in: Lohm, U., Persson, T. (Eds.), Soil Organisms as Components of Ecosystems. Ecological Bulletin 25, Stockholm, Sweden, pp. 122-132.

Bouma, T.J., Nielsen, K.L., Koutstaal, B., 2000. Sample preparation and scanning protocol for computerised analysis of root length and diameter. Plant Soil 218, 185-196. doi:10.1023/A:1014905104017

Bouwman, L., Goldewijk, K.K., Van Der Hoek, K.W., Beusen, A.H.W., Van Vuuren, D.P., Willems, J., Rufino, M.C., Stehfest, E., 2013. Exploring global changes in nitrogen and phosphorus cycles in agriculture induced by livestock production over the 1900-2050 period. Proc. Natl. Acad. Sci. U. S. A. 110, 20882-20887. doi:10.1073/pnas.1012878108

Bray, R.H., Kurtz, L.T., 1945. Determination of total, organic, and available forms of phosphorus in soils. Soil Sci. 59, 39-46.

Briones, M.J.I., Ostle, N.J., Piearce, T.G., 2008. Stable isotopes reveal that the calciferous gland of earthworms is a CO2-fixing organ. Soil Biol. Biochem. 40, 554-557. doi:10.1016/ j.soilbio.2007.09.012

Briones, M.J.I., Schmidt, O., 2017. Conventional tillage decreases the abundance and biomass of earthworms and alters their community structure in a global meta-analysis. Glob. Chang. Biol. 23, 4396-4419. doi:10.1111/gcb.13744 
Brown, G.G., Edwards, C.A., Brussaard, L., 2004. How earthworms affect plant growth: burrowing into the mechanisms, in: Edwards, C.A. (Ed.), Earthworm Ecology. CRC Press, pp. 13-49.

Butler, T.J., Muir, J.P., 2006. Dairy manure compost improves soil and increases tall wheatgrass yield. Agron. J. 98, 1090-1096. doi:10.2134/agronj2005.0348

Calvière, I., Duru, M., 1999. The effect of $\mathrm{N}$ and $\mathrm{P}$ fertilizer application and botanical composition on the leaf/stem ratio patterns in spring in Pyrenean meadows. Grass Forage Sci. 54, 255-266. doi:10.1046/j.1365-2494.1999.00178.x

Caraballo, A., Morillo, D.E., Faría-Mármol, J., McDowell, L.R., 1997. Frequency of defoliation and nitrogen and phosphorus fertilization on Andropogon gayanus Kunth. I. Yield, crude protein content, and in vitro digestibility. Commun. Soil Sci. Plant Anal. 28, 823-831. doi:10.1080/00103629709369833

Caradus, J.R., 1980. Distinguishing between grass and legume species for efficiency of phosphorus use. New Zeal. J. Agric. Res. 23, 75-81. doi:10.1080/00288233.1980.10417847

Carpenter, S.R., Bennett, E.M., 2011. Reconsideration of the planetary boundary for phosphorus. Environ. Res. Lett. 6. doi:10.1088/1748-9326/6/1/014009

Carpenter, S.R., Caraco, N.F., Correll, D.L., W.Howarth, R., Sharpley, A.N., Smith, V.H., 1998. Nonpoint pollution of surface waters with phosphorus and nitrogen. Ecol. Appl. 8, 559-568. doi:10.1890/1051-0761(1998)008[0559:NPOSWW]2.0.CO;2

Case, S.D.C., Oelofse, M., Hou, Y., Oenema, O., Jensen, L.S., 2017. Farmer perceptions and use of organic waste products as fertilisers - A survey study of potential benefits and barriers. Agric. Syst. 151, 84-95. doi:10.1016/j.agsy.2016.11.012

Cayley, J.W.D., Hannah, M.C., Kearney, G.A., Clark, S.G., 1998. Effects of phosphorus fertiliser and rate of stocking on the seasonal pasture production of perennial tyegrass-subterranean clover pasture. Aust. J. Agric. Res. 49, 233-248.

CDM, 2018. Advisory report on manure treatment percentages 2018 (in Dutch). Wageningen, the Netherlands.

Cela, S., Ketterings, Q.M., Czymmek, K., Soberon, M.A., Rasmussen, C.N., 2015. Long-term trends of nitrogen and phosphorus mass balances on New York State dairy farms. J. Dairy Sci. 98, 7052-7070. doi:10.3168/jds.2015-9776 
Cela, S., Ketterings, Q.M., Czymmek, K., Soberon, M.A., Rasmussen, C.N., 2014. Characterization of nitrogen, phosphorus, and potassium mass balances of dairy farms in New York State. J. Dairy Sci. 97, 7614-32. doi:10.3168/jds.2014-8467

Celi, L., De Luca, G., Barberis, E., 2003. Effects of interaction of organic and inorganic P with ferrihydrite and kaolinite-iron oxide systems on iron release. Soil Sci. 168, 479-488. doi:10.1097/00010694-200307000-00003

Celi, L., Lamacchia, S., Marsan, F.A., Barberis, E., 1999. Interaction of inositol hexaphosphate on clays: Adsorption and charging phenomena. Soil Sci. 164, 574-585.

Ceulemans, T., Bodé, S., Bollyn, J., Harpole, S., Coorevits, K., Peeters, G., Van Acker, K., Smolders, E., Boeckx, P., Honnay, O., 2017. Phosphorus resource partitioning shapes phosphorus acquisition and plant species abundance in grasslands. Nat. Plants 3. doi:10.1038/nplants.2016.224

Chapuis-Lardy, L., Brossard, M., Lavelle, P., Schouller, E., 1998. Phosphorus transformations in a ferralsol through ingestion by Pantoscolex corethrurus, a geophagous earthworm. Eur. J. Soil Biol. 34, 61-67. doi:10.1016/S1164-5563(99)90002-X

Chapuis-Lardy, L., Ramiandrisoa, R.S., Randriamanantsoa, L., Morel, C., Rabeharisoa, L., Blanchart, E., 2009. Modification of P availability by endogeic earthworms (Glossoscolecidae) in Ferralsols of the Malagasy Highlands. Biol. Fertil. Soils 45, 415-422. doi:10.1007/s00374-008-0350-y

Chen, S., Liang, Z., Webster, R., Zhang, G., Zhou, Y., Teng, H., Hu, B., Arrouays, D., Shi, Z., 2019. A high-resolution map of soil pH in China made by hybrid modelling of sparse soil data and environmental covariates and its implications for pollution. Sci. Total Environ. 655, 273-283. doi:10.1016/j.scitotenv.2018.11.230

Cluzeau, D., Guernion, M., Chaussod, R., Martin-Laurent, F., Villenave, C., Cortet, J., Ruiz-Camacho,N., Pernin, C., Mateille, T., Philippot, L., Bellido, A., Rougé, L., Arrouays, D., Bispo, A., Pérès, G., 2012. Integration of biodiversity in soil quality monitoring: Baselines for microbial and soil fauna parameters for different land-use types. Eur. J. Soil Biol. 49, 63-72. doi:10.1016/j.ejsobi.2011.11.003

Coates, D.B., 1994. The effect of phosphorus as fertiliser or supplement on pasture and cattle productivity in the semi-arid tropics of north Queensland. Trop. Grasslands 28, 90-108. 
Coates, D.B., Kerridge, P.C., Miller, C.P., Winter, W.H., 1990. Phosphorus and beef production in northern Australia. 7. The effect of phosphorus on the composition, yield and quality of legume-based pasture and their relation to animal production. Trop. Grasslands 24, 209-220.

Colwell, J.D., 1963. The estimation of the phosphorus fertilizer requirements of wheat in southern New South Wales by soil analysis. Aust. J. Exp. Agric. 3, 190-198. doi:10.1071/EA9630190

Commissie Bemesting Grasland en Voedergewassen, 2012. Bemestingsadvies (in Dutch). Lelystad, Netherlands.

Condron, L.M., Turner, B.L., Cade-Menun, B.J., 2005. Chemistry and dynamics of soil organic phosphrus, in: Sims, J.T., Sharpley, A.N. (Eds.), Phosphorus: Agriculture and the Environment. ASA/CSSA/SSSA, Madison, Wisconsin, United States of America, pp. 87-121.

Čop, J., Lavrenac, A., Košmelj, K., 2009a. Morphological development and nutritive value of herbage in five temperate grass species during primary growth: analysis of time dynamics. Grass Forage Sci. 64, 122-131. doi:10.1111/j.1365-2494.2008.00676.x

Čop, J., Vidrih, M., Hacin, J., 2009b. Influence of cutting regime and fertilizer application on the botanical composition, yield and nutritive value of herbage of wet grasslands in Central Europe. Grass Forage Sci. 64, 454-465. doi:10.1111/j.1365-2494.2009.00713.x

Cordell, D., Drangert, J.-O., White, S., 2009. The story of phosphorus: global food security and food for thought. Glob. Environ. Chang. 19, 292-305. doi:10.1016/j.gloenvcha.2008.10.009

Cordell, D., White, S., 2011. Peak phosphorus: Clarifying the key issues of a vigorous debate about long-term phosphorus security. Sustainability 3, 2027-2049. doi:10.3390/su3102027

Correll, D.L., 1998. The role of phosphorus in the eutrophication of receiving waters: A review. J. Environ. Qual. 27, 261-266. doi:10.2134/jeq1998.00472425002700020004x

Cortois, R., Schröder-Georgi, T., Weigelt, A., Van der Putten, W.H., De Deyn, G.B., 2016. Plant-soil feedbacks: role of plant functional group and plant traits. J. Ecol. 104, 1608-1617. doi:10.1111/1365-2745.12643

Coulis, M., Bernard, L., Gérard, F., Hinsinger, P., Plassard, C., Villeneuve, M., Blanchart, E., 2014. Endogeic earthworms modify soil phosphorus, plant growth and interactions in a legume-cereal intercrop. Plant Soil 379, 149-160. doi:10.1007/s11104-014-2046-4 
Covacevich, F., Marino, M.A., Echeverría, H.E., 2006. The phosphorus source determines the arbuscular mycorrhizal potential and the native mycorrhizal colonization of tall fescue and wheatgrass. Eur. J. Soil Biol. 42, 127-138. doi:10.1016/j.ejsobi.2005.12.002

Crush, J.R., Easton, H.S., Waller, J.E., Hume, D.E., Faville, M.J., 2007. Genotypic variation in patterns of root distribution, nitrate interception and response to moisture stress of a perennial ryegrass (Lolium perenne L.) mapping population. Grass Forage Sci. 62, 265-273.

Crush, J.R., Waller, J.E., Care, D.A., 2005. Root distribution and nitrate interception in eleven temperate forage grasses. Grass Forage Sci. 60, 385-392. doi:10.1111/j. $1365-2494.2005 .00488 . x$

Csathó, P., Radimszky, L., 2009. Two worlds within EU27: sharp contrasts in organic and mineral nitrogen-phosphorus use, nitrogen-phosphorus balances, and soil phosphorus status: widening and deepening gap between western and central Europe. Commun. Soil Sci. Plant Anal. 40, 999-1019. doi:10.1080/00103620802693151

Curry, J.P., 2004. Factors affecting the abundance of earthworms in soils, in: Edwards, C.A. (Ed.), Earthworm Ecology. CRC Press LLC, Boca Raton, FL, USA, pp. 91-113.

Curry, J.P., Schmidt, O., 2007. The feeding ecology of earthworms - A review. Pedobiologia (Jena). 50, 463-477. doi:10.1016/j.pedobi.2006.09.001

Curtis, P.S., Wang, X., 1998. A meta-analysis of elevated CO2 effects on woody plant mass, form, and physiology. Oecologia 113, 299-313. doi:10.1007/s004420050381

Dalby, P.R., Baker, G.H., Smith, S.E., 1996. "Filter paper method" to remove soil from earthworm intestines and to standardise the water content of earthworm tissue. Soil Biol. Biochem. 28, 685-687. doi:10.1016/0038-0717(95)00157-3

Darwin, C., 1881. The formation of vegetable mould, through the action of worms, with observations on their habits. John Murray, London.

Davidson, E.A., Reis de Carvalho, C.J., Vieira, I.C.G., Figueiredo, R. de O., Moutinho, P., Ishida, F.Y., Primo dos Santos, M.T., Guerrero, J.B., Kalif, K., Sabá, R.T., 2004. Nitrogen and phosphorus limitation of biomass growth in a tropical secondary forest. Ecol. Appl. 14, 150-163. 
Davison, T.M., Orr, W.N., Silver, B.A., Walker, R.G., Duncalfe, F., 1997. Phosphorus fertilizer for nitrogen fertilized dairy pastures. 1. Long term effects on pasture, diet and soil. J. Agric. Sci. 129, 205-217. doi:10.1017/S0021859697004644

De Vries, M.P.C., 1980. How reliable are results of pot experiments? Commun. Soil Sci. Plant Anal. 11, 895-902. doi:10.1080/00103628009367090

Delin, S., 2016. Fertilizer value of phosphorus in different residues. Soil Use Manag. 32, 17-26. doi:10.1111/sum.12227

Deru, J., Schilder, H., Van der Schoot, J.R., Van Eekeren, N., 2014. Genetic differences in root mass of Lolium perenne varieties under field conditions. Euphytica 199, 223-232. doi:10.1007/ s10681-014-1129-x

Deru, J., Van Eekeren, N., De Boer, H., 2000. Rooting density of three grass species and eight Lolium perenne cultivars. Grassl. Sci. Eur. 17, 604-606.

Devliegher, W., Verstraete, W., 1997. Microorganisms and soil physico-chemical conditions in the drilosphere of Lumbricus terrestris. Soil Biol. Biochem. 29, 1721-1729. doi:10.1016/ S0038-0717(97)00068-0

Didden, W.A.M., 2001. Earthworm communities in grasslands and horticultural soils. Biol. Fertil. Soils 33, 111-117. doi:10.1007/s003740000297

Dirks, B., Scheffer, H., 1930. Der Kohlensäure-Bikarbonatauszug und der Wasserauszug als Grundlage zur Ermittlund der Phosphorsäurebedürftigkeit der Böden. Landwirtschaftl. Jahrbücher 71, 73-99.

Don, A., Steinberg, B., Schöning, I., Pritsch, K., Joschko, M., Gleixner, G., Schulze, E.D., 2008. Organic carbon sequestration in earthworm burrows. Soil Biol. Biochem. 40, 1803-1812. doi:10.1016/j.soilbio.2008.03.003

Dou, Z., Ramberg, C.F., Toth, J.D., Wang, Y., Sharpley, A.N., Boyd, S.E., Chen, C.R., Williams, D., $\mathrm{Xu}, \mathrm{Z} . \mathrm{H}$., 2009. Phosphorus speciation and sorption-desorption characteristics in heavily manured soils. Soil Sci. Soc. Am. J. 73, 93-101. doi:10.2136/sssaj2007.0416

Dou, Z., Toth, J.D., Galligan, D.T., Ramberg, C.F., Ferguson, J.D., 2000. Laboratory procedures for characterizing manure phosphorus. J. Environ. Qual. 29, 508-514. doi:10.2134/ jeq2000.00472425002900020019x 
Doube, B.M., Schmidt, O., Killham, K., Correll, R., 1997. Influence of mineral soil on the palatability of organic matter for lumbricid earthworms: A simple food preference study. Soil Biol. Biochem. 29, 569-575. doi:10.1016/50038-0717(96)00032-6

Drake, H.L., Horn, M.A., 2006. Earthworms as a transient heaven for terrestrial denitrifying microbes: A review. Eng. Life Sci. 6, 261-265. doi:10.1002/elsc.200620126

Egnér, H., Riehm, H., Domingo, W.R., 1960. Untersuchungen über die chemische Bodenanalyse als Grundlage für die Beurteilung des Nährstoffzustandes der Böden. II. Chemische Extraktionsmethoden zur Phosphor-und Kaliumbestimmung. K. Lantbrukshögskolans Ann. 26, 199-215.

Eissenstat, D.M., 1992. Costs and benefits of constructing roots of small diameter. J. Plant Nutr. 15, 763-782. doi:10.1080/01904169209364361

Elberse, W.T., Běrendse, F., 1993. A comparative study of the growth and morphology of eight grass species from habitats with different nutrient availabilities. Funct. Ecol. 7, 223-229.

Erkovan, H.I., Güllap, M.K., Daşçi, M., Koç, A., 2010. Effects of phosphorus fertilizer and phosphorus solubilizing bacteria applications on clover dominant meadow: I. Hay yield and botanical composition. Turkish J. F. Crop. 15, 12-17.

Eurostat, 2016. Farm structure statistics [WWW Document]. URL http://ec.europa.eu/eurostat/ statistics-explained/index.php/farm_structure_statistics (accessed 2.6.17).

FAO, 2017. Statistical database of the Food and Agriculture Organization of the United Nations.

FAO, 2006. Guidelines for soil description, Fourth ed. Food and Agriculture Organisation of the United Nations, Rome, Italy.

Feller, C., Brown, G.G., Blanchart, E., Deleporte, P., Chernyanskii, S.S., 2003. Charles Darwin, earthworms and the natural sciences: various lessons from past to future. Agric. Ecosyst. Environ. 99, 29-49. doi:10.1016/S0167-8809(03)00143-9

Foged, H.F., Flotats, X., Blasi, A.B., Palatsi, J., Magri, A., Schelde, K.M., 2011. Inventory of manure processing activities in Europe. 
Foley, J.A., Ramankutty, N., Brauman, K.A., Cassidy, E.S., Gerber, J.S., Johnston, M., Mueller, N.D., O'Connell, C., Ray, D.K., West, P.C., Balzer, C., Bennett, E.M., Carpenter, S.R., Hill, J., Monfreda, C., Polasky, S., Rockstrom, J., Sheehan, J., Siebert, S., Tilman, D., Zaks, D.P.M., 2011. Solutions for a cultivated planet. Nature 478, 337-342.

Fransen, B., Blijjenberg, J., de Kroon, H., 1999. Root morphological and physiological plasticity of perennial grass species and the exploitation of spatial and temporal heterogeneous nutrient patches. Plant Soil 211, 179-189.

Freese, D., Van der Zee, S.E.A.T.M., Van Riemsdijk, W.H., 1992. Comparison of different models for phosphate sorption as a function of the iron and aluminium oxides of soils. J. Soil Sci. 43, 729-738. doi:10.1111/j.1365-2389.1992.tb00172.x

Freschet, G.T., Swart, E.M., Cornelissen, J.H.C., 2015. Integrated plant phenotypic responses to contrasting above- and below-ground resources: Key roles of specific leaf area and root mass fraction. New Phytol. 206, 1247-1260. doi:10.1111/nph.13352

Fujita, Y., Robroek, B.J.M., de Ruiter, P.C., Heil, G.W., Wassen, M.J., 2010. Increased N affects $\mathrm{P}$ uptake of eight grassland species: The role of root surface phosphatase activity. Oikos 119, 1665-1673. doi:10.1111/j.1600-0706.2010.18427.x

García-Montero, L.G., Valverde-Asenjo, I., Grande-Ortíz, M.A., Menta, C., Hernando, I., 2013. Impact of earthworm casts on soil pH and calcium carbonate in black truffle burns. Agrofor. Syst. 87, 815-826. doi:10.1007/s10457-013-9598-9

George, T.S., Giles, C.D., Menezes-Blackburn, D., Condron, L.M., Gama-Rodrigues, A.C., Jaisi, D., Lang, F., Neal, A.L., Stutter, M.I., Almeida, D.S., Bol, R., Cabugao, K.G., Celi, L., Cotner, J.B., Feng, G., Goll, D.S., Hallama, M., Krueger, J., Plassard, C., Rosling, A., Darch, T., Fraser, T., Giesler, R., Richardson, A.E., Tamburini, F., Shand, C.A., Lumsdon, D.G., Zhang, H., Blackwell, M.S.A., Wearing, C., Mezeli, M.M., Almås, Å.R., Audette, Y., Bertrand, I., Beyhaut, E., Boitt, G., Bradshaw, N., Brearley, C.A., Bruulsema, T.W., Ciais, P., Cozzolino, V., Duran, P.C., Mora, M.L., de Menezes, A.B., Dodd, R.J., Dunfield, K., Engl, C., Frazão, J.J., Garland, G., González Jiménez, J.L., Graca, J., Granger, S.J., Harrison, A.F., Heuck, C., Hou, E.Q., Johnes, P.J., Kaiser, K., Kjær, H.A., Klumpp, E., Lamb, A.L., Macintosh, K.A., Mackay, E.B., McGrath, J., McIntyre, C., McLaren, T., Mészáros, E., Missong, A., Mooshammer, M., Negrón, C.P., Nelson, L.A., Pfahler, V., Poblete-Grant, P., Randall, M., Seguel, A., Seth, K., Smith, A.C., Smits, M.M., Sobarzo, J.A., Spohn, M., Tawaraya, K., Tibbett, M., Voroney, P., Wallander, H., Wang, L., Wasaki, J., Haygarth, P.M., 2018. Organic phosphorus in the terrestrial environment: a perspective on the state of the art and future priorities. Plant Soil 427, 191-208. doi:10.1007/s11104-017-3391-x 
Gérard, F., 2016. Clay minerals, iron/aluminum oxides, and their contribution to phosphate sorption in soils - a myth revisited. Geoderma 262, 213-226. doi:10.1016/j.geoderma.2015.08.036

Gerke, J., 2010. Humic (organic matter)-Al(Fe)-phosphate complexes: An underestimated phosphate form in soils and source of plant-available phosphate. Soil Sci. 175, 417-425. doi:10.1097/ SS.0b013e3181f1b4dd

Giannopoulos, G., Van Groenigen, J.W., Pulleman, M.M., 2011. Earthworm-induced N2O emissions in a sandy soil with surface-applied crop residues. Pedobiologia (Jena). 54, S103-S111. doi:10.1016/j.pedobi.2011.09.005

Giovannetti, M., Mosse, B., 1980. An evaluation of techniques for measuring vesicular arbuscular mycorrhizal infection in roots. New Phytol. 84, 489-500.

Godfray, H.C.J., Beddington, J.R., Crute, I.R., Haddad, L., Lawrence, D., Muir, J.F., Pretty, J., Robinson, S., Thomas, S.M., Toulmin, C., 2010. Food security: The challenge of feeding 9 billion people. Science (80-. ). 327, 812-818.

Gordon, A.M., Tallas, M., Van Cleve, K., 1987. Soil incubations in polyethylene bags: effect of bag thickness and temperature on nitrogen transformations and $\mathrm{CO} 2$ permeability. Can. J. Soil Sci. 67, 65-76. doi:10.4141/cjss87-006

Grace, J.B., 2006. Structural equation modeling and natural systems. Cambridge University Press, Cambridge, UK.

Greenway, H., Armstrong, W., Colmer, T.D., 2006. Conditions leading to high CO2 ( $>5 \mathrm{kPa}$ ) in waterlogged-flooded soils and possible effects on root growth and metabolism. Ann. Bot. 98, 9-32. doi:10.1093/aob/mcl076

Griffin, R.A., Jurinak, J.J., 1973. Estimation of activity coefficients from the electrical conductivity of natural aquatic systems and soil extracts. Soil Sci. 116, 26-30.

Groenenberg, J.E., Lofts, S., 2014. The use of assemblage models to describe trace element partitioning, speciation, and fate: A review. Environ. Toxicol. Chem. 33, 2181-2196. doi:10.1002/etc. 2642

Guretzky, J., Kering, M., Mosali, J., Funderburg, E., Biermacher, J.T., 2010. Fertilizer rate effects on forage yield stability and nutrient uptake of midland Bermudagrass. J. Plant Nutr. 33, 1819-1834. doi:10.1080/01904167.2010.503831 
Güsewell, S., 2004. N:P ratios in terrestrial plants: Variation and functional significance. New Phytol. 164, 243-266. doi:10.1111/j.1469-8137.2004.01192.x

Ha, S., Tran, L.-S., 2014. Understanding plant responses to phosphorus starvation for improvement of plant tolerance to phosphorus deficiency by biotechnological approaches. Crit. Rev. Biotechnol. 34, 16-30. doi:10.3109/07388551.2013.783549

Haby, V.A., 2002. Soil fertility and management of acid coastal plain soils for crop production. Commun. Soil Sci. Plant Anal. 33, 2497-2520. doi:10.1081/CSS-120014462

Haling, R.E., Simpson, R.J., Culvenor, R.A., Lambers, H., Richardson, A.E., 2011. Effect of soil acidity, soil strength and macropores on root growth and morphology of perennial grass species differing in acid-soil resistance. Plant, Cell Environ. 34, 444-456. doi:10.1111/j. 1365-3040.2010.02254.x

Hamel, S.C., Heckman, J.R., 2006. Predicting need for phosphorus fertilizer by soil testing during seeding of cool season grasses. HortScience 41, 1690-1697.

Harrison, A.F., 1987. Soil organic phosphorus: a review of world literature. CAB International, Wallingford, U.K.

Hawkesford, M., Horst, W., Kichey, T., Lambers, H., Schjoerring, J., Møller, I.S., White, P., 2012. Functions of macronutrients, in: Marschner, P. (Ed.), Mineral Nutrition of Higher Plants. Academic Press, pp. 135-189. doi:10.1016/B978-0-12-384905-2.00006-6

Hayes, J.E., Richardson, A.E., Simpson, R.J., 1999. Phytase and acid phosphatase activities in extracts from roots of temperate pasture grass and legume seedlings. Aust. J. Plant Physiol. 26, 801-809.

Haynes, R.J., Williams, P.H., 1992. Long-term effect of superphosphate on accumulation of soil phosphorus and exchangeable cations on a grazed, irrigated pasture site. Plant Soil 142, 123-133. doi:10.1007/BF00010182

Hedges, L. V., Gurevitch, J., Curtis, P.S., 1999. The meta-analysis of response ratios in experimental ecology. Ecology 80, 1150-1156.

Hedges, L. V., Olkin, I., 1985. Statistical methods for meta-analysis, 1st ed. ed. Academic Press, London, UK. 
Heffer, P., Gruère, A., Roberts, T., 2017. Assessment of fertilizer use by crop at the global level.

Hejcman, M., Strnad, L., Hejcmanova, P., Pavlů, V., 2012. Response of plant species composition, biomass production and biomass chemical properties to high N, P and $\mathrm{K}$ application rates in Dactylis glomerata- and Festuca arundinacea-dominated grassland. Grass Forage Sci. 67, 488-506. doi:10.1111/j.1365-2494.2012.00864.x

Hendricksen, R.E., Ternouth, J.H., Punter, L.D., 1994. Seasonal nutrient intake and phosphorus kinetics of grazing steers in northern Australia. Aust. J. Agric. Res. 45, 1817-1829.

Hengl, T., Leenaars, J.G.B., Shepherd, K.D., Walsh, M.G., Heuvelink, G.B.M., Mamo, T., Tilahun, H., Berkhout, E., Cooper, M., Fegraus, E., Wheeler, I., Kwabena, N.A., 2017a. Soil nutrient maps of Sub-Saharan Africa: assessment of soil nutrient content at $250 \mathrm{~m}$ spatial resolution using machine learning. Nutr. Cycl. Agroecosystems 109, 77-102. doi:10.1007/s10705-017-9870-x

Hengl, T., Mendes de Jesus, J., Heuvelink, G.B.M., Ruiperez Gonzalez, M., Kilibarda, M., Blagotić, A., Shangguan, W., Wright, M.N., Geng, X., Bauer-Marschallinger, B., Guevara, M.A., Vargas, R., MacMillan, R.A., Batjes, N.H., Leenaars, J.G.B., Ribeiro, E., Wheeler, I., Mantel, S., Kempen, B., 2017b. SoilGrids250m: Global gridded soil information based on machine learning. PLoS One 12.

Hesterberg, D., 2010. Chapter 11 - Macroscale chemical properties and X-ray absorption spectroscopy of soil phosphorus, in: Developments in Soil Science. pp. 313-356. doi:10.1016/S0166-2481(10)34011-6

Hiemstra, T., 2013. Surface and mineral structure of ferrihydrite. Geochim. Cosmochim. Acta 105, 316-325. doi:10.1016/j.gca.2012.12.002

Hiemstra, T., Antelo, J., Rahnemaie, R., Van Riemsdijk, W.H., 2010a. Nanoparticles in natural systems I: the effective reactive surface area of the natural oxide fraction in field samples. Geochim. Cosmochim. Acta 74, 41-58. doi:10.1016/j.gca.2009.10.018

Hiemstra, T., Antelo, J., Van Rotterdam, A.M.D., Van Riemsdijk, W.H., 2010b. Nanoparticles in natural systems II: the natural oxide fraction at interaction with natural organic matter and phosphate. Geochim. Cosmochim. Acta 74, 59-69. doi:10.1016/j.gca.2009.10.019 
Hiemstra, T., Mia, S., Duhaut, P.-B., Molleman, B., 2013. Natural and pyrogenic humic acids at goethite and natural oxide surfaces interacting with phosphate. Environ. Sci. Technol. 47, 9182-9189. doi:10.1021/es400997n

Hiemstra, T., Van Riemsdijk, W.H., 2009. A surface structural model for ferrihydrite I: Sites related to primary charge, molar mass, and mass density. Geochim. Cosmochim. Acta 73, 4423-4436. doi:10.1016/j.gca.2009.04.032

Hiemstra, T., Van Riemsdijk, W.H., 1996. A surface structural approach to ion adsorption: the Charge Distribution (CD) model. J. Colloid Interface Sci. 179, 488-508. doi:10.1006/ jcis. 1996.0242

Hiemstra, T., Van Riemsdijk, W.H., Bolt, G.H., 1989. Multisite proton adsorption modeling at the solid/solution interface of (hydr)oxides: a new approach. J. Colloid Interface Sci. 133, 91-104. doi:10.1016/0021-9797(89)90284-1

Hiemstra, T., Venema, P., Van Riemsdijk, W.H., 1996. Intrinsic proton affinity of reactive surface groups of metal (hydr)oxides: the bond valence principle. J. Colloid Interface Sci. 184, 680-692. doi:10.1006/jcis.1996.0666

Hiemstra, T., Zhao, W., 2016. Reactivity of ferrihydrite and ferritin in relation to surface structure, size, and nanoparticle formation studied for phosphate and arsenate. Environ. Sci. Nano 3, 1265-1279. doi:10.1039/c6en00061d

Hill, J.O., Simpson, R.J., Moore, A.D., Chapman, D.F., 2006. Morphology and response of roots of pasture species to phosphorus and nitrogen nutrition. Plant Soil 286, 7-19. doi:10.1007/s11104-006-0014-3

Hill, J.O., Simpson, R.J., Ryan, M.H., Chapman, D.F., 2010. Root hair morphology and mycorrhizal colonisation of pasture species in response to phosphorus and nitrogen nutrition. Crop Pasture Sci. 61, 122-131. doi:10.1071/CP09217

Hill, J.O., Simpson, R.J., Wood, J.T., Moore, A.D., Chapman, D.F., 2005. The phosphorus and nitrogen requirements of temperate pasture species and their influence on grassland botanical composition. Aust. J. Agric. Res. 56, 1027-1039.

Hillard, J.B., Haby, V.A., Hons, F.M., 1992. Annual ryegrass response to limestone and phosphorus on an Ultisol. J. Plant Nutr. 15, 1253-1268. doi:10.1080/00103629209368580 
Hinsinger, P., 2001. Bioavailability of soil inorganic $P$ in the rhizosphere as affected by root-induced chemical changes: a review. Plant Soil 237, 173-195.

Hodge, A., Robinson, D., Griffiths, B.S., Fitter, A.H., 1999. Why plants bother: root proliferation results in increased nitrogen capture from an organic patch when two grasses compete. Plant, Cell Environ. 22, 811-820. doi:10.1046/j.1365-3040.1999.00454.x

Honsová, D., Hejcman, M., Klaudisová, M., Pavlů, V., Kocourková, D., Hakl, J., 2007. Species composition of an alluvial meadow after 40 years of applying nitrogen, phospohorus and potassium fertilizer. Preslia 79, 245-258.

Hou, Y., 2016. Towards improving the manure management chain. Wageningen University, Wageningen.

Hou, Y., Velthof, G.L., Case, S.D.C., Oelofse, M., Grignani, C., Balsari, P., Zavattaro, L., Gioelli, F., Bernal, M.P., Fangueiro, D., Trindade, H., Jensen, L.S., Oenema, O., 2018.

Stakeholder perceptions of manure treatment technologies in Denmark, Italy, the Netherlands and Spain. J. Clean. Prod. 172, 1620-1630. doi:10.1016/j.jclepro.2016.10.162

Houba, V.J.G., Temminghoff, E.J.M., Gaikhorst, G.A., Van Vark, W., 2000. Soil analysis procedures using $0.01 \mathrm{M}$ calcium chloride as extraction reagent. Commun. Soil Sci. Plant Anal. 31, 1299-1396. doi:10.1080/00103620009370514

Houba, V.J.G., Van der Lee, J.J., Novozamsky, I., 1997. Soil analysis procedures: other procedures (soil and plant analysis, part 5B). Agricultural University, Wageningen, the Netherlands.

Hristov, A.N., Hanigan, M., Cole, A., Todd, R., McAllister, T.A., Ndegwa, P.M., Rotz, A., 2011. Review: Ammonia emissions from dairy farms and beef feedlots. Can. J. Anim. Sci. 91, 1-35. doi:10.4141/CJAS10034

Humphreys, J., Tunney, H., Duggan, P., 1998. Soil phosphorus determination using three extraction procedures, the effect of sampling depth and comparison of phosphorus fertiliser recommendations for grassland. Irish J. Agric. Food Res. 37, 29-38.

Hungate, B.A., Van Groenigen, K.J., Six, J., Jastrow, J.D., Luo, Y., De Graaff, M.A., Van Kessel, C., Osenberg, C.W., 2009. Assessing the effect of elevated carbon dioxide on soil carbon: A comparison of four meta-analyses. Glob. Chang. Biol. 15, 2020-2034. doi:10.1111/j. 1365-2486.2009.01866.x 
Jacobsen, J.S., Surber, G.W., 1995. Alfalfa/grass response to nitrogen and phosphorus applications. Commun. Soil Sci. Plant Anal. 26, 1273-1282. doi:10.1080/00103629509369369

Jambor, J.L., Dutrizac, J.E., 1998. Occurrence and constitution of natural and synthetic ferrihydrite, a widespread iron oxyhydroxide. Chem. Rev. 98, 2549-2586. doi:10.1021/cr970105t

Jančík, F., Koukolová, V., Homolka, P., 2010. Ruminal degradability of dry matter and neutral detergent fibre of grasses. Czech J. Anim. Sci. 55, 359-371.

Jarvie, H.P., Sharpley, A.N., Flaten, D., Kleinman, P.J.A., Jenkins, A., Simmons, T., 2015. The pivotal role of phosphorus in a resilient water-energy-food security nexus. J. Environ. Qual. 44, 1049-1062. doi:10.2134/jeq2015.01.0030

Jiménez, J.J., Cepeda, A., Decaëns, T., Oberson, A., Friesen, D.K., 2003. Phosphorus fractions and dynamics in surface earthworm casts under native and improved grasslands in a Colombian savanna Oxisol. Soil Biol. Biochem. 35, 715-727. doi:10.1016/S0038-0717(03)00090-7

Johnston, A.E., Poulton, P.R., White, R.P., 2013. Plant-available soil phosphorus. Part II: The response of arable crops to Olsen P on a sandy clay loam and a silty clay loam. Soil Use Manag.

29, 12-21. doi:10.1111/j.1475-2743.2012.00449.x

Jones, C.G., Lawton, J.H., Shachak, M., 1994. Organisms as ecosystem engineers. Oikos 69, 373-386.

Jones, M.B., Vaughn, C.E., Williams, W.A., 1995. Soil phosphorus requirements for maximum growth of northern California subclover-annual grass pastures. Commun. Soil Sci. Plant Anal. 26, 197-207. doi:10.1080/00103629509369290

Jones, R.J., Betteridge, K., 1994. Effect of superphosphate, or its component elements (phosphorus, sulfur, and calcium), on the grazing preference of steers on a tropical grass-legume pasture grown on a low phosphorus soil. Aust. J. Exp. Agric. 34, 349-353. doi:10.1071/EA9940349

Jordan-Meille, L., Rubæk, G.H., Ehlert, P.A.I., Genot, V., Hofman, G., Goulding, K., Recknagel, J., Provolo, G., Barraclough, P., 2012. An overview of fertilizer-P recommendations in Europe: Soil testing, calibration and fertilizer recommendations. Soil Use Manag. 28, 419-435. doi:10.1111/j.1475-2743.2012.00453.x

Jungk, A., Claassen, N., 1997. Ion diffusion in the soil-root system, Advances in Agronomy. Elsevier Masson SAS. doi:10.1016/S0065-2113(08)60662-8 
Junquan, Z., Michalk, D.L., Yifei, W., Kemp, D.R., Guozhen, D., Nicol, H., 2007. Effect of phosphorus, potassium and lime application on pasture in acid soil in Yunnan Province, China. New Zeal. J. Agric. Res. 50, 523-535. doi:10.1080/00288230709510320

Kabala, C., Musztyfaga, E., Galka, B., Labunska, D., Manczynska, P., 2016. Conversion of soil pH $1: 2.5 \mathrm{KCl}$ and $1: 2.5 \mathrm{H} 2 \mathrm{O}$ to $1: 5 \mathrm{H} 2 \mathrm{O}$ : Conclusions for soil management, environmental monitoring, and international soil databases. Polish J. Environ. Stud. 25, 647-653. doi:10.15244/pjoes/61549

Kalbitz, K., Sollinger, S., Park, J.H., Michalzik, B., Matzner, E., 2000. Controls on the dynamics of dissolved organic matter in soils: A review. Soil Sci. 165, 277-304.

Kastner, T., Rivas, M.J.I., Koch, W., Nonhebel, S., 2012. Global changes in diets and the consequences for land requirements for food. Proc. Natl. Acad. Sci. 109, 6868-6872. doi:10.1073/pnas.1117054109

Keizer, M.G., Van Riemsdijk, W.H., 1998. ECOSAT, Equilibrium Calculation of Speciation and Transport.

Kering, M.K., Biermacher, J.T., Butler, T.J., Mosali, J., Guretzky, J.A., 2012. Biomass yield and nutrient responses of switchgrass to phosphorus application. Bioenergy Res. 5, 71-78. doi:10.1007/ s12155-011-9174-y

Kirkham, F.W., Wilkins, R.J., 1994. The productivity and response to inorganic fertilizers of speciesrich wetland hay meadows on the Somerset Moors: the effect of nitrogen, phosphorus and potassium on herbage production. Grass Forage Sci. 49, 163-175. doi:10.1111/j.1365-2494.1994.tb01989.x

Kleinman, P., Sharpley, A.N., Buda, A., McDowell, R., Allen, A., 2011. Soil controls of phosphorus in runoff: Management barriers and opportunities. Can. J. Soil Sci. 91, 329-338. doi:10.4141/ cjss09106

Kleinman, P.J.A., Sharpley, A.N., 2003. Effect of broadcast manure on runoff phosphorus concentrations over successive rainfall events. J. Environ. Qual. 32, 1072-1081.

Klootwijk, C.W., Van Middelaar, C.E., Berentsen, P.B.M., De Boer, I.J.M., 2016. Dutch dairy farms after milk quota abolition: Economic and environmental consequences of a new manure policy. J. Dairy Sci. 99, 8384-8396. doi:10.3168/jds.2015-10781

Knowles, R., 1982. Denitrification. Microbiol. Rev. 46, 43-70. 
Koc, A., 2013. Effect of phosphorus doses and application time on the yield and quality of hay and botanical composition of clover dominant meadow in highlands of Turkey. Turkish J. F. Crop. 18, 205-210.

Koerselman, W., Meuleman, A.F.M., 1996. The vegetation N:P ratio: A new tool to detect the nature of nutrient limitation. J. Appl. Ecol. 33, 1441-1450.

Koopmans, G.F., Chardon, W.J., Dekker, P.H.M., Römkens, P.F.A.M., Schoumans, O.F., 2006. Comparing different extraction methods for estimating phosphorus solubility in various soil types. Soil Sci. 171, 103-116. doi:10.1097/01.ss.0000187361.00600.d6

Koopmans, G.F., Chardon, W.J., Ehlert, P.A.I., Dolfing, J., Suurs, R.A.A., Oenema, O., Van Riemsdijk, W.H., 2004. Phosphorus availability for plant uptake in a phosphorusenriched noncalcareous sandy soil. J. Environ. Qual. 33, 965-975.

Koopmans, G.F., Chardon, W.J., McDowell, R.W., 2007. Phosphorus movement and speciation in a sandy soil profile after long-term animal manure applications. J. Environ. Qual. 36, 305. doi:10.2134/jeq2006.0131

Koopmans, G.F., Groenenberg, J.E., 2011. Effects of soil oven-drying on concentrations and speciation of trace metals and dissolved organic matter in soil solution extracts of sandy soils. Geoderma 161, 147-158. doi:10.1016/j.geoderma.2010.12.012

Koopmans, G.F., Van Der Zeeuw, M.E., Römkens, P.F.A.M., Chardon, W.J., Oenema, O., 2001. Identification and characterization of phosphorus-rich sandy soils. NJAS - Wageningen J. Life Sci. 49, 369-384. doi:10.1016/S1573-5214(01)80024-5

Kovar, J.L., Claassen, N., 2005. Soil-root interactions and phosphorus nutrition of plants, in: Sims, J.T., Sharpley, A.N. (Eds.), Phosphorus: Agriculture and the Environment. American Society of Agronomy, Inc., Crop Science Society of America, Inc., Soil Science Society of America, Inc., Madison, Wisconsin, USA, Madison, WI, USA, pp. 379-414.

Kuczak, C.N., Fernandes, E.C.M., Lehmann, J., Rondon, M.A., Luizão, F.J., 2006. Inorganic and organic phosphorus pools in earthworm casts (Glossoscolecidae) and a Brazilian rainforest Oxisol. Soil Biol. Biochem. 38, 553-560. doi:10.1016/j.soilbio.2005.06.007

Kuligowski, K., Poulsen, T.G., Rubæk, G.H., Sørensen, P., 2010. Plant-availability to barley of phosphorus in ash from thermally treated animal manure in comparison to other manure based materials and commercial fertilizer. Eur. J. Agron. 33, 293-303. doi:10.1016/j.eja.2010.08.003 
Kuo, S., 1996. Phosphorus, in: Sparks, D.L., Page, A.L., Helmke, P.A., Loeppert, R.H. (Eds.), Methods of Soil Analysis Part 3-Chemical Methods, SSSA Book Series SV - 5.3.

Soil Science Society of America, American Society of Agronomy, Madison, WI, p. 52. doi:10.2136/sssabookser5.3.c32

Lambkin, D.C., Gwilliam, K.H., Layton, C., Canti, M.G., Piearce, T.G., Hodson, M.E., 2011. Production and dissolution rates of earthworm-secreted calcium carbonate. Pedobiologia (Jena). 54, S119-S129. doi:10.1016/j.pedobi.2011.09.003

Lattaud, C., Zhang, B.G., Locati, S., Rouland, C., Lavelle, P., 1997. Activities of the digestive enzymes in the gut and in tissue culture of a tropical geophagous earthworm, Polypheretima elongata (Megascolecidae). Soil Biol. Biochem. 29, 335-339. doi:10.1016/S0038-0717(96)00021-1

Le Bayon, R.-C., Milleret, R., 2009. Effects of earthworms on phosphorus dynamics - A review. Dyn. Soil, Dyn. Plant. Glob. Sci. Books 21-27.

Le Bayon, R.C., Binet, F., 2006. Earthworms change the distribution and availability of phosphorous in organic substrates. Soil Biol. Biochem. 38, 235-246. doi:10.1016/j.soilbio.2005.05.013

Lee, K.E., 1985. Earthworms: their ecology and relationships with soils and land use. Academic Press.

Lehmann, J., Lan, Z., Hyland, C., Sato, S., Solomon, D., Ketterings, Q.M., 2005. Long-term dynamics of phosphorus forms and retention in manure-amended soils. Environ. Sci. Technol. 39, 6672-6680. doi:10.1021/es047997g

Leikam, D.F., Achorn, F.P., 2005. Phosphate rertilizers: Production, characteristics, and technologies, in: Sims, J.T., Sharpley, A.N. (Eds.), Phosphorus: Agriculture and the Environment. ASA/CSSA/ SSSA, Madison, Wisconsin, United States of America, pp. 23-50.

Leytem, A.B., Mikkelsen, R.L., Gilliam, J.W., 2002. Sorption of organic phosphorus compounds in atlantic coastal plain soils. Soil Sci. 167, 652-658. doi:10.1097/01.ss.0000034854.98442.39

Li, C., Kuyper, T.W., van der Werf, W., Zhang, J., Li, H., Zhang, F., Hoffland, E., 2018. Testing for complementarity in phosphorus resource use by mixtures of crop species. Plant Soil. doi:10.1007/s11104-018-3732-4 
Li, L., Li, S.-M., Sun, J.-H., Zhou, L.-L., Bao, X.-G., Zhang, H.-G., Zhang, F.-S., 2007.

Diversity enhances agricultural productivity via rhizosphere phosphorus facilitation on phosphorus-deficient soils. Proc. Natl. Acad. Sci. 104, 11192-11196. doi:10.1073/ pnas. 0704591104

Liang, Z., Chen, S., Yang, Y., Zhao, R., Shi, Z., Viscarra Rossel, R.A., 2019. Baseline map of soil organic matter in China and its associated uncertainty. Geoderma 335, 47-56. doi:10.1016/j. geoderma.2018.08.011

Liebisch, F., Bünemann, E.K., Huguenin-Elie, O., Jeangros, B., Frossard, E., Oberson, A., 2013. Plant phosphorus nutrition indicators evaluated in agricultural grasslands managed at different intensities. Eur. J. Agron. 44,67-77. doi:10.1016/j.eja.2012.08.004

Liebisch, F., Keller, F., Huguenin-Elie, O., Frossard, E., Oberson, A., Bünemann, E.K., 2014. Seasonal dynamics and turnover of microbial phosphorusin a permanent grassland. Biol. Fertil. Soils 50, 465-475. doi:10.1007/s00374-013-0868-5

Liu, H., Hull, R.J., Duff, D.T., 1995. Comparing cultivars of three cool-season turfgrasses for phosphate uptake kinetics and phosphorus recovery in the field. J. Plant Nutr. 18, 523-540.

Liu, Q., Wang, J., Bai, Z., Ma, L., Oenema, O., 2017. Global animal production and nitrogen and phosphorus flows. Soil Res. 55, 451-462.

Lkhagvasuren, B., Schoenau, J.J., Anderson, D.W., Malhi, S.S., 2011. Plant and soil responses to nitrogen and phosphorus fertilization of bromegrass-dominated haylands in Saskatchewan, Canada. Grass Forage Sci. 66, 351-360. doi:10.1111/j.1365-2494.2011.00790.x

Loeppky, H.A., Horton, P.R., Bittman, S., Wright, T., Nuttall, W.F., 1999. Forage seed yield response to $\mathrm{N}$ and $\mathrm{P}$ fertilizers and soil nutrients in northeastern Saskatchewan. Can. J. Soil Sci. 79, 265-271.

Lookman, R., 1995. Phosphate chemistry in excessively fertilised soils. PhD Thesis. Catholic University Leuven, Leuven, Belgium.

Lopez-Hernandez, D., Lavelle, P., Fardeau, J.C., Niño, M., 1993. Phosphorus transformations in two P-sorption contrasting tropical soils during transit through Pontoscolex corethrurus (Glossoscolecidae : Oligochaeta). Soil Biol. Biochem. 25, 789-792. doi:10.1016/00380717(93)90124-T 
Lubbers, I.M., Van Groenigen, K.J., Fonte, S.J., Six, J., Brussaard, L., Van Groenigen, J.W., 2013. Greenhouse-gas emissions from soils increased by earthworms. Nat. Clim. Chang. 3, 187-194. doi:10.1038/nclimate1692

Lynch, J.P., 2007. Roots of the second green revolution. Aust. J. Bot. 55, 493-512. doi:10.1071/BT06118

Lynch, J.P., Brown, K.M., 2001. Topsoil foraging - an architectural adaptation of plants to low phosphorus availability. Plant Soil 237, 225-237. doi:10.1023/A:1013324727040

MacDonald, G.K., Bennett, E.M., Potter, P.A., Ramankutty, N., 2011. Agronomic phosphorus imbalances across the world's croplands. Proc. Natl. Acad. Sci. 108, 3086-3091. doi:10.1073/pnas.1010808108

Mackay, A.D., Syers, J.K., Springett, J.A., Gregg, P.E.H., 1982. Plant availability of phosphorus in superphosphate and a phosphate rock as influenced by earthworms. Soil Biol. Biochem. 14, 281-287. doi:10.1016/0038-0717(82)90038-4

Maguire, R.O., Foy, R.H., Bailey, J.S., Sims, J.T., 2001. Estimation of the phosphorus sorption capacity of acidic soils in Ireland. Eur. J. Soil Sci. 52, 479-487. doi:10.1046/j.1365-2389.2001.00394.x

Maguire, R.O., Kleinman, P.J.A., Dell, C.J., Beegle, D.B., Brandt, R.C., McGrath, J.M., Ketterings, Q.M., 2011. Manure application technology in reduced tillage and forage systems: a review. J. Environ. Qual. 40, 292-301. doi:10.2134/jeq2009.0228

Manning, B.A., Goldberg, S., 1996a. Modeling competitive adsorption of arsenate with phosphate and molybdate on oxide minerals. Soil Sci. Soc. Am. J. 60, 121-131.

Manning, B.A., Goldberg, S., 1996b. Modeling arsenate competitive adsorption on kaolinite, montmorillonite and illite. Clays Clay Miner. 44, 609-623.

Marschner, H., 2012. Mineral nutrition of higher plants, Third Edit. ed. Academic Press.

Martiniello, P., Berardo, N., 2007. Residual fertilizer effects on dry-matter yield and nutritive value of Mediterranean pastures. Grass Forage Sci. 62, 87-99.

doi:10.1111/j.1365-2494.2007.00567.x 
Massey, P.A., Creamer, R.E., Whelan, M.J., Ritz, K., 2015. Insensitivity of soil biological communities to phosphorus fertilization in intensively managed grassland systems. Grass Forage Sci. 71, 39-152. doi:10.1111/gfs.12163

McIntosh, J.L., 1969 Bray and Morgan soil extractants modified for testing acid soils from different parent materials. Agron. J. 61, 259-65. doi:10.2134/agronj1969.00021962006100020025x

McLaughlin, M.J., McBeath, T.M., Smernik, R., Stacey, S.P., Ajiboye, B., Guppy, C., 2011. The chemical nature of $\mathrm{P}$ accumulation in agricultural soils -implications for fertiliser management and design: an Australian perspective. Plant Soil 349, 69-87. doi:10.1007/s11104-011-0907-7

Meersmans, J., Martin, M.P., Lacarce, E., De Baets, S., Jolivet, C., Boulonne, L., Lehmann, S., Saby, N.P.A., Bispo, A., Arrouays, D., 2012. A high resolution map of French soil organic carbon. Agron. Sustain. Dev. 32, 841-851. doi:10.1007/s13593-012-0086-9

Mehlich, A., 1984. Mehlich 3 soil test extractant: A modification of Mehlich 2 extractant. Commun. Soil Sci. Plant Anal. 15, 1409-1416. doi:10.1080/00103628409367568

Mehlich, A., 1953. Determination of P, Ca, Mg, K, Na, NH4. Raleigh, North Carolina, USA.

Mendez, J.C., Hiemstra, T., 2018. Carbonate adsorption to ferrihydrite: competitive interaction with phosphate for applications in natural soil systems. ACS Earth Sp. Chem. doi:10.1021/acsearthspacechem.8b00160

Mendoza, R., Bailleres, M., García, I., Ruiz, O., 2016. Phosphorus fertilization of a grass-legume mixture: Effect on plant growth, nutrients acquisition and symbiotic associations with soil microorganisms. J. Plant Nutr. 39, 691-701. doi:10.1080/01904167.2015.1087032

Menezes-Blackburn, D., Giles, C., Darch, T., George, T.S., Blackwell, M., Stutter, M., Shand, C., Lumsdon, D., Cooper, P., Wendler, R., Brown, L., Almeida, D.S., Wearing, C., Zhang, H., Haygarth, P.M., 2018. Opportunities for mobilizing recalcitrant phosphorus from agricultural soils: a review. Plant Soil 427, 5-16. doi:10.1007/s11104-017-3362-2

Messiga, A.J., Ziadi, N., Bélanger, G., Morel, C., 2014. Relationship between soil phosphorus and phosphorus budget in grass sward with varying nitrogen applications. Soil Sci. Soc. Am. J. 78, 1481-1488. doi:10.2136/sssaj2013.05.0200 
Michael, N., Bradshaw, A.D., Hall, J.E., 1991. The value of fertilizer, surface applied and injected sewage sludge to vegetation established on reclaimed colliery spoil suffering from regression. Soil Use Manag. 7, 233-239.

Michalk, D.L., Nan-Ping, F., Chin-Ming, Z., 1998. Improvement of dry tropical rangelands in Hainan Island, China: 4. Effect of seedbed on pasture establishment. J. Range Manag. 51, 106-114. doi:10.2307/4002468

Milleret, R., Le Bayon, R.-C., Gobat, J.-M., 2008. Root, mycorrhiza and earthworm interactions: their effects on soil structuring processes, plant and soil nutrient concentration and plant biomass. Plant Soil 316, 1-12. doi:10.1007/s11104-008-9753-7

Milne, C.J., Kinniburgh, D.G., van Riemsdijk, W.H., Tipping, E., 2003. Generic NICA-Donnan model parameters for metal-ion binding by humic substances. Environ. Sci. Technol. 37, 958-971. doi:10.1021/es0258879

Moir, J.L., Edwards, G.R., Berry, L.N., 2013. Nitrogen uptake and leaching loss of thirteen temperate grass species under high N loading. Grass Forage Sci. 68, 313-325. doi:10.1111/j.1365-2494.2012.00905.x

Moody, P.W., Speirs, S.D., Scott, B.J., Mason, S.D., 2013. Soil phosphorus tests I: What soil phosphorus pools and processes do they measure? Crop Pasture Sci. 64, 461-468. doi:10.1071/CP13112

Morel, C., Tunney, H., Plénet, D., Pellerin, S., 2000 Transfer of phosphate ions between soil and solution: Perspectives in soil testing. J Environ. Qual. 29, 50-59.

Morgan, M.F., 1941. Chemical soil diagnosis by the universal soil testing system. University of Connecticut, Storrs, CT, US.

Morton, J.D., Wheeler, D.M., Smith, N.S., 1998. Effect of lime and form of superphosphate on productivity of dryland pastures. New Zeal. J. Agric. Res. 41, 65-74.

doi:10.1080/00288233.1998.9513289

Moyer, J.L., Sweeney, D.W., Lamond, R.E., 1995. Response of tall fescue to fertilizer placement at different levels of phosphorus, potassium, and soil pH. J. Plant Nutr. 18, 729-746. doi:10.1080/01904169509364934 
Mullen, R.W., Phillips, S.B., Raun, W.R., Johnson, G. V., Thomason, W.E., 2000. Forage yield and crude protein of interseeded legume-bermudagrass mixtures as affected by phosphorus fertilizer. J. Plant Nutr. 23, 673-681. doi:10.1080/01904160009382049

Muller, A., Schader, C., El-Hage Scialabba, N., Brüggemann, J., Isensee, A., Erb, K.-H., Smith, P., Klocke, P., Leiber, F., Stolze, M., Niggli, U., 2017. Strategies for feeding the world more sustainably with organic agriculture. Nat. Commun. 8. doi:10.1038/s41467-017-01410-w

Murphy, J., Riley, J.P., 1962. A modified single solution method for the determination of phosphate in natural waters. Anal. Chim. Acta 27, 31-36. doi:10.1016/S0003-2670(00)88444-5

Nash, D.M., Haygarth, P.M., Turner, B.L., Condron, L.M., McDowell, R.W., Richardson, A.E., Watkins, M., Heaven, M.W., 2014. Using organic phosphorus to sustain pasture productivity: A perspective. Geoderma 221-222, 11-19. doi:10.1016/j.geoderma.2013.12.004

Nawara, S., Van Dael, T., De Cooman, E., Elsen, A., Merckx, R., Smolders, E., Amery, F., 2018. Testing soil phosphorus in a depleting $\mathrm{P}$ scenario: an accelerated soil mining experiment. Eur. J. Soil Sci. 69, 804-815. doi:10.1111/ejss.12684

Nawara, S., Van Dael, T., Merckx, R., Amery, F., Elsen, A., Odeurs, W., Vandendriessche, H., Mcgrath, S., Roisin, C., Jouany, C., Pellerin, S., Denoroy, P., Eichler-Löbermann, B., Börjesson, G., Goos, P., Akkermans, W., Smolders, E., 2017. A comparison of soil tests for available phosphorus in long-term field experiments in Europe. Eur. J. Soil Sci. 68, 873-885. doi:10.1111/ejss.12486

Nie, Z.N., Miller, S., Moore, G.A., Hackney, B.F., Boschma, S.P., Reed, K.F.M., Mitchell, M., Albertsen, T.O., Clark, S., Craig, A.D., Kearney, G., Li, G.D., Dear, B.S., 2008. Field evaluation of perennial grasses and herbs in southern Australia. 2. Persistence, root characteristics and summer activity. Aust. J. Exp. Agric. 48, 424-435. doi:10.1071/EA07136

Obour, A.K., Silveira, M.L., Vendramini, J.M.B., Sollenberger, L.E., O'Connor, G.A., Jawitz, J.W., 2011. Agronomic and environmental impacts of phosphorus fertilization of low input bahiagrass systems in Florida. Nutr. Cycl. Agroecosystems 89, 281-290. doi:10.1007/s10705-010-9393-1 
Oenema, J., Koskamp, G.J., Galama, P.J., 2001. Guiding commercial pilot farms to bridge the gap between experimental and commercial dairy farms; the project "Cows \& Opportunities." NJAS - Wageningen J. Life Sci. 49, 277-296. doi:10.1016/S1573-5214(01)80011-7

Oenema, J., Van Keulen, H., Schils, R.L.M., Aarts, H.F.M., 2011. Participatory farm management adaptations to reduce environmental impact on commercial pilot dairy farms in the Netherlands. NJAS - Wageningen J. Life Sci. 58, 39-48. doi:10.1016/j.polymdegradstab.2016.02.004

Oenema, O., de Klein, C., Alfaro, M., 2014. Intensification of grassland and forage use: driving forces and constraints. Crop Pasture Sci. 65, 524-537. doi:10.1071/CP14001

Ognalaga, M., Frossard, E., Thomas, F., 1994. Glucose-1-phosphate and myo-inositol hexaphosphate adsorption mechanisms on goethite. Soil Sci. Soc. Am. J. 58, 332-337.

Okajima, H., Kubota, H., Sakuma, T., 1983. Hysteresis in the phosphorus sorption and desorption processes of soils. Soil Sci. Plant Nutr. 29, 271-283. doi:10.1080/00380768.1983.10434628

Olde Venterink, H., Güsewell, S., 2010. Competitive interactions between two meadow grasses under nitrogen and phosphorus limitation. Funct. Ecol. 24, 877-886. doi:10.1111/j.1365-2435.2010.01692.x

Olsen, S.R., Cole, C. V, Watanabe, F.S., 1954. Estimation of available phosphorus in soils by extraction with sodium bicarbonate, Circular / United States Department of Agriculture;no. 939. USDA, Washington.

Otabbong, E., Börling, K., Kätterer, T., Mattssona, L., 2009. Compatibility of the ammonium lactate $(\mathrm{AL})$ and sodium bicarbonate (Olsen) methods for determining available phosphorus in Swedish soils. Acta Agric Scand Sect B Soil Plant Sci 59, 373-378. doi:10.1080/09064710902777091

Paredes, C., Menezes-Blackburn, D., Cartes, P., Gianfreda, L., Luz Mora, M., 2011. Phosphorus and nitrogen fertilization effect on phosphorus uptake and phosphatase activity in ryegrass and tall fescue grown in a Chilean andisol. Soil Sci. 176, 245-251. doi:10.1097/SS.0b013e3182147fd3

Paul, B.K., Lubbers, I.M., Van Groenigen, J.W., 2012. Residue incorporation depth is a controlling factor of earthworm-induced nitrous oxide emissions. Glob. Chang. Biol. 18, 1141-1151. doi:10.1111/j.1365-2486.2011.02525.x 
Paynter, R.M., Dampney, P.M.R., 1991. The effect of rate and timing of phosphate fertilizer on the yield and phosphate off take of grass grown for silage at moderate to high levels of soil phosphorus. Grass Forage Sci. 46, 131-137. doi:10.1111/j.1365-2494.1991.tb02215.x

Pérez-Harguindeguy, N., Díaz, S., Garnier, E., Lavorel, S., Poorter, H., Jaureguiberry, P., Bret-Harte, M.S., Cornwell, W.K., Craine, J.M., Gurvich, D.E., Urcelay, C., Veneklaas, E.J., Reich, P.B., Poorter, L., Wright, I.J., Ray, P., Enrico, L., Pausas, J.G., de Vos, A.C., Buchmann, N., Funes, G., Quétier, F., Hodgson, J.G., Thompson, K., Morgan, H.D., Ter Steege, H., Sack, L., Blonder, B., Poschlod, P., Vaieretti, M. V., Conti, G., Staver, A.C., Aquino, S., Cornelissen, J.H.C., 2013. New handbook for standardised measurement of plant functional traits worldwide. Aust. J. Bot. 61, 167-234.

Peters, M., Tarawali, S.A., Alkämper, J., 1997. Dry season performance of four tropical pasture legumes in subhumid west Africa as influenced by superphosphate application and weed control. Trop. Grasslands 31, 201-213.

Phillips, J.M., Hayman, D.S., 1970. Improved procedures for clearing roots and staining parasitic and vesicular-arbuscular mycorrhizal fungi for rapid assessment of infection. Trans. Br. Mycol. Soc. 55, 158-161. doi:10.1016/s0007-1536(70)80110-3

Picon-Cochard, C., Pilon, R., Tarroux, E., Pagès, L., Robertson, J., Dawson, L., 2012. Effect of species, root branching order and season on the root traits of 13 perennial grass species. Plant Soil 353, 47-57. doi:10.1007/s11104-011-1007-4

Polat, T., Bükün, B., Okant, M., 2007. Dose response effect of nitrogen and phosphorus on forage quality, yield and economic return of rangelands. Pakistan J. Bot. 39, 807-816.

Postma-Blaauw, M.B., Bloem, J., Faber, J.H., van Groenigen, J.W., de Goede, R.G.M., Brussaard, L., 2006. Earthworm species composition affects the soil bacterial community and net nitrogen mineralization. Pedobiologia (Jena). 50, 243-256. doi:10.1016/j.pedobi.2006.02.001

Potthast, K., Hamer, U., Makeschin, F., 2012. In an Ecuadorian pasture soil the growth of Setaria sphacelata, but not of soil microorganisms, is co-limited by N and P. Appl. Soil Ecol. 62, 103-114. doi:10.1016/j.apsoil.2012.08.003

Power, V., Tunney, H., Jeffrey, D.W., 2005. The phosphorus requirements for silage production on high fertility soils. Irish J. Agric. Food Res. 44, 281-296.

Price, G., 2006. Australian soil fertility manual, 3rd editio. ed. CSIRO Publishing. 
Qi, J., Nie, Z., Jiao, T., Zhang, D., 2015. Phosphorus and defoliation interact and improve the growth and composition of the plant community and soil properties in an alpine pasture of qinghai-tibet plateau. PLoS One 10. doi:10.1371/journal.pone.0141701

Qian, P., Schoenaru, J.J., Karamanos, R.E., 1994. Simultaneous extraction of available phosphorus and potassium with a new soil test: A modification of Kelowna extraction. Commun. Soil Sci. Plant Anal. 25, 627-635. doi:10.1080/00103629409369068

Raghothama, K.G., 1999. Phosphate acquisition. Annu. Rev. Plant Biol. 50, 665-693.

Rao, A.S., Singh, K.C., Wight, J.R., 1996. Productivity of Cenchms ciliaris in relation to rain- fall and fertilization. J. Range Manag. 49, 143-146.

Rao, C.R., 1964. The Use and Interpretation of Principal Component Analysis in Applied Research. SankhyĐ Indian J. Stat. 26, 329-358.

Rasmussen, P.E., 1995. Effects of fertilizer and stubble burning on downy brome competition in winterwheat.Commun. SoilSci.PlantAnal.26,951-960.doi:Doi10.1080/00103629509369347

Rawls, W.J., 1983. Estimating soil bulk density from particle size analysis and organic matter content. Soil Sci. 135, 123-125.

Regelink, I.C., Koopmans, G.F., Van der Salm, C., Weng, L., Van Riemsdijk, W.H., 2013.

Characterization of colloidal phosphorus species in drainage waters from a clay soil using asymmetric flow field-flow fractionation. J. Environ. Qual. 42, 464-473. doi:10.2134/jeq2012.0322

Regelink, I.C., Weng, L., Lair, G.J., Comans, R.N.J., 2015. Adsorption of phosphate and organic matter on metal (hydr)oxides in arable and forest soil: A mechanistic modelling study. Eur. J. Soil Sci. 66, 867-875. doi:10.1111/ejss.12285

Reijneveld, J.A., Ehlert, P.A.I., Termorshuizen, A.J., Oenema, O., 2010. Changes in the soil phosphorus status of agricultural land in the Netherlands during the 20th century. Soil Use Manag. 26, 399-411. doi:10.1111/j.1475-2743.2010.00290.x

Richardson, A.E., 2001. Prospects for using soil microorganisms to improve the acquisition of phosphorus by plants. Aust. J. Plant Physiol. 28, 897-906. 
Richardson, A.E., Barea, J.-M., McNeill, A.M., Prigent-Combaret, C., 2009a. Acquisition of phosphorus and nitrogen in the rhizosphere and plant growth promotion by microorganisms. Plant Soil 321, 305-339. doi:10.1007/s11104-009-9895-2

Richardson, A.E., Hocking, P.J., Simpson, R.J., George, T.S., 2009b. Plant mechanisms to optimise access to soil phosphorus. Crop Pasture Sci. 60, 124. doi:10.1071/CP07125

Richardson, A.E., Lynch, J.P., Ryan, P.R., Delhaize, E., Smith, F.A., Smith, S.E., Harvey, P.R., Ryan, M.H., Veneklaas, E.J., Lambers, H., Oberson, A., Culvenor, R.A., Simpson, R.J., 2011. Plant and microbial strategies to improve the phosphorus efficiency of agriculture. Plant Soil 349, 121-156. doi:10.1007/s11104-011-0950-4

Rietra, R.P.J.J., Hiemstra, T., van Riemsdijk, W.H., 2001. Interaction between calcium and phosphate adsorption on goethite. Environ. Sci. Technol. 35, 3369-3374. doi:10.1021/es000210b

Robinson, D., Rorison, I.H., 1987. Root hairs and plant growth at low nitrogen availabilities. New Phytol. 107, 681-693.

Rockström, J., Steffen, W., Noone, K., Persson, Å., Chapin, F.S., Lambin, E., Lenton, T.M., Scheffer, M., Folke, C., Schellnhuber, H.J., Nykvist, B., de Wit, C.A., Hughes, T., Van der Leeuw, S., Rodhe, H., Sörlin, S., Snyder, P.K., Costanza, R., Svedin, U., Falkenmark, M., Karlberg, L., Corell, R.W., Fabry, V.J., Hansen, J., Walker, B., Liverman, D., Richardson, K., Crutzen, P., Foley, J., 2009. Planetary boundaries: Exploring the safe operating space for humanity. Ecol. Soc. 14. doi:10.5751/ES-03180-140232

Romero, C., Márquez, O., 2002. Effect of phosphorus in grass Brachiaria humidicola on the milky production of cow's double purpose (in Spanish). Rev. Científica 12, 578-580.

Ros, M.B.H., De Deyn, G.B., Koopmans, G.F., Oenema, O., van Groenigen, J.W., 2018. What root traits determine grass resistance to phosphorus deficiency in production grassland? J. Plant Nutr. Soil Sci. 181, 323-335. doi:10.1002/jpln.201700093

Rosenberg, M.S., Adams, D.C., Gurevitch, J., 2000. Metawin: Statistical Software for Meta-Analysis.

Rosenthal, R., Rosnow, R.L., 1991. Essentials of Behavioral Research: Methods and Data Analysis, 2nd ed. McGraw-Hill, New York.

Rosseel, Y., 2012. Lavaan: An R package for structural equation modeling. J. Stat. Softw. 48, 1-36. doi:10.18637/jss.v048.i02 
Rotz, C.A., Kleinman, P.J.A., Dell, C.J., Veith, T.L., Beegle, D.B., 2011. Environmental and economic comparisons of manure application methods in farming systems. J. Environ. Qual. 40, 438-448. doi:10.2134/jeq2010.0063

Rotz, C.A., Taube, F., Russelle, M.P., Oenema, J., Sanderson, M.A., Wachendorf, M., 2005. Whole-farm perspectives of nutrient flows in grassland agriculture. Crop Sci. 45, 2139-2159. doi:10.2135/cropsci2004.0523

Rutgers, M., Orgiazzi, A., Gardi, C., Römbke, J., Jänsch, S., Keith, A.M., Neilson, R., Boag, B., Schmidt, O., Murchie, A.K., Blackshaw, R.P., Pérès, G., Cluzeau, D., Guernion, M., Briones, M.J.I., Rodeiro, J., Piñeiro, R., Cosín, D.J.D., Sousa, J.P., Suhadolc, M., Kos, I., Krogh, P.H., Faber, J.H., Mulder, C., Bogte, J.J., Wijnen, H.J. va., Schouten, A.J., Zwart, D. de, 2016. Mapping earthworm communities in Europe. Appl. Soil Ecol. 97, 98-111. doi:10.1016/j.apsoil.2015.08.015

Rutgers, M., Schouten, A.J., Bloem, J., Van Eekeren, N., De Goede, R.G.M., Jagers Op Akkerhuis, G.A.J.M., Van Der Wal, A., Mulder, C., Brussaard, L., Breure, A.M., 2009. Biological measurements in a nationwide soil monitoring network. Eur. J. Soil Sci. 60, 820-832. doi:10.1111/j.1365-2389.2009.01163.x

Saarela, I., Huhta, H., Virkajärvi, P., 2006. Effects of repeated phosphorus fertilisation on field crops in Finland 2. Sufficient phosphorus application rates on silty and sandy soils. Agric. Food Sci. 15, 423-443. doi:10.2137/145960606778644548

Sale, P.W.G., Simpson, P.G., Lewis, D.C., Gilkes, R.J., Bolland, M.D.A., Ratkowsky, D.A., Gilbert, M.A., Garden, D.L., Cayley, J.W.D., Johnson, D., 1997. The agronomic effectiveness of reactive phosphate rocks 1. Effect of the pasture environment. Aust. J. Exp. Agric. 37, 921-936.

Sanchez, P.A., 2002. Soil fertility and hunger in Africa. Science (80-. ). 295, 2019-2020. doi:10.1126/science.1065256

Satchell, J.E., Martin, K., 1984. Phosphatase activity in earthworm faeces. Soil Biol. Biochem. 16, 191-194. doi:10.1016/0038-0717(84)90111-1

Sattari, S.Z., Bouwman, A.F., Giller, K.E., van Ittersum, M.K., 2012. Residual soil phosphorus as the missing piece in the global phosphorus crisis puzzle. Proc. Natl. Acad. Sci. 109, 6348-6353. doi:10.1073/pnas.1113675109 
Sattari, S.Z., Bouwman, A.F., Martinez Rodríguez, R., Beusen, A.H.W., van Ittersum, M.K., 2016. Negative global phosphorus budgets challenge sustainable intensification of grasslands. Nat. Commun. 7. doi:10.1038/ncomms10696

Schellberg, J., Möseler, B.M., Kühbauch, W., Rademacher, I.F., 1999. Long-term effects of fertilizer on soil nutrient concentration, yield, forage quality and floristic composition of a hay meadow in the Eifel mountains, Germany. Grass Forage Sci. 54, 195-207. doi:10.1046/j.1365-2494.1999.00166.x

Scheu, S., 2003. Effects of earthworms on plant growth: patterns and perspectives. Pedobiologica 47, 846-856.

Scheu, S., 1987. Microbial activity and nutrient dynamics in earthworm casts (Lumbricidae). Biol. Fertil. Soils 5, 230-234. doi:10.1007/BF00256906

Schils, R., Snijders, P., 2004. The combined effect of fertiliser nitrogen and phosphorus on herbage yield and changes in soil nutrients of a grass/clover and grass-only sward. Nutr. Cycl. Agroecosystems 68, 165-179. doi:10.1023/B:FRES.0000019045.90791.a4

Schmieder, F., Bergström, L., Riddle, M., Gustafsson, J.P., Klysubun, W., Zehetner, F., Condron, L., Kirchmann, H., 2018. Phosphorus speciation in a long-term manure-amended soil profile - Evidence from wet chemical extraction,31P-NMR and P K-edge XANES spectroscopy. Geoderma 322, 19-27. doi:10.1016/j.geoderma.2018.01.026

Scholefield, D., Sheldrick, R.D., Martyn, T.M., Lavender, R.H., 1999. A comparison of triple superphosphate and Gafsa ground rock phosphate fertilisers as P-sources for grass-clover swards on a poorly-drained acid clay soil. Nutr. Cycl. Agroecosystems 53, 147-155. doi:10.1023/A:1009750623318

Schoumans, O.F., 2014. Description of the phosphorus sorption and desorption processes in coarse calcareous sandy soils. Soil Sci. 179, 221-229. doi:10.1097/SS.0000000000000065

Schoumans, O.F., Chardon, W.J., 2015. Phosphate saturation degree and accumulation of phosphate in various soil types in The Netherlands. Geoderma 237, 325-335. doi:10.1016/j.geoderma.2014.08.015

Schoumans, O.F., Groenendijk, P., 2000. Modeling soil phosphorus levels and phosphorus leaching from agricultural land in the Netherlands. J. Environ. Qual. 29, 111-116. doi:10.2134/jeq2000.00472425002900010014x 
Schrader, S., Rogasik, H., Onasch, I., Jégou, D., 2007. Assessment of soil structural differentiation around earthworm burrows by means of X-ray computed tomography and scanning electron microscopy. Geoderma 137, 378-387. doi:10.1016/j.geoderma.2006.08.030

Schröder, J., Buisonjé, F. De, Kasper, G., Verdoes, N., Verloop, K., 2009. Mestscheiding: relaties tussen techniek, kosten, milieu en landbouwkundige waarde (in Dutch). Wageningen. doi:10.1134/S1062359012080043

Schwertmann, U., 1991. Solubility and dissolution of iron oxides. Plant Soil 130, 1-25. doi:10.1007/BF00011851 \&nbsp;\&nbsp;Published: JAN 1991

Schwertmann, U., 1964. Differenzierung der Eisenoxide des Bodens durch Extraktion mit Ammoniumoxalat-Lösung. Zeitschrift für Pflanzenernährung, Düngung, Bodenkd. 105, 194-202. doi:10.1002/jpln.3591050303

Sechi, V., Brussaard, L., De Goede, R.G.M., Rutgers, M., Mulder, C., 2015. Choice of resolution by functional trait or taxonomy affects allometric scaling in soil food webs. Am. Nat. 185, 142-149. doi:10.1086/678962

Seither, M., Wrage-Mönnig, N., Isselstein, J., 2014. Biomass production of Lolio-Cynosuretum grassland is not increased by plant-species richness. J. Plant Nutr. Soil Sci. 177, 613-623. doi:10.1002/jpln.201100349

Sharpley, A., Beegle, D., Bolster, C., Good, L., Joern, B., Ketterings, Q., Lory, J., Mikkelsen, R., Osmond, D., Vadas, P., 2012. Phosphorus indices: Why we need to take stock of how we are doing. J. Environ. Qual. 41, 1711-1719. doi:10.2134/jeq2012.0040

Sharpley, A., Jarvie, H.P., Buda, A., May, L., Spears, B., Kleinman, P., 2013. Phosphorus legacy: overcoming the effects of past management practices to mitigate future water quality impairment. J. Environ. Qual. 42, 1308-1326. doi:10.2134/jeq2013.03.0098

Sharpley, A.N., Syers, J.K., 1976. Potential role of earthworm casts for the phosphorus enrichment of run-off waters. Soil Biol. Biochem. 8, 341-346. doi:10.1016/0038-0717(76)90030-4

Sheil, T.S., Wall, D.P., Culleton, N., Murphy, J., Grant, J., Lalor, S.T.J., 2016. Long-term effects of phosphorus fertilizer on soil test phosphorus, phosphorus uptake and yield of perennial ryegrass. J. Agric. Sci. 154, 1068-1081. doi:10.1017/S0021859615001100 
Shen, J., Yuan, L., Zhang, J., Li, H., Bai, Z., Chen, X., Zhang, W., Zhang, F., 2011. Phosphorus dynamics: from soil to plant. Plant Physiol. 156, 997-1005. doi:10.1104/pp.111.175232

Shi, Y., Ziadi, N., Hamel, C., Lajeunesse, J., Lafond, J., 2016. Phosphorus fertilization effect on Timothy root growth, and associated arbuscular mycorrhizal development. Agron. J. 108, 930-938. doi:10.2134/agronj2015.0459

Shipitalo, M.J., Gibbs, F., 2000. Potential of earthworm burrows to transmit injected animal wastes to tile drains. Soil Sci. Soc. Am. J. 64, 2103-2109. doi:10.2136/sssaj2000.6462103x

Shipitalo, M.J., Nuutinen, V., Butt, K.R., 2004. Interaction of earthworm burrows and cracks in a clayey, subsurface-drained, soil. Appl. Soil Ecol. 26, 209-217. doi:10.1016/j.apsoil.2004.01.004

Simpson, R.J., Oberson, A., Culvenor, R.A., Ryan, M.H., Veneklaas, E.J., Lambers, H., Lynch, J.P., Ryan, P.R., Delhaize, E., Smith, F.A., Smith, S.E., Harvey, P.R., Richardson, A.E., 2011. Strategies and agronomic interventions to improve the phosphorus-use efficiency of farming systems. Plant Soil 349, 89-120. doi:10.1007/s11104-011-0880-1

Simpson, R.J., Richardson, A.E., Nichols, S.N., Crush, J.R., 2014. Pasture plants and soil fertility management to improve the efficiency of phosphorus fertiliser use in temperate grassland systems. Crop Pasture Sci. 65, 556-575. doi:10.1071/CP13395

Sims, J.T., Ma, L., Oenema, O., Dou, Z., Zhang, F.S., 2013. Advances and challenges for nutrient management in China in the 21st century. J. Environ. Qual. 42, 947-950. doi:10.2134/jeq2013.05.0173

Sims, J.T., Simard, R.R., Joern, B.C., 1998. Phosphorus loss in agricultural drainage: Historical perspective and current research. J. Environ. Qual. 27, 277-293.

Six, L., Smolders, E., Merckx, R., 2013. The performance of DGT versus conventional soil phosphorus tests in tropical soils-maize and rice responses to P application. Plant Soil 366, 49-66. doi:10.1111/1751-486X.12152

Sizmur, T., Watts, M.J., Brown, G.D., Palumbo-Roe, B., Hodson, M.E., 2011. Impact of gut passage and mucus secretion by the earthworm Lumbricus terrestris on mobility and speciation of arsenic in contaminated soil. J. Hazard. Mater. 197, 169-75. doi:10.1016/j.jhazmat.2011.09.071 
Smit, H.J., Tas, B.M., Taweel, H.Z., Elgersma, A., 2005. Sward characteristics important for intake in six Lolium perenne varieties. Grass Forage Sci. 60, 128-135.

doi:10.1111/j.1365-2494.2005.00459.x

Smith, L.C., Moss, R.A., Morton, J.D., Metherell, A.K., Fraser, T.J., 2012. Pasture production from a long-term fertiliser trial under irrigation. New Zeal. J. Agric. Res. 55, 105-117. doi:10.1080/00288233.2012.662897

Smith, S.E., Read, D.J., 2008. Mycorrhizal symbiosis, third edit. ed. Academic Press, London, UK. Sø, H.U., Postma, D., Jakobsen, R., Larsen, F., 2011. Sorption of phosphate onto calcite; results from batch experiments and surface complexation modeling. Geochim. Cosmochim. Acta 75, 2911-2923. doi:10.1016/j.gca.2011.02.031

Speirs, S.D., Scott, B.J., Moody, P.W., Mason, S.D., 2013. Soil phosphorus tests II: A comparison of soil test-crop response relationships for different soil tests and wheat. Crop Pasture Sci. 64, 469-479. doi:10.1071/CP13111

Steffen, W., Richardson, K., Rockstrom, J., Cornell, S.E., Fetzer, I., Bennett, E.M., Biggs, R., Carpenter, S.R., de Vries, W., de Wit, C.A., Folke, C., Gerten, D., Heinke, J., Mace, G.M., Persson, L.M., Ramanathan, V., Reyers, B., Sorlin, S., 2015. Planetary boundaries: guiding human development on a changing planet. Science (80-. ). 347. doi:10.1126/science.1259855

Steinfeld, H., Gerber, P., Wassenaar, T., Castel, V., Rosales, M., de Haan, C., 2006. Livestock's long shadow - Environmental issues and options. FAO, Rome.

Stroia, C., Morel, C., Jouany, C., 2007. Dynamics of diffusive soil phosphorus in two grassland experiments determined both in field and laboratory conditions. Agric. Ecosyst. Environ. 119, 60-74. doi:10.1016/j.agee.2006.06.007

Stutter, M.I., Shand, C.A., George, T.S., Blackwell, M.S.A., Bol, R., MacKay, R.L., Richardson, A.E., Condron, L.M., Turner, B.L., Haygarth, P.M., 2012. Recovering phosphorus from soil: A root solution? Environ. Sci. Technol. 46, 1977-1978. doi:10.1021/es2044745

Suárez, E.R., Pelletier, D.M., Fahey, T.J., Groffman, P.M., Bohlen, P.J., Fisk, M.C., 2004. Effects of exotic earthworms on soil phosphorus cycling in two broadleaf temperate forests. Ecosystems 7, 28-44. doi:10.1007/s10021-003-0128-x 
Sutton, M.A., Bleeker, A., Howard, C.M., Bekunda, M., Grizzetti, B., De Vries, W., Van Grinsven, H.J.M., Abrol, Y.P., Adhya, T.K., Billen, G., Davidson, E.A., Datta, A., Diaz, R., Erisman, J.W., Liu, X.J., Oenema, O., Palm, C., Raghuram, N., Reis, S., Scholz, R.W., Sims, T., Westhoek, H., Zhang, F.S., Ayyappan, S., Bouwman, A.F., Bustamante, M., Fowler, D., Galloway, J.N., Gavito, M.E., Garnier, J., Greenwood, S., Hellums, D.T., Holland, M., Hoysall, C., Jaramillo, V.J., Klimont, Z., Ometto, J.P., Pathak, H., Plocq Fichelet, V., Powlson, D., Ramakrishna, K., Roy, A., Sanders, K., Sharma, C., Singh, B., Singh, U., Yan, X.Y., Zhang, Y., 2013. Our Nutrient World: The challenge to produce more food and energy with less polution. doi:http://dx.doi.org/10.1146/annurev.arplant.47.1.569

Sweeney, D.W., Moyer, J.L., Havlin, J.L., 1996. Multinutrient fertilization and placement to improve yield and nutrient concentration of Tall Fescue. Agron. J. 88, 982-986.

Swietlik, J., Sikorska, E., 2006. Characterization of natural organic matter fractions by high pressure size-exclusion chromatography, specific UV absorbance and total luminescence spectroscopy. Polish J. Environ. Stud. 15, 145-153.

Syers, J.K., Johnston, A.E., Curtin, D., 2008. Efficiency of soil and fertilizer phosphorus use. Reconciling changing concepts of soil phosphorus behaviour with agronomic information. FAO Fertil. Plant Nutr. Bull.

Tarafdar, J.C., Jungk, A., 1987. Phosphatase activity in the rhizosphere and its relation to the depletion of soil organic phosphorus. Biol. Fertil. Soils 3, 199-204. doi:10.1007/BF00640630

Temminghoff, E.J.M., Houba, V.J.G., 2004. Plant analysis procedures, Second ed. Kluwer Academic Publishers, Dordrecht, The Netherlands.

Texas Agriculture Extension Service, 1980. Soil testing procedures.

Tilman, D., Balzer, C., Hill, J., Befort, B.L., 2011. Global food demand and the sustainable intensification of agriculture. Proc. Natl. Acad. Sci. 108, 20260-20264. doi:10.1073/pnas.1116437108

Tilman, D., Cassman, K.G., Matson, P.A., Naylor, R., Polasky, S., 2002. Agricultural sustainability and intensive production practices. Nature. doi:10.1038/nature01014

Tipping, E., Rey-Castro, C., Bryan, S.E., Hamilton-Taylor, J., 2002. Al(III) and Fe(III) binding by humic substances in freshwaters, and implications for trace metal speciation. Geochim. Cosmochim. Acta 66, 3211-3224. doi:10.1016/S0016-7037(02)00930-4 
Tisdale, S.L., Nelson, W.L., Beaton, J.D., 1985. Soil fertility and fertilizers.

Collier Macmillan Publishers.

Tiunov, A. V., Scheu, S., 2000. Microbial biomass, biovolume and respiration in Lumbricus terrestris L. cast material of different age. Soil Biol. Biochem. 32, 265-275. doi:10.1016/S0038-0717(99)00165-0

Tiwari, S.C., Tiwari, B.K., Mishra, R.R., 1989. Microbial populations, enzyme activities and nitrogen-phosphorus-potassium enrichment in earthworm casts and in the surrounding soil of a pineapple plantation. Biol. Fertil. Soils 8, 178-182. doi:10.1007/BF00257763

Toor, G.S., Cade-Menun, B.J., Sims, J.T., 2005. Establishing a linkage between phosphorus forms in dairy diets, feces, and manures. J. Environ. Qual. 34, 1380-1391. doi:10.2134/jeq2004.0232

Toor, G.S., Sims, J.T., 2015. Managing phosphorus leaching in Mid-Atlantic soils: importance of legacy sources. Vadose Zo. J. 14. doi:10.2136/vzj2015.08.0108

Torrent, J., Delgado, A., 2001. Using phosphorus concentration in the soil solution to predict phosphorus desorption to water. J. Environ. Qual. 30, 1829-1835. doi:10.2134/jeq2001.3051829x

Tunney, H., Breeuwsma, A., Withers, P.J.A., Ehlert, P.A.I., 1997. Phosphorus fertilizer strategies: present and future, in: Tunny, H., Carton, O.T., Brookes, P.C., Johnston, A.E. (Eds.), Phosphorus Loss from Soil to Water. CAB International, Wallingford, UK, pp. 177-203.

Turner, B.L., 2008. Resource partitioning for soil phosphorus: a hypothesis. J. Ecol. 96, 698-702. doi:10.1111/j.1365-2745.2008.01384.x

Turner, B.L., Kay, M.A., Westermann, D.T., 2004. Colloidal phosphorus in surface runoff and water extracts from semiarid soils of the Western United States. J. Environ. Qual. 33, 1464-1472.

Turner, B.L., Papházy, M.J., Haygarth, P.M., McKelvie, I.D., 2002. Inositol phosphates in the environment. Philos. Trans. R. Soc. B Biol. Sci. 357, 449-469. doi:10.1098/rstb.2001.0837

Unger, S., Friede, M., Hundacker, J., Volkmar, K., Beyschlag, W., 2016. Allocation trade-off between root and mycorrhizal surface defines nitrogen and phosphorus relations in 13 grassland species. Plant Soil 407, 279-292. doi:10.1007/s11104-016-2994-y 
USDA (Soil Survey Staff), 1999. Soil Taxonomy: a basic system of soil classification for making and interpreting soil surveys.

USGS, 2018. Phosphate rock- Mineral commodity summaries.

Valk, H., Šebek, L.B.J., 1999. Influence of long-term feeding of limited amounts of phosphorus on dry matter intake, milk production, and body weight of dairy cows. J. Dairy Sci. 82, 2157-2163. doi:10.3168/jds.S0022-0302(99)75459-7

Valkama, E., Virkajärvi, P., Uusitalo, R., Ylivainio, K., Turtola, E., 2016. Meta-analysis of grass ley response to phosphorus fertilization in Finland. Grass Forage Sci. 71, 36-53. doi:10.1111/gfs. 12156

Van der Salm, C., Chardon, W.J., Koopmans, G.F., Van Middelkoop, J.C., Ehlert, P.A.I., 2009. Phytoextraction of phosphorus-enriched grassland soils. J. Environ. Qual. 38, 751-761. doi:10.2134/jeq2008.0068

Van der Salm, C., Köhlenberg, L., De Vries, W., 1998. Assessment of weathering rates in Dutch loess and river-clay soils at pH 3.5, using laboratory experiments. Geoderma 85, 41-62. doi:10.1016/S0016-7061(98)00024-X

Van der Salm, C., Van den Toorn, A., Chardon, W.J., Koopmans, G.F., 2012. Water and nutrient transport on a heavy clay soil in a fluvial plain in the Netherlands. J. Environ. Qual. 41, 229-241. doi:10.2134/jeq2011.0292

Van der Salm, C., Van Middelkoop, J.C., Ehlert, P.A.I., 2017. Changes in soil phosphorus pools of grasslands following 17 yrs of balanced application of manure and fertilizer. Soil Use Manag. 33, 2-12. doi:10.1111/sum.12333

Van der Velde, M., Folberth, C., Balkovič, J., Ciais, P., Fritz, S., Janssens, I.A., Obersteiner, M., See, L., Skalský, R., Xiong, W., Peñuelas, J., 2014. African crop yield reductions due to increasingly unbalanced Nitrogen and Phosphorus consumption.

Glob. Chang. Biol. 20, 1278-1288. doi:10.1111/gcb.12481

Van der Zee, S.E.A.T.M., Nederlof, M.M., Van Riemsdijk, W.H., De Haan, F.A.M., 1988.

Spatial variability of phosphate adsorption parameters. J. Environ. Qual. 17, 682-688.

Van der Zee, S.E.A.T.M., Van Riemsdijk, W.H., 1988. Model for long-term phosphate reaction kinetics in soil. J. Environ. Quali. 17, 35-41. doi:10.2134/jeq1988.00472425001700010005x 
Van Eekeren, N., Bommelé, L., Bloem, J., Schouten, T., Rutgers, M., de Goede, R., Reheul, D., Brussaard, L., 2008. Soil biological quality after 36 years of ley-arable cropping, permanent grassland and permanent arable cropping. Appl. Soil Ecol. 40, 432-446.

doi:10.1016/j.apsoil.2008.06.010

Van Groenigen, J.W., Lubbers, I.M., Vos, H.M.J., Brown, G.G., De Deyn, G.B., Van Groenigen, K.J., 2014. Earthworms increase plant production: a meta-analysis. Sci. Rep. 4, 6365. doi:10.1038/srep06365

Van Kauwenbergh, S., 2010. World Phosphate Rock Reserves and Resources. Muscle Shoals, AL, USA. doi:ISBN 978-9-88999-167-3

Van Middelkoop, J.C., Van der Salm, C., Ehlert, P.A.I., De Boer, I.J.M., Oenema, O., 2016. Does balanced phosphorus fertilisation sustain high herbage yields and phosphorus contents in alternately grazed and mown pastures? Nutr. Cycl. Agroecosystems 106, 93-111. doi:10.1007/s10705-016-9791-0

Van Moorleghem, C., Six, L., Degryse, F., Smolders, E., Merckx, R., 2011. Effect of organic P forms and $\mathrm{P}$ present in inorganic colloids on the determination of dissolved $\mathrm{P}$ in environmental samples by the diffusive gradient in thin films technique, ion chromatography, and colorimetry. Anal. Chem. 83, 5317-5323. doi:10.1021/ac200748e

Van Noordwijk, M., De Willigen, P., Ehlert, P.A.I., Chardon, W.J., 1990. A simple model of P uptake by crops as a possible basis for $\mathrm{P}$ fertilizer recommendations. Netherlands J. Agric. Sci. 38, 317-332.

Van Riemsdijk, W.H., Boumans, L.J.M., De Haan, F.A.M., 1984a. Phosphate sorption by soils: I. A model for phosphate reaction with metal-oxides in soil. Soil Sci. Soc. Am. J. 48, 537-541.

Van Riemsdijk, W.H., Van der Linden, A.M.A., Boumans, L.J.M., 1984b. Phosphate sorption by soils: III. The P diffusion-precipitation model tested for three acid sandy soils. Soil Sci. Soc. Am. J. 48, 545-548.

Van Rotterdam, A.M.D., Bussink, D.W., Temminghoff, E.J.M., Van Riemsdijk, W.H., 2012. Predicting the potential of soils to supply phosphorus by integrating soil chemical processes and standard soil tests. Geoderma 189-190, 617-626. doi:10.1016/j.geoderma.2012.07.003 
Van Vuuren, D.P., Bouwman, A.F., Beusen, A.H.W., 2010. Phosphorus demand for the 1970-2100 period: A scenario analysis of resource depletion. Glob. Environ. Chang. 20, 428-439. doi:10.1016/j.gloenvcha.2010.04.004

Vance, C.P., Uhde-Stone, C., Allan, D.L., 2003. Phosphorus acquisition and use: critical adaptations by plants for securing a nonrenewable resource. New Phytol. 157, 423-447. doi:10.1046/j.1469-8137.2003.00695.x

Verloop, J., Oenema, J., Burgers, S.L.G., Aarts, H.F.M., Van Keulen, H., 2010.

P-equilibrium fertilization in an intensive dairy farming system: Effects on soil-P status, crop yield and P leaching. Nutr. Cycl. Agroecosystems 87, 369-382. doi:10.1007/s10705-010-9344-x

Vos, H.M.J., Ros, M.B.H., Koopmans, G.F., Van Groenigen, J.W., 2014. Do earthworms affect phosphorus availability to grass? A pot experiment. Soil Biol. Biochem. 79, 34-42. doi:10.1016/j.soilbio.2014.08.018

Waddell, H.A., Simpson, R.J., Henderson, B., Ryan, M.H., Lambers, H., Garden, D.L., Richardson, A.E., 2016. Differential growth response of Rytidosperma species (wallaby grass) to phosphorus application and its implications for grassland management. Grass Forage Sci. 71, 245-258. doi:10.1111/gfs.12170

Waddell, H.A., Simpson, R.J., Ryan, M.H., Lambers, H., Garden, D.L., Richardson, A.E., 2017. Root morphology and its contribution to a large root system for phosphorus uptake by Rytidosperma species (wallaby grass). Plant Soil 412, 7-19. doi:10.1007/s11104-016-2933-y

Wang, X., Li, W., Harrington, R., Liu, F., Parise, J.B., Feng, X., Sparks, D.L., 2013. Effect of ferrihydrite crystallite size on phosphate adsorption reactivity. Environ. Sci. Technol. 47, 10322-10331. doi:10.1021/es401301z

Wedderburn, M.E., Barker, D.J., Chapman, D.F., Orr, S.J., Dymock, N., 2005. Genetic differentiation in white clover (Trifolium repens) populations during 8 years of contrasting phosphorus supply in New Zealand hill country. New Zeal. J. Agric. Res. 48, 63-74. doi:10.1080/00288233.2005.9513632 
Weishaar, J.L., Aiken, G.R., Bergamaschi, B.A., Fram, M.S., Fujii, R., Mopper, K., 2003.

Evaluation of specific ultraviolet absorbance as an indicator of the chemical composition and reactivity of dissolved organic carbon. Environ. Sci. Technol. 37, 4702-4708. doi:10.1021/es030360x

Weng, L., Van Riemsdijk, W.H., Hiemstra, T., 2012. Factors controlling phosphate interaction with iron oxides. J. Environ. Qual. 41, 628-35. doi:10.2134/jeq2011.0250

Weng, L., Van Riemsdijk, W.H., Hiemstra, T., 2008. Humic nanoparticles at the oxide-water interface: interactions with phosphate ion adsorption. Environ. Sci. Technol. 42, 8747-8752. doi:10.1021/es801631d

Weng, L., Vega, F.A., Van Riemsdijk, W.H., 2011. Competitive and synergistic effects in $\mathrm{pH}$ dependent phosphate adsorption in soils: LCD modeling. Environ. Sci. Technol. 45, 8420-8428. doi:10.1021/es201844d

Whitehead, D.C., 2000. Nutrient elements in grassland: Soil - plant - animal relationships. CABI Publishing, Wallingford, UK. doi:10.1079/9780851994376.0000

Wilson, G.W.T., Hartnett, D.C., 1998. Interspecific variation in plant responses to mycorrhizal colonization in tallgrass prairie. Am. J. Bot. 85, 1732-1738.

Wolf, A.M., Baker, D.E., 1985. Comparisons of soil test phosphorus by Olsen, Bray P1, Mehlich I and Mehlich III methods 1. Commun. Soil Sci. Plant Anal. 16, 467-484. doi:10.1080/00103628509367620

Yang, X., Post, W.M., Thornton, P.E., Jain, A., 2013. The distribution of soil phosphorus for global biogeochemical modeling. Biogeosciences 10, 2525-2537. doi:10.5194/bg-10-2525-2013

Yang, Z., Culvenor, R.A., Haling, R.E., Stefanski, A., Ryan, M.H., Sandral, G.A., Kidd, D.R., Lambers, H., Simpson, R.J., 2017. Variation in root traits associated with nutrient foraging among temperate pasture legumes and grasses. Grass Forage Sci. 72, 93-103. doi:10.1111/gfs.12199

Yolcu, H., Serin, Y., Tan, M., 2010. The effects of seeding patterns, nitrogen and phosphorus fertilizations on production and botanical composition in lucerne-smooth bromegrass mixtures. Bulg. J. Agric. Sci. 16, 719-727. 


\section{Affiliations of co-authors}

\section{Diego Abalos}

Soil Biology Group, Wageningen University, Wageningen, The Netherlands.

\section{Anupol Chareesri}

Soil Biology Group, Wageningen University, Wageningen, The Netherlands.

\section{Gerlinde B. De Deyn}

Soil Biology Group, Wageningen University, Wageningen, The Netherlands.

\section{Tjisse Hiemstra}

Soil Chemistry and Chemical Soil Quality Group, Wageningen University, Wageningen, The Netherlands.

\section{Gerwin F. Koopmans}

Soil Chemistry and Chemical Soil Quality Group, Wageningen University, Wageningen, The Netherlands.

\section{Oene Oenema}

Wageningen Environmental Research, Wageningen, The Netherlands; Soil Biology Group, Wageningen University, Wageningen, The Netherlands.

\section{Jan Willem van Goenigen}

Soil Biology Group, Wageningen University, Wageningen, The Netherlands.

\section{Hannah M.J. Vos}

Soil Biology Group, Wageningen University, Wageningen, The Netherlands; Soil Chemistry and Chemical Soil Quality Group, Wageningen University, Wageningen, The Netherlands. 


\section{Summary}


With a growing world population and increasing rates of food consumption, there is a large pressure on agriculture to increase its production and resource use efficiency. Grasslands cover a large part of the earth's surface and dairy farming is a major agricultural system in terms of landand resource use. Therefore, increasing nutrient use efficiency in grassland-based dairy farming will be essential to support a growing demand for dairy and also beef products.

Phosphorus $(\mathrm{P})$, one of the essential nutrients required for the development and growth of all life on earth, is often a growth-limiting factor in grassland, and a relatively scarce resource. Proper use and management of $\mathrm{P}$ resources is therefore key to a productive and resource-efficient agriculture. On a global scale, soils vary widely in their $\mathrm{P}$ status as a result of differences in parent material, weathering and erosion, management (balance of $P$ inputs via fertilisers, manure and composts on the one hand, and P withdrawal via harvested crops on the other), and soil physicochemical characteristics that affect the availability of $P$ for plant uptake. Highly weathered soils in tropical areas often cannot supply crops with sufficient $P$ to sustain optimal growth and development, whereas heavily manured soils in areas with intensive animal agriculture frequently have a high $\mathrm{P}$ status, which increases the risk of $\mathrm{P}$ losses from soils to surface waters. The latter leads to eutrophication of surface waters and biodiversity loss.

In the next decades, $\mathrm{P}$ inputs via mineral fertilisers and animal manures into intensively managed grasslands may decline, partly due to increasing prices of mineral $P$ fertilisers and partly due to $\mathrm{P}$ application limits due to agri-environmental regulations. Finding new ways to utilise less available $\mathrm{P}$ pools in soil or to increase the use efficiency of $\mathrm{P}$ inputs can help to maintain or even increase yield from managed grasslands at lower $P$ inputs.

The main objective of my PhD thesis is to investigate mechanisms and driving factors that determine $P$ availability in grassland soils and to explore the potential of these factors to increase the $\mathrm{P}$ utilisation in managed grasslands. The specific objectives of my thesis research are (i) to identify the (soil) factors that drive the success of $P$ fertilisation of grassland on a global scale; (ii) to assess the possible differences in resistance of various grass species to $\mathrm{P}$ deficiency and link these to their morphological root traits; (iii) to quantify the effects of different earthworm species on $P$ availability and grass $\mathrm{P}$ uptake; and (iv) to explore the temporal $\mathrm{P}$ dynamics in earthworm casts and to model the mechanisms that drive $P$ availability in casts. My thesis contains four research chapters, an introduction (Chapter 1), and a general discussion (Chapter 6).

In Chapter 2, I review published peer-reviewed studies of field experiments on $\mathrm{P}$ fertilisation of grasslands through a meta-analysis. Data on experimental conditions, soil properties, and crop responses were collected to investigate possible driving factors. In the 67 studies (1227 pairwise comparisons) that were included, $\mathrm{P}$ fertilisation increased grass yield on average with $36 \%$, which was equivalent to $23 \mathrm{~kg} \mathrm{~kg}^{-1} \mathrm{P}$ applied. There was a large variation in responses of grass to $\mathrm{P}$ fertilisation across the investigated studies, but $\mathrm{P}$ application rate and $\mathrm{P}$ status were major factors for the success of $P$ fertilisation. A kilogram of $P$ in the form of mineral $P$ fertiliser was 5-10 times more effective in Oceania or Africa than in other parts of the world. Moreover, the response was highest in (i) studies that included legumes, (ii) soils with a pH between 5 and 6 , and (iii) soils with a 
relatively high organic matter $(\mathrm{OM})$ content. The results clearly showed that small $\mathrm{P}$ applications to $\mathrm{P}$-deficient soils lead to stronger yield benefits in absolute terms than relatively large $\mathrm{P}$ applications to soils with a relatively high $P$ status.

In Chapter 3, a 9-month greenhouse experiment with eight commonly used grass species is described. The aim of this study was to link differences in resistance to P limitation (defined as the yield penalty induced by P-limiting conditions) amongst species to their root characteristics. Phosphorus fertilisation was applied or withheld with the intention to create ideal or P-limiting growth conditions. Omitting $P$ fertilisation strongly reduced yield (from 33.4-85.8 $\mathrm{g} \mathrm{pot}^{-1}$ to 17.1$72.1 \mathrm{~g} \mathrm{pot}^{-1}$ in the fertilised and unfertilised $P$ treatments, respectively) as well as $\mathrm{N}$ and $\mathrm{P}$ uptake by the grasses. Yields and $\mathrm{P}$ uptake varied widely amongst species, and so did root traits. Phosphorus fertilisation however did not affect root traits, indicating limited plasticity of root traits under the experimental conditions. Structural equation modelling identified total root length as key factor for grass resistance to $P$ deficiency, especially when roots explored the subsoil. This information can be used in the selection of grass species under conditions of decreasing soil P availability.

Chapter 4 describes an incubation study in the greenhouse where three different earthworm species (Lumbricus rubellus, Aporrectodea caliginosa, and L. terrestris) were incubated for 2.5 months in pots with a soil with a low $P$ availability and grown over with perennial ryegrass. Phosphorus application treatments included a control in which $\mathrm{P}$ fertilisation was withheld, a treatment with application of organic $P$ (phytic acid), and one with application of mineral $\mathrm{P}\left(\mathrm{K}_{2} \mathrm{HPO}_{4}\right)$. The effects of individual species on the growth and $P$ uptake of the grass was determined and linked to the water-extractable $\mathrm{P}$ concentration in the earthworm casts, which is used here as a proxy for the amount of readily available P. Levels of water-extractable orthophosphate (ortho-P) concentrations in earthworm casts were orders of magnitude higher (up to $10 \mathrm{mg} \mathrm{L}^{-1}$ ) than those found in bulk soil $\left(0.02 \mathrm{mg} \mathrm{L}^{-1}\right)$. The magnitude of the P effect in earthworm casts strongly depends on species: $L$. rubellus showed larger increases in readily available $P$ than $L$. terrestris and $A$. caliginosa. Although the effect of introducing earthworms in soil on $\mathrm{P}$ availability was not detectable at the bulk soil level, grass plants were able to utilise these local increases in P availability and increased yield and $\mathrm{P}$ uptake compared to the control treatment without earthworms.

In Chapter 5, I use a combination of pot and laboratory experiments and surface complexation modelling to further explore mechanisms that could contribute to the elevated $\mathrm{P}$ availability in earthworm casts. Several mechanisms were proposed: i) a higher $\mathrm{pH}$ observed in the earthworm casts, compared to the bulk soil, may induce desorption of ortho-P; ii) selective feeding and accumulation of P-rich material, such as plant litter or a clay fraction including reactive particles with a higher P loading and soil organic matter content may cause an increased P content in casts; iii) increased mineralisation rates can result in an elevated P concentration in casts; and iv) higher concentrations of dissolved organic matter (DOM) in casts, resulting from increased mineralisation rates, may compete with ortho-P for adsorption sites, causing desorption of the latter. In the pot experiment, the presence of $L$. terrestris increased grass yield and $\mathrm{P}$ uptake of annual ryegrass under P-limiting conditions. Strong changes in the solution chemistry of the cast were observed: 
ortho-P concentrations in the water extracts of the casts were up to 1000 times higher than the levels found in the extracts from the bulk soil. Additionally, the $\mathrm{pH}$ increased by more than 1.5 unit and dissolved organic carbon concentrations were elevated. Modelling the cast and bulk soil samples with the Charge Distribution (CD) model suggested that competition for adsorption sites between ortho-P and OM may be a major factor influencing the readily available amounts of $\mathrm{P}$ in earthworm casts. Nevertheless, the high ortho-P concentrations in the casts could not be explained entirely with the CD model, and other processes, such as the release of ortho-P to solution due to reductive dissolution of Fe oxide particles, could have played a role as well.

The general discussion (Chapter 6), addresses the main findings of the executed research in a broader context. In my thesis, I showed that $\mathrm{P}$ fertilisation is most effective when applied to grasslands with a low $\mathrm{P}$ status - not only in relative terms, but also in terms of kg yield per kg P applied. Moreover, selecting deep-rooting grass species with a high total root length may provide opportunities to increase P use efficiency under declining P availability. Finally, I showed that earthworms casts contain highly elevated levels of readily available $\mathrm{P}$ as compared to the bulk soil. Grass species are able to utilise these spatiotemporal hotspots, leading to increased yield under P-limiting conditions. The elevated $\mathrm{pH}$ in the casts can only partially explain the increase in available $\mathrm{P}$, but competition for adsorption sites between DOM and ortho-P might play an important role.

Directions for future research and factors that should be included in that research are discussed. In general, the consistency of the results obtained in my PhD research should be verified under field conditions, for a range of different soils, and within a farm context. As most results were obtained through laboratory or greenhouse experiments, drawing far-reaching conclusions for farming practices would be premature. Nevertheless, the current results provide a variety of avenues to increase P cycling in intensive dairy farms. These avenues should be further explored in future field and farm studies. 


\section{Samenvatting}


Een groeiende wereldbevolking en een toenemende voedselconsumptie per capita leggen druk op de landbouw om de productie, en de efficiëntie waarmee grondstoffen gebruikt worden, te verhogen. Graslanden beslaan een groot gedeelte van 's werelds landoppervlak en de melkveehouderij is mondiaal een belangrijke landbouwsector. Het verbeteren van het nutriëntengebruik in deze graslanden, die vaak een integraal onderdeel van een melkveesysteem vormen, is daarom essentiëel om in de groeiende behoefte naar melk- en vleesproducten te voorzien.

De beschikbaarheid van fosfor $(\mathrm{P})$, één van de belangrijkste nutriënten en een bouwsteen voor al het leven op aarde, is dikwijls een limiterende factor voor plantengroei in graslanden. Verstandig gebruik van $\mathrm{P}$ draagt dus bij aan productieve en efficiënte landbouw. Mondiaal gezien variëert de hoeveelheid $\mathrm{P}$ in de bodem, en de beschikbaarheid ervan voor planten, enorm. Dit komt door verschillen in moedermateriaal, verwering en erosie van de bodem, nutriëntenbeheer (de balans tussen aanvoer van P via kunstmest of dierlijke mest en afvoer via opname door het gewas), en de fysisch-chemische bodemeigenschappen. Sterk verweerde tropische gronden kunnen bijvoorbeeld vaak niet genoeg P leveren om het gewas optimaal te laten groeien, terwijl veel bodems in intensieve landbouwgebieden door een lange bemestingsgeschiedenis juist een hoge P-status hebben. Dit laatste kan leiden tot een verhoogd risico op verliezen van $\mathrm{P}$ vanuit bodems naar het grond- en oppervlaktewater, met eutroficatie en biodiversiteitsverlies als gevolg.

Het is te verwachten dat de aanvoer van P naar bodems, in de vorm van kunstmest of dierlijke mest, zal afnemen in de komende decennia als gevolg van hogere kunstmestprijzen en strengere landbouw- en milieuwetgeving. Het wordt daarom steeds belangrijker manieren te vinden om de minder-beschikbare delen van de P-bodemvoorraad aan te boren, of om de gebruiksefficiëntie van $P$ te verhogen. Dit zou mogelijkheden bieden om, met een lagere aanvoer van $P$, de opbrengst te handhaven of zelfs te verhogen.

Het hoofddoel van dit proefschrift is om mechanismen en factoren te onderzoeken die de beschikbaarheid van $\mathrm{P}$ in beheerde graslanden bepalen en beïnvloeden, en om te verkennen of we deze kunnen gebruiken om de gebruiksefficiëntie van $\mathrm{P}$ te verhogen. De specifieke doelen zijn: (i) het identificeren van (bodem)factoren die bepalend zijn voor het succes van P-bemesting van grasland op een mondiale schaal; (ii) het onderzoeken van de groei bij, en weerstand tegen, P-gebrek van verschillende grassoorten, en het verband hierbij met worteleigenschappen van het gras; (iii) het in kaart brengen van de effecten van verschillende soorten regenwormen op de P-beschikbaarheid in de bodem en de opname van P door gras; en (iv) het vaststellen van de P-beschikbaarheid in wormencasts over de tijd, en het modelleren van de factoren die deze beschikbaarheid bepalen. Mijn proefschrift bevat vier inhoudelijke hoofdstukken, een inleiding (Hoofdstuk 1), en een algemene discussie met synthese (Hoofdstuk 6).

In Hoofdstuk 2 analyseer ik, met behulp van een meta-analyse, gepubliceerde studies met veldexperimenten waarin gras bemest wordt met P. Informatie over de experimentele opzet, 
bodemeigenschappen, en gewasrespons was verzameld om onderzoek te doen naar factoren die het succes van P-bemesting bepalen. In de 67 studies (bestaande uit 1227 vergelijkingen) die waren meegenomen, nam de grasopbrengst met gemiddeld 36\% toe na P-bemesting. Dit komt overeen met een toename van $23 \mathrm{~kg} \mathrm{kg-1}$ toegediend P. De respons variëerde sterk in de onderzochte studies, maar de hoeveelheid toegediend $\mathrm{P}$ en de P-status van de bodem bepaalden in grote mate het succes van de bemesting. Een kilo $P$ was 5-10 keer effectiever in Oceanië en Afrika dan in andere delen van de wereld. Daarnaast was de gewasrespons het sterkst in (i) graslanden met vlinderbloemigen, (ii) bodems met een $\mathrm{pH}$ tussen 5 en 6 , en (iii) bodems met een relatief hoog gehalte aan organisch stof (OM; organic matter). De resultaten lieten duidelijk zien dat kleine P-giften op bodems met een lage P-status leiden tot de sterkere absolute toename in opbrengst dan grote P-giften op bodems met een hoge P-status.

In Hoofdstuk 3 wordt een broeikasexperiment van negen maanden met acht veelgebruikte grassoorten beschreven. Het doel van deze studie was om de verschillen in de weerstand tegen P-gebrek van de soorten (gedefiniëerd als de afname in opbrengst resulterend uit P-gebrek) te verbinden aan hun worteleigenschappen. In twee bemestingsbehandelingen werd $\mathrm{P}$ wel of niet toegediend om zo ideale of P-gelimiteerde groeicondities te creëren. Het onthouden van P-bemesting resulteerde in een sterk verminderde opbrengst (van 33.4-85.8 g pot-1 bij bemesting met $\mathrm{P}$ naar 17.1-72.1 g pot-1 bij bemesting zonder $\mathrm{P}$ ) en in lagere opnames van stikstof $(\mathrm{N})$ en $P$ door het gras. Daarnaast verschilden opbrengst en P-opname sterk van soort tot soort, en hetzelfde gold voor de worteleigenschappen. De bemestingsbehandeling had echter geen effect op de worteleigenschappen van de grassoorten, wat duidt op een beperkte plasticiteit van deze eigenschappen onder de proefopzet. Uit een analyse met structural equation modelling bleek dat wortellengte een belangrijke factor is die de weerstand van grassen tegen P-gebrek bepaalt, in het bijzonder wanneer het gras diep wortelt. Deze informatie kan gebruikt worden bij het selecteren van grassoorten voor bodems met een lagere P-beschikbaarheid.

Hoofdstuk 4 beschrijft een incubatiestudie in de broeikas waarin drie verschillende regenwormsoorten (Lumbricus rubellus, Aporrectodea caliginosa, en L. terrestris) voor tweeëneenhalve maand werden geïncubeerd in potten met P-arme grond, waarop Engels raaigras was ingezaaid. Er werden drie verschillende P-behandelingen toegepast: er was een behandeling zonder extra toegevoegd $P$, één waarin organisch $P$ (als fytinezuur) werd toegevoegd, en één met anorganisch P (als K2PO4). De effecten van de regenwormsoorten op de opbrengst en P-opname van het gras werd bepaald en verbonden aan het gehalte water-extraheerbaar $\mathrm{P}$ in de casts van de wormen, dat hier wordt gebruikt als een benadering voor de hoeveelheid $\mathrm{P}$ die direct beschikbaar is voor de plant. De concentraties water-extraheerbaar orthofosfaat (ortho-P) in casts (tot $10 \mathrm{mg} \mathrm{L}-1$ ) lagen ver boven de concentraties gemeten in de bodem $(0.02 \mathrm{mg} \mathrm{L-1})$. De grootte van het regenwormeffect op P-beschikbaarheid verschilde sterk per soort: de concentraties in de cast van L. rubellus waren hoger dan die in de casts van L. terrestris en A. caliginosa. Hoewel dit effect gemiddeld in de 
bodem niet terug te meten was, bleek het gras toch in staat om gebruik te maken van deze lokale verhogingen in P-beschikbaarheid, en werden een hogere opbrengst en P-opname gemeten in potten met wormen dan in potten zonder wormen.

In Hoofdstuk 5 gebruik ik een combinatie van pot- en lab-experimenten en een modelstudie om de mechanismen te ontrafelen die leiden tot de verhoogde P-beschikbaarheid in de wormencasts. Er worden verschillende mechanismen aangedragen: (i) de relatief hogere $\mathrm{pH}$ in de casts kan desorptie van ortho-P tot gevolg hebben; (ii) de casts kunnen meer $\mathrm{P}$ bevatten door een selectief voedingspatroon van de wormen met P-rijke fracties, zoals vers dood plantenmateriaal of de kleifractie uit de bodem, die een hoger reactief oppervlak heeft en dus meer OM en ortho-P kan binden; (iii) hogere microbiële activiteit in wormencasts kan leiden tot snellere mineralisatie van organisch $\mathrm{P}$ en verhoogde ortho-P concentraties; en (iv) uit mineralisatie resulterende hoge concentraties opgeloste organische stof (DOM; dissolved organic matter) in de casts kunnen leiden tot concurrentie tussen DOM en ortho-P voor adsorptie aan bodemdeeltjes, met eventuele desorptie van ortho-P als gevolg. In het potexperiment verhoogde de worm L. terrestris de groei en P-opname van Italiaans raaigras onder P-arme omstandigheden. Er waren grote verschillen tussen de chemische samenstelling van de wormencast en die van de bodem: de concentraties waterextraheerbaar ortho-P waren tot 1000 keer hoger in de casts dan in de bodem. Daarnaast was de $\mathrm{pH}$ in de casts anderhalve eenheid hoger en werden er verhoogde concentraties opgeloste koolstof gevonden. Het modelleren van de cast en bodemmonsters met behulp van het Charge Distribution (CD) model liet zien dat concurrentie tussen ortho-P en DOM voor adsorptie aan bodemdeeltjes een belangrijke rol kan spelen bij het verklaren van de hoge ortho-P-concentraties in de wormencasts. Desondanks konden de hoge concentraties niet in zijn geheel verklaard worden met het CD model en moet de rol van andere processen, zoals het vrijkomen van ortho-P bij het oplossen van ijzeroxiden onder gereduceerde omstandigheden, niet worden uitgesloten.

De algemene discussie (Hoofdstuk 6) beschouwt de belangrijkste bevindingen van het uitgevoerde onderzoek in een breder perspectief. In mijn proefschrift heb ik laten zien dat P-bemesting het effectiefst is wanneer het op graslanden met een lage P-status wordt toegepast, zowel relatief gezien als op basis van absolute opbrengsttoename. Daarnaast kan het selecteren van diep wortelende grassoorten met een grote wortellengte mogelijkheden creëren om P-efficiëntie te verhogen bij een lagere P-beschikbaarheid. Tenslotte heb ik laten zien dat casts van regenwormen uitzonderlijk hoge concentraties direct beschikbaar P bevatten, in vergelijking met de bodem. Planten zijn in staat om deze lokale en tijdelijke 'hot-spots' te gebruiken om hun opbrengst te verhogen onder P-arme omstandigheden. De verhoogde $\mathrm{pH}$ in de casts kan slechts een deel van de ortho-P-concentraties verklaren, maar de concurrentie tussen DOM en ortho-P voor adsorptie aan bodemdeeltjes zou hier een belangrijke rol kunnen spelen. 
Verder bespreek ik richtingen voor vervolgonderzoek en factoren die daarin moeten worden meegenomen. Over het algemeen moeten de resultaten die dit onderzoek heeft opgeleverd geverifieerd worden in het veld, voor een serie bodems met uiteenlopende eigenschappen en in de context van een boerenbedrijf. Omdat de meeste resultaten zijn verkregen door middel van lab- en broeikasexperimenten is het nog te vroeg om hieraan verregaande conclusies en managementstrategieën te verbinden. Desalniettemin bieden de resultaten een aantal duidelijke en veelbelovende richtingen om P-efficiëntie op melkveebedrijven te verbeteren. Deze richtingen moeten verder uitgewerkt worden in toekomstige studies in het veld en op de boerderij. 


\section{Dankwoord}


Na meer dan zes jaar is mijn scriptie dan eindelijk voltooid en kan ik beginnen aan de sectie van dit boekje dat, naar mijn verwachting, de meeste lezers zal trekken. Ik ben erg gelukkig met het onderzoekswerk dat dit project me geboden heeft, en trots op dit proefschrift waarin het grootste gedeelte van mijn onderzoek is samengevat. Hoewel het gebruikelijk is om in (gedeelten van) een proefschift vanuit de eerste persoon enkelvoud te schrijven, is deze thesis verre van een eenmansproject geweest. Ik heb de succesvolle afronding te danken aan de directe en indirecte steun van talloze collega's, vrienden, en familie. Dit zijn er meer dan ik kan opnoemen, maar ik zou hier graag een begin maken.

Allereerst wil ik mijn begeleiders Gerwin Koompans, Jan Willem van Groenigen, en Oene Oenema bedanken. Ik prijs mezelf gelukkig dat ik onder de hoede van zo'n divers en complementair team heb mogen werken en leren. Onze overleggen waren voor mij intellectueel soms intimiderend, maar vaak een bron van inspiratie, en ik heb de vriendschappelijke en ongedwongen sfeer, waarin ik dikwijls jullie kantoor heb kunnen binnenstormen met vragen of ideeën, altijd erg gewaardeerd. Gerwin, ik ben ervan overtuigd dat jouw kennis van de bodemchemie, je vermogen om dingen goed uit te leggen, en je oog voor detail me tot een betere wetenschapper hebben gemaakt. Meer dan eens kwam je één of twee uur na een intensief overleg mijn kantoor binnen om samen de proefresultaten opnieuw te evalueren, want je 'had nog eens nagedacht'. Daarnaast heb ik jouw nauwkeurige en constructieve manier van het becommentariëren van mijn manuscripten erg bruikbaar gevonden. De aanblik van een rood document en een kantlijn vol ballonnetjes was aanvankelijk soms even slikken, maar alle tijd en energie die je erin gestoken hebt hebben de kwaliteit van dit proefschrift aanzienlijk verbeterd. Jan Willem, jij hebt me niet alleen begeleid gedurende de laatste zes jaar, maar ook daarvoor bij mijn MSc- en BSc-onderzoek. Tijdens het vak Biological Interactions in Soils, waarin we voor het eerst een experiment mochten bedenken, opzetten, en uitvoeren, ben ik mede door jouw enthousiaste manier van lesgeven verslingerd geraakt aan Soil Quality. Daarna heb je me als stikstof- en regenwormenexpert veel geleerd over de biologische en ecologische kant van de bodem, wat tijdens dit project ook duidelijk naar voren is gekomen. Ik heb veel bewondering voor je vlotte manier van schrijven, je positieve benadering van proefresultaten ('Je moet het wel willen zien!'), en je intuïtie voor een goed verhaal. Ik hoop dat ik een fractie van die eigenschappen heb kunnen meenemen. Oene, jij was als promotor de begeleider die wat meer op afstand opereerde en de grote lijnen bewaakte. Je stond altijd klaar om met de gevleugelde woorden 'So what?' aan te geven dat het onderzoek in een maatschappelijke context geplaatst diende te worden en ik daarom het nut van mijn experimenten en resultaten moest kunnen uitleggen. Vanaf het begin ben ik onder de indruk geweest van je veelzijdigheid, vooral je vermogen om over een reeks van onderwerpen te spreken met wetenschappers, managers, boeren, en beleidsmakers. Alledrie zijn jullie naast een goed begeleidingsteam ook prettige figuren om buiten werktijd mee te fietsen, hardlopen, pubquizen, of gewoon een biertje mee te drinken, en dat heb ik tijdens mijn promotieonderzoek dan ook graag mogen doen. 
In addition to my supervisors, I would like to thank my co-authors Tjisse Hiemstra, Gerlinde De Deyn, and Diego Abalos, whose expertise on adsorption of phosphate, plant-soil interactions, and meta-analysis, respectively, have raised the Chapters in this thesis to a higher level. I am also greatly indebted to the (at that time) master students Hannah Vos, Anupol Chareesri, and Sasja van Rosmalen, who have all worked very hard to bring their projects, two of which are incorporated in this thesis, to a good end. Your contributions to the design and management of different experiments, the search for the right earthworm species under imperfect weather conditions, the exploration of various novel analytical procedures, and the production of manuscripts, have been very valuable. I hope that the experience was as educational for you as it was for me.

Ik werd in mijn onderzoek bijgestaan en geadviseerd door een klankbordgroep bestaande uit vetegenwoordigers van verschillende bedrijven uit de Nederlandse melkveesector. Ik wil daarom de leden van deze commissie, René Knook, Arjan Reijneveld, Guus van Laarhoven, Piet Aerts, en Stefan van der Heijden, hartelijk bedanken voor al hun input en voor de interessante discussies. I would also like to take the opportunity here to thank Quirine Ketterings and all the other members of the Cornell University Nutrient Management Spear Program. Your applied research and extension work have helped me to shape my vision on science and collaboration with farmers. This has ultimately aided me in writing the last parts of this thesis.

Soil Quality has been my home in the university for a long time. I have greatly enjoyed working with all the intelligent, dedicated, fun, and inspiring people in this department. Due to the nature of this project, I was part of both the soil biology and soil chemistry chair groups, which I have always considered to be a privilege. I hope there will continue to be many fruitful collaborations between members of both groups in the future. The value of having a fun and safe place to work from can hardly be overestimated and I would like to thank my fellow PhD candidates, the Soil Quality faculty and postdocs, and all associated students for creating such a stimulating and supportive environment. The weekly seminars provided a great place to keep up with each other's research, and the joint lunch and coffee breaks were excellent to share food, cakes, and the joys and sorrows of doing a PhD. Furthermore, it was always nice to see many of you at the yearly SOQ outing, Christmas party, and chair group drinks.

Ik wil graag de medewerkers van de beide bodemlaboratoria bedanken, en in het bijzonder Jaap Nelemans, Willeke van Tintelen, Tamás Salanki, André van Leeuwen, Peter Nobels, en Gerlinde Vink. Jullie expertise, flexibiliteit, en advies zijn bij alle experimenten die ik gedaan heb van grote waarde gebleken. Daarnaast genoot ik net als mijn collega's uitstekende administratieve ondersteuning door onder anderen Esther van den Burg, Anita Kok, en Freddy Pracht. Hier is ook nog een speciaal bedankje naar Marnella van der Tol op zijn plaats. Marnella, je bent de ruggengraat van de groep, nooit te beroerd om iedereen met van alles te helpen, bedankt! 
Arguably, the people that have seen the most of me in Atlas were my D319 office mates. I am grateful for them sticking around, despite my constant coughing and the occasional yelp of terror at the computer screen. Giulia Bongiorno, you brought some Italian passion into our office. I really appreciated your way of communicating and enjoyed talking to you about science. Jingmeng Wang, thanks for introducing me to all sorts of Chinese goodness, like special tea, (some of the) Chinese candy, and most of all, hotpot. Ingrid Lubbers, ik heb mijn volledige PhD-tijd in Wageningen een kantoor met je mogen delen en ik denk dat ik het enorm getroffen had. Bedankt voor alle advies, discussies, humor, en sportiviteit die je hebt ingebracht als bodemecoloog, voetbalsheriff, catwoman, Pineaukoerier, Blackadderbuddy, en bananenplantoppas. Het enige dat nog ontbreekt is een goed vensterbankexperiment, maar ik heb hoop dat hiervoor zich binnenkort goede mogelijkheden gaan ontvouwen.

Er zijn veel mensen geweest die me buiten Atlas hebben geholpen tijdens de moeilijke perioden die elk PhD project met zich meebrengt, het zij door het geven van advies, of gewoon door afleiding te bieden. De wekelijkse voetbalpot op dinsdag was een belangrijk onderdeel van mijn routine en heeft me vaak nieuwe energie en een gezonde dosis afleiding gegeven. Ik wil dan ook iedereen die de afgelopen jaren heeft meegespeeld of heeft meegeholpen om dit een succes te laten worden hartelijk bedanken.

Daarnaast ben ik een aantal vrienden zeer erkentelijk. Rima Porre, ik ben je veel dank verschuldigd voor je vriendschap. Voor alle gezelligheid, alle grappen, voor de diners, de potjes pool, de gymsessies, de bedenkelijke TV-series, het uitblijven van winterkamperen (!), maar boven alles voor je onaflatende bereidheid om samen een biertje te drinken. Diego Abalos and Laura Velle, I am very grateful for all the laughs, the ideas, and the stories (mostly in Café Onder de Linden), which always got better as the evening progressed. Thanks as well for always being prepared to give sound advice when asked. Simon Jeffery, thank you for introducing me to climbing (something that I still greatly enjoy), for the rugby matches we watched and the Civ games we played. Natalie Oram, you know well how I admire your infallible sense for innuendos, whatever the situation. Our trips to the gym for spinning or TRX sessions during our lunch breaks were very enjoyable (mostly afterwards). Thanks for the talks and your friendship throughout my MSc and PhD. Imke Kuiper, je bent één van de meest opgewekte en nuchtere personen die ik ken, en die houding vrolijkt me vaak op. Je baksels zijn ongeëvenaard, net als je toewijding aan onze weddenschappen. Lisette Bakker en Dina In 't Zand, samen met Natalie en Imke kon ik altijd op jullie rekenen voor een goede curry, een slechte film, en genoeg gin-tonics om de avond door te komen. Angie Straathof, thank you for being a very important source of inspiration and joy during the first years of my PhD. Wim Joost van Hoek, we zijn samen in Atlas begonnen voor ons bacheloronderzoek. Ik ben blijven plakken, jij bent weggegaan, maar sinds die tijd hebben we veel discussies, sigaren, en glazen whisky gedeeld, bedankt daarvoor. Tom van den Bergh, Sophia Jonkers, en Susan Arts, dankjulliewel voor alle fijne tijden voor en tijdens mijn promotieonderzoek, eerst in Renkum, en nu in Utrecht. Sonia Meller, 
your slightly cynical sense of humour and unbridled enthusiasm for everything complicated are entertaining and contagious. Thank you for all the fun times and for the phosphorus-related and -unrelated conversations.

Dan wil ik graag mijn paranimfen bedanken. Ik ben erg blij dat zij deze belangrijke taak op zich hebben willen nemen. Sanne Diek, sinds de bodem- en landschapsexcursie naar Andalusië hebben we het heel goed kunnen vinden. Ik blijf versteld staan van je creativiteit, van je kennis betreft voetbal en mollen. Bedankt voor alle Skype-sessies, alle lopende to-do-lijstjes, en vooral voor de gastvrijheid in Zürich. Pepijn Aarnink, al jarenlang ben je als een broer voor me. Het spreekt voor zich dat jouw vriendschap, en die van je familie, onmisbaar is geweest tijdens mijn promotietraject en daarvoor.

Ten slotte is er mijn familie. Lieve ma, pa, Sanne en Frank, bedankt voor het zijn van de meest stabiele factor in mijn leven, voor het creëren van een veilig thuis als uitvalsbasis, en vooral voor jullie onvoorwaardelijke liefde en steun tijdens mijn promotie, tijdens mijn studie, en daarvoor. 


\section{PE\&RC Training and Education Statement}

With the training and education activities listed below the PhD candidate has complied with the requirements set by the C.T. de Wit Graduate School for Production Ecology and Resource Conservation (PE\&RC) which comprises of a minimum total of 32 ECTS (= 22 weeks of activities)

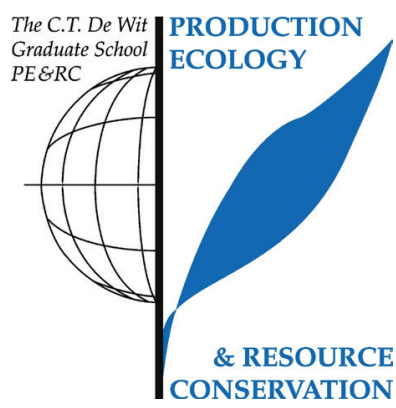

\section{Review of literature (6 ECTS)}

- The effectivity of phosphorus fertilisation on grasslands (2018)

\section{Writing of project proposal (4.5 ECTS)}

- Improving the utilisation of soil phosphorus on dairy farms

\section{Post-graduate courses (5.2 ECTS)}

- Introduction to R for statistical analysis; PE\&RC (2014)

- Linear models; PE\&RC (2014)

- Generalized linear models; PE\&RC (2014)

- Mixed linear models; PE\&RC (2014)

- Soil ecology \& the planetary boundaries; PE\&RC, SENSE, RSEE (2016)

- Applications of stable isotopes in plant sciences; Univ. of Zürich, ETH and Univ. of Basel (2016)

\section{Invited review of (unpublished) journal manuscript (2 ECTS)}

- Biogeosciences: phosphorus and carbon in soil particle size fractions

- Geoderma: soil moisture and phosphorus pools in the detritusphere

- Geoderma: phosphorus availability from biochar

\section{Competence strengthening / skills courses (1.6 ECTS)}

- Career perspectives; WGS (2016)

\section{PE\&RC Annual meetings, seminars and the PE\&RC weekend (1.5 ECTS)}

- PE\&RC First year weekend (2013)

- PE\&RC Day (2014-2015)

\section{Discussion groups / local seminars / other scientific meetings (5 ECTS)}

- Discussions in soil quality (2013-2014)

- Plant soil interactions (2016-2017)

- Southern Extension and Research Activity (SERA) (2017-2018) 
International symposia, workshops and conferences (10.7 ECTS)

- Phosphorus in soil and plants; Montpellier, France (2014)

- Annual meetings of the ASA/CSSA/SSSA; Minneapolis, MN, USA (2015)

- Wageningen soil conference; Wageningen, Netherlands (2015)

- Annual meetings of the ASA/CSSA/SSSA; Tampa, FL, USA (2017)

- Annual meetings of the ASA/CSSA; Baltimore, MD, USA (2018)

\section{Supervision of MSc students (3 ECTS)}

- Do earthworms affect phosphorus availability to grass?

- Phosphorus dynamic in the casts of Lumbricus terrestis and their effect on plant growth

- Do interactions between manure composition and earthworms affect phosphorus uptake by plants? 
This PhD project was funded through the Wageningen University Fund. I am very thankful to De Heus b.v., whose generous donation to this project, on the occasion of their 100th anniversary, has enabled me to conduct my research and write this thesis.

Dit AIO-project werd gefinancierd door het Wageningen University Fonds. Ik ben De Heus b.v. erg dankbaar voor hun gulle donatie aan dit project, naar aanleiding van het 100-jarig jubileum van het bedrijf, waardoor ik dit onderzoek heb kunnen uitvoeren en dit proefschrift heb kunnen schrijven.

This thesis is designed and printed by Straver reclame en vormgeving 


\section{Propositions}

1. Stimulating earthworm populations in grassland soils has the potential to increase the availability of both organic and inorganic soil phosphorus sources. (this thesis)

2. Inherent root traits are more important to consider than root trait plasticity when selecting phosphorus efficient grass species for intensively managed grasslands. (this thesis)

3. Standardised quantity-intensity soil nutrient assessments are critical for moving towards efficient nutrient use in global agriculture.

4. The most difficult thing in scientific research is asking the right questions.

5. Developing successful agri-environmental policies begins with understanding farms and farmers.

6. The continuous evolution of language is not a valid argument to use it carelessly.

7. Brexit will have negative impacts on the scientific community for years to come.

Propositions belonging to the thesis, entitled:

Towards better utilisation of soil phosphorus in managed grassland systems

Mart Berend Henrik Ros

Wageningen, 29 March 2019 


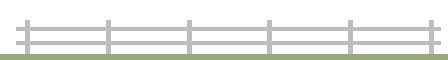

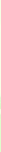

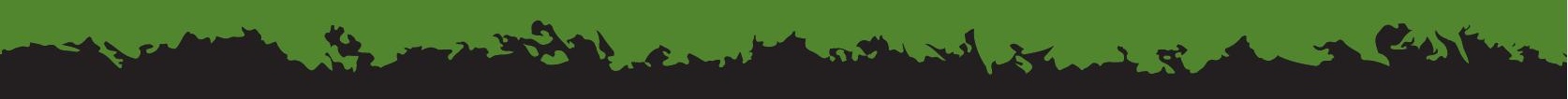

